\title{
Pulse charging lead-acid batteries to improve performance and reverse the effects of sulfation
}

\author{
Robert B. Cooper \\ West Virginia University
}

Follow this and additional works at: https://researchrepository.wvu.edu/etd

\section{Recommended Citation}

Cooper, Robert B., "Pulse charging lead-acid batteries to improve performance and reverse the effects of sulfation" (2002). Graduate Theses, Dissertations, and Problem Reports. 1223.

https://researchrepository.wvu.edu/etd/1223

This Thesis is protected by copyright and/or related rights. It has been brought to you by the The Research Repository @ WVU with permission from the rights-holder(s). You are free to use this Thesis in any way that is permitted by the copyright and related rights legislation that applies to your use. For other uses you must obtain permission from the rights-holder(s) directly, unless additional rights are indicated by a Creative Commons license in the record and/ or on the work itself. This Thesis has been accepted for inclusion in WVU Graduate Theses, Dissertations, and Problem Reports collection by an authorized administrator of The Research Repository @ WVU. For more information, please contact researchrepository@mail.wvu.edu. 


\title{
Pulse Charging Lead-Acid Batteries to Improve Performance and Reverse the Effects of Sulfation
}

\author{
Robert B. Cooper \\ Thesis submitted to the \\ College of Engineering and Mineral Resources \\ at West Virginia University \\ in partial fulfillment of the requirements \\ for the degree of
}

Master of Science
in
Electrical Engineering

Dr. Roy Nutter Jr., Ph.D., (chair)

Dr. Robert L. McConnell, Ph.D.

Dr. Kathleen Meehan, Ph.D.

Lane Department of Computer Science and Electrical Engineering

Morgantown, WV

2002

Keywords: EV Battery Charging, Battery Recovery, Discharge Test, and Battery Impedance

Copyright 2002, Robert B. Cooper 


\section{Abstract \\ Pulse Charging Lead-Acid Batteries \\ to Improve Performance and \\ Reverse the Effects of Sulfation}

\section{Robert B. Cooper}

When lead-acid batteries are improperly charged or discharged, useful power delivered to loads diminishes. One cause for this is a phenomenon generally referred to as sulfation. One possible method that has been proposed by many to reverse the effects of sulfation is to recharge the lead-acid battery using a pulse charger. To gain a better understanding of the possible benefits of this type of charging, a pulse charger / discharger was constructed. Cycle testing was then done on six pairs of batteries to compare the pulse charged batteries to conventional full-wave rectifier charged batteries. The results of the tests showed that pulse charging failed to improve the condition of sulfated batteries. Pulse charging did resulted in substantial improvements if the battery's condition was classified as fair. However, pulse charging had little effect on the condition of batteries in excellent condition. 


\section{Acknowledgments}

I would like to take this opportunity to thank my research advisor, Dr. Roy Nutter, for his help and guidance during my research. I would also like to thank Dr. Nutter for providing me with the tools and equipment to make my research possible. I would also like to thank Dr. Kathleen Meehan and Dr. Robert McConnell for serving on my research committee and providing me with advice and guidance throughout my research.

Finally, I would like to thank my parents, Russell and Martha Cooper for their unconditional love and support. Without their help I would not have been able to achieve my educational goals. 


\section{Table of Contents}

List of Tables viii

List of Figures $\quad$ ix

Chapter 1: Introduction 1

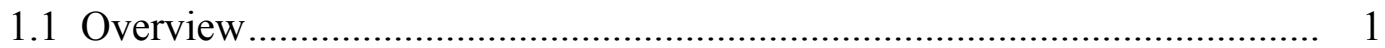

1.2 Lead-Acid Battery Charging .......................................................... 1

1.3 Review of Technical Literature ............................................................. 4

Chapter 2: Statement of Problem 5

$\begin{array}{ll}\text { Chapter 3: Pulse Charger Design } & 6\end{array}$

3.1 Introduction to Pulse Charging ........................................................ 6

3.2 Design Requirements ................................................................. 8

3.2.1 Output Waveform Specifications.................................................... 8

3.2.2 Embedded Computer Requirements ........................................ 10

3.2.3 User Interface Requirements ................................................. 12

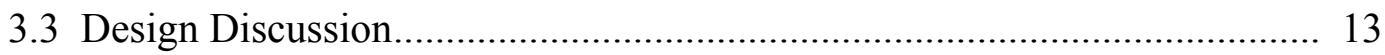

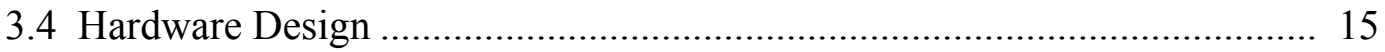

3.4.1 Charge / Discharge Pulse Control.................................................. 16

3.4.2 Pulse Charger to Battery Interface.............................................. 29

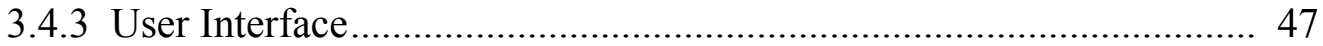

3.4.4 Power Supplies ...................................................................... 55

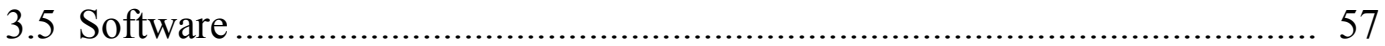

3.5.1 'Pulse Control Microcontroller' Software ....................................... 57 
3.5.2 'User Interface Microcontroller' Software

$\begin{array}{ll}\text { Chapter 4: Experimentation } & 75\end{array}$

4.1 Charging Algorithms ..................................................................... 75

4.1.1 Pulse Charging ................................................................. 75

4.1.2 Normal Charging ................................................................ 77

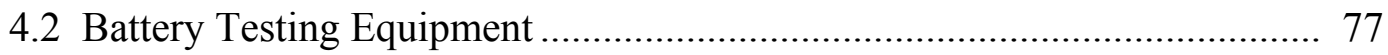

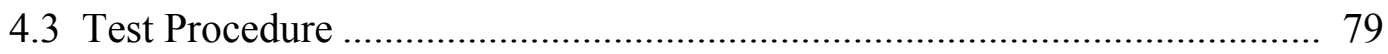

4.3.1 Initial Condition Test ......................................................... 79

4.3.2 Charger Comparison Test .......................................................... 82

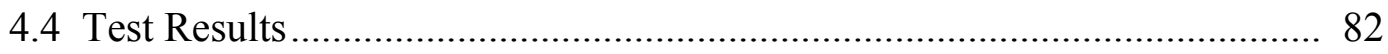

4.4.1 Battery Discharge Tests ......................................................... 83

4.4.2 Battery Discharge Voltages .................................................... 86

4.4.3 Battery Impedance Calculations ............................................ 93

4.4.4 Battery Post-Charge + 24 Hours Voltage Measurements .................. 93

4.4.5 Miscellaneous Battery Test Data ............................................... 93

Chapter 5: Conclusions and Recommendations 95

5.1 Conclusion on the Benefits of Pulse Charging …................................... 95

5.2 Recommendations for Pulse Charger Design Improvements .................... 97

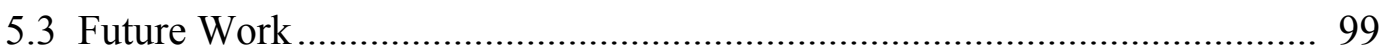

$\begin{array}{lr}\text { Appendix A: Battery Data Files } & 100\end{array}$

A.1 Battery Test Set A - Discharge Time .......................................................100

A.2 Battery Test Set B - Discharge Time ...................................................101

A.3 Battery Test Set C - Discharge Time ….................................................102 
A.4 Battery Test Set D - Discharge Time 103

A.5 Battery Test Set E - Discharge Time 104

A.6 Battery Test Set F - Discharge Time 105

A.7 Miscellaneous Battery Tests - Discharge Voltage Curves 106

A.8 Battery Test Set A - Battery Impedance 107

A.9 Battery Test Set B - Battery Impedance 107

A.10 Battery Test Set C - Battery Impedance 108

A.11 Battery Test Set D - Battery Impedance. 108

A.12 Battery Test Set E - Battery Impedance 109

A.13 Battery Test Set F - Battery Impedance 109

A.14 Battery Test Set A - Post-Charge + 24 Hours Voltage 110

A.15 Battery Test Set B - Post-Charge + 24 Hours Voltage 110

A.16 Battery Test Set C - Post-Charge +24 Hours Voltage.

A.17 Battery Test Set D - Post-Charge +24 Hours Voltage

A.18 Battery Test Set E - Post-Charge +24 Hours Voltage

A.19 Battery Test Set F - Post-Charge +24 Hours Voltage

Appendix B: Pulse Charger Schematics

B.1 Schematic for Components on Printed Circuit Board \#1: Pulse Control.....113

B.2 Schematic for Components on Printed Circuit Board \#2: User Interface ....114

B.3 Schematic for Components on Printed Circuit Board \#3: MOSFETs 115

B.4 Schematic for Components on Printed Circuit Board \#4: +5V Supply .......116

B.5 Schematic for Components on Printed Circuit Board \#5: $\pm 15 \mathrm{~V},+12 \mathrm{~V}$......117

B.6 Schematic for Components Not Mounted on a Printed Circuit Board.........118 
C.1 User Interface Microcontroller Source Code File LCD FUNC.C................119

C.2 User Interface Microcontroller Source Code File TMR_FUNC.C ...............121

C.3 User Interface Microcontroller Source Code File SLAVE.C …....................124

C.4 User Interface Microcontroller Source Code File SLAVE.H ........................140

C.5 Pulse Control Microcontroller Source Code File MASTER.C …………......148

C.6 Pulse Control Microcontroller Source Code File MASTER.H.....................158

$\begin{array}{ll}\text { References: } & 163\end{array}$ 


\section{List of Tables}

Table 3.1 Current requirements summary for the 'Pulse Control Microcontroller

Hardware Block'

Table 3.2 Current requirements summary for the 'Analog Charge Pulse Hardware Block'

Table 3.3 Current requirements summary for the 'Analog Discharge Pulse

Hardware Block'

Table 3.4 Current requirements summary for the 'Analog Switch Hardware

Block' 26

Table 3.5 Current requirements summary for the 'Pulse Charger Internal Temperature Sensor Hardware Block' 28

Table 3.6 Current requirements summary for the 'LCD Hardware Block' 50

Table 3.7 DS1602 control pin states 54

Table 3.8 Current requirements summary for the 'User Interface Microcontroller Hardware Block'

Table 3.9 Current requirements for all low voltage power supplies...................... 55

Table 3.10 Power supply current and design requirements summary .................... 56

Table 3.11 Summary of the fixed execution times and duty cycles for the different pulse charger output waveform sections. ....................................... 62

Table 4.1 Distinguishing characteristics of the battery tests sets ........................ 83

Table 4.2 Summary of the changes in the discharge test times for batteries that were charged normally ............................................................ 85

Table 4.3 Summary of the changes in the discharge test times for batteries that were pulse charged

Table 4.4 Comparison between discharge test time changes using normal charging and pulse charging 86

Table 4.5: Discharge time comparison of two initially unusable batteries. 94 


\section{List of Figures}

Figure 3.1 Example of the charging current from a basic pulse charger operating at $1 \mathrm{kHz}$

Figure 3.2 Example of the charging current from a standard 'off the self' charger. 7

Figure 3.3 Hardware block diagram ...................................................................... 14

Figure 3.4 Charge / Discharge Pulse Control Hardware Block Diagram................. 16

Figure 3.5 Schematic for the 'Pulse Control Microcontroller Hardware Block' ..... 17

Figure 3.6 Schematic for the 'Analog Charge Pulse Hardware Block' .................... 19

Figure 3.7 Schematic for the 'Analog Discharge Pulse Hardware Block' ............... 23

Figure 3.8 Schematic for the 'Analog Switch Hardware Block' .............................. 25

Figure 3.9 Schematic for the 'Pulse Charger Internal Temperature Sensor Hardware Block' ............................................................................. 26

Figure 3.10 Pulse Charger to Battery Interface Hardware Block Diagram .............. 29

Figure 3.11 Schematic for the 'Power Supply Voltage Sensor Hardware Block' .... 30

Figure 3.12 Schematic for the 'Battery Voltage Sensor Hardware Block' ............. 32

Figure 3.13 Schematic for the 'Battery Current Sensor Hardware Block' ............... 34

Figure 3.14 Schematic for the 'Battery Charge Current Hardware Block' and 'Battery Charger Cables Hardware Block' ........................................... 36

Figure 3.15 P-Channel MOSFET voltages and the control pulses using wirewound resistors in the gate drive circuit ................................................ 41

Figure 3.16 P-Channel MOSFET voltages and the control pulses using carbon Resistors in the gate drive circuit.......................................................... 42

Figure 3.17 P-Channel MOSFET turn-off time...................................................... 43

Figure 3.18 User Interface Hardware Block Diagram ............................................ 48

Figure 3.19 Schematic for the 'LCD Hardware Block' ............................................ 49

Figure 3.20 Schematic for the 'Keypad Hardware Block' ...................................... 51

Figure 3.21 Schematic for the 'User Interface Microcontroller Hardware Block' ... 52

Figure 3.22 Main Program Flowchart for the 'Pulse Control Microcontroller' ....... 58

Figure 3.23 Source code segment that calculates charge pulse delay times............. 59

Figure 3.24 Source code segment that generates the charge pulse using the fast charging algorithm ................................................................... 60 
Figure 3.25 Interrupt handler routine for the 'Pulse Control Microcontroller' ....... 65

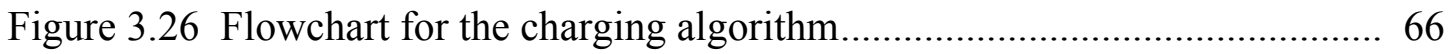

Figure 3.27 Main Program Flowchart for the 'User Interface Microcontroller' ...... 68

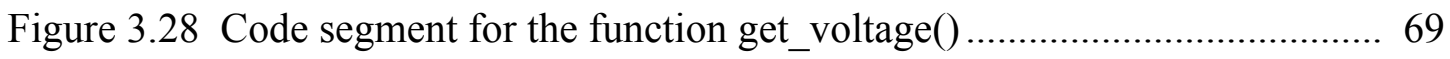

Figure 3.29 Code segment for the function get_battery_current () ......................... 70

Figure 3.30 Code segment for the function get_internal_temperature () ................. 71

Figure 3.31 Code segment for the elapsed timer lookup table ............................ 73

Figure 4.1 Example of the Pulse Charger's output as measured at the battery

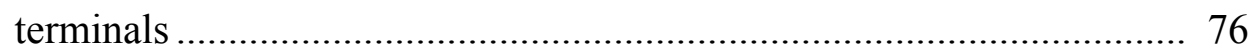

Figure 4.2 Example of the Normal Charger's output as measured at the battery terminals ..................................................................................... 78

Figure 4.3 Segment of a discharge test data file with scaled and actual voltage and current data .................................................................. 80

Figure 4.4 Comparison between pulse charged and normally charged batteries...... 84

Figure 4.5 Initial and final discharge test voltage curves for Battery Test Set A..... 87

Figure 4.6 Initial and final discharge test voltage curves for Battery Test Set B ..... 88

Figure 4.7 Initial and final discharge test voltage curves for Battery Test Set C.... 89

Figure 4.8 Initial and final discharge test voltage curves for Battery Test Set D.... 90

Figure 4.9 Initial and final discharge test voltage curves for Battery Test Set E ..... 91

Figure 4.10 Initial and final discharge test voltage curves for Battery Test Set F ... 92 


\section{Chapter 1: Introduction}

\subsection{Overview}

Improper charging of lead acid batteries or leaving them in a discharged state for long periods of time often leads to premature failure of the battery. One of the major causes for premature failure is a condition commonly known as battery sulfation. This accounts for $84 \%$ of all lead acid battery failures [4]. Sulfation is a condition characterized by the battery not being able to hold the proper voltage, unable to provide useful current, possessing a higher than normal internal impedance, or any combination of the three. Since the premature failure of batteries can add significantly to the maintenance costs of electric vehicles and other systems that use lead-acid batteries, any process that can prevent premature failure is highly desirable.

\subsection{Lead-Acid Battery Charging}

As a lead acid battery is discharged the following reaction takes place [1]:

$$
\begin{aligned}
& \text { Negative plate: } \quad \begin{array}{l}
\mathrm{Pb} \rightarrow \mathrm{Pb}^{2+}+2 \mathrm{e} \\
\\
\mathrm{Pb}^{2+}+\mathrm{SO}_{4}{ }^{2-} \rightarrow \mathrm{PbSO}_{4} \\
\text { Positive plate: } \quad \mathrm{PbO}_{2}+2 \mathrm{H}^{+}+2 \mathrm{e} \rightarrow \mathrm{Pb}^{2+}+2 \mathrm{H}_{2} \mathrm{O} \\
\\
\mathrm{Pb}^{2+}+\mathrm{SO}_{4}{ }^{2-} \rightarrow \mathrm{PbSO}_{4}
\end{array}
\end{aligned}
$$


In a fully charged battery, there should be no lead sulfate $\left(\mathrm{PbSO}_{4}\right)$ present on the battery's plate grids. As can be seen from equations 1.1 and 1.2 when a battery is discharged, lead $(\mathrm{Pb})$ from the negative battery plate and lead oxide $\left(\mathrm{PbO}_{2}\right)$ from the positive battery plate are converted to lead sulfate. As the battery discharge process progresses, the electrochemical reactions will continue until no more lead sulfate can be formed. At this point, the battery will be in a fully discharged state and unable to provide further current to a load.

In order to recharge the lead-acid battery, the reverse electro-chemical reactions to the ones described by equations 1.1 and 1.2 must take place. The reverse processes are implemented by the application of an external electrical power source which provides the energy to overcome the thermodynamically favored direction. The reactions that take place are described by equations shown below [1].

$$
\begin{array}{ll}
\text { Negative plate: } & \mathrm{PbSO}_{4} \rightarrow \mathrm{Pb}^{2+}+\mathrm{SO}_{4}{ }^{2-} \\
& \mathrm{Pb}^{2+}+2 \mathrm{e} \rightarrow \mathrm{Pb} \\
\text { Positive plate: } & \mathrm{PbSO}_{4} \rightarrow \mathrm{Pb}^{2+}+\mathrm{SO}_{4}{ }^{2-} \\
& \mathrm{Pb}^{2+}+2 \mathrm{H}_{2} \mathrm{O} \rightarrow \mathrm{PbO}_{2}+2 \mathrm{H}^{+}+2 \mathrm{e}
\end{array}
$$

As the battery is recharged, the lead sulfate is converted back into lead and lead oxide.

The lead sulfate that remains after recharging the battery is what is commonly called sulfation. When the sulfation condition occurs, lead sulfate crystals grow on the plates of the lead acid battery. As the crystals grow larger, their solubility within the 
electrolyte solution decreases [2], making it very difficult to convert the lead sulfate back to lead and lead-oxide during the next recharge cycle. Eventually, the crystals become hard and chemically inactive [3]. When this happens, the lead sulfate can no longer be converted using conventional charging techniques and the battery's capacity is permanently reduced due to the loss of active material.

Although lead sulfate is a normal product in the discharge / charge cycle of a lead acid battery, subjecting the battery to certain conditions or practices will make the problem of sulfation arise more quickly. By examining equations 1.1, 1.2, 1.3, and 1.4, the two ways that sulfation can occur in a lead acid battery become apparent [3]. If the battery has been discharged to a point where there is mostly lead sulfate present on the battery plates, then it will be difficult to convert all of the lead sulfate back to lead and lead oxide during the recharge process. Although an excessively discharged battery, less than $10 \%$ capacity remaining, is more susceptible to the effects of sulfation, leaving any lead-acid battery in a discharged state for an extended period of time will produce sulfation [3]. Equations 1.1 and 1.2 also show how excessive discharge can lead to cell reversal, a condition where the polarity of the battery's individual cells reverse. Also, if the battery has not been recharged completely, thereby leaving a small amount of lead sulfate present on the plates, this lead sulfate will harden over time and become chemically inactive and thereby reducing the overall quantity of active material within the battery. Although there are many reasons for lead sulfate to remain on the plates after recharge, two of the most preventable ones are when a user removes a battery from the charger before it has completely recharged and when a user uses an improper charging technique to recharge the battery. 


\subsection{Review of Technical Literature}

One possible method to reverse the effects of sulfation is to use a pulsed current source to charge the lead-acid battery $[3,8]$. Although several commercially available pulse-charging systems exist, such as the "RediPulse Charger" from PulseTech Products Corporation, there have been very few independent tests done to prove their effectiveness $[4,5]$. In addition to the lack of independent tests of pulse chargers, there are no published papers dealing with the design parameters of pulse chargers. Most of the information obtained regarding the design of the pulse charger was obtained from relevant patents $[11,12,13,14,15,16,17,18,19]$. While some research has been done with regards to pulse charging techniques, a large portion of this research has dealt with rapid charging of lead-acid batteries $[9,10]$.

Currently, there are two groups of devices that claim to reverse the effects of lead acid battery sulfation. One group consists of those devices that do not charge the battery but instead apply a pulsed current ranging from a few milliamps up to one amp. They are generally referred to as pulse rejuvenators. These devices are intended to revive the battery and return it to a condition where a conventional constant voltage / constant current charger could be used to recharge the battery to full capacity. The other group consists of devices that are actually battery chargers that use a pulsed current instead of the d. c. constant voltage sources used in conventional chargers. These pulse chargers actually combine the functions of the pulse rejuvenators and conventional chargers into one unit. 


\section{Chapter 2: Statement of Problem}

A pulse charger and experimental procedure will be developed to determine if pulse charging is useful in reversing the effects sulfation and improving a lead-acid battery's overall condition. The pulse charger parameters will be determined using average parameter values from commercially available pulse chargers and pulse rejuvenators.

Once a pulse charger has been built and tested, charge / discharge tests will be run on several lead-acid batteries of various ages and conditions in order to determine the effectiveness of pulse charging as compared to conventional constant voltage / constant current charging. The test batteries that will be used are Optima "Red Top" Model 800S Absorbed Glass Matt (AGM) lead-acid batteries.

This research will attempt to answer two basic questions regarding pulsed current charging.

- Is pulse charging effective in improving the condition of lead-acid batteries that are in a condition that is significantly lower than that of new lead-acid batteries?

- If pulse charging did not restore the battery, is the battery's discharge test time, internal impedance, or no-load terminal voltage any worse after having been subjected to this type of charging? 


\section{Chapter 3: Pulse Charger Design}

\subsection{Introduction to Pulse Charging}

Pulse charging is a process of charging a battery with a current that alternates between the desired charging current, $\mathrm{I}_{\mathrm{CHRG}}$, and zero. This differs from standard 'offthe-shelf' battery chargers that provide a non-controlled charging current. Example outputs from each type of charger are shown in Figures 3.1 and 3.2.

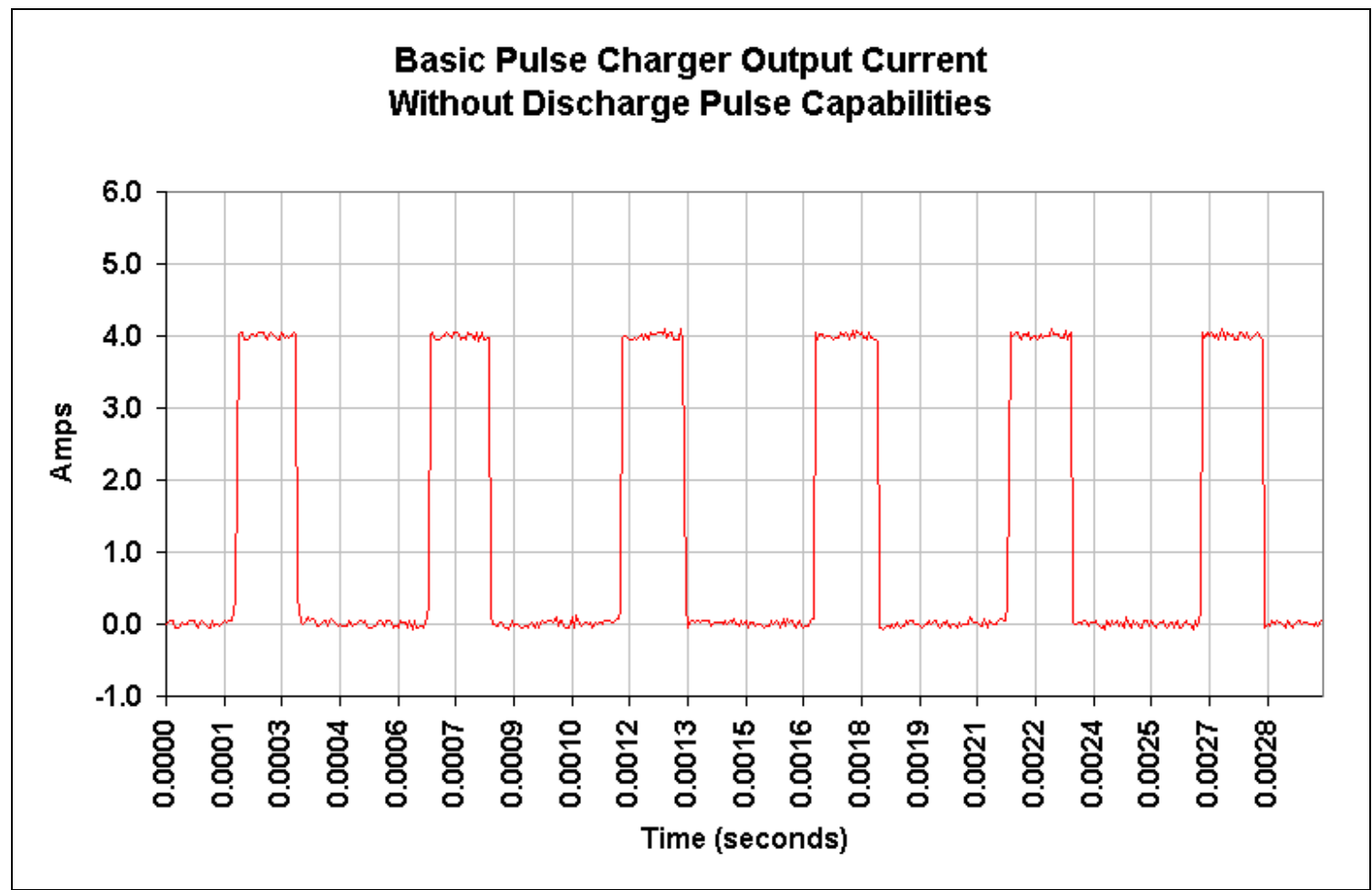

Figure 3.1: Example of the charging current from a basic pulse charger operating at $1 \mathrm{kHz}$. 


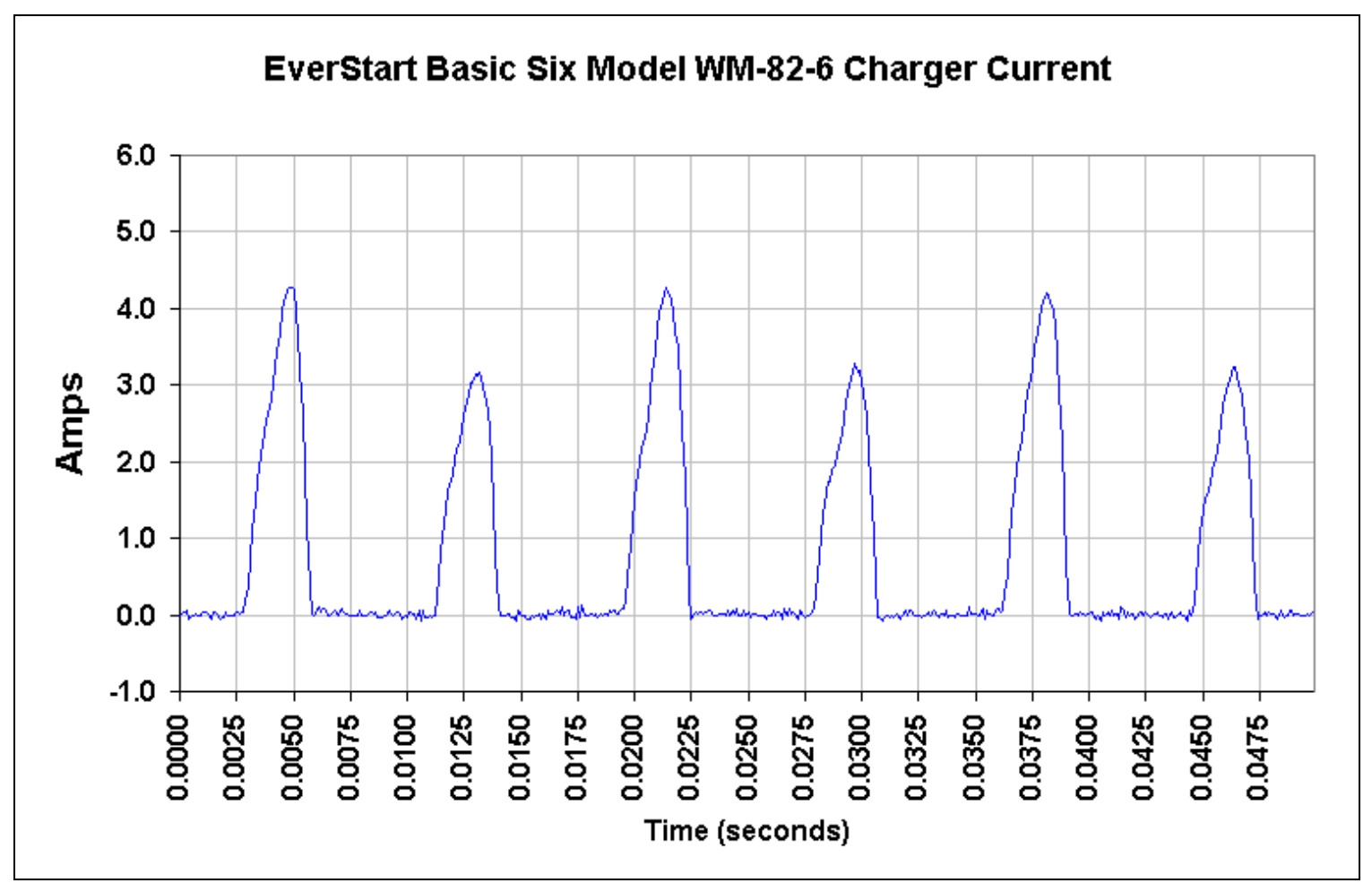

Figure 3.2: Example of the charging current from a standard 'off the self' charger.

Although the current from the pulse charger is shown as rectangular pulses, the output waveform can be any shape as long as the current goes to zero for some portion of the oscillation period. Other parameters for the description of the pulse charger output waveform can also be varied from those shown in Figure 3.1. Some of these other parameters are pulse frequency, current amplitude, and pulse duty cycle.

The amplitude of the output current from a standard 'off-the-shelf' charger can also vary from that shown in Figure 3.2. By examining the output current of the standard charger, it appears that the charging current is also pulsed into the battery. However, these current pulses are uncontrolled. They are simply the result of the standard charger using unfiltered unregulated full-wave rectified AC line current as the source of charging current. 


\subsection{Design Requirements}

To test how effective pulse charging is in rejuvenating lead-acid batteries in various conditions, certain parameters of the pulse charger itself needed to be determined before the design and construction of the charger could take place.

\subsubsection{Output Waveform Specifications}

The following list consists of the design criteria related to the output waveform of the charger. The list includes all the required information to construct the output waveform along with a brief discussion regarding the reasons for each choice. The output waveform consists of a charge pulse, a discharge pulse, a rest period between the charge pulse and the discharge pulse, and a rest period between the discharge pulse and the charge pulse of the next cycle.

- $\quad$ Pulse Frequency $\left(\mathrm{f}_{\mathrm{P}}\right)=1 \mathrm{kHz}$

The few pulse chargers that are commercially available use a pulse frequency ranging from a few hertz to $20 \mathrm{kHz}$. There was no one pulse frequency that all manufacturers and patent holders agreed upon. The decision to use $1 \mathrm{kHz}$ was made based on the fact that this was the highest frequency that the PIC16F877 Microcontroller could provide and still perform other required functions.

- $\quad$ Charge Pulse Time $\left(\mathrm{t}_{\mathrm{CHRG}}\right)=0.2 * \mathrm{f}_{\mathrm{P}}^{-1}=200 \mu \mathrm{s}$

A $20 \%$ duty cycle was selected in order to achieve the longest possible charge time while leaving enough time to fit in a substantial rest period before a discharge pulse was applied to the battery. 
- Rest time between charge pulse and discharge pulse $\left(t_{\mathrm{OFF} 1}\right)=0.6 * \mathrm{f}_{\mathrm{P}}^{-1}=600 \mu \mathrm{s}$

- $\quad$ Discharge Pulse Time $\left(t_{\mathrm{DCHRG}}\right)=0.1 * \mathrm{f}_{\mathrm{P}}^{-1}=100 \mu \mathrm{s}$

Since the length of the discharge pulse was unimportant a $10 \%$ duty cycle was selected since this was the minimum time required by the microcontroller to turn on the discharge pulse, read two analog voltages, and then turn off the discharge pulse.

- $\quad$ Rest time until next charge pulse $\left(\mathrm{t}_{\mathrm{OFF} 2}\right)=0.1 * \mathrm{f}_{\mathrm{P}}^{-1}=100 \mu \mathrm{s}$ A second rest period was added to the charger waveform to allow time for the discharge current to turn off before the charge pulse was again applied to the battery.

- $\quad$ Charge Pulse Rise Time $\left(t_{R C P}\right)=1 \mu$ s or less

The pulse rise time is the one parameter that most manufacturers and patent holders agreed upon. All relevant information that was examined stated that the charge pulse should have as fast a rise time as possible. A time of $1 \mu$ s was selected because this was the fastest that could be produced using reasonably priced components and not needing special printed circuit board layouts.

- Charge Pulse Fall Time $\left(\mathrm{t}_{\mathrm{FCP}}\right)=50 \mu$ s or less

This is one of the parameters than no one can agree on. A time of $50 \mu$ s was selected as a value that could be achieved without special components.

- Discharge Pulse Rise Time $\left(t_{\mathrm{RDP}}\right)=1 \mu \mathrm{s}$ or less.

The discharge pulse's rise and fall times were selected for the same reasons that the charge pulse's rise and fall times were selected.

- $\quad$ Discharge Pulse Fall Time $\left(\mathrm{t}_{\mathrm{FDP}}\right)=50 \mu$ s or less 
The discharge pulse's fall time was one of the most critical design criteria that had to be meet. The discharge pulse had to be completely turned off by the time the next charge pulse was applied to the battery or excessive current could flow from the external power supply through the charge pulse controller and discharge resistor.

- Maximum Charge Voltage $\left(V_{\text {CHRG_MAX }}\right)=40$ Volts

Both the maximum charge voltage and the maximum charge current were set by the use of the external power supply.

- Maximum Charge Current ( $\left.\mathrm{I}_{\text {CHRG_MAX }}\right)=60$ Amps

- Maximum Discharge Current $\left(\mathrm{I}_{\mathrm{DCHRG} \_\mathrm{MAX}}\right)=0.1 * \mathrm{I}_{\mathrm{CHRG}}$ It was decided that the maximum discharge current should be no more than $10 \%$ of the charging current. The battery will still have a net charging current of up to $90 \%$. The prototype pulse charger actually has a discharge current that is about $2 \%$ of the charging current.

\subsubsection{Embedded Computer Requirements}

With the requirements for the output waveform of the pulse charger determined, the next set of design criteria needed relates to generating the specified waveform itself. These criteria are listed below.

- The waveform will be generated using a software control algorithm to minimize stability problems and increase frequency accuracy.

- Required external data that will be needed to monitor and control the output waveform: 
○ Battery voltage at the end of the first rest period. This voltage will be referred to as the battery open-circuit voltage $\left(\mathrm{V}_{\mathrm{BOC}}\right) . \mathrm{V}_{\mathrm{BOC}}$ is required to make the battery impedance calculation and to assist in the determination of the battery's state of charge.

- Battery voltage during the period when the charge pulse is on. This voltage will be referred to as the battery charging voltage $\left(\mathrm{V}_{\mathrm{BCHRG}}\right)$.

- Battery voltage during the period when discharge pulse is on. This voltage will be referred to as the battery discharge voltage $\left(\mathrm{V}_{\mathrm{DCHRG}}\right)$. The value of $\mathrm{V}_{\mathrm{DCHRG}}$ along with $\mathrm{V}_{\mathrm{BOC}}$ are used to calculate the battery's internal impedance. $\mathrm{V}_{\mathrm{DCHRG}}$ is also used to assist in the determination of the battery's state of charge.

- Charging Current $\left(\mathrm{I}_{\mathrm{CHRG}}\right)$. The value of $\mathrm{I}_{\mathrm{CHRG}}$ and $\mathrm{V}_{\mathrm{BCHRG}}$ are used to give the user information on how the pulse charger is charging the battery.

- Discharge Current $\left(\mathrm{I}_{\mathrm{DCHRG}}\right)$. The value $\mathrm{I}_{\mathrm{DCHRG}}$ is displayed to provide the user with information regarding the battery's ability to supply current.

- Charging Current Power Supply Voltage $\left(\mathrm{V}_{\mathrm{PS}}\right)$. The power supply voltage needs to be monitored so that adjustments can be made if the charging voltage or charging current become too excessive or if either needs to be increased.

- Charger Internal Temperature $\left(\mathrm{T}_{\mathrm{INT}}\right)$. The internal temperature is monitored so that the charger can be safely shutdown before causing damage to the internal components if the charge current control hardware begins to overheat. 
- Any microcontroller used for the control of the charge and discharge pulses will need to have a minimum of 5 analog input pins. The three battery voltages, opencircuit, charge, and discharge, can share one analog input pin since these voltages are read at different times from the same connection point in the circuit.

- Any microcontroller used for the control of the charge and discharge pulses will require a minimum of 18 digital output pins. Since 8-bit digital-to-analog converters are used, the charge and discharge pulse are described by 8 bits each. 2 control bits are required for an analog switch used to .

- Any microcontroller used for the control of the charge and discharge pulses will be required to have built-in hardware support for RS232 serial communications. Using the built-in serial hardware of the microcontroller will simplify circuit design and minimize components. A serial communications capability is required so that the pulse charger's two microcontrollers can communicate with each other.

- Minimum operating speed of the pulse control microcontroller will need to be $20 \mathrm{MHz}$. This is so that the microcontroller will operate at a speed that will allow it to read analog data and at the same time be able to generate and control the pulse charger's output waveform.

\subsubsection{User Interface Requirements}

The final set of design criteria deals with the user interface aspect of the pulse charger. These requirements are listed below.

- Any microcontroller used for user interface control will be required to have builtin hardware support for RS232 serial communications. 
- Any microcontroller used for user interface control will need to have a minimum of 26 digital I/O pins.

- 8 pins for LCD display data

- 6 pins for the LCD and elapsed timer control lines

○ 12 pins for keypad data input

- An LCD with a minimum display capability of 2 lines with 20 characters per line. An LCD is required so that information regarding the pulse charger's operating parameters can be displayed to the user.

- A 12-key keypad for user input to the pulse charger.

A keypad is required so that the user can modify selected charger settings.

- An elapsed timer capably of keeping track of the elapsed time for a minimum of 24 hours.

A timer is required for the 'Timed Charge' feature of the microcontroller.

- The user interface microcontroller will need to operate at a frequency of $4 \mathrm{MHz}$. This is to accommodate the timing requirements of the LCD. Although a faster clock could be used, it would have resulted in wasted clock cycles since the LCD is a much slower device than the microcontroller.

\subsection{Design Discussion}

To facilitate a clear understanding for the design of the pulse charger, the process will be divided into several sections. Overall, the design of the pulse charger can be divided into a hardware element and a software element. The hardware element can be further divided into three general sections: User Interface, Charge / Discharge Pulse 
Control, and Pulse Charger Battery Interface. The block diagram in Figure 3.3 shows the interaction between each of these sections. In addition to the three hardware blocks of

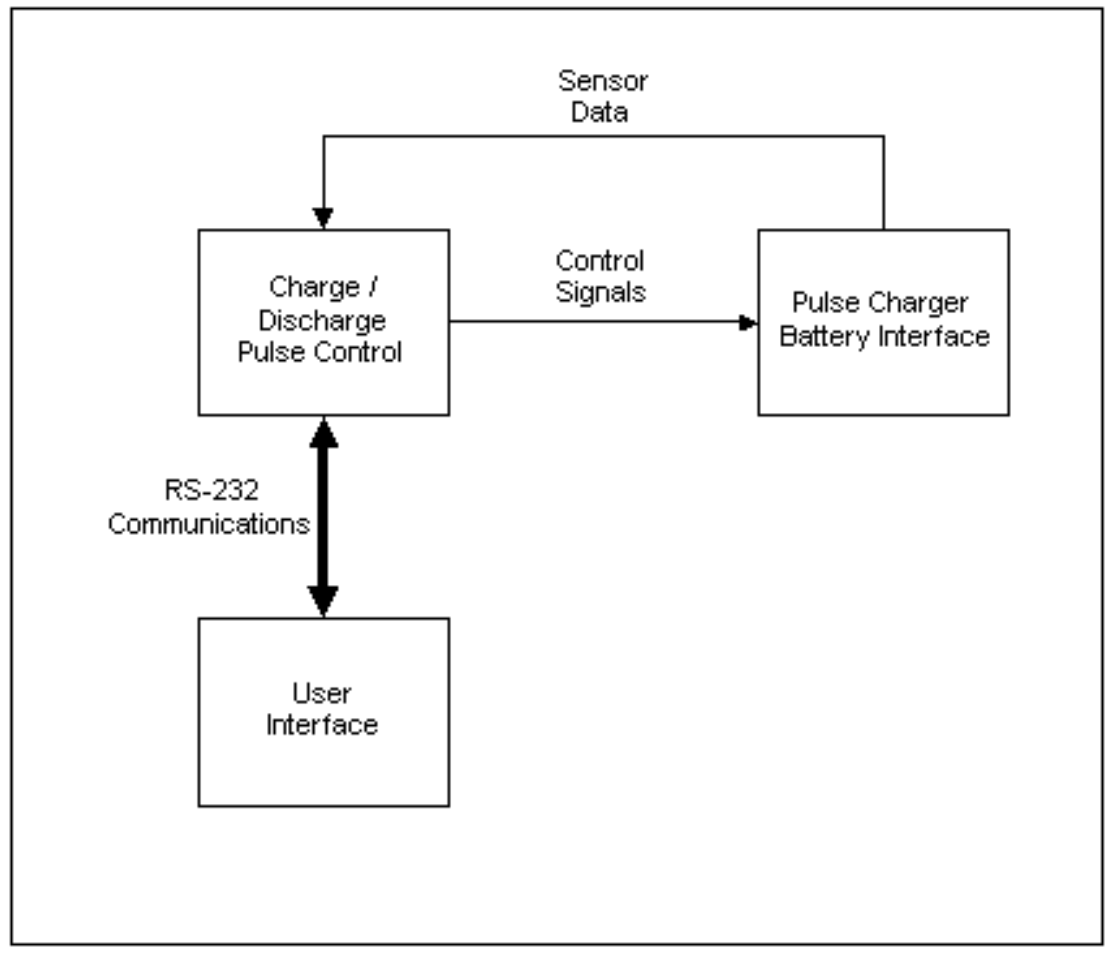

Figure 3.3: Hardware block diagram.

Figure 3.3, several power supplies were designed and built to fulfill the different voltage requirements of the pulse charger's electronic components. The power supplies constructed include a +5 volt supply to power the majority of the charger's electronics, a \pm 15 volt supply to power to several operational amplifiers and a Hall-effect current sensor, and a +12 volt supply to provide power to the pulse charger's cooling fans. A more detailed explanation of each hardware block and power supply as well as design information will be provided later in this chapter. 
The software for the pulse charger was written in $\mathrm{C}$ and compiled using the PIC-C Compiler by Custom Computer Services, Inc of Brookfield, WI. Their website is located at www.ccsinfo.com. Two separate programs were produced, one for the Pulse Control Microcontroller and the other for the User Interface Microcontroller. Flowcharts for the programs and a discussion of the code will be presented in the software section of this chapter.

\subsection{Hardware Design}

The Charge / Discharge Pulse Control Block of Figure 3.3 contains the primary electronic components for the operation of the pulse charger. This block consists of the microcontroller that generates the digital data used to construct the charge and discharge pulse. Since this microcontroller controls the charge and discharge pulses, it will be referred to as the Pulse Control Microcontroller. The Pulse Control Microcontroller also receives data from several external sensors used in the pulse charger. There are also two digital-to-analog converters that transform the digital data from the microcontroller to an analog signal suitable for amplification by operational amplifiers before the signal is applied to the charging and discharge current switching devices. Communication between the Pulse Control Microcontroller and the User Interface Microcontroller, discussed in a later section, is provided by the use of the microcontroller's built-in serial hardware. The serial hardware supports the RS232 communications protocol and so this will be the protocol used by all serial communications. 


\subsubsection{Charge / Discharge Pulse Control}

The block diagram of Figure 3.4 shows the interactions between the hardware of the Charge / Discharge Pulse Control Block. The Charge / Discharge Pulse Control Block Diagram consists of five individual sub-blocks representing the major functions that are performed with regards to generating and controlling the charge and discharge pulses. To better explain the design of the pulse charger, each block will be examined separately with a detailed analysis of the components performing the functions of the block being discussed. This will also be the format used for subsequent discussions concerning the hardware design procedure.

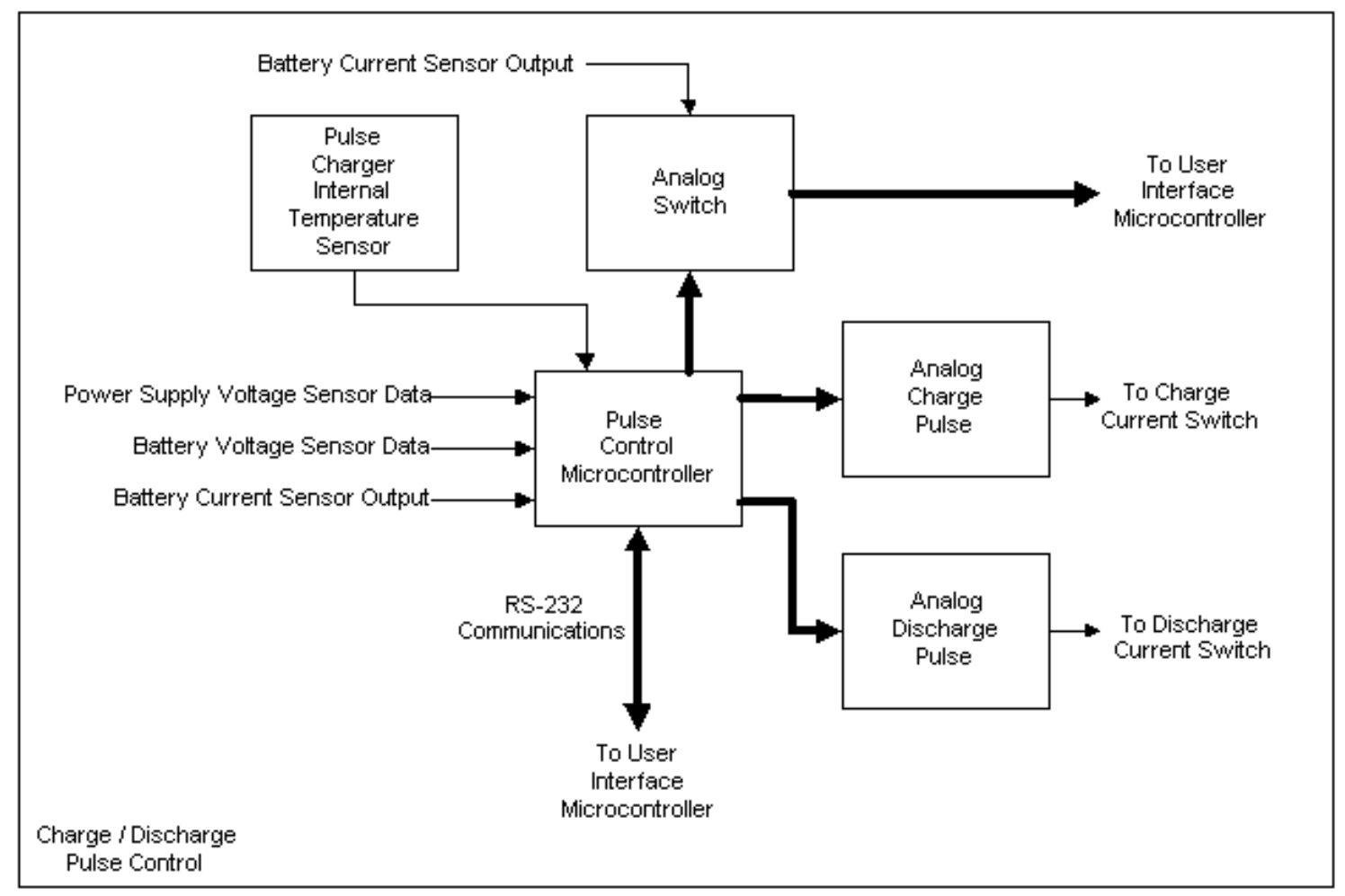

Figure 3.4: Charge / Discharge Pulse Control Hardware Block Diagram. 
The first block that will be examined in more detail is the Pulse Control Microcontroller since it is the central block with which all remaining hardware blocks interact with. The schematic representing the electronic components in this block is shown in Figure 3.5. From the design criteria, it was apparent that the best

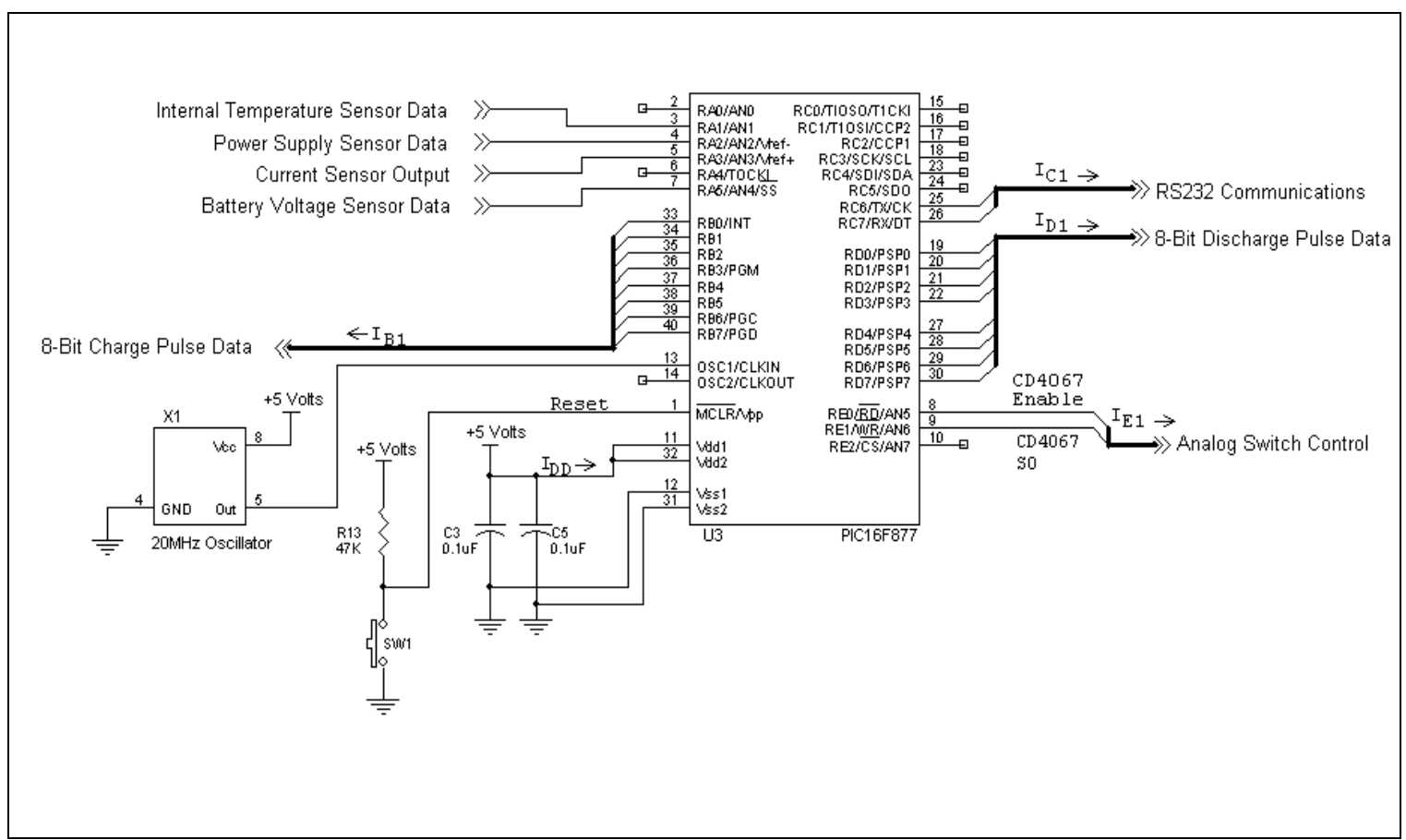

Figure 3.5: Schematic for the 'Pulse Control Microcontroller Hardware Block'

microcontroller to use for U3 was the PIC16F877 from Microchip, Inc., www.microchip.com. The PIC16F877 contains a total of 33 multipurpose I/O pins. It also has eight analog input pins and hardware support for the RS232 communications protocol. Using five of the $\mathrm{I} / \mathrm{O}$ pins for analog input and two for serial communications leaves 26 pins to be used for general I/O, which was more than sufficient. Other advantages of using the PIC16F877 verses other microcontrollers was the PIC's tolerance to 'electrically noisy' conditions, a minimum amount of required support hardware, and 
the ability to run at the required operating frequency of $20 \mathrm{MHz}$. Support hardware for U3 consists of the two $0.1 \mu \mathrm{F}$ power supply bypass capacitors, C3 and C5, the pull-up resistor, R13, which is used for resetting the microcontroller, and the $20 \mathrm{MHz}$ oscillator, $\mathrm{X} 1$.

The power used by $\mathrm{U} 3$ and $\mathrm{X} 1$ is provided by a +5 volt supply. The average supply current, $\mathrm{I}_{\mathrm{DD}}$, required by microcontroller $\mathrm{U} 3$ during standby mode is $6.5 \mathrm{~mA}$ at a supply voltage, $\mathrm{V}_{\mathrm{DD}}$, of 5 Volts and frequency of oscillation, $\mathrm{F}_{\mathrm{OSC}}$, of $20 \mathrm{MHz}$. Additional power will be required by $\mathrm{U} 3$ for the operation of the Port B, C, D and E I/O pins. Each Port A pin will have draw a maximum operating current of $500 \mathrm{nA}$ for a total Port A current of $2 \mu \mathrm{A}$. Therefore, for the purposes of calculating current capacity of the power supply, the Port A pins will be ignored. Each pin of Port B and Port D will need to source a maximum of $100 \mu \mathrm{A}$, resulting in a total current of $1.6 \mathrm{~mA}, \mathrm{I}_{\mathrm{B}}=800 \mu \mathrm{A}$ and $\mathrm{I}_{\mathrm{D}}$ $=800 \mu \mathrm{A}$. The serial transmit and serial receive pins of U3 will source a maximum of 25 $\mathrm{mA}$ and sink a maximum of $25 \mathrm{~mA}$, respectively. Like Port A, the I/O pins of Port E will draw a negligible amount of current from the power supply, on the order of $1 \mu \mathrm{A}$, and so will be ignored for the purposes of calculating the required power supply current capacity. At this point, all of U3's current requirements have been determined. Therefore, the maximum value of $\mathrm{I}_{\mathrm{DD}}$ is $33.1 \mathrm{~mA}$ at worst case. This is given by the following equation:

$$
I_{D D}=I_{D D \min }+I_{B}+I_{D}+I_{R S 232}
$$


The maximum supply current requirement for the oscillator X1 is $25 \mathrm{~mA}$. Pull-up resistor, R13, is used to limit the reset current to a value less than $1 \mathrm{~mA}$. Consequently, the chosen value of R13 must satisfy the following equation:

$$
R 13 \geq \frac{V_{D D}}{I_{\text {RESET_MAX }}}
$$

With the value of $V_{\text {DD }}$ being set at 5 volts and the value of $\mathrm{I}_{\text {RESET_MAX }}$ set at $1 \mathrm{~mA}$, it can be seen that the value of R13 must be at least $5 \mathrm{k} \Omega$. By choosing a resistance of $47 \mathrm{k} \Omega$, the current drawn from the power supply when the microcontroller is reset will be no more than $0.1 \mathrm{~mA}$.

At this point, all current requirements for the electronic components of the Pulse Controller Microcontroller Block have been calculated. These requirements are summarized in Table 3.1.

\begin{tabular}{|c|c|c||}
\hline \hline $\begin{array}{c}\text { PART } \\
\text { INDENTIFIER }\end{array}$ & $\begin{array}{c}\text { POWER } \\
\text { SUPPLY }\end{array}$ & $\begin{array}{c}\text { CURRENT } \\
\text { REQUIREMENT }\end{array}$ \\
\hline U3 & +5 Volt & $33.1 \mathrm{~mA}$ \\
\hline $\mathrm{X} 1$ & +5 Volt & $25.0 \mathrm{~mA}$ \\
\hline R13 & +5 Volt & $0.10 \mathrm{~mA}$ \\
\hline
\end{tabular}

Table 3.1: Current requirements summary for the 'Pulse Control Microcontroller Hardware Block'.

The Analog Charge Pulse Block of Figure 3.4 consists of an 8-bit digital-toanalog converter and a precision rail-to-rail operational amplifier. The schematic for this block is shown in Figure 3.6. 


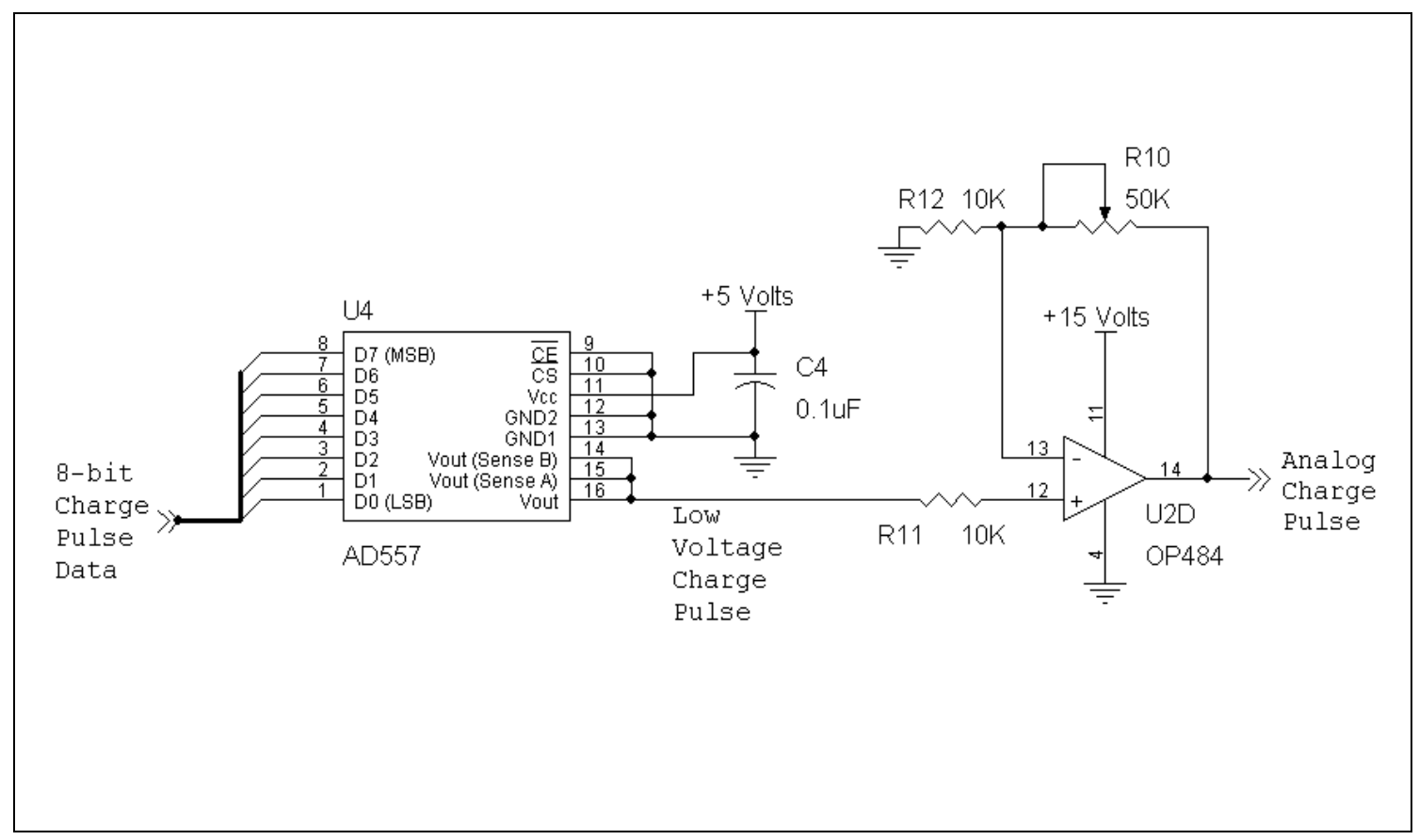

Figure 3.6: Schematic for the 'Analog Charge Pulse Hardware Block'

The function that the components contained in the Analog Charge Pulse Block perform is to convert the digital charge pulse data from microcontroller U3 of Figure 3.5 into an analog voltage pulse of sufficient amplitude to drive the gate of an N-Channel MOSFET. To convert the digital data to an analog signal a microprocessor compatible digital-to-analog convert (DAC) was selected. The AD557 was selected due to its fast settling time and ease with which it could be incorporated into the circuit design. Although the DAC is microprocessor controllable, this feature was not used due to the lack of a common data bus and the total absence of an address bus in the pulse charger's hardware design. Because of this, the chip select pin, CS, and the chip enable pin, CE, of U4 in Figure 3.6 have been connected to ground. Also, since U4 is to be operated with a full-range output of $0-2.56$ volts, the voltage output sensor pins have been tied to $\mathrm{V}_{\text {OUT }}$. According to the datasheet for the AD557, the output settling time for U4 is typically $0.8 \mu$ s with an error of $\pm 1 / 2$ LSB. Since the settling time of U4 is much shorter than the 
slew rate of the op-amp that is driven, U4's settling time will have a minimal effect on the rise times of the charge and discharge pulses that are eventually applied to the battery. In order to satisfy the design requirements, it was extremely important that the operational amplifier, U2D, have a high slew rate. Therefore, the op-amp chosen was the OP-484. This op-amp was wired in a non-inverting configuration in order to maintain the input and output voltages in phase. Although the OP-484's slew rate of $4 \mathrm{~V} / \mu \mathrm{s}$ at a load resistance of $2 \mathrm{k} \Omega$ was not as fast as desired, it was sufficient to meet the design criteria. The time required for the OP-484's output voltage to transition from minimum to maximum is given by the following equation:

$$
t_{\text {SLEW }}=\frac{V_{\text {OUT }}}{\text { SlewRate }}
$$

With a desired output voltage from the op-amp of 10 volts, the transition time, $\mathrm{t}_{\text {SLEW }}$, will be $2.5 \mu \mathrm{s}$. The reason for an output voltage of 10 volts is that a higher voltage will more quickly charge the gate capacitance of the MOSFET being driven by U2D and, thereby, produce a faster rise time for the charge pulse that is applied to the lead-acid battery. Although the output from U2D will require $2.5 \mu$ s to reach 10 volts, the MOSFET will have turned on by the time the voltage has reached the maximum gate threshold voltage of 4 volts. By substituting a value of 4 for $V_{\text {Out }}$ in equation 3.3, it can be seen that the

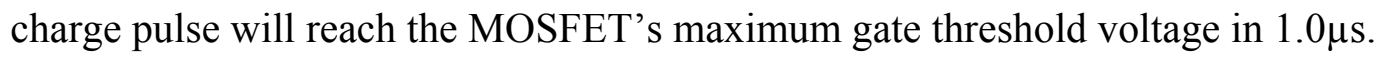

In order to obtain the correct output voltage from U2D, its gain needs to be adjusted by controlling the values of resistors R10 and R12 of Figure 3.6. With an input voltage of approximately 2.5 volts and a desired output voltage of 10 volts, the required 
ideal gain for $\mathrm{U} 2 \mathrm{D}$ is 4 . The gain for an op-amp in a non-inverting configuration is given by the following equation:

$$
\frac{V_{\text {out }}}{V_{\text {in }}}=1+\frac{R_{10}}{R_{12}}
$$

By using a potentiometer for resistor R10 the gain can be adjusted to account for component tolerances and give the desired value of 4 . With the value of resistor R12 set at $10 \mathrm{k} \Omega$, the ideal value for resistor R 10 will be $30 \mathrm{k} \Omega$. A $50 \mathrm{k} \Omega$ potentiometer was selected for R10 since this is the closest standard value that is higher than the calculated value of R10. The resistance of R10 is given by the equation below.

$$
R_{10}=R_{12}\left(\frac{V_{\text {out }}}{V_{\text {in }}}-1\right)
$$

Since the AD557 DAC, U4, is a low power device, the maximum operating current required from the +5 volt supply is $15 \mathrm{~mA}$. The required output current from the U4 is negligible since its output is connected to the input of the op-amp U2D. The maximum operating current for $\mathrm{U} 2$ is $250 \mu \mathrm{A}$ in addition to any sourcing currents from the four individual op-amps contained in the complete IC. The output current of U2D is $1 \mathrm{~mA}$, which is calculated by dividing the output voltage by the load resistance. The output voltage is 10 volts and the load resistance is approximately $10 \mathrm{k} \Omega$. U2's supply current will be provided by the +15 volt supply. Table 3.2 summarizes the current 
requirements for the Analog Charge Pulse Block and will be used in the power supply design section later in this chapter.

\begin{tabular}{||c|c|c||}
\hline PART & POWER & CURRENT \\
INDENTIFIER & SUPPLY & REQUIREMENT \\
\hline U2 + U2D & +15 Volt & $1.25 \mathrm{~mA}$ \\
\hline $\mathrm{U} 4$ & +5 Volt & $15.0 \mathrm{~mA}$ \\
\hline
\end{tabular}

Table 3.2: Current requirements summary for the 'Analog Charge Pulse Hardware Block'.

The Analog Discharge Pulse Block of Figure 3.4 consists of an 8-bit digital-toanalog converter and a precision rail-to-rail operational amplifier. The schematic for this block is shown in Figure 3.7. Since the Analog Discharge Pulse Block contains the same electronic components as the Analog Charge Pulse Block and must satisfy the same design requirements, only a brief description of the operation and design will be provided.

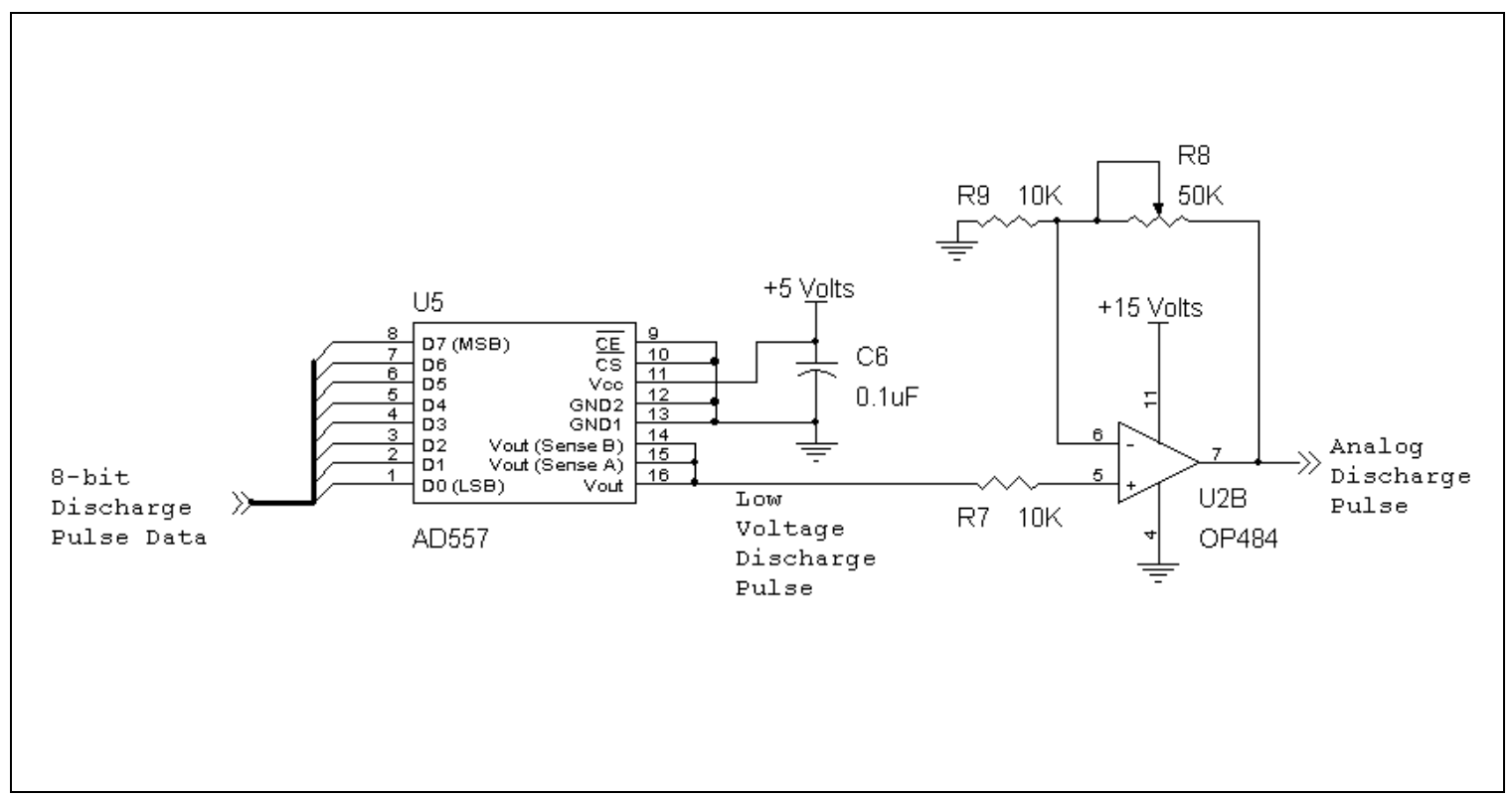

Figure 3.7: Schematic for the 'Analog Discharge Pulse Hardware Block' 
The only difference between the Analog Discharge Pulse Block and the Analog Charge Pulse Block is the op-amp's output current. Since the op-amp of the discharge block connects directly to the gate of the discharge pulse MOSFET, only a small gate leakage current will be required from the op-amp. According to the datasheet for the MOSFET, the gate leakage current, both forward and reverse, will be no more than 100 nA. Because less output current is required from the op-amp and U2's operating current has already been accounted for in Table 3.2, the overall power requirements for this block are lower than those of the Analog Charge Pulse Block as can be seen in Table 3.3.

\begin{tabular}{|c|c|c||}
\hline PART & POWER & CURRENT \\
INDENTIFIER & SUPPLY & REQUIREMENT \\
\hline U5 & +5 Volt & $15.0 \mathrm{~mA}$ \\
\hline
\end{tabular}

Table 3.3: Current requirements summary for the 'Analog Discharge Pulse Hardware Block'.

The Analog Switch Block in Figure 3.4 takes the single current sensor output signal and splits it into a charging current data signal and a discharge current data signal. While separate signals are not required for the direct operation of the pulse charger, they were needed for the LabView interface feature that has been included. Microcontroller U3 will control the analog switch since it will collect and process the data regarding at what times the current sensor output contains charging current data and at what times the sensor output contains discharge current data. The analog switch that was used is a CD4067 Analog Multiplexer / Demultiplexer. The schematic for the Analog Switch Block is shown in Figure 3.8. Since only 2 of the 16 outputs are required address lines, S1, S2, and S3 of U6 are unused and so have been connected to ground. The remaining 


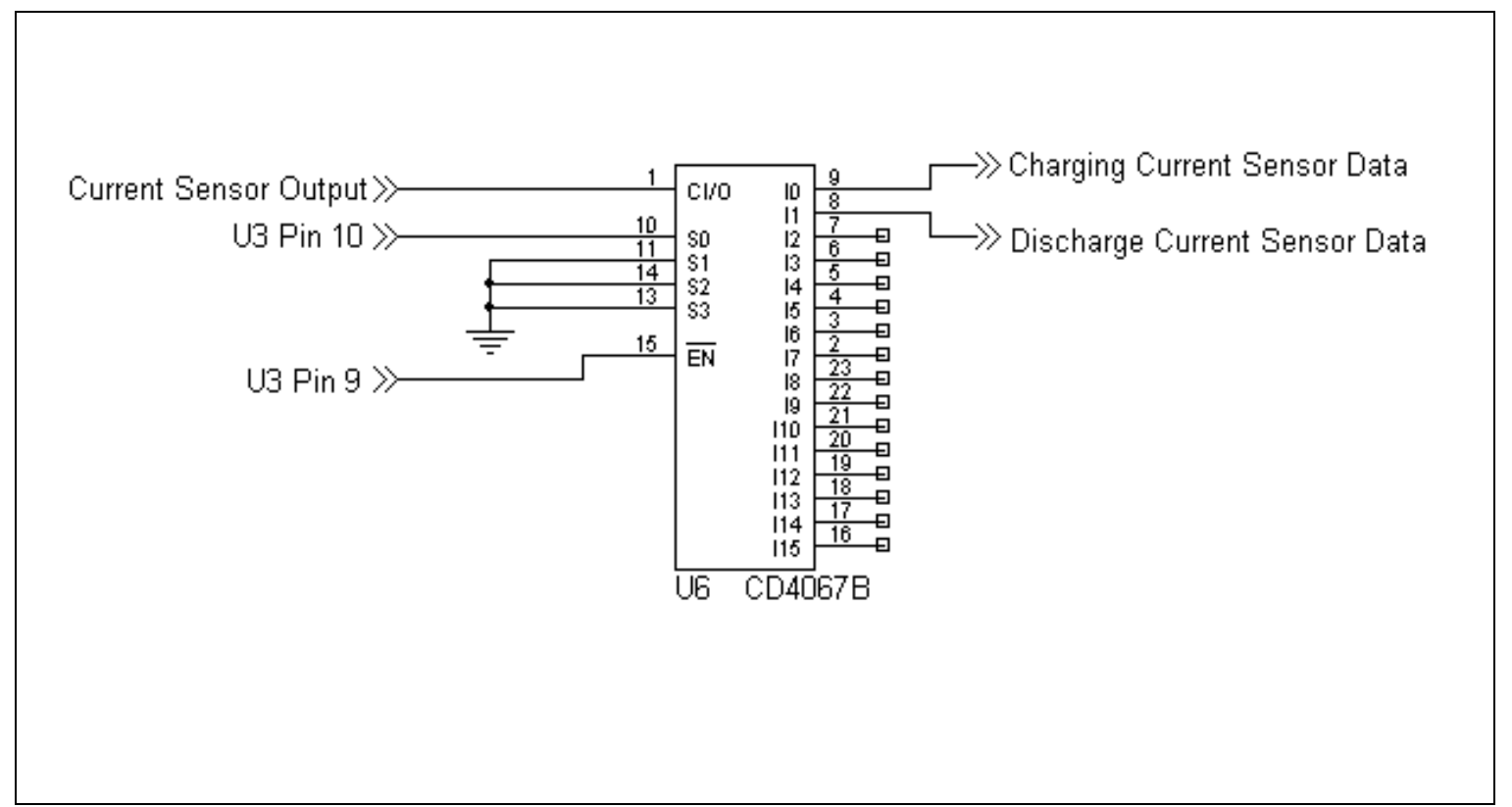

Figure 3.8: Schematic for the 'Analog Switch Hardware Block'

address pin, S0, is used to control the selected output pin. Whenever address line S0 is low the signal on the input pin, $\mathrm{CI} / \mathrm{O}$ will be connected to output pin $\mathrm{I} 0$. When $\mathrm{S} 0$ is high, the signal on $\mathrm{CI} / \mathrm{O}$ will be connected to $\mathrm{I} 1$, assuming that $\mathrm{U} 6$ is enabled by placing a low signal on pin 15. If the enable pin is high, then the input of U6 is disconnected from all output pins.

To pass the input signal through U6 to one of its outputs results in a maximum propagation delay of $650 \mathrm{~ns}$. A maximum propagation delay of $440 \mathrm{~ns}$ results when the any output of U6 is disconnected for the input. Since these delays are much shorter than the $1 \mathrm{~ms}$ delays that are imposed by the LabView VI used read the pulse charger's analog data signals, they will be ignored. It will be assumed that U6's input is instantaneously connected to and disconnected from its outputs. U6's operating power requirements are given in Table 3.4 . 


\begin{tabular}{|c|c|c||}
\hline $\begin{array}{c}\text { PART } \\
\text { INDENTIFIER }\end{array}$ & $\begin{array}{c}\text { POWER } \\
\text { SUPPLY }\end{array}$ & $\begin{array}{c}\text { CURRENT } \\
\text { REQUIREMENT }\end{array}$ \\
\hline U6 & +5 Volt & $0.15 \mathrm{~mA}$ \\
\hline
\end{tabular}

Table 3.4: Current requirements summary for the 'Analog Switch Hardware Block'.

The Pulse Charger Internal Temperature Sensor Block of Figure 3.4 is made up of a temperature sensor and an op-amp to amplify the sensor's output signal. The schematic for this block is shown in Figure 3.9. The LM35 Precision Centigrade Temperature Sensor was selected because of its ease of use. Using the LM35 in the basic configuration shown in Figure 3.9, the output of U9 will be a voltage that is directly

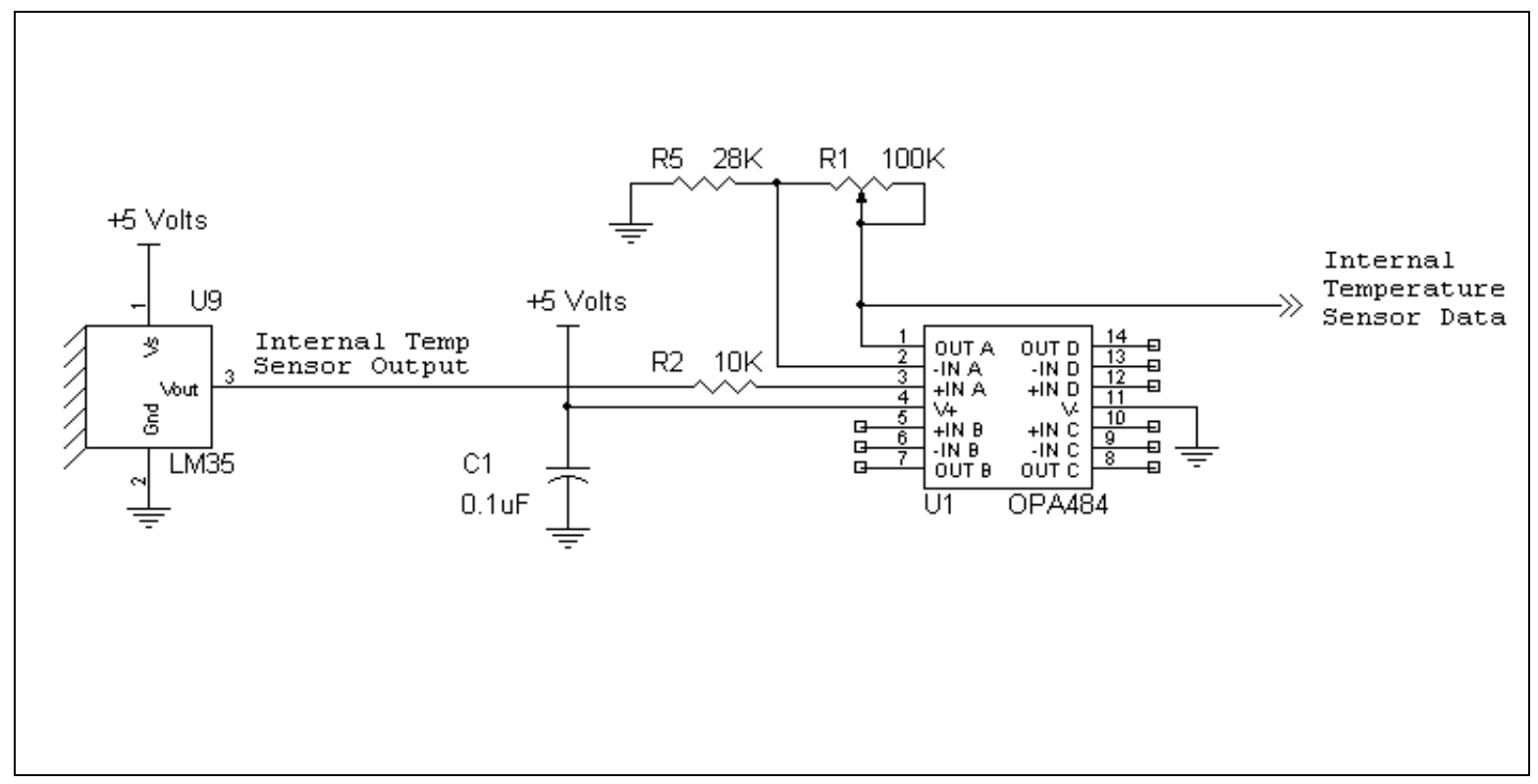

Figure 3.9: Schematic for the 'Pulse Charger Internal Temperature Sensor Hardware Block'

proportional to the temperature on the surface of the device. The output voltage and temperature is given by the following equation: 


$$
T=\frac{V_{\text {OUT }}}{0.01}
$$

The temperature given by equation 3.6 will be in degrees Celsius. The valid sensed temperature range for $\mathrm{U} 9$ is from $2{ }^{\circ} \mathrm{C}$ to $150{ }^{\circ} \mathrm{C}$. Using equation 3.6 , an output voltage range of 0.02 volts to 1.5 volts is obtained. To increase the conversion resolution, U9's output voltage will be amplified to a maximum of 5 volts. If U9's output voltage was 1.5 volts and not amplified, the minimum temperature change, $\Delta \mathrm{T}_{\mathrm{MIN}}$, that can be detected by the microcontroller using 10-bit analog-to-digital conversion is $0.490{ }^{\circ} \mathrm{C}$. By amplifying the output voltage of $U 9$ to make use of the full input voltage range of $0-5$ volts, the microcontroller can detect a temperature change as small as $0.147^{\circ} \mathrm{C}$. The equation shown below was used to determine the value of $\Delta \mathrm{T}_{\mathrm{MIN}}$.

$$
\Delta T_{M I N}=\frac{T_{M A X}}{V_{\text {OUT }}\left(\frac{1023}{5}\right)}
$$

The value $\mathrm{V}_{\text {OUT }}$ in equation 3.7 is the output voltage from $\mathrm{U} 9$ and the value of $\mathrm{T}_{\mathrm{MAX}}$ is the maximum temperature to be sensed.

Signal noise is also a reason to amplify U9's output. When the output voltage from U9 is amplify, its signal-to-noise ratio is increased. This assumes that any noise that may interfere with the desired signal is added after the amplification stage. The chances of signal noise being introduced prior to amplification are reduced by placing the amplifier as close as possible to the output of U9. 
To obtain an output voltage of 5 volts from U1A with an input voltage of 1.5 volts, U1A's gain needs to be adjusted by controlling the values of resistors R1 and R5 of Figure 3.9. The required gain for U1A is approximately 3.33. By using a potentiometer for resistor R1, the gain can be preciously adjusted to provided an output of 5 volts with an input voltage of 1.5 volts. Using a resistor with a $1 \%$ tolerance for R5 and a value of $28 \mathrm{k} \Omega$, the ideal value for resistor R1 is approximately $65.33 \mathrm{k} \Omega$. A $100 \mathrm{k} \Omega$ potentiometer was selected for R1 since this is the closest standard value that is higher than the calculated value of R1. The resistance of R1 is given by the following equation:

$$
R_{1}=R_{5}\left(\frac{V_{\text {OUT }}}{V_{I N}}-1\right)
$$

The output current of the temperature sensor, U9, depends on the temperature of the surrounding environment. For the purpose of calculating power supply current requirements, U9's maximum output current of $10 \mathrm{~mA}$ will be used. The maximum operating current for U1 will be $0.25 \mathrm{~mA}$. Output current from U1 will be limited to the leakage currents associated with the analog inputs of the microcontroller. The maximum power requirements for the Pulse Charger Internal Temperature Sensor Block are summarized in Table 3.5.

\begin{tabular}{||c|c|c||}
\hline PART & POWER & CURRENT \\
INDENTIFIER & SUPPLY & REQUIREMENT \\
\hline U1 & +5 Volt & $0.25 \mathrm{~mA}$ \\
\hline U9 & +5 Volt & $10.0 \mathrm{~mA}$ \\
\hline
\end{tabular}

Table 3.5: Current requirements summary for the 'Pulse Charger Internal Temperature Sensor Hardware Block. 


\subsubsection{Pulse Charger to Battery Interface}

The Pulse Charge Battery Interface Block of Figure 3.3 contains the hardware required to interface the low power control signals from the Charge / Discharge Pulse Control Block to the electronic components used to control the charge and discharge current. The components that make up the sensors that monitor all battery related voltages and currents are also contained in this block. The block diagram of Figure 3.10 shows the connections between the hardware contained in the Pulse Charge Battery Interface Block.

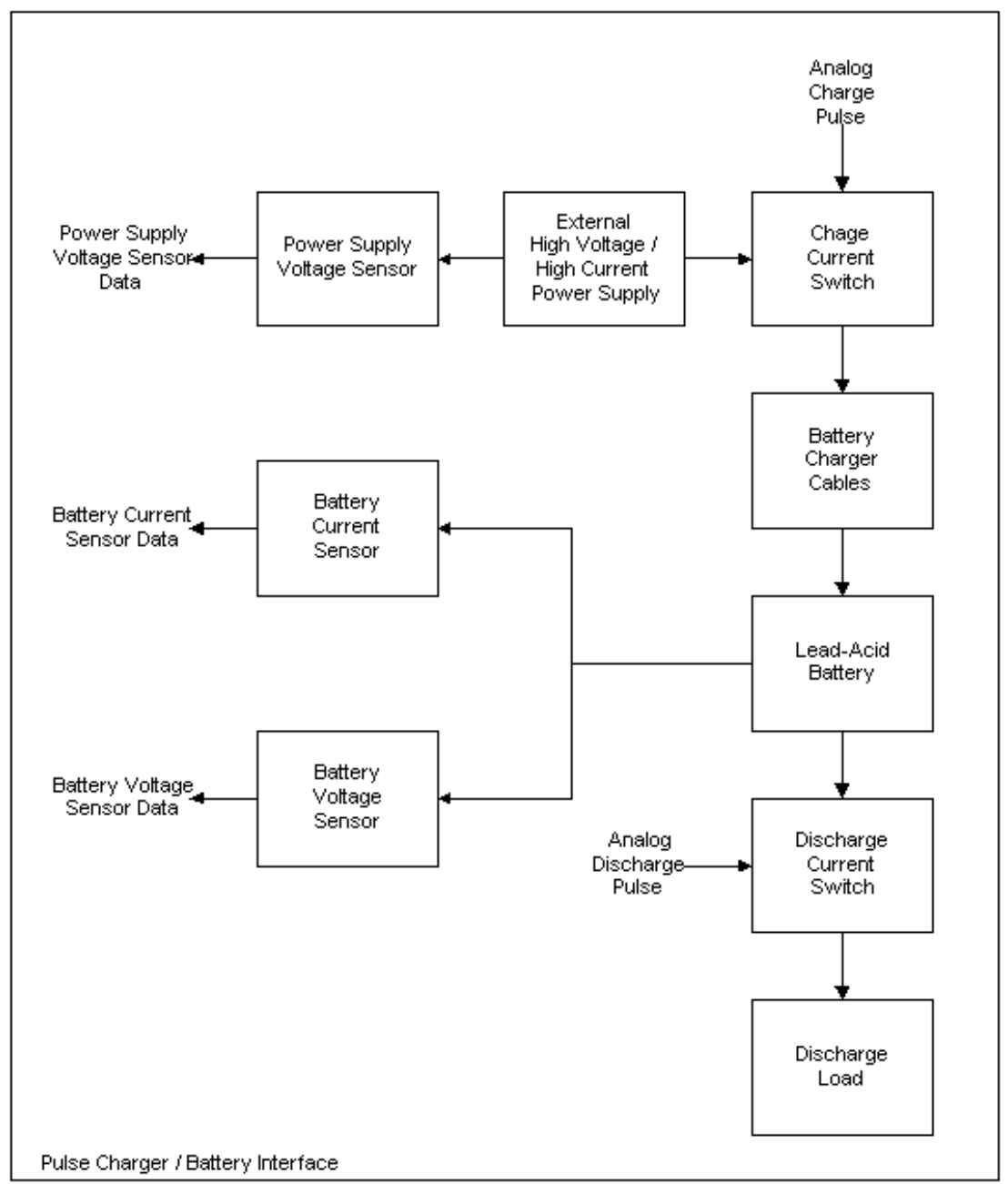

Figure 3.10: Pulse Charger to Battery Interface Hardware Block Diagram 
The External High Voltage / High Current Power Supply Block of Figure 3.10 is a Sorenson DCR40-60A constant voltage / constant current regulated power supply. The DCR40-60A has over-voltage, over-current, and thermal protection circuitry. It is used to provide the charging current to the battery.

The Battery Block of Figure 3.10 consists of the lead-acid battery that is being charged. All batteries that will be charged during this research will be 12 volt Optima “Red Top" Model 800S Absorbed Glass Matt (AGM) lead-acid batteries.

The Power Supply Voltage Sensor Block in Figure 3.10 contains a resistive voltage divider circuit. The schematic for this block is shown in Figure 3.11. The nominal maximum external power supply voltage is 40 volts. To provide a margin of safety against a higher than normal output voltage from damaging the microcontroller that the sensor output is connected to, it is assumed that the maximum external power supply voltage is 50 volts for design purposes. The voltage divider that is formed by resistors R32 and R33 in Figure 3.11 scales the power supply voltage range of $0-50$

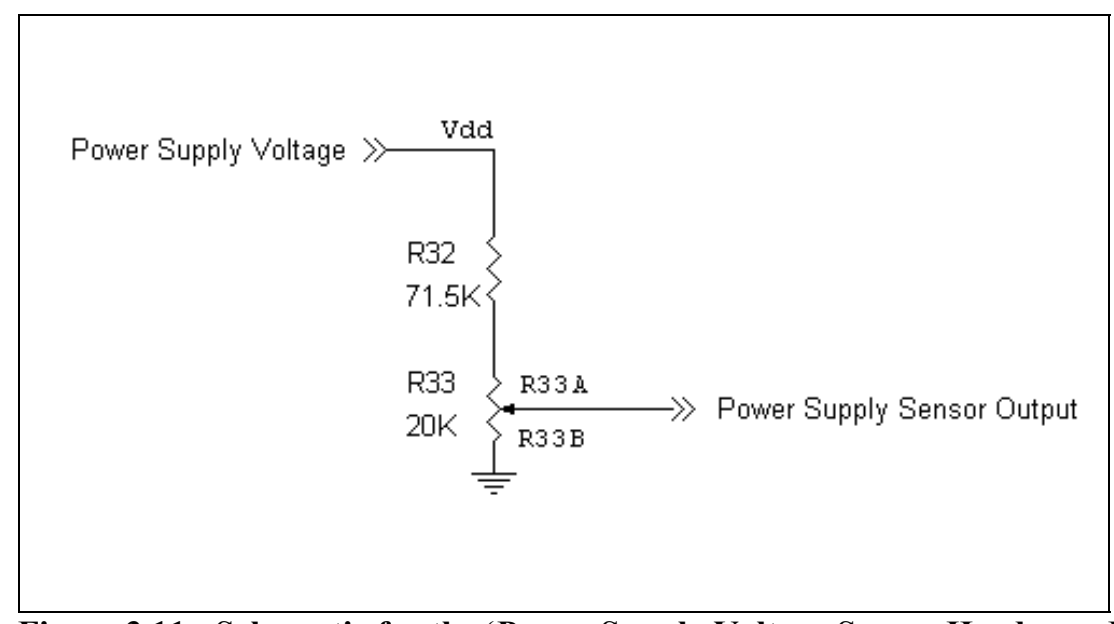

Figure 3.11: Schematic for the 'Power Supply Voltage Sensor Hardware Block' 
volts down to a range of $0-5$ volts. Therefore, the sum of the resistances of R32 and the upper portion of potentiometer R33 will need to have a voltage drop of 0.9 times the external power supply voltage and the resistance of the lower portion of R33 will need to drop 0.1 times the external power supply voltage. Another important factor in determining the resistor values is that the voltage sensor should have a minimal current drain from the power supply. It was determined that the sensor should draw less than 1 $\mathrm{mA}$ from the power supply while, at the same time, the resistors should not be so large that any noise that may be present in the signal could inundate the desired current flow in the resistors and result in false voltage measurements. Also, the effective output impedance of the voltage sensor needed to be less than $10 \mathrm{k} \Omega$, in order to satisfy the requirement that any component connected to any of the microcontroller's analog inputs have an output impedance of less than $10 \mathrm{k} \Omega$. Using the following equation,

$$
V_{\text {out }}=\frac{V_{d d}\left(R_{33 B}\right)}{R_{32}+R_{33 A}+R_{33 B}}
$$

it was determined that the resistance between the power supply voltage input and the sensor output should be 9 times the value of $\mathrm{R}_{33 \mathrm{~B}}$. A total resistance of no more than 100 $\mathrm{k} \Omega$ was also chosen. Using standard $1 \%$ tolerance resistors, a $20 \mathrm{k} \Omega$ potentiometer was selected for $\mathrm{R} 33$ and a $71.5 \mathrm{k} \Omega$ resistor for $\mathrm{R} 32$. Referring to equation 3.9 , the wiper position of $\mathrm{R}_{33}$ should be set so that the lower portion's resistance, $\mathrm{R}_{33 \mathrm{~B}}$, is $9.15 \mathrm{k} \Omega$.

The Battery Voltage Sensor Block in Figure 3.10 is also made up of a resistive voltage divider circuit consisting of a fixed resistor and a potentiometer. The schematic for this block is shown in Figure 3.12. This voltage sensor had two conflicting design 


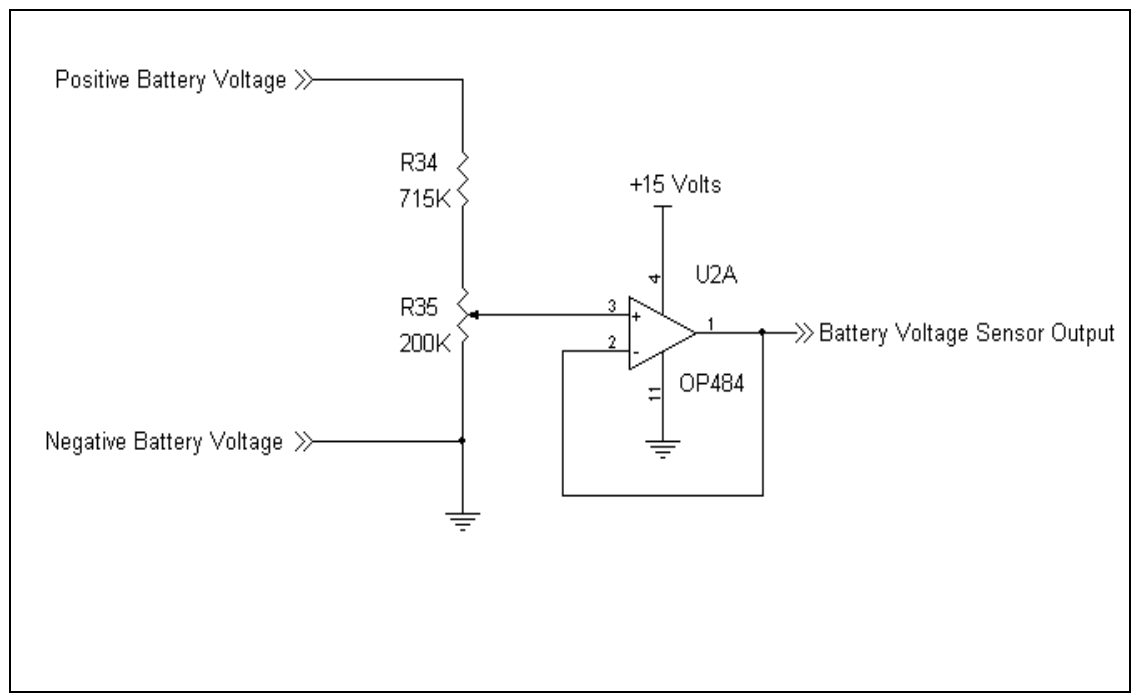

Figure 3.12: Schematic for the 'Battery Voltage Sensor Hardware Block'

constraints with regards to the selection of the resistor values. First, the microcontroller's source impedance restriction of less than $10 \mathrm{k} \Omega$ had to be adhered too. Second, the values for resistors R34 and R35 needed to be large enough so that very little of the charging current would flow through them. For the selection of resistors R34 and R35, it was determined that their the total resistance should be approximately 10,000 times greater than the highest battery impedance that could be expected to minimize their effect on the lead-acid battery. By choosing a total resistance between $900 \mathrm{k} \Omega$ and $1 \mathrm{M} \Omega$, the battery's impedance could be between $90 \Omega$ and $100 \Omega$. The voltage divider formed by resistors R34 and R35 in Figure 3.12 scales the charging voltage to a range of $0-5$ volts. Because the maximum charging voltage of 50 volts had already been determined and a maximum sensor output voltage of 5 volts was required, the exact resistor values had to be chosen to provide a scaling factor of $1 / 10$. By choosing resistor values that were 10 times larger than the power supply voltage sensor resistors and referring to the calculations for power supply voltage sensor, it is simple to see that the resistance between R35's wiper arm and ground would need to be set at $91.5 \mathrm{k} \Omega$. Also, the total 
sensor resistance of $915 \mathrm{k} \Omega$ limited the current drain from the power supply to a maximum of $54.6 \mu \mathrm{A}$ which is insignificant when the total current output from the supply could be as high as $60 \mathrm{~A}$.

By choosing such high resistances for R34 and R35 results in an approximate sensor output impedance of $91.5 \mathrm{k} \Omega$. Since this is much greater than the required maximum of $10 \mathrm{k} \Omega$, something was needed to reduce to sensor's output impedance to below $10 \mathrm{k} \Omega$. The chosen solution was to use an operational amplifier wired in a voltage follower configuration. This can be seen in Figure 3.12. When an op-amp is used as a voltage follower, the output voltage will follow the input voltage with no amplification hence, the name: voltage follower. Using a supply voltage of +15 volts, an operating frequency of less than $1 \mathrm{kHz}$, a gain of 1 , and referring to the datasheet for the OP484 opamp, it was determined that the new output impedance of the battery voltage sensor is less than $1 \Omega$, which is definitely less than $10 \mathrm{k} \Omega$.

The Battery Current Sensor Block in Figure 3.10 consists of a Honeywell CSNA111 Hall-Effect Current Sensor and a $1 / 2$ watt output resistor. The schematic for this block is shown in Figure 3.13. In designing the battery charger, it was determined that data for two current values would be needed, the charge and discharge currents. To accommodate the collection of the required current values, two solutions were examined. The first possible solution was to use two separate Hall-effect sensors. However, this was rejected due to sensor cost. The second solution, which was chosen, was to run two wires through the same current sensor. This was possible because only one of the wires will be conducting current at any one time. The microcontroller that the sensor output is connected to will be able to distinguish between the charge current and discharge 


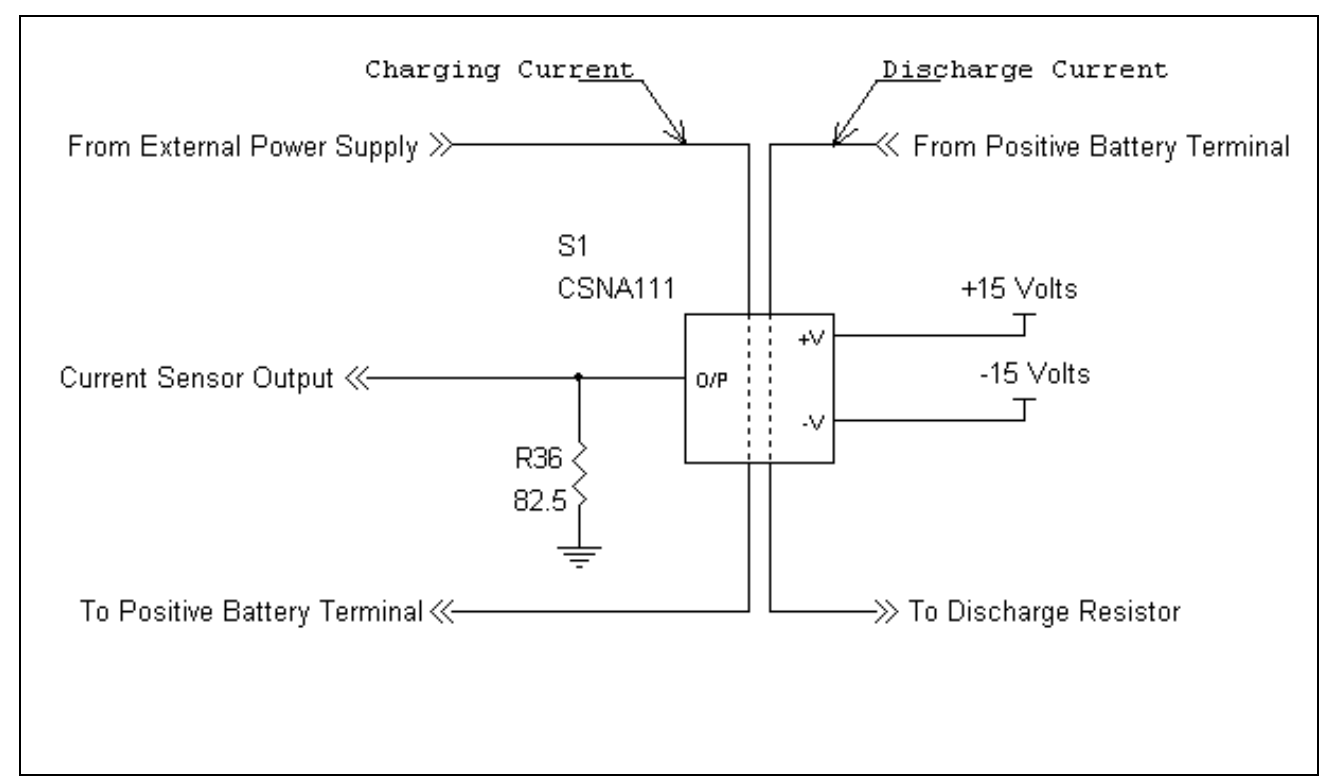

Figure 3.13: Schematic for the 'Battery Current Sensor Hardware Block'

current values because the microcontroller will have information regarding which pulse is turned on at the time. If the microcontroller is sending charge pulse data, then the current sensor is sending charge current data. If the microcontroller is sending discharge pulse data, then the current sensor is sending discharge current data. Even through the current sensor, $\mathrm{S} 1$ of Figure 3.13, is capable of both positive and negative output voltages, it is desired that the output from the sensor only consist of positive voltages. This is so that the sensor output can be connected directly to the microcontroller without the need for intermediate circuitry to convert any negative voltages to positive voltages. To accomplish a positive-only output from the current sensor, the wires were run through the sensor in such a way so that the current in each wire flowed in the same direction.

The value of resistor R36 in Figure 3.13 was chosen so that the sensor output current at the maximum sensed current would produce a voltage drop as close to but less than 5 volts. Referring to the datasheet for the CSNA111, the output current from the 
sensor is $1 \mathrm{~mA}$ for each amp of sensed current. Since the maximum charging current was set at 60 amps, it can be seen that the maximum output current from the sensor will be 60 mA. The discharge current will be much lower than the charge current so it was not used to determine the value of R36. Because the analog input on the microcontroller does not draw any current other than small leakage currents, all of the sensor's output current will flow through R36. Using the following equation and substituting 5 for $\mathrm{V}_{\mathrm{MAX}}$ and 0.06 for

$$
R_{36_{-} M A X}=\frac{V_{M A X}}{I_{\text {OUT }}}
$$

$\mathrm{I}_{\text {OUT }}$, it was determined that the resistance of R36 could be no greater than $83.33 \Omega$. Therefore, a $82.5 \Omega 1 \%$ resistor was selected for R36. Using the nominal resistance of 82.5 results in an output voltage from S1 of 4.95 volts. Since this is very close to the maximum input voltage of the microcontroller, the upper tolerance limits for R36 and S1 were examined to determine if the voltage could possibly go over 5 volts. The tolerance for $\mathrm{S} 1$ is $\pm 0.5 \%$. Using the following equation where the value of $\mathrm{I}_{\mathrm{NOM}}$ is the nominal

$$
V_{\text {OUT }}=1.005\left(I_{\text {NOM }}\right) * 1.01\left(R_{36}\right)
$$

output current from S1 and the value of R36 is its nominal resistance value, it was determined that at worst case the output voltage from the current sensor will be 5.02 volts.

The CSNA111 current sensor requires operating power from a \pm 15 volt power supply. The sensor draws a primary operating current of $10 \mathrm{~mA}$. There is also a 
secondary current of up to $60 \mathrm{~mA}$. The secondary current will vary according to the sensed current with a relationship of $1 \mathrm{~mA}$ of secondary current for every amp of sensed current.

The next two blocks of Figure 3.10 to be examined will be the Charge Current Switch Block and the Battery Charger Cables Block. They are being discussed together since both contribute to the total charge path resistance. The schematic for both blocks is shown in Figure 3.14. The Battery Charger Cables Block consists of an equivalent resistor, Rcable, representing to total resistance of the cable connecting the battery to the charger.

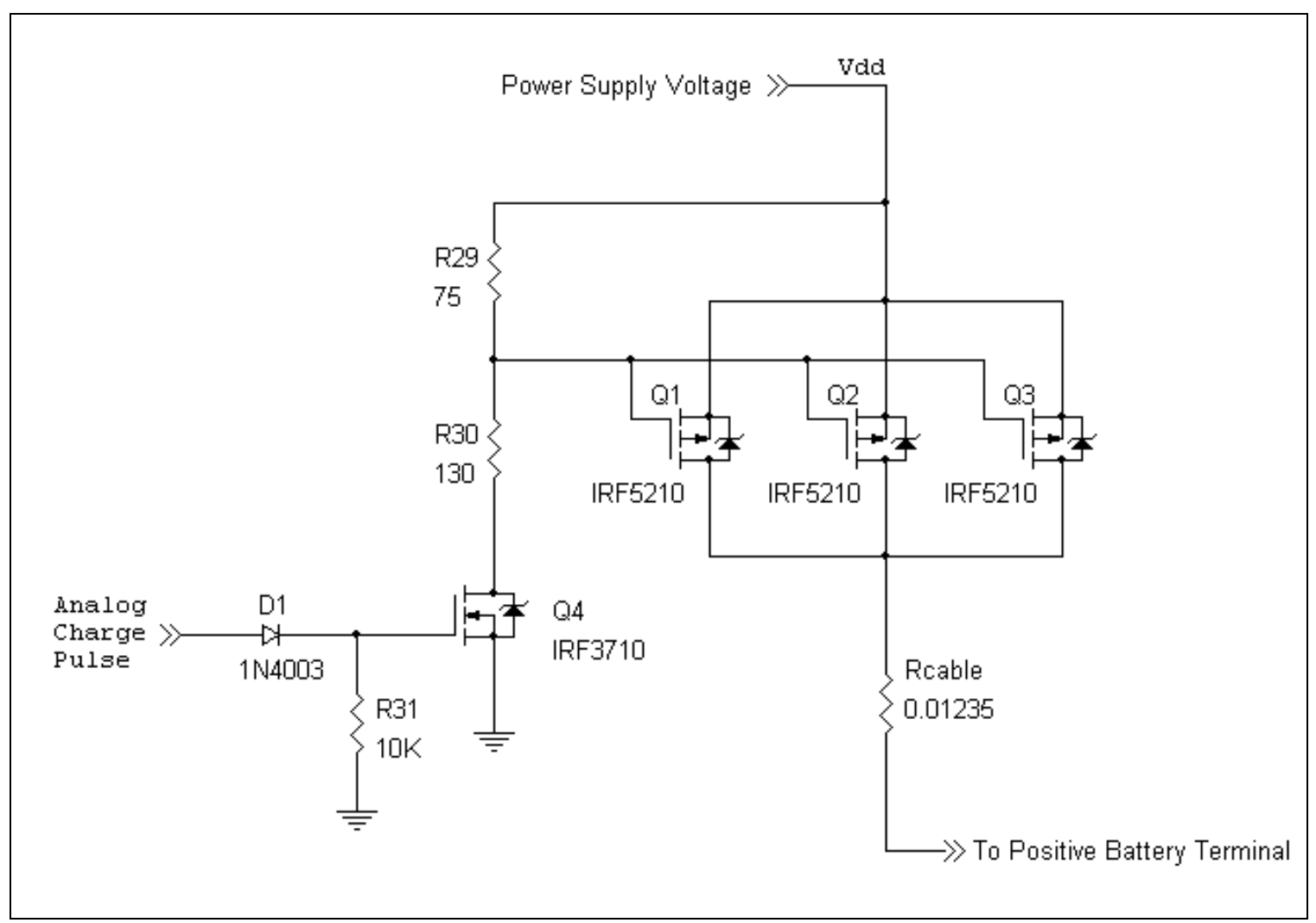

Figure 3.14: Schematic for the 'Battery Charge Current Hardware Block' and 'Battery Charger Cables Hardware Block' 
The charging current is switched on and off by turning the P-Channel MOSFETs, $\mathrm{Q} 1$ - Q3, on and off. The gate voltages for Q1 - Q3 are derived from the external power supply voltage, Vdd. The gate voltage level is controlled by turning Q4 on and off and by a resistive voltage divider consisting of resistors R29 and R30. To turn Q1 - Q3 on, their gate-to-source voltage must satisfy the following equation:

$$
V_{G S} \leq V_{G S(t h)}
$$

At any time when equation 3.12 is not satisfied, Q1 - Q3 will be off and not conducting current. To turn Q4 on, its gate-to source voltage must satisfy the following equation:

$$
V_{G S} \geq V_{G S(t h)}
$$

Otherwise, it will be off and not conducting current. When Q4 is turned on by applying a gate voltage that satisfies equation 3.13, current will flow through resistors R29 and R30. The voltage applied to the gate terminals of Q1 - Q3 will then be more negative than Vdd, which is applied to the source terminals of Q1 - Q3, due to the voltage drop across R29. When Q4 is turned back off, no current will flow through resistors R29 and R30 and Q1 - Q3's gate voltage will return to the level of Vdd. This will then violate equation 3.12 and Q1 - Q3 will turn off, allowing no further charging current to flow to the battery.

The values of resistors R29 and R30 were chosen so that the gate voltages of Q1 Q3 are sufficiently negative to turn the P-Channel MOSFETs on when Vdd is equal to 13 
volts and Q1 - Q3's gate-to-source voltages are less than 20 volts when Vdd is equal to 40 volts. Resistors 29 and R30 also had to be small enough to allow sufficient current to flow to the gate terminals of $\mathrm{Q} 1-\mathrm{Q} 3$ so that the maximum gate charge, $\mathrm{Q}_{\mathrm{G}}$, of $180 \mathrm{nC}$ could charge as quickly as possible. Also, the resistors had to be large enough to keep an excessive amount of current from flowing though Q4, reducing the available current to charge the battery.

The gate voltages of Q1 - Q3 are determined by the resistances of R29 and R30. Referring to the datasheet for the IRF5210, the maximum gate-to-source threshold voltage is -4 volts. This means that the gate must be at least 4 volts more negative than the source before it is certain that the MOSFET has turned on. Although the gate-tosource voltage can be as high as 20 volts, it is undesirable to operate at that level. Therefore, it was decided that the gate-to-source voltage should never go above 15 volts. Using the equation below and setting the values of $V_{\mathrm{GS}}$ to 4 volts and $\mathrm{V}_{\mathrm{DD}}$ to 13 volts, it

$$
R_{30}=\left[\frac{V_{D D}}{V_{G S}}-1\right]\left(R_{29}\right)
$$

can be seen that the value of R30 must be approximately 2.25 times the value of R29. Using equation 3.14 again and this time setting the values of $\mathrm{V}_{\mathrm{GS}}$ to 15 volts and $\mathrm{V}_{\mathrm{DD}}$ to 40 volts, it can be seen that the value of R30 must be approximately 1.67 times the value of R29. Therefore, to satisfy both conditions simultaneously the value of R30 must satisfy the inequality of equation below. 


$$
1.67 \leq R_{30} \leq 2.25
$$

The value of $\mathrm{R}_{\mathrm{DS}(\mathrm{on})}$ for $\mathrm{Q} 4$ was ignored since it is much smaller than any potential resistor values.

Resistors R29 and R30, in addition to providing a voltage divider function, must also allow sufficient current to flow in order to quickly charge to gate capacitances of Q1 - Q3, thereby turning off the MOSFETs. According to the IRF5210 datasheet, each MOSFET requires a maximum gate charge of $180 \mathrm{nC}$ to switch a drain current, $\mathrm{I}_{\mathrm{D}}$, of 21 amps with a drain-to-source voltage, $\mathrm{V}_{\mathrm{DS}}$, of 80 volts and a gate-to-source voltage, $\mathrm{V}_{\mathrm{GS}}$, of 10 volts. As a general rule, the value of $\mathrm{V}_{\mathrm{DS}}$ when $\mathrm{Q} 1-\mathrm{Q} 3$ are switched off will be between 25 and 30 volts, assuming that a battery is connected to the charger with a terminal voltage between 10 and 15 volts. Referring to Figure 3 contained in International Rectifier's Application Note AN-944, it can be seen that a higher gate charge, $\mathrm{Q}_{\mathrm{G}}$, will be required before the MOSFET can turn off as $\mathrm{V}_{\mathrm{DS}}$ increases. To complicate matters even further, it can be seen that the relationship between $\mathrm{I}_{\mathrm{D}}, \mathrm{V}_{\mathrm{DS}}$, and $\mathrm{Q}_{\mathrm{G}}$ is not linear. A doubling of the drain current does not produce a doubling of the required gate charge. Faced with this dilemma and aware of the fact that the turn-off time of Q1 - Q3 would only effect the falling edge of the charge pulse, it was decided that the gate current should be between $100 \mathrm{~mA}$ and $400 \mathrm{~mA}$. The $400 \mathrm{~mA}$ upper limit was selected since this was approximately as large a current that could be safely carried through a 2 watt resistor. The gate charge time would later be calculated from the completed circuit and adjustments made, if needed. Using this current range, the relationship given by equation 3.15 , and a table of standard resistors available in power 
ratings of 2 watts, it was decided that R 29 should be $75 \Omega$ and R 30 should be $130 \Omega$.

Wire-wound type resistors were first selected for R29 and R30, but were later changed to carbon-type resistors. After the circuit was built, it was determined that the inductance of the wire-wound resistors was sufficiently large to cause MOSFETs Q1 - Q3 turn-off time to be extended beyond an acceptable limit. Examining the graph of Q1 - Q3's source-todrain voltage in Figure 3.15, it can be seen that the time required for the voltage to rise for 0 volts to a constant level of approximately 1 volt is $160 \mu$ s. By replacing the wirewound resistors with carbon resistors, the problem of the resistor's inductance has been minimized. Figure 3.16 shows the improvement when carbon resistors are used instead of wire-wound resistors. The time required for the voltage to rise for 0 volts to a constant level of approximately 1 volt is now $60 \mu$ s.

As stated earlier, the gate charge time calculations were difficult to make using only the datasheet information. To determine if the chosen values for R29 and R30 would satisfy all design criteria, measurements were made in order to produce a graph of the actual turn-off time of the P-Channel MOSFETs. It was determined that the longest turn-off time would result when the external power supply voltage, $V_{P S}$, was at its minimum value. This would, also, correspond to a minimum gate drive current flowing through resistors R29 and R30.

Referring to Figure 3.17, it can be seen that at point A Q4 has completely turned off thus allowing Q1 - Q3's gate voltages to start to rise. From point A to point B the PChannel MOSFET's gate capacitances as well as several undetermined parasitic capacitances are charging. The time required for these capacitances to charge is $78 \mu \mathrm{s}$. 


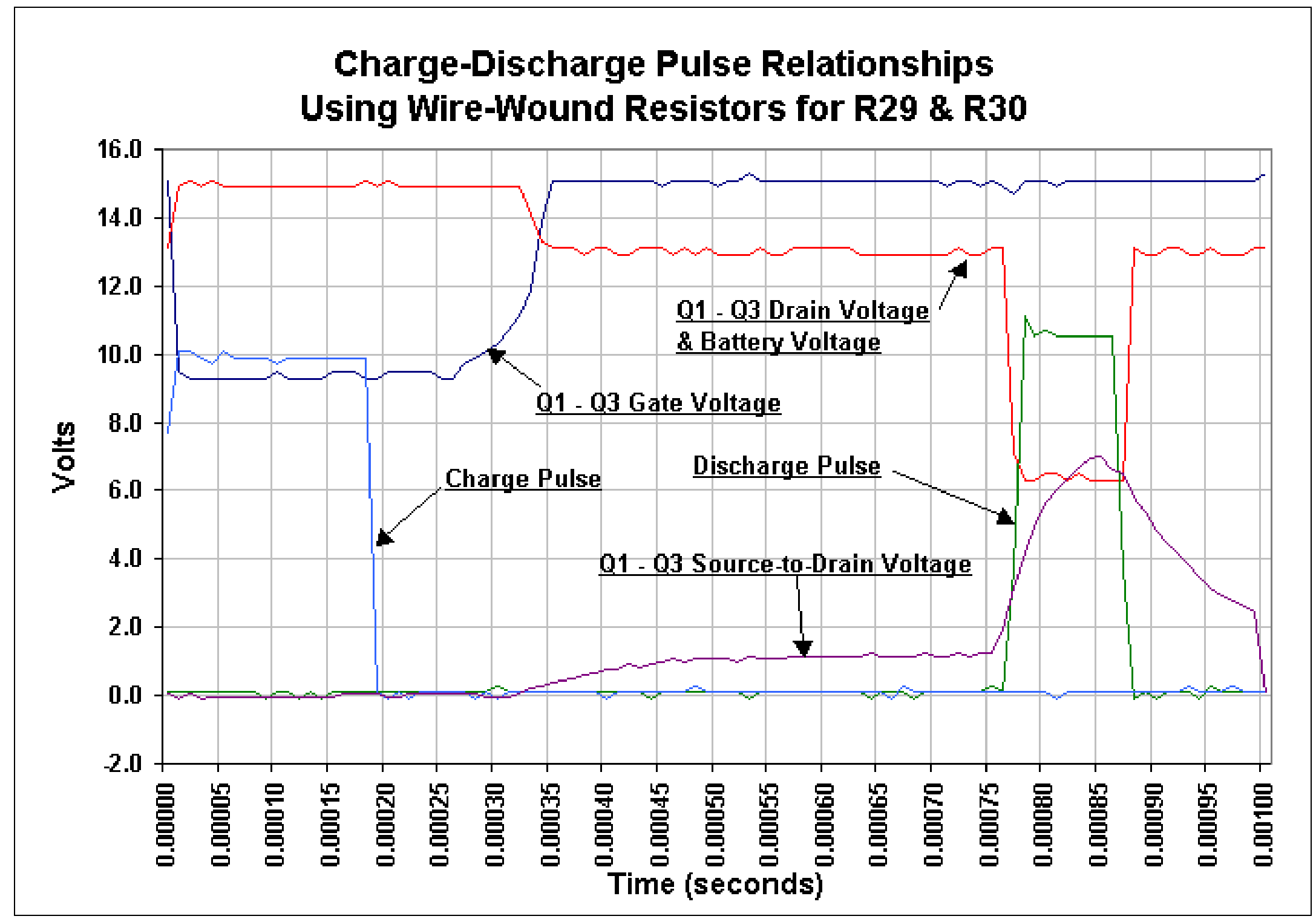

Figure 3.15: P-Channel MOSFET voltages and the control pulses using wire-wound resistors in the gate drive circuit. 


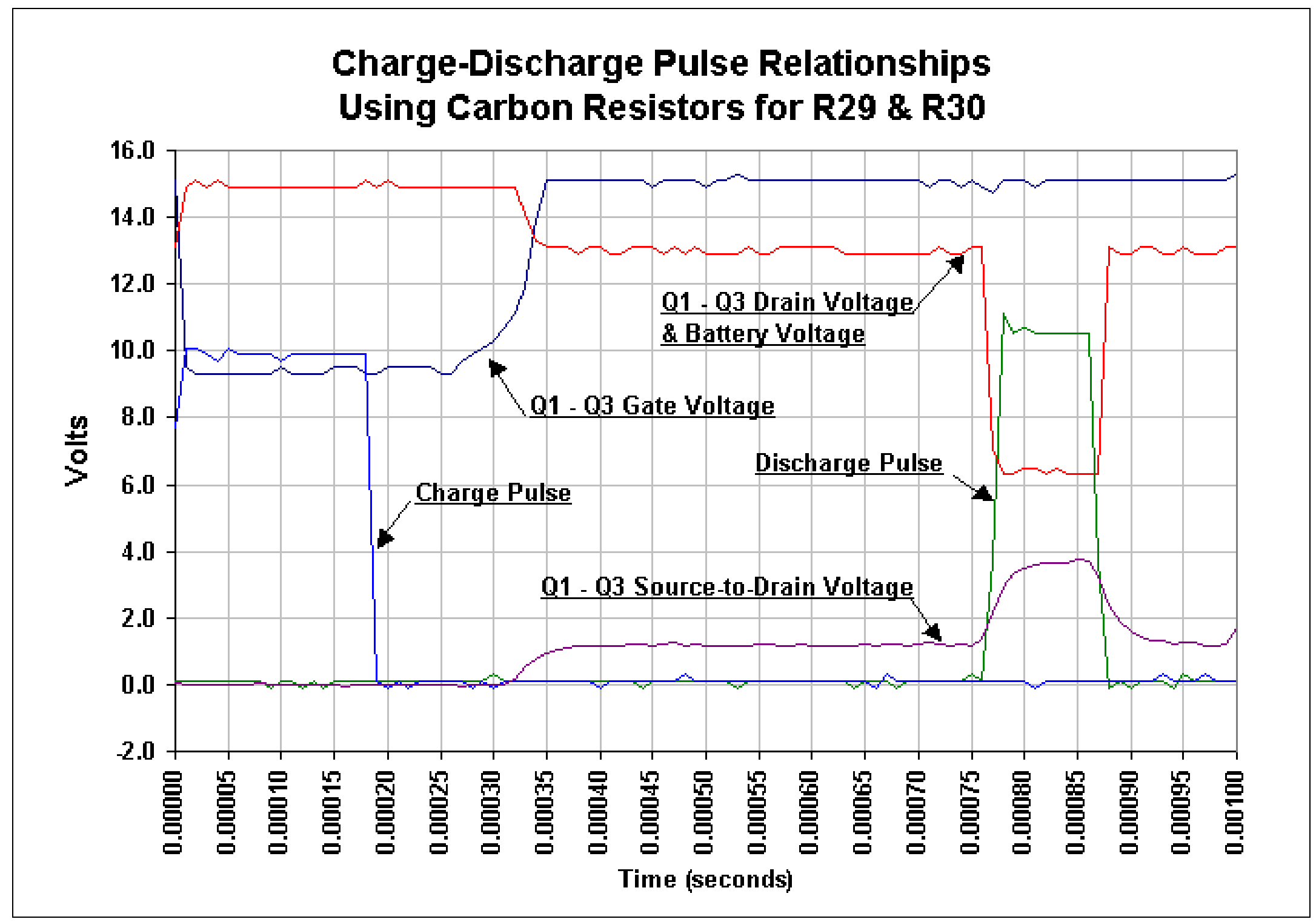

Figure 3.16: P-Channel MOSFET voltages and the control pulses using carbon resistors in the gate drive circuit. 


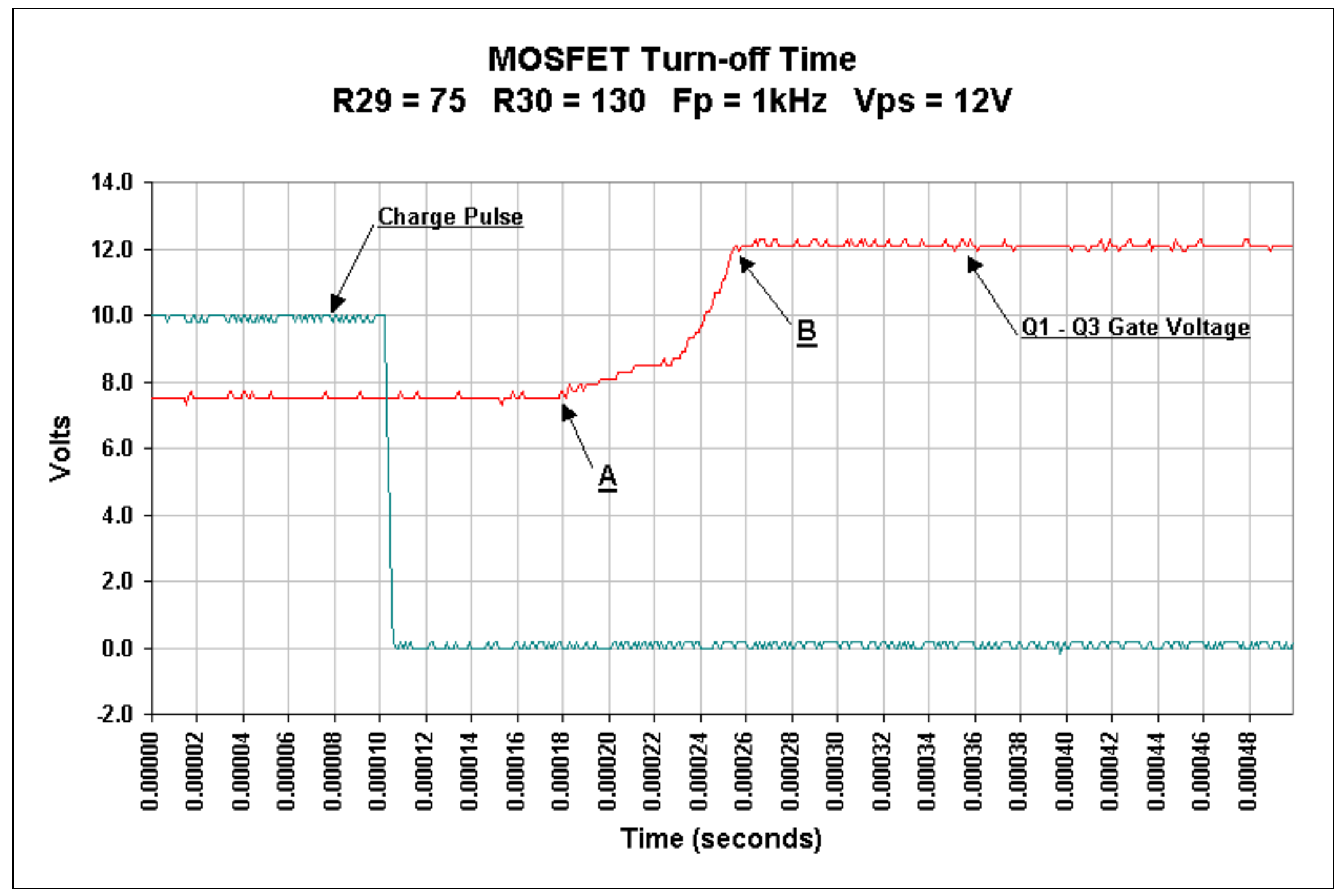

Figure 3.17: P-Channel MOSFET turn-off time. 
Since the supply voltage is set at 12 volts, the resulting gate drive current is 12 / (R29+ R30) or $58.537 \mathrm{~mA}$. Using the relationship between charge and current given by the following equation,

$$
i=\frac{d q}{d t}
$$

the total charge, $\mathrm{C}_{\mathrm{TOTAL}}$, consumed during the period between points $\mathrm{A}$ and $\mathrm{B}$ of Figure 3.17 is $4.566 \mu \mathrm{C}$.

The time required to turn on $\mathrm{Q} 1-\mathrm{Q} 3$, as well as MOSFETs $\mathrm{Q} 4-\mathrm{Q} 6$, is controlled extensively by the internal drain inductance, $\mathrm{L}_{\mathrm{D}}$, and the internal source inductance, $\mathrm{L}_{\mathrm{S}}$, of the MOSFETs. Since the switching frequency is relatively low, $1 \mathrm{kHz}$, the inductances have very little effect on turn-on time. Thus, all MOSFETs in this application can be assumed to turn on instantaneously.

The last part of the design process relating to Q1 $-\mathrm{Q} 3$ and $\mathrm{Q} 4$ is the required size of the heat sinks. Starting with the P-Channel MOSFETs Q1 - Q3 and referring once again to the IRF5210 datasheet, two parameters relating to thermal resistance are examined. They are the junction-to-case thermal resistance, $R_{\theta J C}$, which has a maximum value of $0.75{ }^{\circ} \mathrm{C} / \mathrm{W}$, and the case-to-sink thermal resistance, $\mathrm{R}_{\theta \mathrm{CS}}$, with a typical value of $0.5^{\circ} \mathrm{C} / \mathrm{W}$. Additionally, to calculate the maximum thermal resistance of the heat sink, the power dissipated by the device must be known. The maximum peak charging current will be 60 amps with a duty cycle of 0.2 , which corresponds to an average of 12 amps. Since the 12 amps will be shared equally between Q1 - Q3, each MOSFET will conduct an average maximum of 4 amps of current. When Q1 - Q3 are turned on, they will have 
a maximum drain-to-source resistance, $\mathrm{R}_{\mathrm{DS}(\mathrm{ON})}$, of $0.06 \Omega$. Therefore, each MOSFET will dissipate a maximum average power, $\mathrm{P}_{\mathrm{DAVG}}$, of 0.96 watts and a maximum peak power, $\mathrm{P}_{\text {DPEAK }}$ of 8.64 watts. Assuming a maximum ambient temperature, $\mathrm{T}_{\mathrm{A}}$, of $38^{\circ} \mathrm{C}$ and a desired junction temperature, $\mathrm{T}_{\mathrm{J}}$, of no more than $125^{\circ} \mathrm{C}$, enough information is now known to calculate the maximum thermal resistance, $\mathrm{R}_{\theta \mathrm{SA}}$, of the heat sink. Using the following equation,

$$
R_{\theta S A}=\frac{T_{J}-T_{A}}{P_{D P E A K}}-\left(R_{\theta J C}+R_{\theta C S}\right)
$$

the heat sink that is required for Q1 - Q3 can have a thermal resistance no greater than $8.8^{\circ} \mathrm{C} / \mathrm{W}$. The heat sink requirements for MOSFET Q4 are much lower since it conducts a maximum current of $195 \mathrm{~mA}$. Referring to the datasheet for the IRF3710, the values of $\mathrm{R}_{\theta J \mathrm{C}}$ is $0.74{ }^{\circ} \mathrm{C} / \mathrm{W}, \mathrm{R}_{\theta C \mathrm{CS}}$ is $0.5^{\circ} \mathrm{C} / \mathrm{W}$, and $\mathrm{R}_{\mathrm{DS}(\mathrm{ON})}$ is $0.023 \Omega$. Assuming the same temperature conditions of Q1 - Q3 and using equation 3.17, it can be seen that Q4 will not require a heat sink since the junction-to-ambient thermal resistance, $\mathrm{R}_{\theta \mathrm{JA}}$, of the TO220 package style has a maximum value of $62^{\circ} \mathrm{C} / \mathrm{W}$ which is sufficient to provide the required cooling.

Looking back at Figure 3.14, diode D1 is used to provide protection against an over-voltage condition caused by a failure of Q4. If the drain-to-gate junction of Q4 were to break down, then a voltage as high as 40 volts could be applied to the output of the preceding component. This condition would most likely result in its failure. By adding a diode, this cause for failure can by eliminated. If Q4 were to fail, then D1 would become reversed biased, allowing no current flow back into the devices of the preceding sections. 
Because of the presence of $\mathrm{D} 1$, a pull-down resistor, $\mathrm{R} 31$, was required to insure that Q4's gate would never be in a floating condition. Such as the case when the desired gate voltage is below the junction voltage of D1. In this case, D1 would effectively be reversed biased and no current would flow to Q4 to charge its gate capacitance.

Lastly, the resistance of the cables, $\mathrm{R}_{\mathrm{CABLE}}$, connecting the pulse charger to the battery was calculated for two reasons. First, it was desired that the cables have a minimum voltage drop when carrying maximum current to the battery. This allowed more efficient charging since most of the power provided by the pulse charger would actually be delivered to the battery terminals. The second reason for calculating the resistance of the cables was so that the required cable size could accurately be ascertained to satisfy the minimum voltage drop requirement. Knowing that the cable length from the interior of the pulse charger to the battery terminals would be approximately 3 meters per conductor for a total cable length of 6 meters and that copper wire would be used, the value of $\mathrm{R}_{\mathrm{CABLE}}$ could be calculated. Using the following equation,

$$
R=\frac{l}{\sigma S}
$$

where $\sigma$ is the resistivity of copper and $\mathrm{S}$ is the cross-sectional area of the conductor, it was determined that 8 AWG wire would be the best size to use for the cables. The resistance of 8 AWG wire is $0.0020583 \Omega / \mathrm{m}$. This results in a total cable resistance of $0.01235 \Omega$. At the maximum current of $60 \mathrm{amps}$, the cable will have a voltage drop of 0.741 volts, which was deemed to be acceptable. $10 \mathrm{AWG}$ wire would have had a maximum voltage drop of 1.182 volts. It was felt that this amount of voltage drop would 
have been too great and would have reduced the charger's ability to provide power to the battery. 6 AWG wire would have had a lower voltage drop, but would have introduce problems in making connections inside the charger due to its physical dimensions.

\subsubsection{User Interface}

The final block in Figure 3.3 is the User Interface Block. It contains all necessary hardware to provide the user interaction features of the pulse charger. A 12-key keypad was used to acquire user input to the charger. This keypad is a generic non-matrix type which means that one data line is required for each key. Therefore, if all twelve keys are used, then the microcontroller must have twelve available data input pins. Information regarding the operation of the pulse charger is displayed to the user using an Optrex DMC-20261 20x2 LCD. The LCD requires eight data lines and three control lines. Both the keypad and LCD are controlled by a second PIC16F877 microcontroller. The microcontroller receives data from two sources. One source is provided directly from the user via the 12 data inputs from the keypad. The second source, which consists of the battery voltage data, battery current data, and MOSFET temperature data, is received from the Pulse Control Microcontroller over the two serial communication wires connecting the two microcontrollers together. Figure 3.18 shows the relationship between the hardware making up the User Interface Block.

The LCD Block of Figure 3.18 contains only one part, the DMC-20261 LCD. The operation of the LCD is straight forward as long as the initialization procedure given in the datasheet is preciously followed and all timing requirements are meet. For more 
information regarding the initialization procedure, refer to the source code in section C.1 of Appendix C. The LCD is controlled by three I/O pins, the Enable Pin, which turns

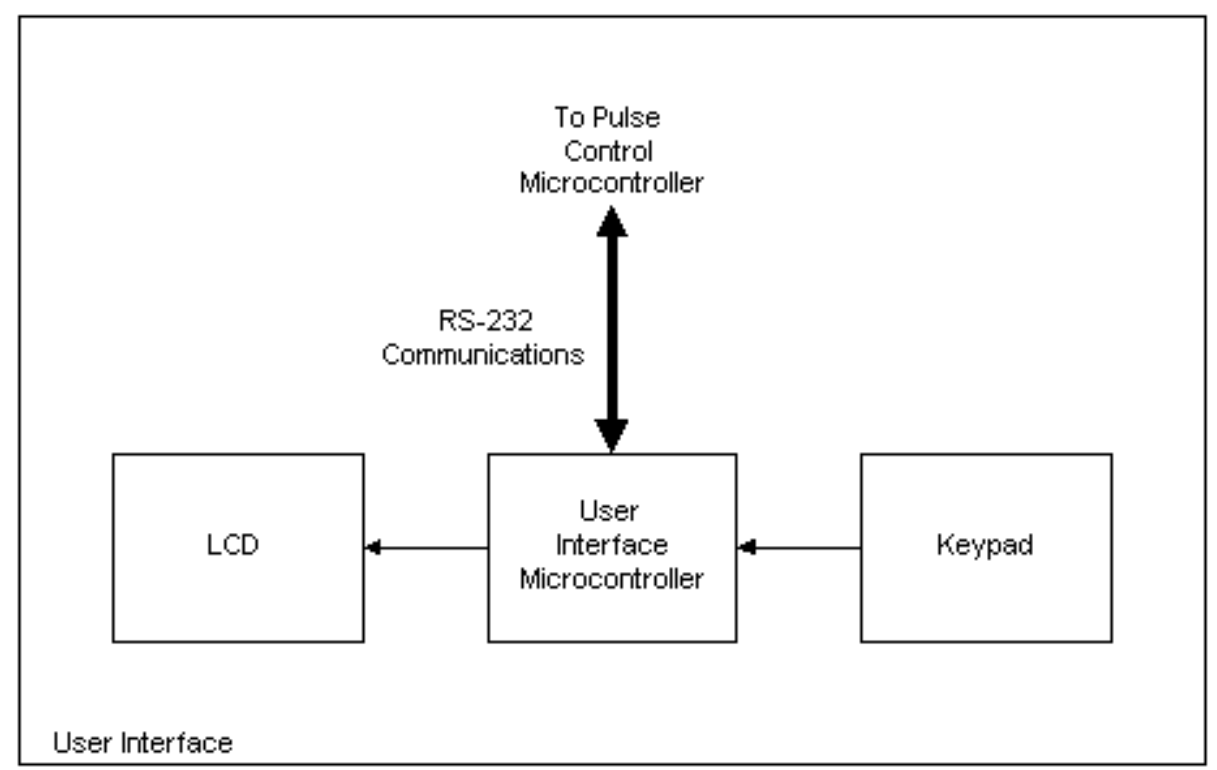

Figure 3.18: User Interface Hardware Block Diagram.

the entire LCD on and off, the RS pin which selects the instruction register of the LCD if low or the data register if high, and the $\mathrm{R} / \mathrm{W}$ pin which allows data to be written to the LCD if low or read from the LCD if high. The 8-bit data mode of the LCD was used to simplify the LCD related software functions. This allowed each 8-bit instruction of character data to be sent to the LCD at once. However, using the 8-bit mode also requires more I/O pins from the microcontroller. Since the additional I/O pins were available, it was decided that the trade-off between software simplicity and circuit complexity was warranted.

Using the LCD is relatively easy since all control hardware for the display device is built into the LCD module. The schematic for the few external pieces of hardware is shown in Figure 3.19. Resistor Rext2 provides a variable LCD drive voltage, $\mathrm{V}_{\mathrm{D}}$, for the 
LCD. By varying the drive voltage, the contrast between the displayed characters and the background can be adjusted. The value of Rext 2 was arbitrarily chosen since the current requirements are insignificant. Its only purpose is to provide a variable voltage between

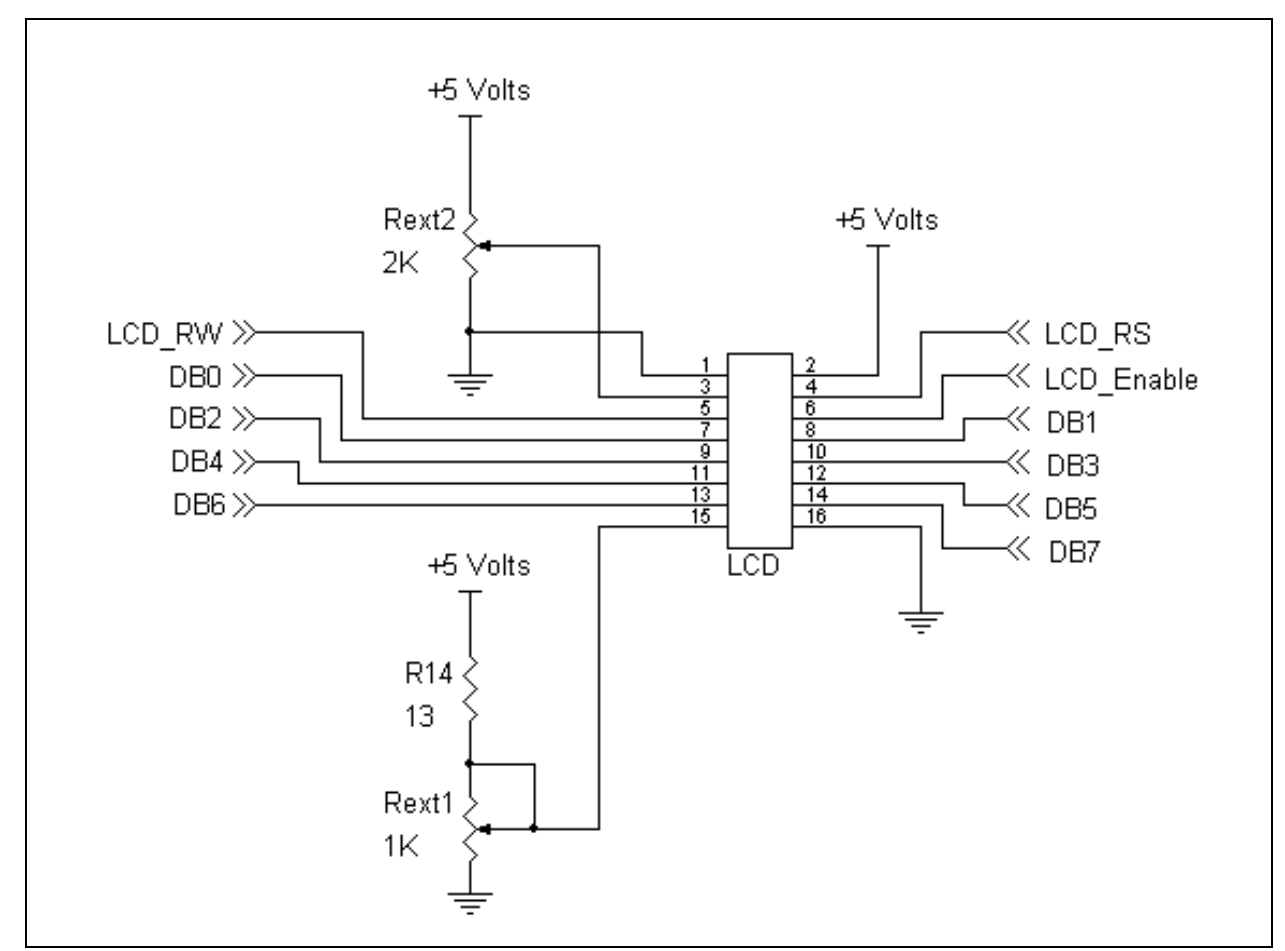

Figure 3.19: Schematic for the 'LCD Hardware Block'

4.4 and 5.0 volts. No steps were taken to insure that the drive voltage does not go below 4.4 volts since the only effect of a lower voltage would be the inability to read the displayed text. Also, no temperature compensation circuitry was designed since the charger would be primarily operated in a temperature-controlled environment. If the charger is operated in an area where the temperature is below $15^{\circ} \mathrm{C}$, resistor Rext 2 will need to be adjusted to provide a higher drive voltage.

The LCD's backlight intensity is controlled by resistors R14 and Rext1. R14 is used to limit the maximum possible current provided to the backlight LED assembly. Using the equation 3.19 with the values of $\mathrm{V}_{\mathrm{S}}$ equal to 5 volts, $\mathrm{V}_{\mathrm{F}}$ equal to 4.4 volts, 


$$
R_{14}+R_{E X T 1}=\frac{V_{S}-V_{F}}{I_{F}}
$$

and $\mathrm{I}_{\mathrm{F}}$ equal to $260 \mathrm{~mA}$, the minimum total resistance needed was $2.3 \Omega$. However, $\mathrm{I}_{\mathrm{F}}$ should be limited to a much lower value because the LED assembly can withstand a maximum current of only $152 \mathrm{~mA}$ when the ambient temperature increases to $50{ }^{\circ} \mathrm{C}$. Therefore, the value of resistor R14 was selected as $13 \Omega$ in order to limit $\mathrm{I}_{\mathrm{F}}$ to no more than $31 \mathrm{~mA}$. This current would provide sufficient illuminated to a dark or dimly light area and would minimize power requirements. Resistor Rext1 was added to further limit $\mathrm{I}_{\mathrm{F}}$ in order to provide a variable backlight level.

Power requirements for the LCD Hardware Block are summarized in Table 3.6. The LCD module's power requirements are highly dependent on temperature so each calculated value has been doubled to insure adequate current is available from the +5 volt power supply.

\begin{tabular}{||c|c|c||}
\hline \hline PART & $\begin{array}{c}\text { POWER } \\
\text { SUPPLY }\end{array}$ & $\begin{array}{c}\text { CURRENT } \\
\text { REQUIREMENT }\end{array}$ \\
\hline $\begin{array}{c}\text { LCD Drive } \\
\text { Current }\end{array}$ & +5 Volt & $3.0 \mathrm{~mA}$ \\
\hline $\begin{array}{c}\text { Backlight LED } \\
\text { Assembly }\end{array}$ & +5 Volt & $62.0 \mathrm{~mA}$ \\
\hline
\end{tabular}

Table 3.6: Current requirements summary for the 'LCD Hardware Block'.

The keypad consists of 12 individual keys arranged in a $4 \times 3$ grid. Each key is a pushbutton-type switch that closes a contact connecting the key's data wire to a common ground when pressed. When the key is released, the electrical connection is broken and is no longer connected to the common ground. Pull-up resistors were used so that +5 
volts would be applied to the microcontroller's input pin when a key was not pressed. When the key is pressed, the voltage applied to the microcontroller's input pin would then be connected to ground or 0 volts. Switch de-bouncing is handled in the software for the User Interface Microcontroller, thereby, simplifying the hardware design process. The schematic shown in Figure 3.20 illustrates how the keypad was used with the microcontroller. The values of the pull-up resistors R16 - R22 and R24-28 were selected in order to minimize current when a key is pressed. The current required for the Keypad Hardware Block is $0.34 \mathrm{~mA}$, assuming that only one key is pressed at any one time.

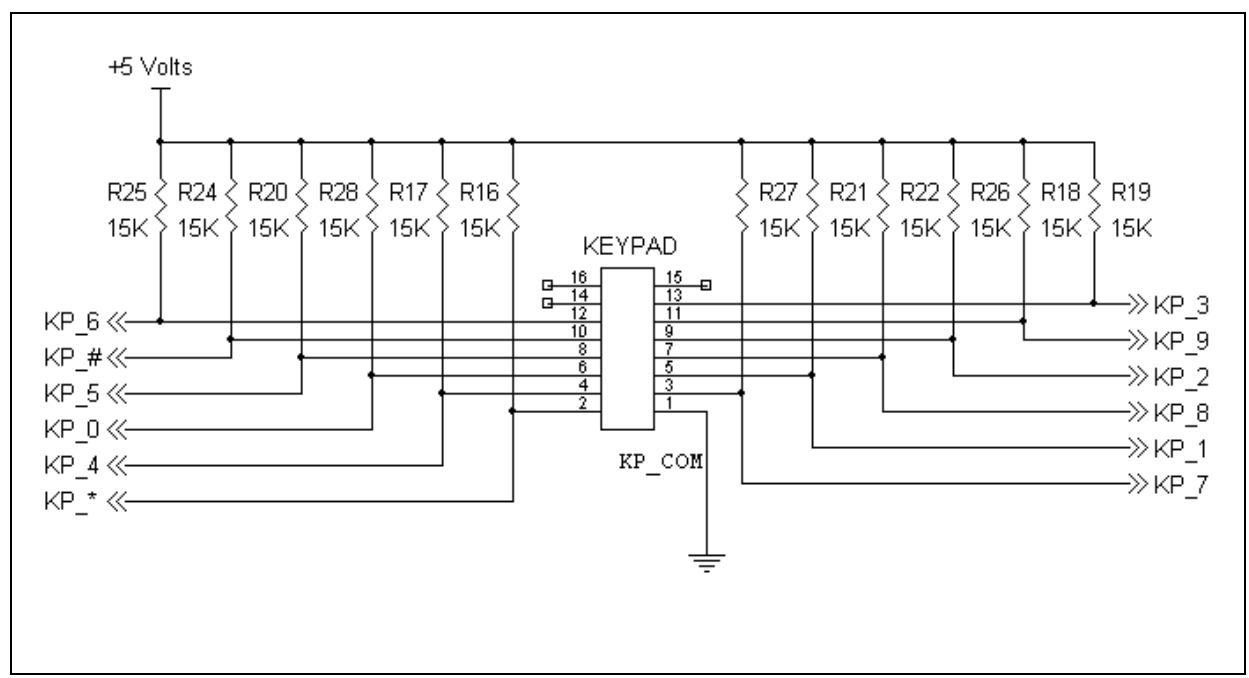

Figure 3.20: Schematic for the 'Keypad Hardware Block'

The User Interface Microcontroller Block in Figure 3.18 consists of a PIC16F877 Microcontroller and a DS1602 Elapsed Timer. The microcontroller performs all user interface functions such as displaying information on the LCD and receiving user input from the keypad. In addition to theses tasks, the User Interface Microcontroller also performs all operational-related calculations using battery voltage and current data as well as determining when the selected charge completion condition has been reached. 
Values calculated by the microcontroller include battery impedance, MOSFET temperatures, and the state of battery charge. The elapsed timer is used to provide realtime clock data to the microcontroller. This information is used to display elapsed charge time to the user. Figure 3.21 shows the schematic for the User Interface Block.

As with the Pulse Control Microcontroller that was discussed previously, ceramic capacitors, $\mathrm{C} 7$ and $\mathrm{C} 8$, that are connected between the microcontroller's power supply pins provide a low impedance path to ground for high frequency noise that may be present. The microcontroller's clock signal is provided by the $4 \mathrm{MHz}$ oscillator. The reset signal comes from the reset switch that is also connected to the Pulse Control Microcontroller. Refer to Figure 3.5 for further information regarding how the reset switch is connected to the microcontroller.

Quickly looking at the schematic of Figure 3.21, one would assume that this

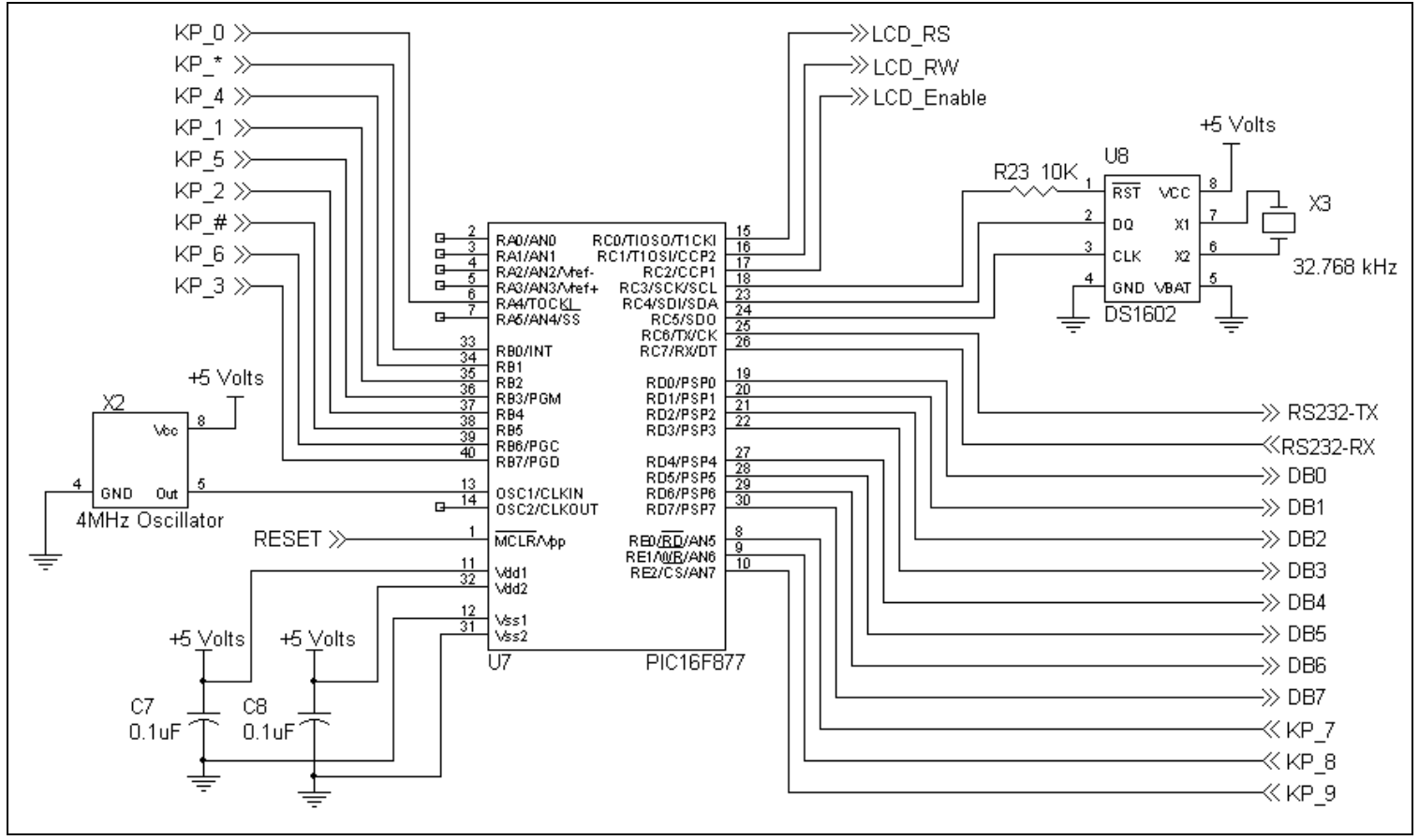

Figure 3.21: Schematic for the 'User Interface Microcontroller Hardware Block' 
microcontroller would require a large amount of power. However, due to the fact that the LCD module is a CMOS based device, there is very little current flowing in the three LCD control lines as well as the eight LCD data lines DB0 - DB7. The same is also true for the three control lines connected to U8. The keypad data lines do consume some power, but not as much as one might think. Although there are twelve data lines, only one of those data lines that start with $\mathrm{KP}_{-}$will be active at a time and even then the microcontroller will not need to sink or source any current other than very small leakage currents. The standby current used by U7 will be no more than $6.5 \mathrm{~mA}$. The actual standby current will actually be less since this assumes a frequency of oscillation of 20 MHz instead of U7's frequency of $4 \mathrm{MHz}$. The largest single power user of U7 is the serial communication lines. They will consume approximately $25 \mathrm{~mA}$ of current, according to the PIC16F877 datasheet.

The elapsed timer U8 is operated by three control lines. The RST pin of U8 performs two functions. First, it turns on the serial port to allow the microcontroller to send commands the timer. Second, it is used to terminate timer commands or timer data transfers. The DQ pin is used as the serial transfer line. Timer commands and timer data transfers come through this pin. The CLK pin is the clock signal to the timer. Depending on the state of the RST and DQ pins, the CLK pin will initiate or terminate command and timer data transfers. Table 3.7 summarizes the pin state combinations and the corresponding function the elapsed timer will perform. All DS1602 functions are initiated or terminated when a pin transitions from high-to-low or low-to-high as seen in Table 3.7. For a more complete understanding of the DS1602 operation, refer to the source code for the timer related functions contained in section C.2 of Appendix C. The 
power requirements of the DS1602 are very low. According to the datasheet for the DS1602, the device will consume a maximum of $1 \mathrm{~mA}$ of current for active operation.

\begin{tabular}{||c|c|c|c||}
\hline \hline RST & DQ & CLK & FUNCTION \\
\hline \hline High & Data & Low-to-High & $\begin{array}{c}\text { Write Data } \\
\text { to DS1602 }\end{array}$ \\
\hline High & Data & High-to-Low & $\begin{array}{c}\text { Read Data } \\
\text { from DS1602 }\end{array}$ \\
\hline High-to-Low & - & High & $\begin{array}{c}\text { Terminate DS1602 } \\
\text { Data Transfers }\end{array}$ \\
\hline Low-to-High & - & - & $\begin{array}{c}\text { Initiate DS1602 } \\
\text { Data Transfers }\end{array}$ \\
\hline
\end{tabular}

Table 3.7: DS1602 control pin states

Resistor R23 in Figure 3.21 is used to limit the RST pin's sink current. The value of R23 was recommended by the DS1602 datasheet. Component X3 is a $32.768 \mathrm{kHz}$ watch crystal. It provides the clock frequency that the DS1602 uses to keep track of the number of seconds that have elapsed since the timer was last reset to zero. Since the DS1602 is used as an event timer while the pulse charger is turned on, the Vbat pin has been grounded. Normally, a battery is connected to the Vbat pin to provide the elapsed timer with power while the main power supply is turned off. That way, the total time in operation can be tracked. However, this feature of the DS1602 was not used.

The power requirements for the User Interface Microcontroller Hardware Block are summarized in Table 3.8. These currents will be used in the section of this chapter dealing with the design of the pulse chargers low voltage power supplies. 


\begin{tabular}{||c|c|c||}
\hline \hline PART & POWER & CURRENT \\
INDENTIFIER & SUPPLY & REQUIREMENT \\
\hline U7 & +5 Volt & $31.5 \mathrm{~mA}$ \\
\hline $\mathrm{U} 8$ & +5 Volt & $1.0 \mathrm{~mA}$ \\
\hline $\mathrm{X} 2$ & +5 Volt & $25.0 \mathrm{~mA}$ \\
\hline
\end{tabular}

Table 3.8: Current requirements summary for the 'User Interface Microcontroller Hardware Block'.

\subsubsection{Power Supplies}

All low voltage power supplies are built around the 78XX and 79XX series voltage regulators. To provide the correct voltage levels, four individual power supplies were built. These supplies provided voltages of $+5,+12,+15$, and -15 volts. In the previous sections of this chapter, summaries have been given in tables stating the power requirements for all low voltage electronic components. Table 3.9 restates these power

\begin{tabular}{||c|c|c||}
\hline $\begin{array}{c}\text { PART } \\
\text { INDENTIFIER }\end{array}$ & $\begin{array}{c}\text { POWER } \\
\text { SUPPLY }\end{array}$ & $\begin{array}{c}\text { CURRENT } \\
\text { REQUIREMENT }\end{array}$ \\
\hline U2 & +15 Volt & $1.25 \mathrm{~mA}$ \\
\hline S1 & +15 Volt & $70.0 \mathrm{~mA}$ \\
\hline S1 & -15 Volt & $70.0 \mathrm{~mA}$ \\
\hline Fans & +12 Volt & $140.0 \mathrm{~mA}$ \\
\hline U1 & +5 Volt & $0.25 \mathrm{~mA}$ \\
\hline U3 & +5 Volt & $33.1 \mathrm{~mA}$ \\
\hline $\mathrm{U} 4$ & +5 Volt & $15.0 \mathrm{~mA}$ \\
\hline $\mathrm{U} 5$ & +5 Volt & $15.0 \mathrm{~mA}$ \\
\hline $\mathrm{U} 6$ & +5 Volt & $0.15 \mathrm{~mA}$ \\
\hline $\mathrm{U} 7$ & +5 Volt & $31.5 \mathrm{~mA}$ \\
\hline $\mathrm{U} 8$ & +5 Volt & $1.0 \mathrm{~mA}$ \\
\hline $\mathrm{U} 9$ & +5 Volt & $10.0 \mathrm{~mA}$ \\
\hline $\mathrm{X} 1$ & +5 Volt & $25.0 \mathrm{~mA}$ \\
\hline $\mathrm{X} 2$ & +5 Volt & $25.0 \mathrm{~mA}$ \\
\hline R13 & +5 Volt & $0.10 \mathrm{~mA}$ \\
\hline LCD & +5 Volt & $65.0 \mathrm{~mA}$ \\
\hline Keypad & +5 Volt & $0.34 \mathrm{~mA}$ \\
\hline
\end{tabular}

Table 3.9: Current requirements for all low voltage power supplies. 
requirements so they will be available in a single table. The power requirements of the +12 volt supply are being given for the first time. This is because the +12 volt supply is only used to provide power to the two cooling fans that provide air flow through the charger's interior. Table 3.10 shows the total current requirements for each of the four power supplies. The 'Design for Current' column of Table 3.10 is the current value that is used in the power supply design calculations. These values were determined by adding

\begin{tabular}{||c|c|c|c||}
\hline $\begin{array}{c}\text { POWER } \\
\text { SUPPLY }\end{array}$ & $\begin{array}{c}\text { CALCULATED } \\
\text { LOAD } \\
\text { CURRENT }\end{array}$ & $\begin{array}{c}50 \% \text { SAFTY } \\
\text { MARGIN }\end{array}$ & $\begin{array}{c}\text { DESIGN FOR } \\
\text { CURRENT }\end{array}$ \\
\hline+15 Volt & $71.25 \mathrm{~mA}$ & $35.63 \mathrm{~mA}$ & $106.88 \mathrm{~mA}$ \\
\hline-15 Volt & $70.0 \mathrm{~mA}$ & $35.0 \mathrm{~mA}$ & $105.0 \mathrm{~mA}$ \\
\hline+12 Volt & $140.0 \mathrm{~mA}$ & $70.0 \mathrm{~mA}$ & $210.0 \mathrm{~mA}$ \\
\hline+5 Volt & $221.44 \mathrm{~mA}$ & $110.72 \mathrm{~mA}$ & $332.16 \mathrm{~mA}$ \\
\hline
\end{tabular}

Table 3.10: Power supply current and design requirements summary

$50 \%$ to the calculated current requirements for all power consuming components. The additional $50 \%$ was added to account for any possible omissions or incorrect assumptions made during the design process. It is also good engineering practice to design the power supplies to be able to provide more current than the bare minimum.

Since all of the values in the 'Design for Current' column of Table 3.10 are below 1 Amp, the power supplies can use the 78XX and 79XX series voltage regulators. Also, since no special features were required, it was decided that the power supplies would be built using the suggested circuits and component values given in the 78XX and 79XX voltage regulator datasheets. The main consideration in building the power supplies was the voltage rating of the capacitors and bridge rectifiers that were used. These parts were 
chosen with voltage ratings of at least 3 times the expected maximum applied voltage. Schematics for all four power supplies are in sections B.4 and B.5 of Appendix B.

\subsection{Software}

Two microcontrollers were used in the design of the pulse charger, one to handle user interface related functions and the other to generate and control the charging waveform. By using two microcontrollers, there was a need to develop two separate programs, one for each microcontroller. A discussion on the development of these programs will be presented in the next two sections. Emphasis will be placed on describing the logic and coding of functions whose purpose is not readily apparent or contains equations that require a derivation to fully understand. Although each function and many of the individual commands have comments in the source code, some features could not be adequately explained in a limited space or without referring to complicated formulas.

\subsection{1 'Pulse Control Microcontroller' Software}

The primary purpose of the Pulse Control Microcontroller is to generate the charging waveform. This includes controlling the on-time and amplitude of the charge and discharge pulses, controlling the off-time between the charge and discharge pulses, and read analog data representing the current state of the battery and charger. The flowchart in Figure 3.22 represents the program that was written for the Pulse Control Microcontroller. Source code listings for this microcontroller are contained in Appendix C, sections C.5 and C.6. 
Referring to the source code listing of section C.5 and the flowchart of Figure 3.22 , the first task that the microcontroller does upon power-up is to initialize all I/O pins

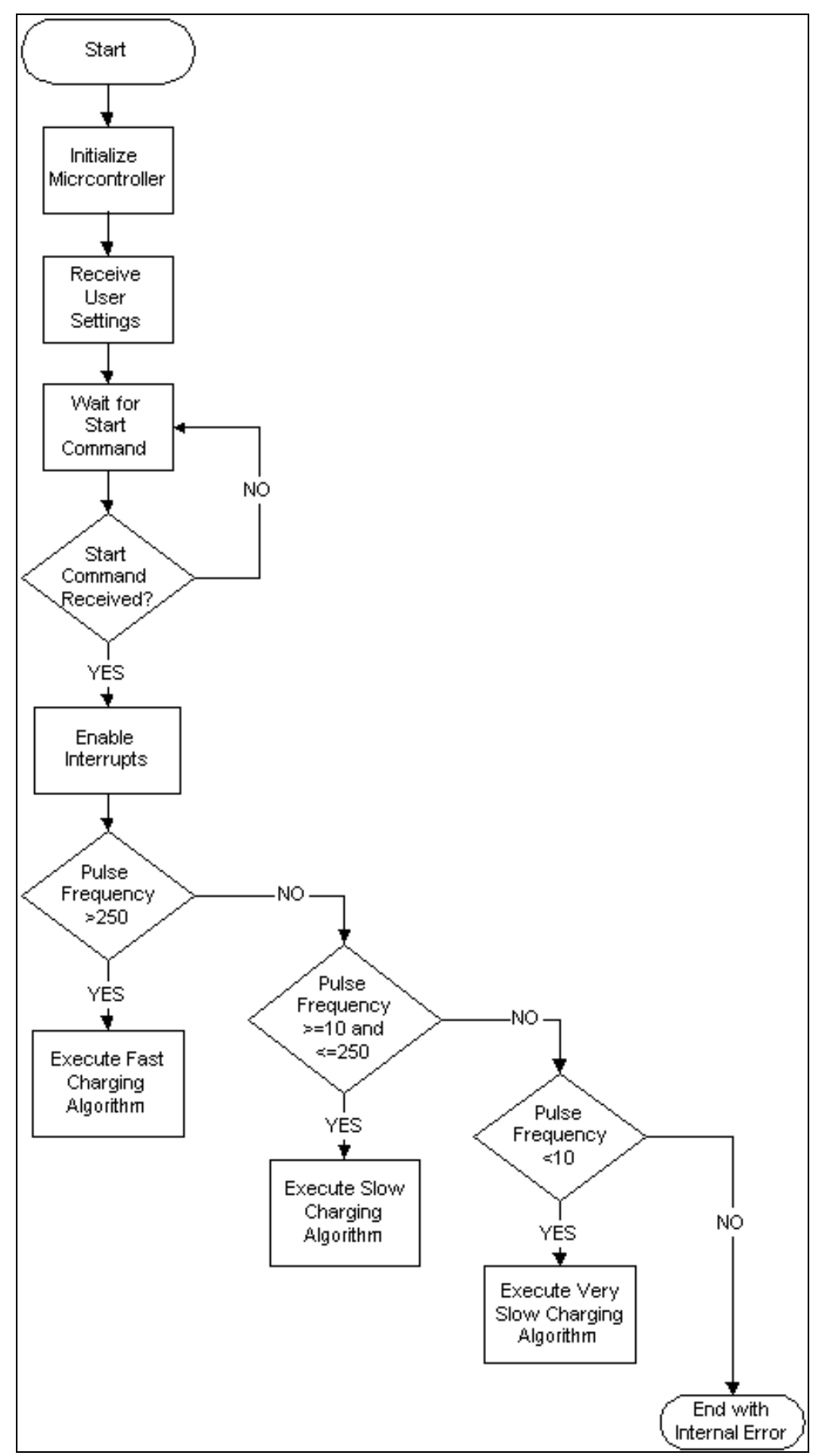

Figure 3.22: Main Program Flowchart for the 'Pulse Control Microcontroller' 
as either inputs or outputs. The analog input pins have additional initialization procedures performed on them. The initialization routine is performed by the init() function of the file MASTER.C.

Once the Pulse Control Microcontroller has completed the initializing communication takes place between it and the User Interface Microcontroller. The user setup procedure is handled by the user_setup() function of the file MASTER.C. Most of this function is well commented except of where the values of the variables delay_chrg, delay_dchrg, delay_off1, and delay_off2 are calculated. A segment of code from the user_setup () function is shown in Figure 3.23. It performs the necessary calculations to determine the delay length needed to obtain the correct charge pulse on-time.

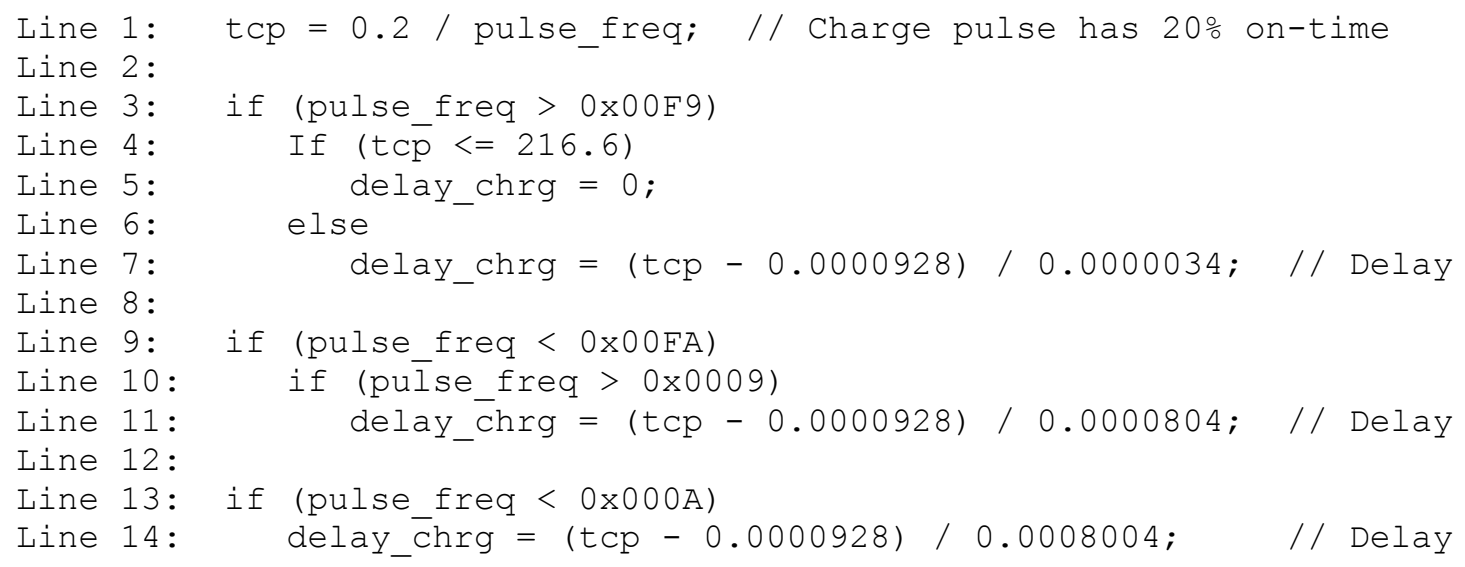

Figure 3.23: Source code segment that calculates charge pulse delay times.

The code of Line 1 of Figure 3.23 determines the charge pulse on-time that is required for the given pulse frequency, represented by the variable pulse_freq. It performs the calculation of equation 3.20. Line 3 of the code segment determines if the 


$$
t c p=d u t y \_c y c l e\left(\frac{1}{\text { Frequency }}\right)
$$

pulse frequency is greater than $250 \mathrm{Hertz}$. If so, then another check is made to determine if the required delay time is less than the minimum delay time that can be provided by the microcontroller. If this is true, then the delay time is set to zero otherwise a delay time is calculated. The values on Lines 7, 11 and 14 of Figure 3.23 were derived by first determining the fixed amount of time that the source code of Figure 3.24 took to execute. The difference between the fixed execution time and the charge pulse time gave a delay that needed to be performed by the code on Lines $6-9$ of Figure 3.24. The difference between the fixed execution time and the charge pulse time gave a delay that needed to

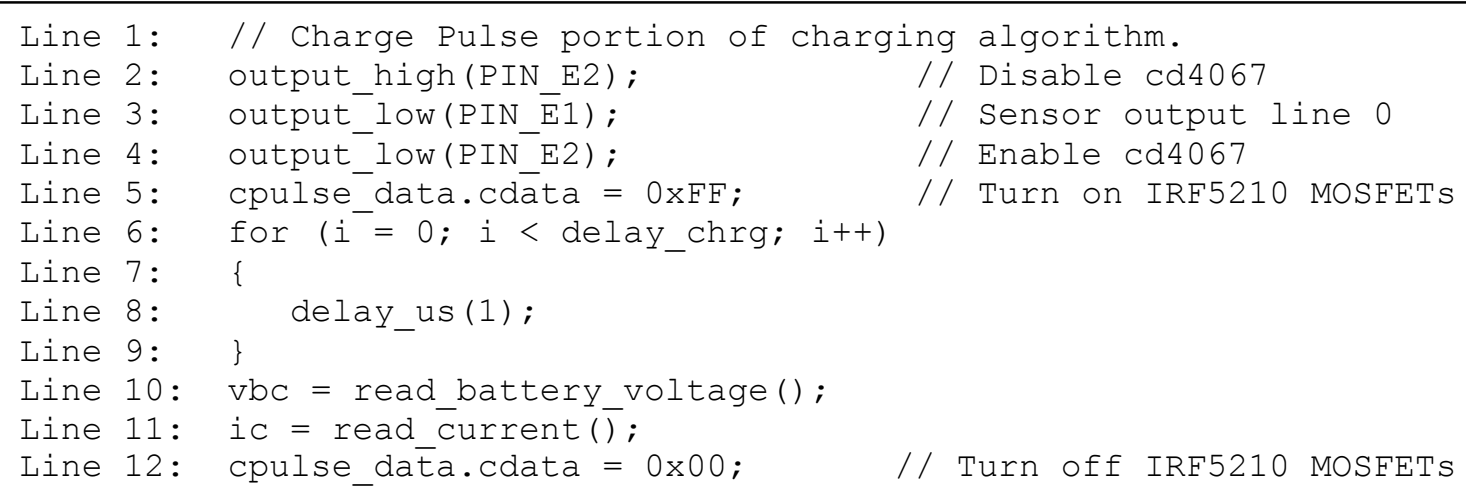

Figure 3.24: Source code segment that generates the charge pulse using the fast charging algorithm.

be performed by the code on Lines $6-9$ of Figure 3.24. By first compiling the code of Figure 3.24, it was determined that the code on Lines $2,3,4,5$, and 12 would take $1.2 \mu$ s to execute. Each of the instructions on Lines 2, 3, 4, 5, and 12 produce one Assembly language instruction and none alter the program counter of the microcontroller so each 
will take only 1 instruction cycle to execute. Each instruction cycle is made up of 4 clock cycles and a clock cycle is equal to 50ns. Instructions that do alter the program counter will take 2 instruction cycles or 8 clock cycles. The code on Lines 10 and 11 of Figure 3.24 each take an estimated $45.2 \mu$ s. This gives a software-related fixed execution time of 91.6 $\mu$ s. The time of $45.2 \mu$ s is an estimated time since the time required for analog-todigital conversions to complete could only be approximated. The analog acquisition time and conversion time were both estimated at $20 \mu$ s each. The Assembly language instructions then took another $5.2 \mu$ s to execute. Equations 3.21 and 3.24 given the analog acquisition time and the conversion time respectively. The formulas as well as the values used were obtained from the analog-to-digital conversion section of the PIC16F877 datasheet.

$$
\begin{aligned}
& T_{A C Q}=T_{A M P}+T_{C}+T_{\text {COEF }} \\
& T_{C}=\left[C_{H O L D}\left(R_{I C}+R_{S S}+R_{S}\right) \ln \left(\frac{1}{2047}\right)\right] \\
& T_{\text {COEF }}=\left[\left(T e m p-25^{\circ} \mathrm{C}\right)\left(\frac{0.05 \mu \mathrm{S}}{{ }^{\circ} \mathrm{C}}\right)\right] \\
& T_{\text {CONV }}=12\left[32\left(T_{\text {OSC }}\right)\right]
\end{aligned}
$$

Because the turn-off time of the P-Channel MOSFETs was so long, it could not be ignored. Through experimentation, it was determined that the average turn-off time of 
the P-Channel MOSFETs was $125 \mu$ s. This value was added to the software-related fixed execution time in order to compensate for the length of time the MOSFETs took to turn off and stop conducting current.

It is now known that the fixed execution time of the charge pulse code segment will take $216.6 \mu$ s to execute. A similar method was followed to calculate the fixed execution times for the discharge pulse code and the code for the first and second rest periods. They are much shorter because these segments of code do not depend on the turn-off time of the p-Channel MOSFETs. The fixed times for all code segments are summarized in Table 3.11. The duty cycles for each code segment are also given in this table.

\begin{tabular}{|c|c|c|}
\hline CODE SEGMENT & FIXED TIME ( $\left.T_{\text {FIXED }}\right)$ & DUTY CYCLE \\
\hline Charge Pulse Code & $216.6 \mu \mathrm{s}$ & $\begin{array}{l}0.2 \\
\end{array}$ \\
\hline Discharge Pulse Code & $91.6 \mu \mathrm{s}$ & 0.1 \\
\hline $1^{\text {st }}$ Rest Period Code & $90.4 \mu \mathrm{s}$ & 0.6 \\
\hline $2^{\text {nd }}$ Rest Period Code & $45.2 \mu \mathrm{s}$ & 0.1 \\
\hline
\end{tabular}

Table 3.11: Summary of the fixed execution times and duty cycles for the different pulse charger output waveform sections.

It is now know that the code of Figure 3.24 will take $216.6 \mu$ s to execute. The delay loop formed by the code on Lines 6 and 8 of Figure 3.24 will need to have an execution time equal to the charge pulse on-time minus $216.6 \mu$ s. Next, a formula was developed for the execution time of the 'for loop' on Line 6. This formula is given in equation 3.25 where the value of ' $i$ ' is the number of times the 'for loop' is to be executed and the value of 'delay' is given by the chosen fixed delay time on Line 8 of Figure 3.24. Also, for this formula to be valid, the value of ' $i$ ' must always be less than 


$$
t_{F O R_{-} L O O P}=1.2 \mu s+i(1.4 \mu s+\text { delay })
$$

or equal to 255 . The reason is that the code for the 'for loop' becomes very complicated when ' $i$ ' becomes large enough to need a 9-bit representation and the execution time for the loop can no longer be given by a single equation.

At this point, enough information has been developed so that the values on Lines 7, 11 and 14 of Figure 3.23 can be calculated. The steps outlined below show how the delay formula coefficients in the user_setup() function of the MASTER.C source code file were calculated.

- Select the desired frequency range of $f_{\mathrm{L}}$ to $\mathrm{f}_{\mathrm{H}}$. Valid ranges for the charger are $\mathrm{f}_{\mathrm{L}}=251 \mathrm{~Hz} \& \mathrm{f}_{\mathrm{H}}=1000 \mathrm{~Hz}, \mathrm{f}_{\mathrm{L}}=10 \mathrm{~Hz}$ \& $\mathrm{f}_{\mathrm{H}}=250 \mathrm{~Hz}$, and $\mathrm{f}_{\mathrm{L}}=1 \mathrm{~Hz} \& \mathrm{f}_{\mathrm{H}}=9 \mathrm{~Hz}$.

- Using Table 3.11, determine the duty cycle that corresponds to the delay being calculated.

- Using equation 3.20, calculate the value of tcp using the value of $f_{\mathrm{L}}$ for frequency

- Using Table 3.11, determine the value of $t_{\text {FIXED }}$ that corresponds to the delay being calculated.

- Set tFOR_LOOP to equal tcp $-t_{\text {FIXED }}$

- Using equation 3.25, calculate the value of 'delay' by setting tFOR_LOOP to the value that was calculated in the previous step and the value of ' $i$ ' to 250 . A value of 250 was used to ensure that the 'for loop' will not execute more than 255 times. A floating point number will result for 'delay'. Round this number up to 
the next integer value if greater than 0.8 . This will be the number of microseconds to use as the fixed delay inside the 'for loop'. If the value of delay less than or equal to 0.8 , then divide the number by 0.2 and round up to the next integer value. This will be the number of instruction cycles to use as the fixed delay inside the 'for loop'.

- Using equation 3.20 once again, calculate the value of tcp using the same duty cycle value previously used and this time using the value of $f_{H}$ for frequency.

- $\quad$ Set $t_{\text {FOR_LOOP }}$ to equal tcp $-t_{\text {FIXED }}$

- Using equation 3.25, substitute the value of $t_{\text {FOR_LOOP }}$ calculated in the previous step and 'delay' and calculate the value of ' $i$ '. This will be the number of times that the 'for loop' will need to be executed. This will be a floating point number but the compiler will charge it to an integer number when the assignment is made in the equations in Lines 7, 11 and 14 of Figure 3.23.

The next portion of code for the Pulse Control Microcontroller to be examined is the interrupt handler. The relevant code segment is shown in Figure 3.25. The source code of Lines 1 and 2 are what make this the interrupt handler. They signal to the compiler that this function is to be executed anytime an interrupt is triggered by data coming into the microcontroller through the RCV pin of Port C. The compiler, then, generates the appropriate Assembly code. The remaining code of Lines 3-37 are simply what is executed according to the data that is received through the RCV pin. 


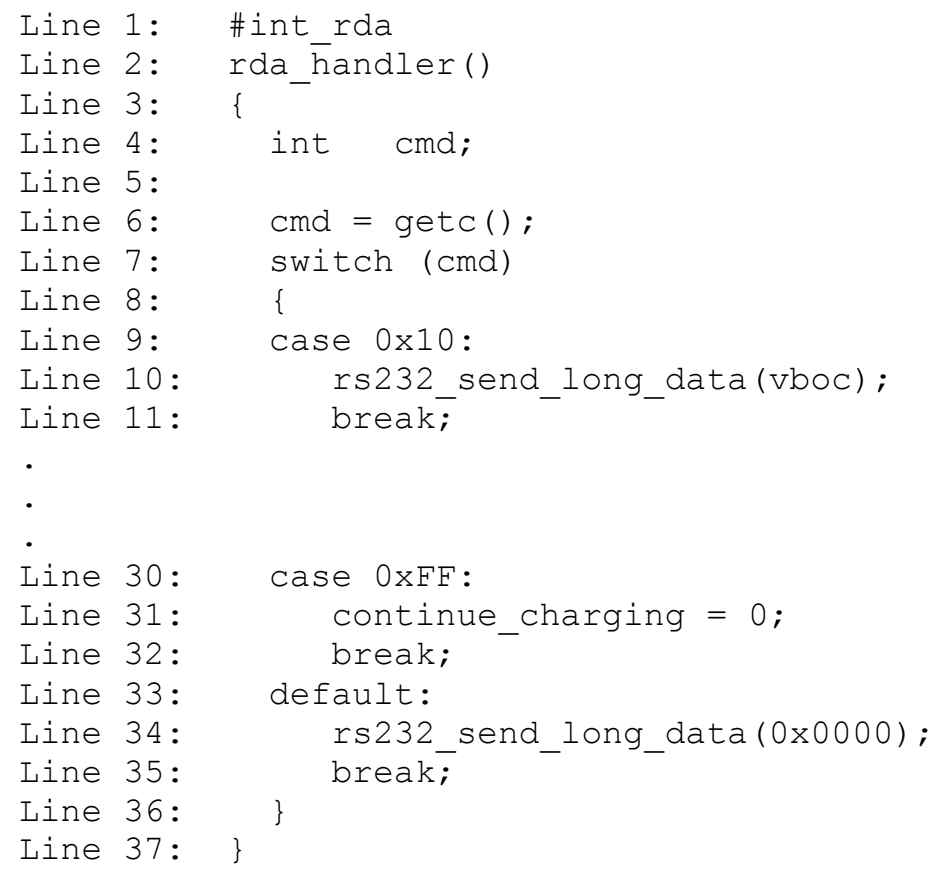

Figure 3.25: Interrupt handler routine for the 'Pulse Control Microcontroller'

Finally, referring back to the flowchart in Figure 3.22, it can be seen that the charging algorithm begins once the charger has completed its setup routines. The flowchart for the charging algorithm is shown in Figure 3.26. This flowchart represents the fast, slow, and very slow charging algorithms since the only difference in these algorithms is the values of the 'for loop' delays and the number of times each loop is executed. All analog input voltages to the microcontroller are read at the end of the code sections for the charger pulse, discharge pulse, rest period 1, and rest period 2. This helps to ensure that the correct voltage is present at the analog input pin of the microcontroller before a reading is made. Whenever the charging algorithm's stopping condition is reached, the microcontroller will enter an endless loop. This is because the Pulse Control Microcontroller is no longer needed for the operation of the charger. 


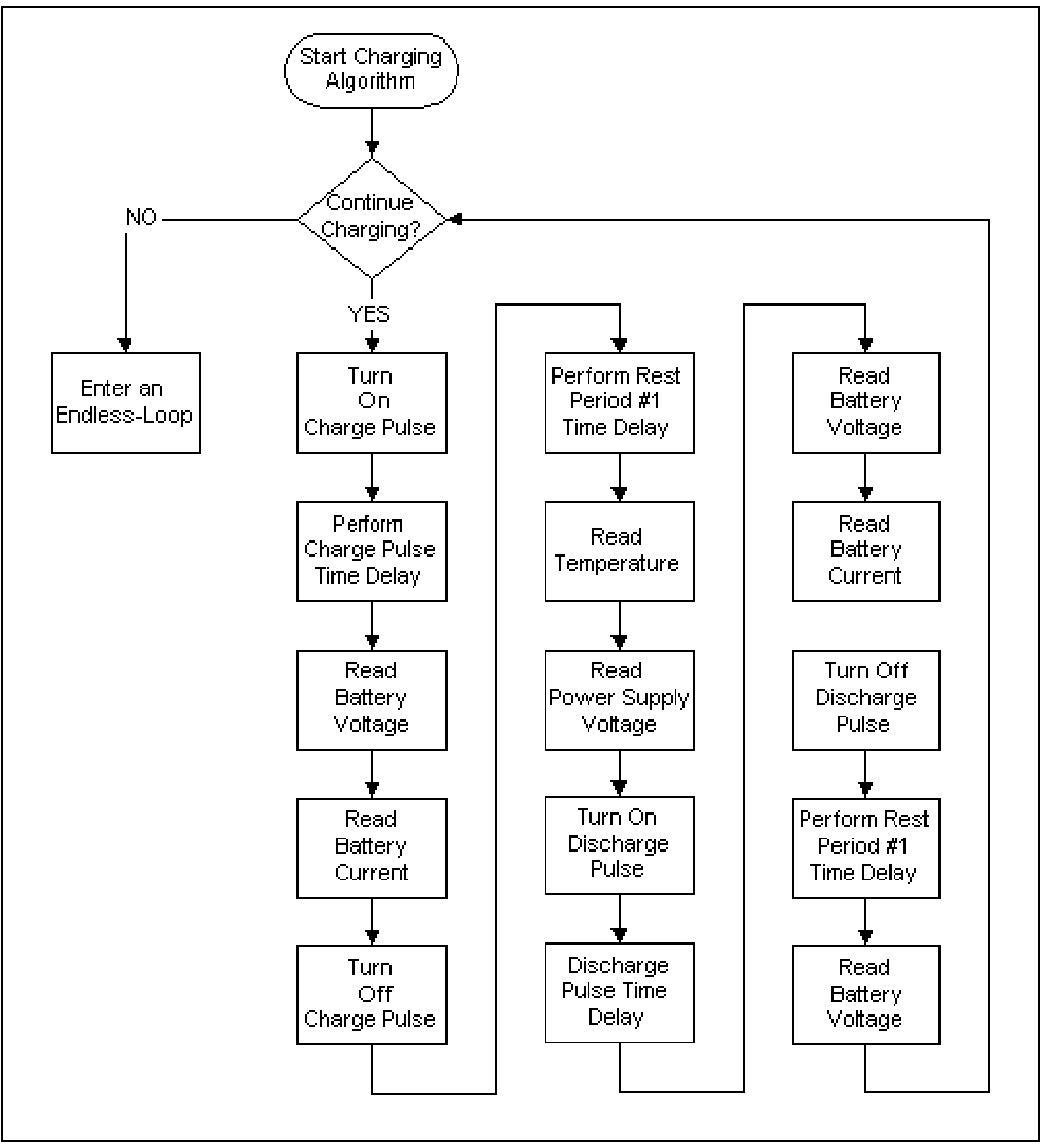

Figure 3.26: Flowchart for the charging algorithm

\subsection{2 'User Interface Microcontroller' Software}

The User Interface Microcontroller is used to display information to the user via an LCD. It also receives user input from a keypad. Besides the user interface functions 
that are performed, the microcontroller is used to control the operation of an elapsed timer, test the initial battery voltage, perform calculations using battery voltage and current data, and to determine when the battery being charged has reached the userdefined stopping condition. Most of the programming techniques and logic that make up the source code for the User Interface Microcontroller should be easily understood by someone knowledgeable with the $\mathrm{C}$ programming language. Therefore, only code segments where formulas were developed or where calculations were made prior to writing the $\mathrm{C}$ code, in order to simplify the microcontroller's tasks will be discussed.

Figure 3.27 is the main program flowchart for the User Interface Microcontroller source code. The four features of the source code that will be discussed in more detail are three formulas that are part of the functions get_voltage(), get_battery_current(), and get_internal_temperature() as well as a lookup table that was written in simplify the task of converting the 32-bit binary output from the elapsed timer into a human readable time format of hours, minutes, and seconds.

The first function that will be examined is get_voltage(). The code for this function is in the SLAVE.C source code listing contained in section C.3 of Appendix C For convenience, it is also shown in Figure 3.28. This function will receive a 10-bit binary representation of the analog voltage that was present at the analog input pin of the microcontroller. Line 7 of Figure 3.28 multiplies this 10-bit number, given by the variable 'data', by an appropriate scaling factor so that the function will return a floating point number representing the actual real world value that will be displayed to the user and used for calculations. 


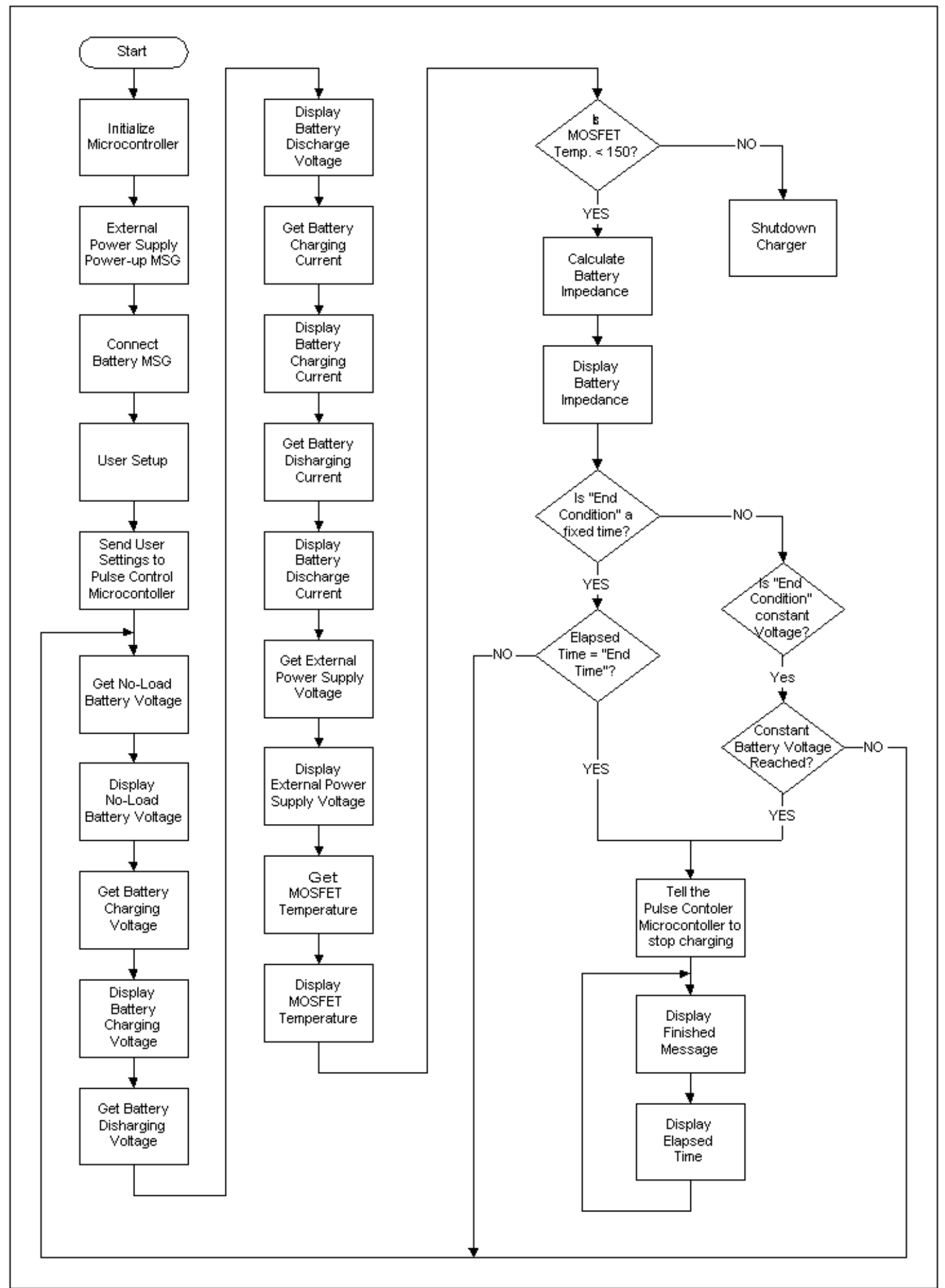

Figure 3.27: Main Program Flowchart for the 'User Interface Microcontroller' 


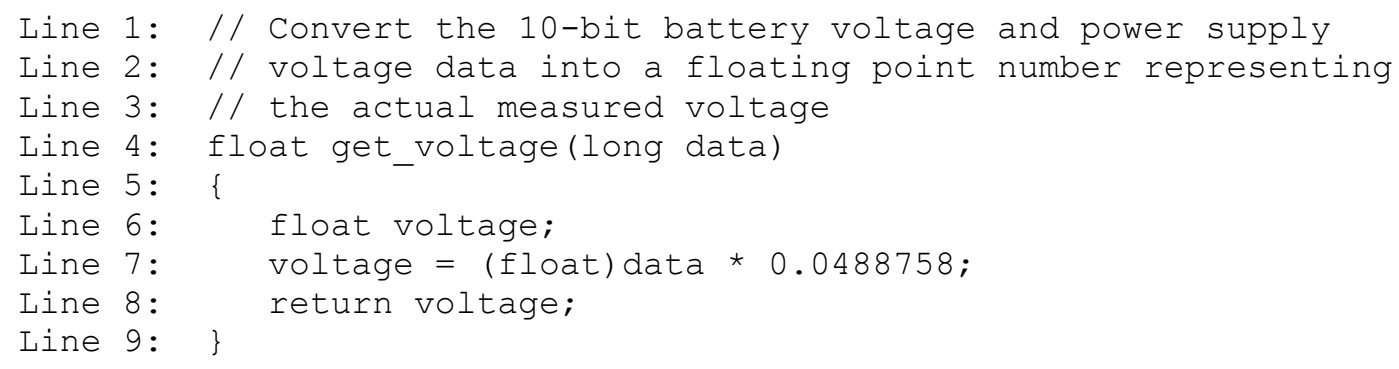

Figure 3.28: Code segment for the function get_voltage()

The first step taken to calculate the scaling factor was to determine the maximum input voltage to the microcontroller. In this case, the maximum voltage was 5 volts. Next, a formula was developed that related the 10-bit binary number to the analog input voltage. Knowing the 10-bit number, the developed formula needed to give the original analog input voltage to the microcontroller. The derived formula is shown below.

$$
V_{A N}=\frac{\text { data }}{1023}\left(V_{A N_{-} M A X}\right)
$$

The value of the variable data is the 10-bit number produced by the analog-to-digital conversion and the variable, $\mathrm{V}_{\mathrm{AN} \_\mathrm{MAX}}$, is the maximum analog input voltage. Since the actual voltage is 10 times greater than the analog input voltage to microcontroller, all that is required at this point is to multiple the value of $\mathrm{V}_{\mathrm{AN}}$ given by equation 3.26 by 10 in order to know the actual voltage at the power supply or battery terminals. The following equation is the one that was used to determine the scaling factor in the code on Line 7 of Figure 3.28. 


$$
V=\frac{\operatorname{data}(10)}{1023}\left(V_{A N_{-} M A X}\right)=\operatorname{data}\left(V_{S C A L E}\right)
$$

The next function to be examined is get_battery_current(). The code for this function is shown in Figure 3.29 as well as in file SLAVE.C contained in section C.4 of Appendix C. This function receives a 10-bit binary representation of the voltage applied

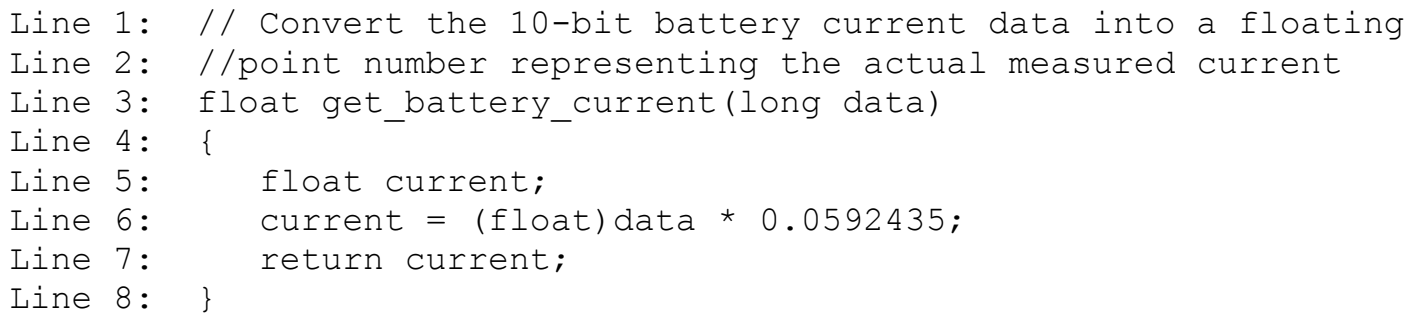

Figure 3.29: Code segment for the function get_battery_current()

to an analog input pin of the microcontroller. To calculate the scaling factor contained in the code on Line 6, equation 3.26 is, once again, used in order to determine the analog input voltage to the microcontroller. Since this voltage was produced by the output current from the current sensor flowing through a $82.5 \Omega$ resistor, dividing the value of $\mathrm{V}_{\mathrm{AN}}$ given by equation 3.26 by 82.5 will give the value of the scaled current output from the current sensor. This calculation is shown in equation 3.28. Since the current sensor

$$
I_{\text {SENSE }}=\frac{\text { data }}{1023(82.5)}\left(V_{A N_{-} M A X}\right)
$$

scales the actual sensed current by a factor of 1000 , multiplying the value of $\mathrm{I}_{\mathrm{SENSE}}$ by 1000 will give the actual current value flowing into and out of the battery. The actual 
current and the scaling factor used in the code of Line 6 of Figure 3.29 was calculated by the following formula.

$$
I=\frac{\operatorname{data}(1000)}{1023(82.5)}\left(V_{A N_{-} M A X}\right)=\operatorname{data}\left(I_{\text {SCALE }}\right)
$$

The last function to be examined is get_internal_temperature(). The code for this function is shown in Figure 3.30 as well as in file SLAVE.C contained in section C.4 of

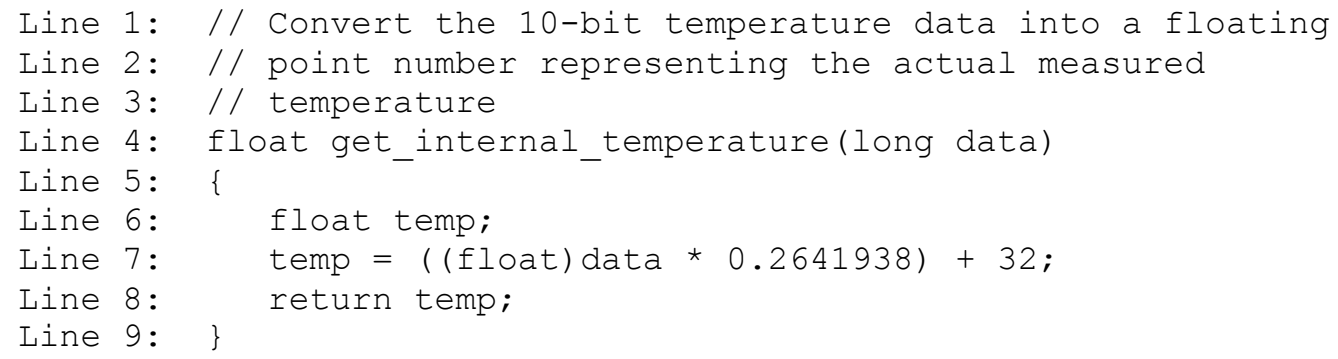

Figure 3.30: Code segment for the function get_internal_temperature $(0$

Appendix C. Like the two previous scaling factor calculations, this one also started with equation 3.26 to give the analog input voltage to the microcontroller. To determine the output voltage from the temperature sensor, the analog input voltage was divided by 3.33 since it was amplified by an operational amplifier with a gain of 3.33 prior to being applied to the microcontroller. This calculation is given by the following equation.

$$
V_{T E M P}=\frac{\text { data }}{1023(3.33)}\left(V_{A N_{-} M A X}\right)
$$


To convert the voltage output from the temperature sensor, $\mathrm{V}_{\text {TEMP }}$, into a temperature in degrees Celsius, the result from equation 3.30 was multiplied by 100 since the temperature sensor's output voltage is $0.01 \mathrm{~V} /{ }^{\circ} \mathrm{C}$. The equation below gives the sensed

$$
T e m p_{C}=\frac{\operatorname{data}(100)}{1023(3.33)}\left(V_{A N_{-} M A X}\right)
$$

temperature in degrees Celsius in terms of the microcontroller's 10-bit binary representation.

Since a temperature in degrees Fahrenheit was desired, the temperature given by equation 3.31 was modified in order to give a scaling factor and an offset value that could be used in the code on Line 7 of Figure 3.30. Equation 3.32 gives the sensed temperature in degrees Fahrenheit. The final equation used for this code is given by equation 3.33.

$$
\begin{aligned}
& \operatorname{Temp}_{F}=\frac{\operatorname{data}(100)(9)}{1023(3.33)(5))}\left(V_{A N_{-} M A X}\right)+32 \\
& \operatorname{Temp}_{F}=\operatorname{data}\left(T_{\text {SCALE }}\right)+T_{\text {OFFSET }}
\end{aligned}
$$

The final piece of code that was used with the User Interface Microcontroller to be discussed is the lookup table that was produced to simplify the elapsed time conversion from a 32-bit binary number into a time format of HR:MIN:SEC. This code is in the file SLAVE.H of Appendix C section C.4. The relevant code segment is shown in Figure 3.31 for convenience. 


\begin{tabular}{|c|c|c|}
\hline Line & 1: & // Hr, min, and sec associated with each bit of the 32-bit \\
\hline Line & 2: & // word from the elapsed timer. Ex: If bits 0 and 12 are \\
\hline Line & 3: & $/ /$ set then the elapsed time is $1: 8: 16+0: 0: 1=1: 8: 17$ \\
\hline Line & 4: & const int time[18] [3] $=\{\{0,0,1\}$ \\
\hline Line & 5: & $\{0$, \\
\hline Line & 6: & $\{0$, \\
\hline Line & $7:$ & $0,8\}$ \\
\hline Line & 8: & $0,16\}$ \\
\hline Line & 9: & $0,32\}$ \\
\hline Line & 10: & $1,4\}$ \\
\hline Line & 11: & $\{0$, \\
\hline Line & 12: & $4,16\}$ \\
\hline Line & 13: & $\{0,8,32\}$ \\
\hline Line & $14:$ & $\{0,17,4\}$ \\
\hline Line & 15: & $\{0,34,8\}$ \\
\hline Line & $16:$ & $\{1,8,16\}$ \\
\hline Line & 17: & $\{2,16,32\}$ \\
\hline Line & 18: & $\{4,33,4\}$ \\
\hline Line & 19: & $\{9,6,8\}$ \\
\hline Line & 20: & $\{18,12,16\}$ \\
\hline Line & 21: & $\{36,24,32\}\} ;$ \\
\hline
\end{tabular}

Figure 3.31: Code segment for the elapsed timer lookup table

The elapsed timer that was used is simply a counter that counts the number of elapsed seconds. The output from the timer is a 32-bit binary number that corresponds to the number of elapsed seconds that the timer has counted. In order to convert the 32-bit number into a human readable form, it was determined that a lookup table should be developed instead of doing the conversion with only equations.

The lookup table of Figure 3.31 is a matrix with 18 rows and 3 columns. Each row of the table represents 1 bit of the 32-bit binary output from the elapsed timer. For example, row 1 corresponds to bit 0 of the output, row 2 corresponds to bit 1 of the output, row 3 corresponds to bit 2 of the output, and so on up to row 18 , which corresponds to bit 17 of the elapsed timer's output. Only 17 of the 32 bits were used in order to save processing time and memory. Also, because 17 bits can represent an elapsed time of 72 hours, 49 minutes, and 3 seconds it was decided that this would 
provided a sufficiently long timing capability for normal charger operation. The columns of the lookup table represent the elapsed time's hours, minutes, and seconds. The first column of the table represents the number of elapsed hours, the second column represents the number of minutes, and the third column represents the number of seconds.

After the output from the elapsed timer is read by the microcontroller, it tests bits 0 through 17 of the 32-bit output to determine which bits are set and which bits are cleared. If the bit is set, then the row of the lookup table that corresponds to the bit number is accessed and the number of hours, minutes, and seconds are read. The total for the hours, minutes, and seconds corresponding to all set bits is maintained and converted into the time format of HR:MIN:SEC once all 17 bits have been checked. 


\section{Chapter 4: Experimentation}

Once the pulse charger was designed, built, and tested, battery testing could begin. Several steps were taken prior to starting the test procedure to insure that each battery's condition included in a test set was as closely matched to the others as possible. To explain the testing of the batteries, the experimental procedure will be broken down into steps that correspond to those that were actually taken in the lab. The sections that follow will show how the testing of the batteries progressed from when they were first paired into test sets to the final charge / discharge cycle.

\subsection{Charging Algorithms}

It was determined that the best method for comparing the effectiveness of using a pulse charger instead of a constant voltage / constant current charger, hereafter referred to as normal charging, was to simultaneously charge two batteries using pulse charging for one battery and normal charging for the other battery.

\subsubsection{Pulse Charging}

As it was explained in a prior chapter, pulse charging is a process in which the charging current is applied to the battery for a short period of time then removed for a period of time and then applied again and so on. The form of pulse charging used for this experiment also had a discharge pulse as part of the charger's output waveform. Figure 4.1 is a plot of the charger's charge and discharge pulses and the battery's resulting 


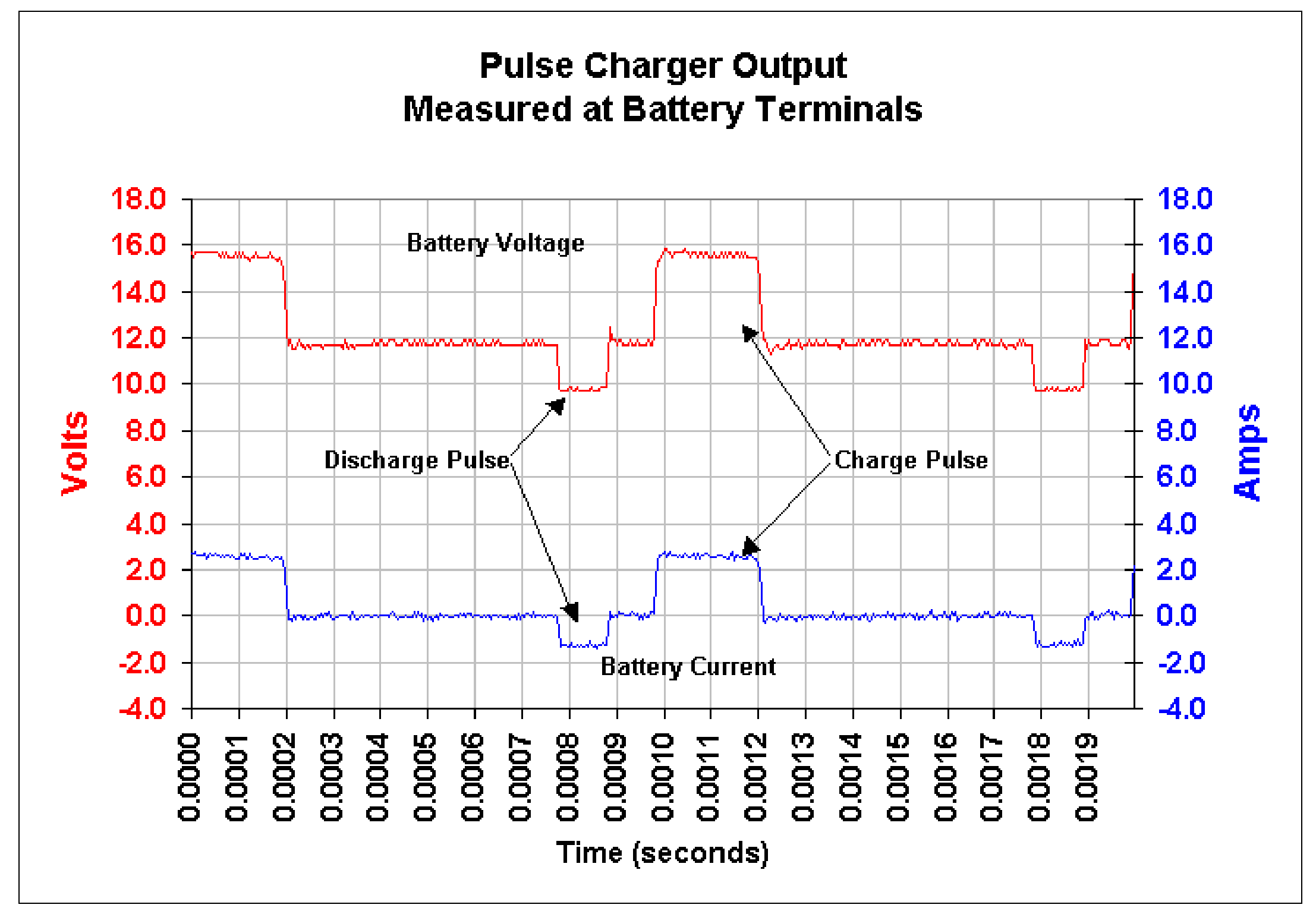

Figure 4.1: Example of the Pulse Charger's output as measured at the battery terminals. 
charging and discharging voltage. The frequency of the charger's output is $1 \mathrm{kHz}$. This frequency was used throughout the experimental procedure.

\subsubsection{Normal Charging}

The normal charging method used an EverStart Basic Six Model WM-82-6 manual charger. Since this is a manual charger, it will continue to apply charging current to the battery even after the battery has reached a fully charged state. As someone can infer, this is a very basic charger that applied a constant non-alternating voltage to the battery. The charging current was a pulsating AC sine wave value with periods of zero charging current. While the charging current is referred to as constant, this statement is not entirely accurate. While the peak value of current is constant for some period of time, its magnitude does drop as the battery's state of charge nears $100 \%$ and as the internal impedance of the battery changes. Figure 4.2 is a plot of the normal charger's output waveform. As it can be seen from the plot, the normal charger's output is much simpler than the output from the pulse charger.

\subsection{Battery Testing Equipment}

The equipment that was used in the battery test procedure consisted of six normal chargers, one custom designed pulse charger, and a discharge test apparatus. Five of the six normal charges were used to give the lead-acid batteries their top-off charge before the first discharge test was run. The remaining normal charger also perform the top-off charge task. But, as the batteries were grouped into test sets, this charger was given the task of performing the normal charge on one of the batteries in a test set. 


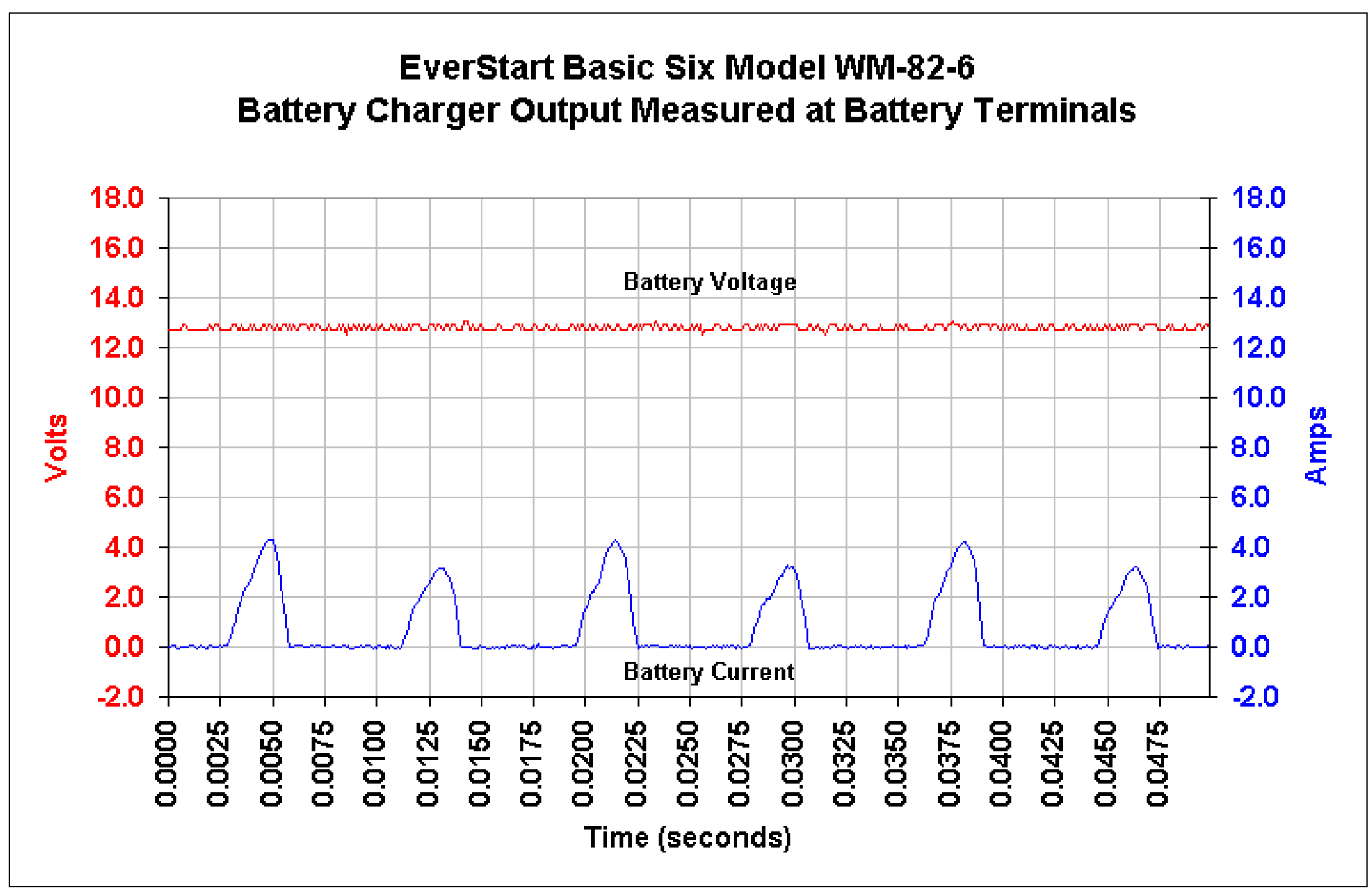

Figure 4.2: Example of the Normal Charger's output as measured at the battery terminals. 
The discharge test apparatus that was used consisted of a $0.1 \Omega$ resistive load, Hall-effect current sensor, voltage sensor, a hold-in circuit breaker, a data acquisition card, and a computer with LabView software. The discharge test apparatus and the LabView virtual instrument program were not created specifically for this research. They were made by another individual for another project.

\subsection{Test Procedure}

The test procedure used in this research can actually be divided into two phases, each with a different goal. The first test phase was used to determine the subject battery's initial condition. This information was needed so that test sets could be formed for the second test phase. The second test phase consisted of collecting data by repeatedly charging and discharging the batteries of each test set. This second phase data was used to make the final determination regard the benefits and usefulness of pulse charging as compared to normal charging.

\subsubsection{Initial Condition Test}

The testing procedure that will be discussed in this section was used to determine a subject battery's initial condition and, so, will be referred to as the Initial Condition Test. The data resulting from the Initial Condition Test was not used in the comparison between pulse charging and normal charging. This test procedures only purpose was to enable the pairing of batteries with similar conditions into test sets.

The testing of the pulse charging technique began with randomly selecting a battery. This battery's pre-charge terminal voltage was measured and recorded. The battery was 
then given a top-off charge using one of several constant voltage / constant current chargers. Once the battery had been charged, its post-charge terminal voltage was measured and recorded. The battery was then placed aside for 24 hours. After the 24 hour period had past, the battery's post-charge +24 terminal voltage was measured and recorded. At this point, the battery's weight was also measured and recorded. The battery was, then, immediately subjected to a discharge test to determine its current condition. The discharge test continued until the battery's terminal voltage reached 10.765 volts for at least 0.4 seconds. At this point, the discharge test was halted and the resulting data file saved for future use. A segment of a discharge test data file is shown in Figure 4.3. The first column of data represents the battery's voltage and the second column represents the battery's current. Each row represents one data sample taken at 0.2 second intervals. The data values in the file have been scaled by the LabView VI. To obtain the actual measured values, the voltage data values need to be multiplied by 10.07 and the current data values multiplied by 149.9 .

\begin{tabular}{|llll|}
\hline LabView & LabView & Actual & Actual \\
Volts & Amps & Voltage & Current \\
1.128 & 0.725 & 11.359 & 108.678 \\
1.125 & 0.725 & 11.329 & 108.678 \\
1.125 & 0.725 & 11.329 & 108.678 \\
$\cdot$ &. &. & $\cdot$ \\
$\cdot$ &. &. & $\cdot$ \\
. &. &. & $\cdot$ \\
1.128 & 0.725 & 11.359 & 108.678 \\
1.125 & 0.725 & 11.329 & 108.678 \\
1.128 & 0.725 & 11.359 & 108.678 \\
\hline
\end{tabular}

Figure 4.3: Segment of a discharge test data file with scaled and actual voltage and current data. 
After the discharge test had completed, the battery was again charged using a normal charger. The pre-charge, post-charge, and post-charge +24 terminal voltages were again measured and recorded at the appropriate times during charging. The battery was, then, placed in a storage area to wait for possibly use as a member of a test set.

Using the data file resulting from the discharge test, the battery's discharge time was determined and recorded. The discharge time is defined as the elapsed time starting when the battery is first connected to the load resistor and ending when the battery's terminal voltage reaches 10.765 volts for 0.4 seconds.

Data from the discharge test was used to calculated the battery's impedance. The following equation was used for this task.

$$
Z=\frac{V_{t=0 s}-V_{t=0.2 s}}{I_{t=0.2 s}}
$$

The process of randomly selecting batteries and subjecting them to a chargedischarge-charge cycle continued as the availability of normal chargers permitted. As each battery was finished, certain parameters concerning its condition were added to a table. The data placed in this table consisted of the battery's identifying number, the most recent post-charge +24 terminal voltage, the discharge time, and the impedance calculated using equation 4.1. As data was added to this table, the batteries were grouped together so that their voltage, impedance, and discharge time were as closely matched as possible. Once two batteries were found with similar characteristics, they became designated as a test set. 


\subsubsection{Charger Comparison Test}

Once two batteries had been grouped into a test set, one of the batteries was designated to be recharged using the normal charger and the other battery was designated to be recharged using the pulse charger. Each battery's pre-discharge terminal voltage was measured and recorded. They were, then, subjected to the discharge test to determine the length of time that they could provide current to a $0.1 \Omega$ resistive load before the terminal voltage reached 10.765 . The resulting time was designated as the Test 0 Discharge Time. After a discharge test had been run on both batteries of the test set, their pre-charge terminal voltages were measured and recorded. The discharge test data, along with equation 4.1 , were then used to determine the battery's internal impedance. They were recharged using the appropriate charging technique. When each battery had reached a fully charged state, it was removed from the charger and a record was made of its post-charge terminal voltage. The batteries were, then, left undisturbed for 24 hours. At the end of the 24 hour period, their post-charge +24 terminal voltages were measured and recorded. Another discharge test was performed, resulting in the Test 1 Discharge Time. The batteries were charged as had previously been done with records being made of terminal voltages at the designated times. The same discharge / charge cycle repeated until the Test 8 Discharge Time had been measured. When this time had been determined, the Charger Comparison Test for the battery test set was complete.

\subsection{Test Results}

Six battery tests set were used to test the pulse charging technique. Each test set used had slightly different characteristics in order to test pulse charging on as wide a 
range of battery conditions as possible. Table 4.1 summarizes the characteristics that each battery test set possessed at the start of the Charger Comparison Test.

\begin{tabular}{||c|c|c|c||}
\hline $\begin{array}{c}\text { TEST SET } \\
\text { DESIGNATION }\end{array}$ & $\begin{array}{c}\text { NORMALLY } \\
\text { CHARGED } \\
\text { BATTERY ID }\end{array}$ & $\begin{array}{c}\text { PULSE } \\
\text { CHARGED } \\
\text { BATTERY ID }\end{array}$ & $\begin{array}{c}\text { TEST SET } \\
\text { CHARACTERISTICS }\end{array}$ \\
\hline \hline A & 161 & 177 & $\begin{array}{c}\text { Batteries that were more than } 4 \\
\text { years old and had a discharge test } \\
\text { time of } 10 \text { minutes or more. }\end{array}$ \\
\hline B & 437 & 438 & $\begin{array}{c}\text { Batteries that were less than } 4 \\
\text { years old and had a discharge test } \\
\text { time of } 10 \text { minutes or more. }\end{array}$ \\
\hline D & 120 & 116 & $\begin{array}{c}\text { Batteries that had a discharge test } \\
\text { time between } 3 \text { and } 5 \text { minutes. }\end{array}$ \\
\hline E & 144 & 129 & $\begin{array}{c}\text { Batteries that had a discharge test } \\
\text { time between } 5 \text { and } 6 \text { minutes } \\
\text { and had an internal impedance of } \\
\text { less than } 0.006 \text { ohms. }\end{array}$ \\
\hline F & 132 & 324 & $\begin{array}{c}\text { Batteries that had a discharge test } \\
\text { time between } 5 \text { and } 6 \text { minutes } \\
\text { and had an internal impedance of } \\
\text { greater than } 0.006 \text { ohms. }\end{array}$ \\
\hline & 148 & $\begin{array}{c}\text { Batteries that still had a terminal } \\
\text { voltage of less then } 12 \text { volts when } \\
\text { charged for } 24 \text { hours using a } \\
\text { normal charger. }\end{array}$ \\
\hline
\end{tabular}

Table 4.1: Distinguishing characteristics of the battery tests sets.

\subsubsection{Battery Discharge Tests}

The results from the discharge tests of the Charge Comparison Test for each battery test set are summarized in Tables 4.2, 4.3, and 4.4. The graphs used to determine the information in these tables are contained in Appendix A. The discharge data has also been included as an embedded attachment in the pdf version of this document. The graph of Figure 4.4 is a compilation of all battery test set discharge data. 


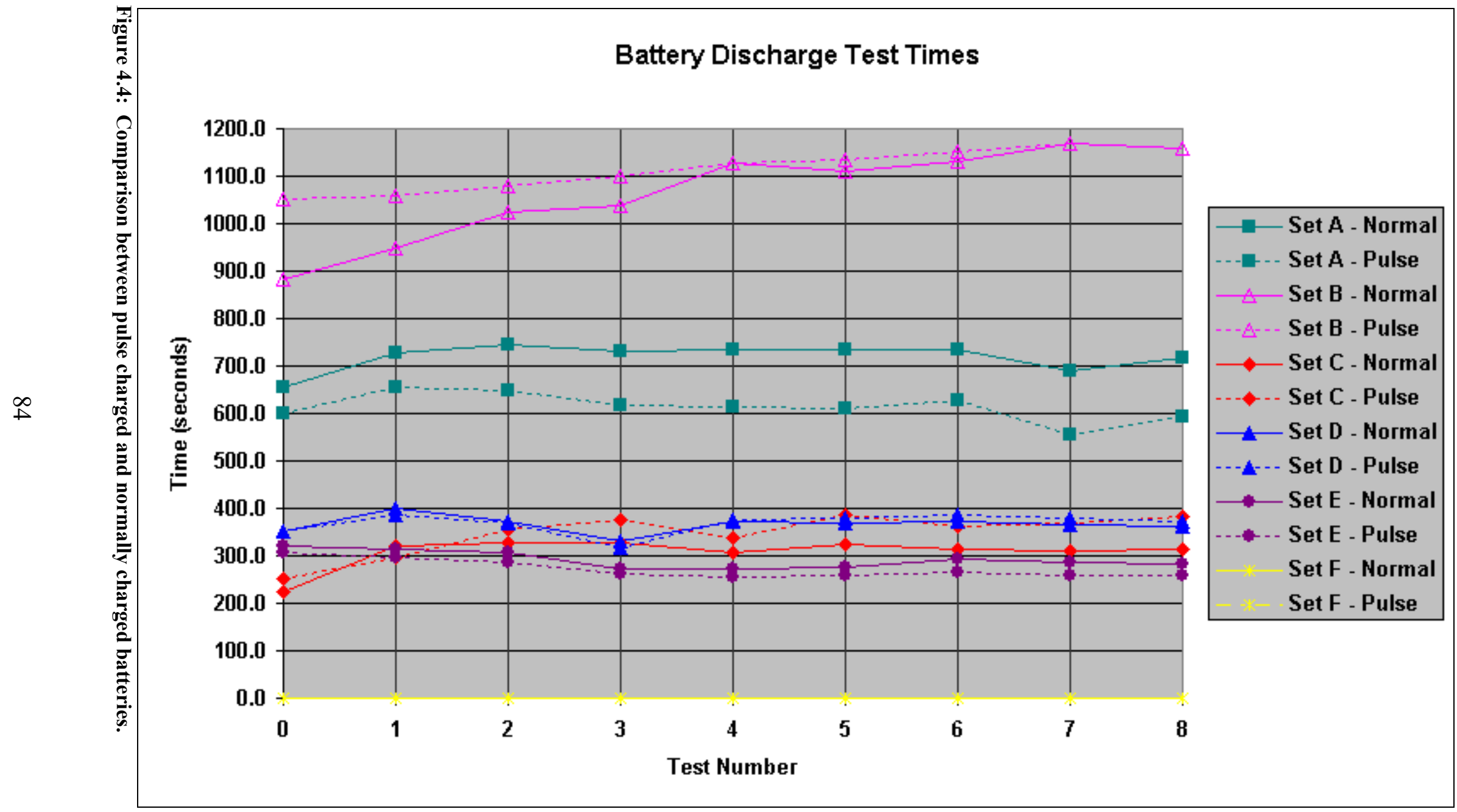

Figure 4.4: Comparison between pulse charged and normally charged batteries. 
Table 4.2 shows the initial and final discharge test times for each battery in the test sets that was charged normally as well as the change in the discharge test times. The time changes are presented in seconds and as a percentage. Table 4.3 shows the same information as Table 4.2, but for the batteries that were charged using the pulse charging technique. Table 4.4 shows a side-by-side comparison of the discharge test time charges. It is from the data in Table 4.4 that most conclusions will be drawn regarding pulse charging. These conclusions will be presented and discussed in Chapter 5.

\begin{tabular}{|c|c|c|c|c|}
\hline $\begin{array}{c}\text { TEST } \\
\text { SET }\end{array}$ & $\begin{array}{c}\text { Test 0 Discharge } \\
\text { Time } \\
\text { (seconds) }\end{array}$ & $\begin{array}{c}\text { Test 8 Discharge } \\
\text { Time } \\
\text { (seconds) }\end{array}$ & $\begin{array}{c}\text { Discharge Time } \\
\text { Change } \\
\text { (seconds) }\end{array}$ & $\begin{array}{c}\text { Discharge Time } \\
\text { Change } \\
\text { (percentage) }\end{array}$ \\
\hline A & 654.8 & 717.2 & 62.4 & $9.530 \%$ \\
\hline B & 883.0 & 1158.2 & 275.2 & $31.166 \%$ \\
\hline C & 222.6 & 315.0 & 92.4 & $41.509 \%$ \\
\hline D & 353.2 & 362.4 & 9.2 & $2.605 \%$ \\
\hline E & 322.4 & 284.2 & -38.2 & $-11.849 \%$ \\
\hline F & 0.2 & 0.2 & 0.0 & $0.000 \%$ \\
\hline
\end{tabular}

Table 4.2: Summary of the changes in the discharge test times for batteries the were charged normally.

\begin{tabular}{|c|c|c|c|c|}
\hline $\begin{array}{c}\text { TEST } \\
\text { SET }\end{array}$ & $\begin{array}{c}\text { Test 0 Discharge } \\
\text { Time } \\
\text { (seconds) }\end{array}$ & $\begin{array}{c}\text { Test 8 Discharge } \\
\text { Time } \\
\text { (seconds) }\end{array}$ & $\begin{array}{c}\text { Discharge Time } \\
\text { Change } \\
\text { (seconds) }\end{array}$ & $\begin{array}{c}\text { Discharge Time } \\
\text { Change } \\
\text { (percentage) }\end{array}$ \\
\hline A & 598.6 & 591.8 & -6.8 & $-1.136 \%$ \\
\hline B & 1053.0 & 1157.8 & 104.8 & $9.953 \%$ \\
\hline C & 251.6 & 382.6 & 131.0 & $52.067 \%$ \\
\hline D & 351.4 & 373.4 & 22.0 & $6.261 \%$ \\
\hline E & 306.8 & 260.2 & -46.6 & $-15.189 \%$ \\
\hline F & 0.2 & 0.2 & 0.0 & $0.000 \%$ \\
\hline
\end{tabular}

Table 4.3 Summary of the changes in the discharge test times for batteries that were pulse charged. 


\begin{tabular}{|c|c|c|c|}
\hline $\begin{array}{c}\text { TEST } \\
\text { SET }\end{array}$ & $\begin{array}{c}\text { Discharge Test Time } \\
\text { Change Using Normal } \\
\text { Charging }\end{array}$ & $\begin{array}{c}\text { Discharge Test Time } \\
\text { Change Using Pulse } \\
\text { Charging }\end{array}$ & $\begin{array}{c}\text { How much better or } \\
\text { worse was pulse charging } \\
\text { as compared to normal } \\
\text { charging? }\end{array}$ \\
\hline A & $9.530 \%$ & $-1.136 \%$ & $-11.920 \%$ \\
\hline B & $31.166 \%$ & $9.953 \%$ & $-68.065 \%$ \\
\hline C & $41.509 \%$ & $52.067 \%$ & $25.435 \%$ \\
\hline D & $2.605 \%$ & $6.261 \%$ & $140.345 \%$ \\
\hline E & $-11.849 \%$ & $-15.189 \%$ & $-28.188 \%$ \\
\hline F & $0.000 \%$ & $0.000 \%$ & $0.000 \%$ \\
\hline
\end{tabular}

Table 4.4: Comparison between discharge test time changes using normal charging and pulse charging

\subsubsection{Battery Discharge Voltages}

For each discharge test that was perform, a series of voltage data points were produced. The times required for the battery voltage to reach the test termination voltage of 10.765 have already been presented. Although the discharge test times reveals a significant amount of information regarding the condition of the battery, it is only part of the overall picture. The other important part of the discharge test data is the voltage curves that were produced. The voltage curves that were obtained for the initial discharge test, test 0 , and the final discharge test, test 8 , for each battery test set are shown in Figures 4.5, 4.6, 4.7, 4.8, 4.9, and 4.10. An important fact about these graphs is the voltage that is maintained at the beginning of each discharge test has risen, even if the discharge time has decreased as in the pulse charge voltage curves of Figure 4.5. 


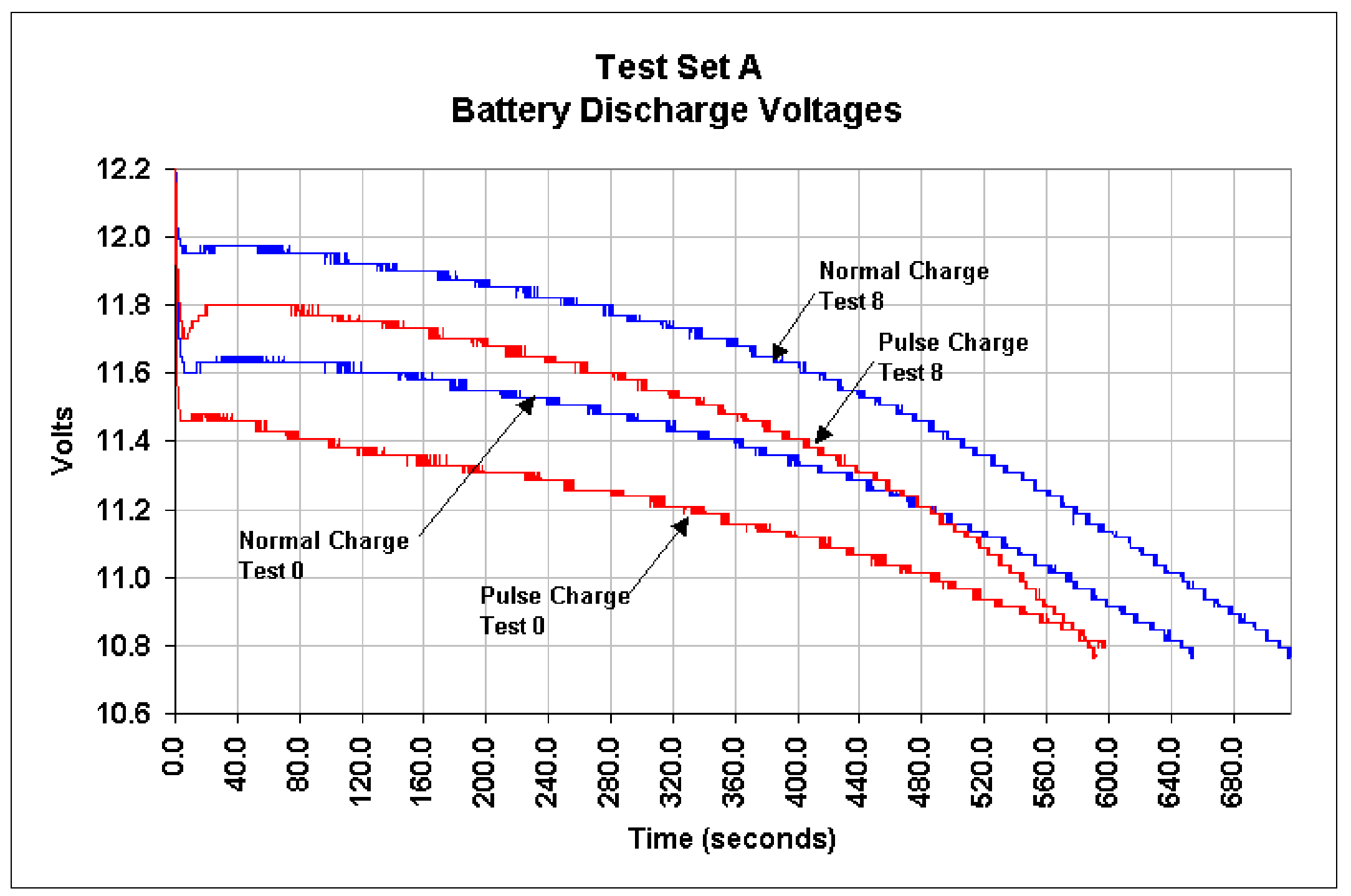

Figure 4.5: Initial and final discharge test voltage curves for Battery Test Set A 


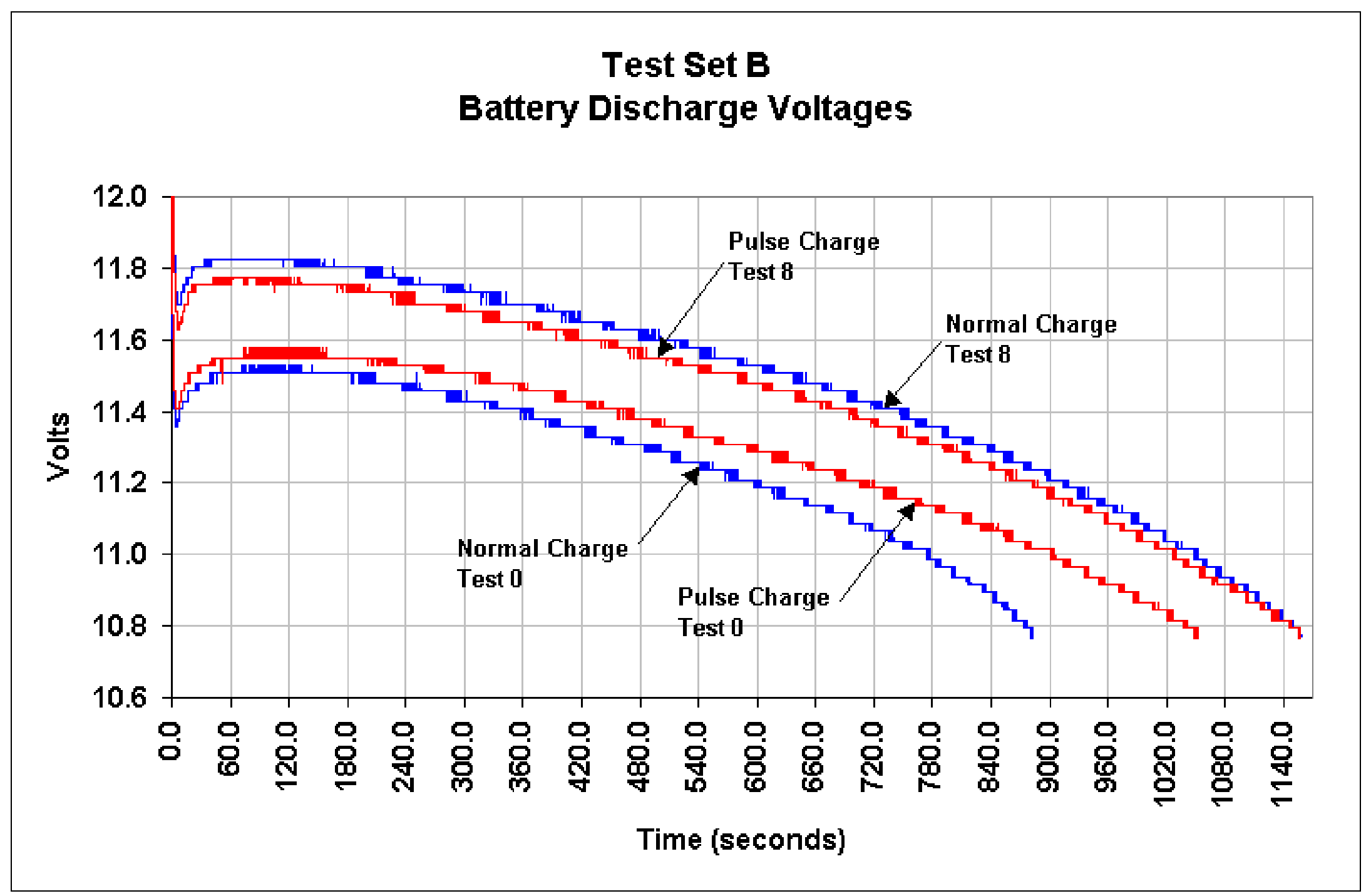

Figure 4.6: Initial and final discharge test voltage curves for Battery Test Set B 


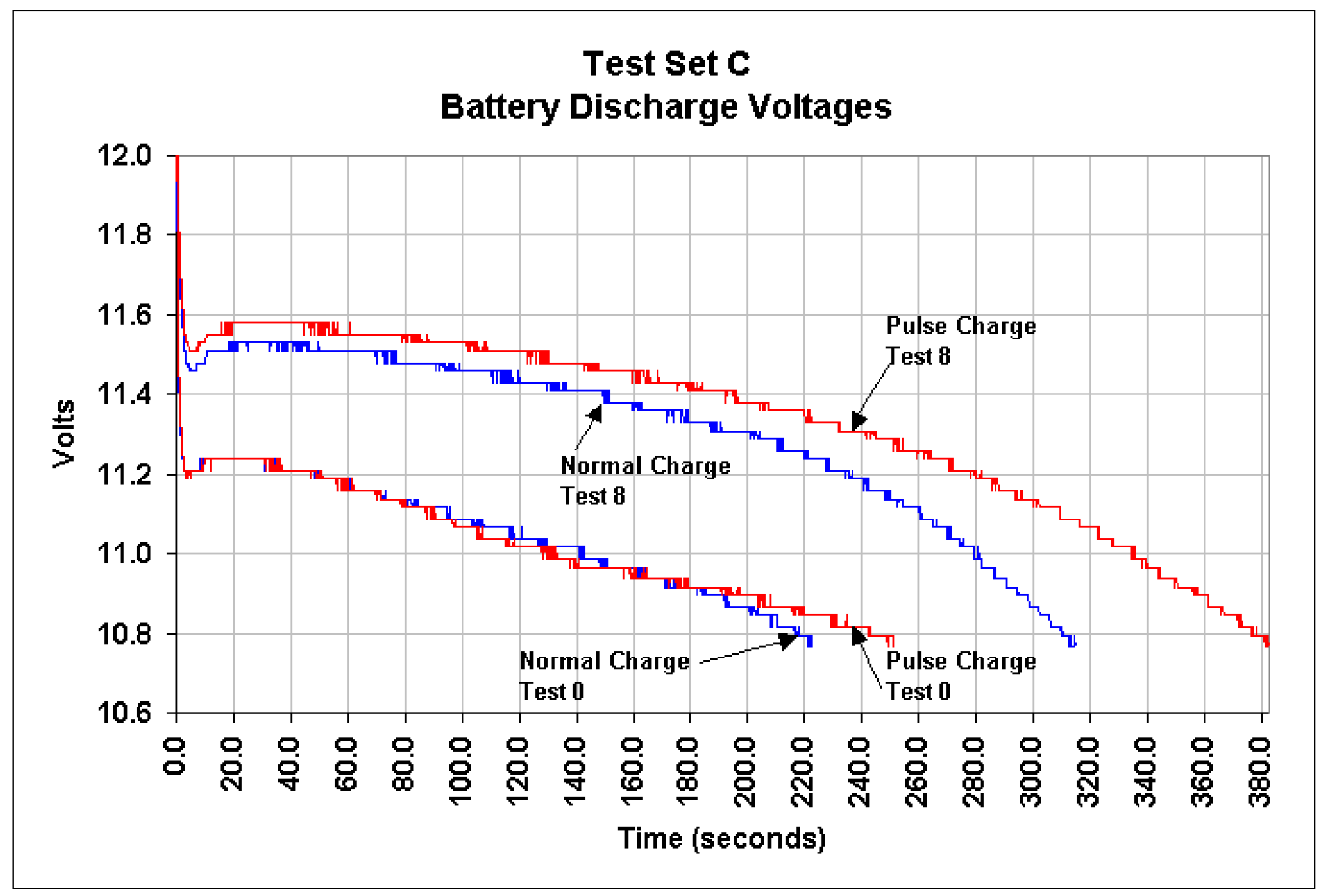

Figure 4.7: Initial and final discharge test voltage curves for Battery Test Set C 


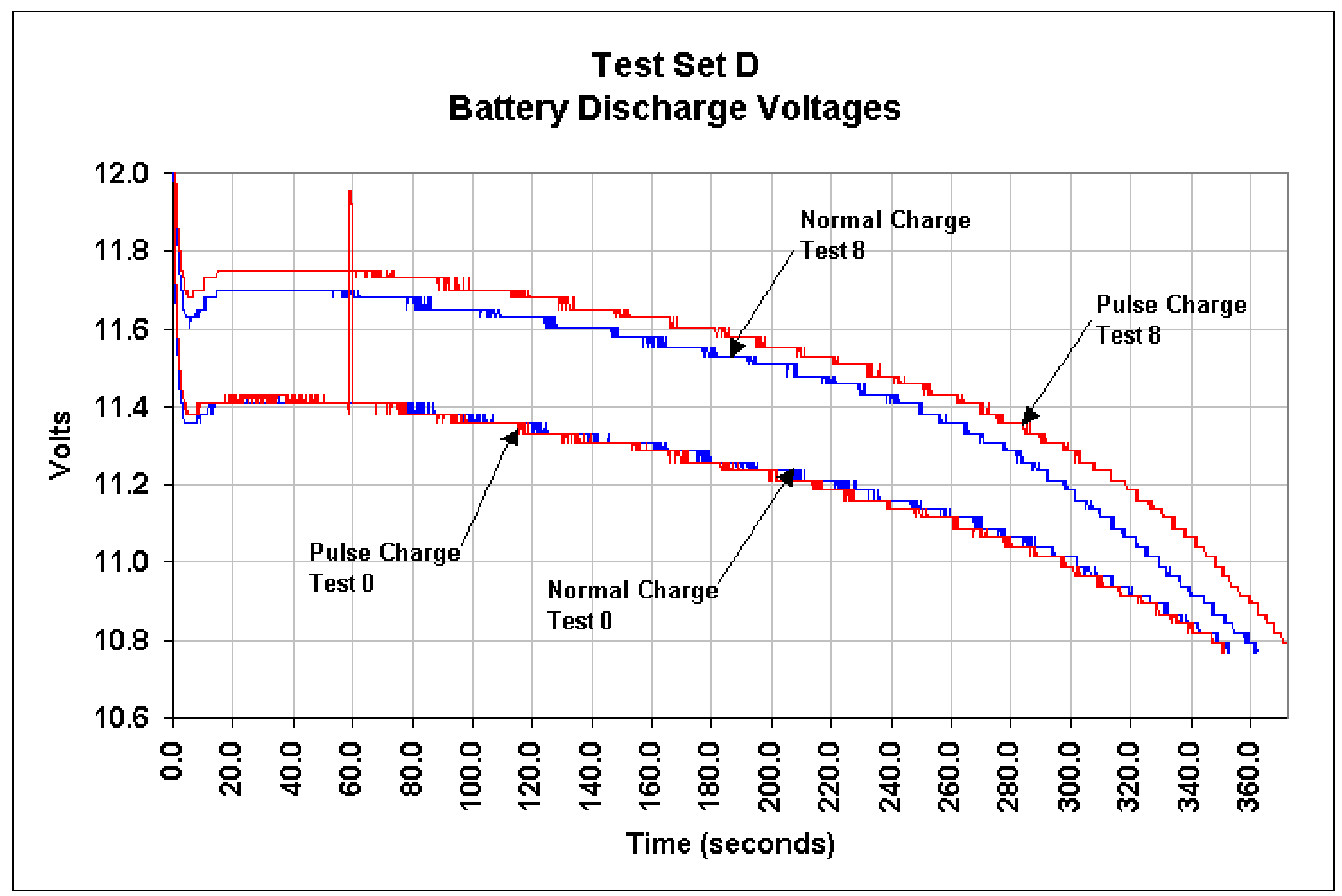

Figure 4.8: Initial and final discharge test voltage curves for Battery Test Set D 


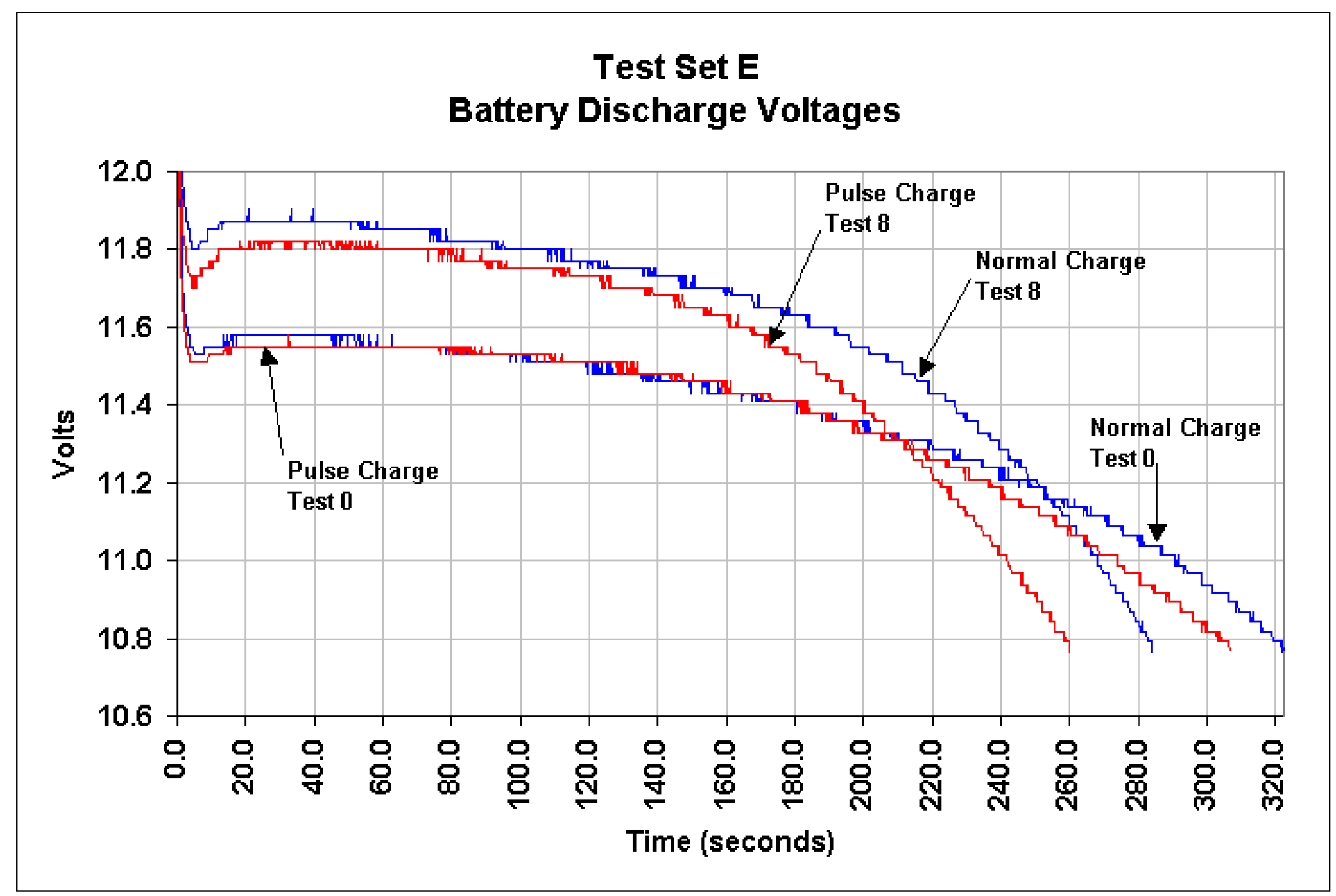

Figure 4.9: Initial and final discharge test voltage curves for Battery Test Set E 


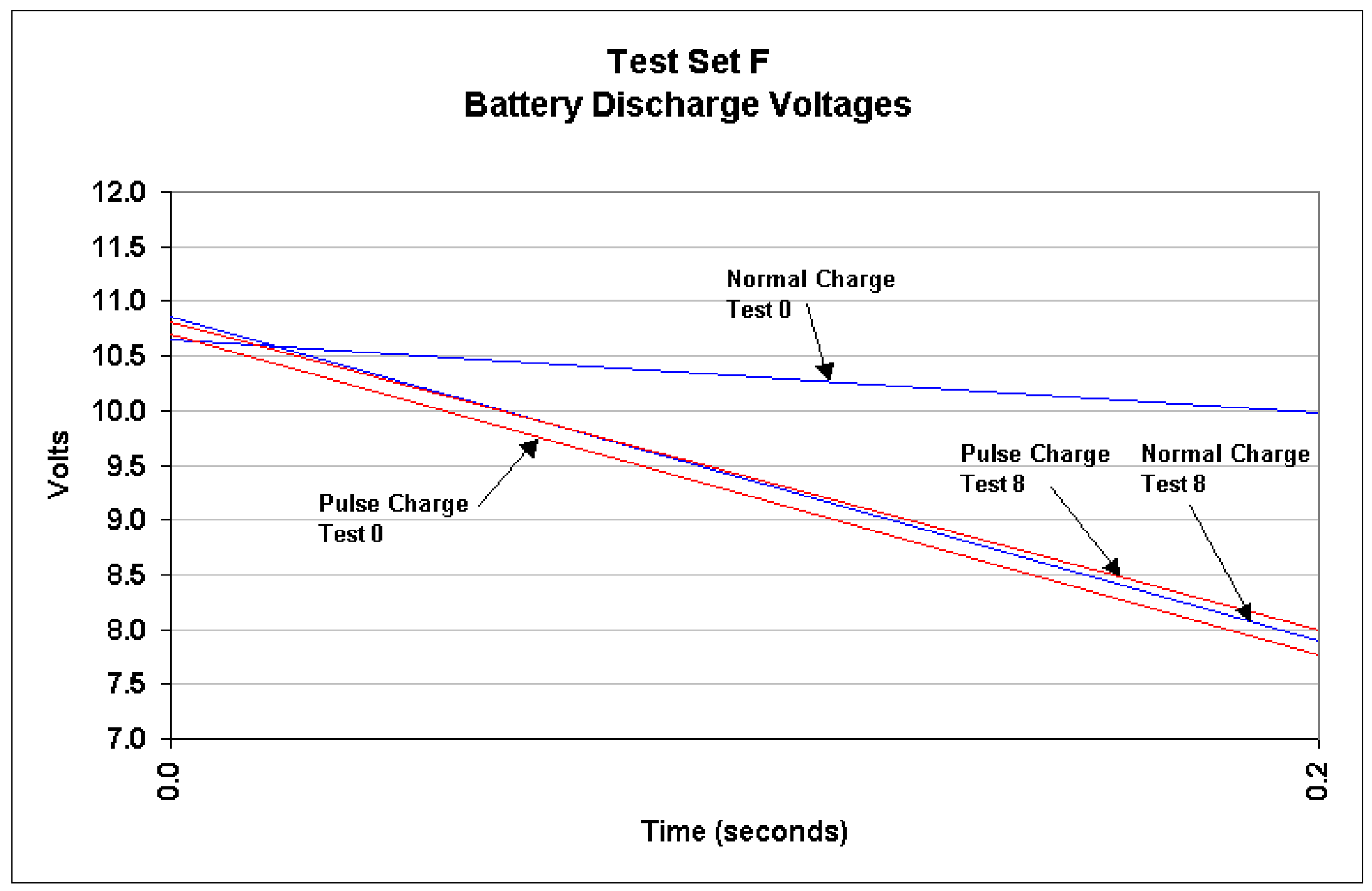

Figure 4.10: Initial and final discharge test voltage curves for Battery Test Set F 


\subsubsection{Battery Impedance Calculations}

The discharge tests also provided the information needed to calculate battery internal impedance. Initially, it was thought that some useful information concerning any changes in battery condition could be seen by examining the impedance history of the battery. Upon completion of the Charger Comparison Tests, it was determined that the impedances that were calculated using equation 4.1 varied unpredictably. The impedance history graphs for the batteries in each test set are included for reference in Appendix A.

\subsubsection{Battery Post-Charge +24 Hours Voltage Measurements}

The post-charge +24 hour voltages for all batteries used in the Charge Comparison Tests were plotted in order to keep a record of the battery's approximate state of charge. It was assumed that a battery that had a terminal voltage of at least 12.8 volts 24 hours after the charging process had completed would have been charged to between $90-100 \%$ capacity. Ideally, the post-charge +24 hours voltage would not vary by large amounts unless the terminal voltage was unable to hold a satisfactory voltage initially. By keeping the post-charge +24 hours voltage of each battery of a test set closely matched, it was estimated that each battery was charged to approximately the same capacity point. The graphs that show these voltage relationship are given for reference in Appendix A.

\subsubsection{Miscellaneous Battery Test Data}

In the process of matching batteries into test sets, it was desired to have a set that contained batteries that appeared to be usable by examination of their terminal voltage 
and internal impedance measurement, but were unable to provide useful current during the discharge test. Two such batteries were found and the first discharge test of the Charger Comparison Test procedure was carried out. During the discharge test, it was found that the batteries were now providing useful current for at least one minute. Table 4.5 lists the discharge times for each battery. Neither battery was pulse charged since the Charger Comparison Test was not carried out to that point.

\begin{tabular}{||c|c|c|c|c||}
\hline $\begin{array}{c}\text { BATTERY } \\
\text { ID }\end{array}$ & $\begin{array}{c}\text { INITIAL } \\
\text { CONDITION } \\
\text { TEST }\end{array}$ & $\begin{array}{c}\text { CHARGER } \\
\text { COMPARISON } \\
\text { TEST \#0 }\end{array}$ & $\begin{array}{c}\text { Discharge Time } \\
\text { Increase } \\
\text { (seconds) }\end{array}$ & $\begin{array}{c}\text { Discharge Time } \\
\text { Increase } \\
\text { (percentage) }\end{array}$ \\
\hline \hline 110 & $14.8 \mathrm{sec}$. & 337.4 sec. & 322.6 & $2179.730 \%$ \\
\hline 160 & $16.6 \mathrm{sec}$ & 108.2 sec. & 91.6 & $551.807 \%$ \\
\hline
\end{tabular}

Table 4.5: Discharge time comparison of two initially unusable batteries. 


\section{Chapter 5: Conclusions and Recommendations}

Using the data obtained from the series of discharge / charge tests on the six sets of batteries, several conclusions were reached. These conclusions are presented in section 5.1 of this document. Also, in the process of using the pulse charger, several areas where design improvements could be made were noticed. These design changes are summarized in section 5.2.

\subsection{Conclusion on the Benefits of Pulse Charging}

By examining the data that was presented in chapter 4 of this document, it was concluded that a battery charged using the pulse technique and one charged using the normal technique showed nearly identical changes in their discharge test characteristics. While the pulse charging technique did not offer any additional advantages over the normal charging technique, it also did not offer any disadvantages. Therefore, when charging an Optima "Red Top" Model 800S Absorbed Glass Matt (AGM) lead-acid battery, it can be said that using the pulse charging technique developed for this research was not better or no worse than using a standard charger. It was also concluded that the process of cycling the batteries provided the best chance for improving a battery's condition.

The pulse charging technique was better for two test sets. The pulse charged batteries of Test Set C and Test Set D showed superior improvements in discharge test time over those that were charged normally, although the normally charged batteries of these test sets also show some improvement. Using the normal charging technique was 
better for Test Set A. Both batteries of Test Set E had a decrease in their discharge test times, although the normally charged battery had less of a decrease. For Test Set B, the normally charged battery had the greatest discharge time increase. It should be noted that the pulse charged battery of Test Set B began the test series with discharge time of 1053 seconds, which is near the maximum possible discharge time for the tested batteries and, so, had little room for improvement. The normally charged battery of Test Set B began the test series with a discharge time of 883 seconds, so had a much greater chance for an increase in discharge test time. Neither battery of Test Set F showed any improvements through the discharge test series.

The battery pulsed charged in Test Set D had the greatest discharge time improvement over the normally charged battery, when measured as a percentage. The pulse charged battery's discharge time improved by 22 seconds, an increase of $6.261 \%$. The battery from this test set that was charged normally improved only 9.2 seconds, an increase of $2.605 \%$. This resulted in a pulse charging vs. normal charging improvement of $140.345 \%$. Although this seems large, the actual improvement in discharge time was below $10 \%$ for both the pulsed and normally charged batteries. Therefore, no clear advantage for pulse charging could be seen in this test set.

The battery pulse charged in Test Set $\mathrm{C}$ also showed a greater improvement over the battery that was normally charged. The pulse charged battery's discharge time improvement was 131.0 seconds. However, the normally charged battery's discharge time improvement was 92.4 seconds. This Test Set showed the largest improvement of any pulse charged battery and clearly indicates an advantage of using pulse charging for this particular pair of batteries. 
With Test Sets A, B and E, the batteries that were normally charged showed greater improvements over those that were pulse charged. These two sets negate any advantages of pulse charging that resulted in Test Sets C and D. Since Test Set A and B consisted of batteries that had an initial discharge time of 10 minutes or longer and Test Set E's batteries had high initial impedances, it can be concluded that performing charge / discharge cycling provided the improvements in discharge time and not any particular charging algorithm.

Another bit of data that supports the fact that performing charge / discharge cycling provides greater benefits than pulse charging is shown in Table 4.5 of Chapter 4 . Although these batteries were not part of any test set, they do show the improvements that can be obtained by simply cycling batteries as a normal part of usage.

The last conclusion to be reached is with regards to reversing the sulfation of lead-acid batteries. The batteries of Test Set F shows most clearly that pulse charging AGM batteries did not reverse sulfation. While it can not be ascertained that sulfation was the only problem that these batteries suffered from, it is reasonable to believe that the batteries were badly sulfated due to their inability to hold a charged voltage greater than 12 volts. The lack of any improvement in the discharge test times of either the pulsed charged or normally charged batteries shows that, at least for the tested AGM batteries, pulse charging was ineffective.

\subsection{Recommendations for Pulse Charger Design Improvements}

Overall, the pulse charge, as designed, works well. However, there are minor areas of the design that could be modified to improve the operational characteristics of 
the charger. If another pulse charger were to be built, it is recommended that the following four modifications be made to the design.

1. Improve power supply filtering in order to reduce $\mathrm{AC}$ power line noise, which caused the pulse charger's microcontrollers to reset. This occurred when the external power supply tried to limit the charging current, causing high frequency noise to appear in the $\mathrm{AC}$ voltage coming into the pulse charger.

2. Modify the input line of the battery voltage sensor by connecting its inputs directly to the battery with 18 AWG wire. As designed, the battery voltage sensor is placed on the same board as the MOSFETs and its input is connected to the drain of the P-Channel MOSFETs. This results in a sensed voltage that is lower than the actual battery voltage when high charging currents are being used and, thus, causing errors in the calculations made my the microcontrollers.

3. Provide a temperature sensing capability for all three P-Channel MOSFETs. As designed, only one temperature sensor is used to detect unsafe operating temperatures. The sensor is placed on one heat sink of one P-Channel MOSFET. This configuration leaves the remaining two P-Channel MOSFETs unprotected.

4. Change the N-Channel MOSFET Q4 shown on the schematic in Appendix B, section B.3 to an audio or other linear type MOSFET. The MOSFET that is currently used is a switching type. It is very difficult to have the MOSFET control the P-Channel gate voltage with sufficient precision to provide a controlled charging voltage. 


\subsection{Future Work}

- Since only six test sets were used, it can be argued that the test results were inconclusive. Therefore, using Optima "Red Top” Model 800S Absorbed Glass Matt (AGM) lead-acid batteries and the same pulse charger setup, perform the same discharge / charge tests on a greater number of battery sets to obtain a more definite data pattern.

- Modify the charger pulse frequency and repeat the discharge / charge tests to determine if a different frequency will work better.

- Repeat the discharge / charge tests using flood-cell type lead acid batteries to determine if the type of battery has any effect on the test results. 


\section{Appendix A: Battery Data Files}

\section{A.1 Battery Test Set A - Discharge Time}

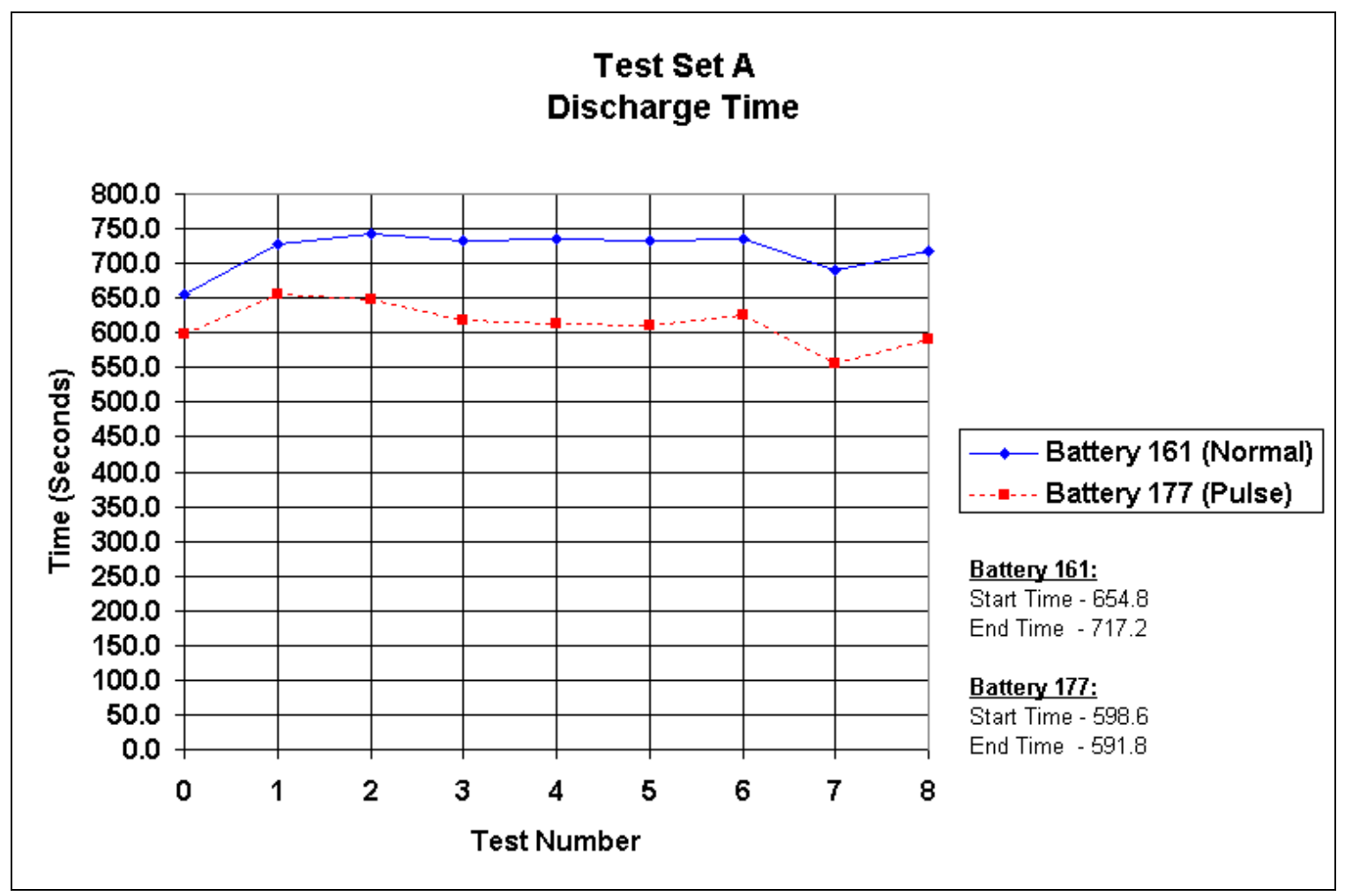

Test Set A Data: Click icon to access file. D]

Battery 161 Discharge Test Data: Click icon to access file.

Battery 177 Discharge Test Data: Click icon to access file. 


\section{A.2 Battery Test Set B - Discharge Time}

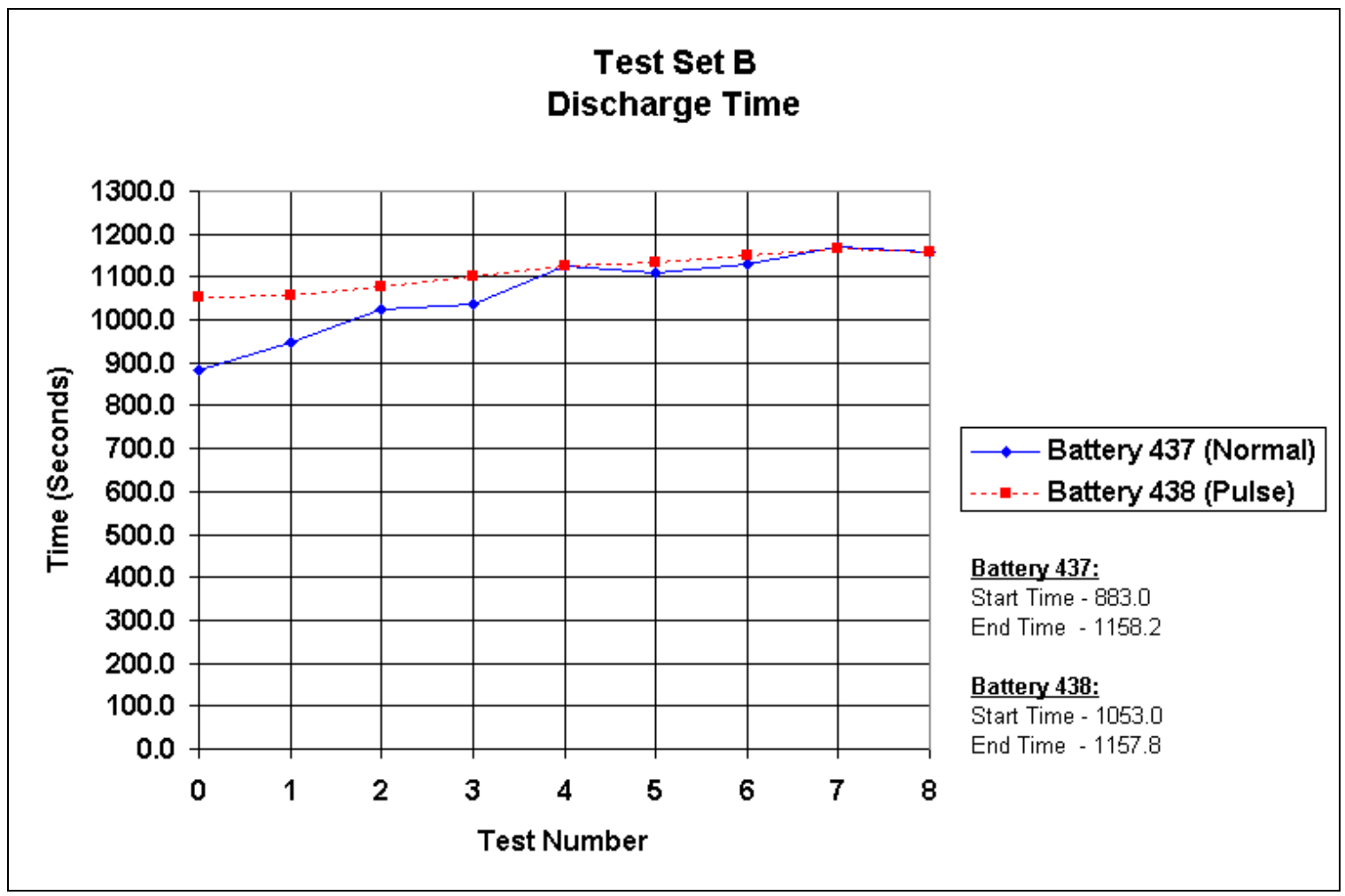

Test Set B Data: Click icon to access file. DI

Battery 437 Discharge Test Data: Click icon to access file.

Battery 438 Discharge Test Data: Click icon to access file. 


\section{A.3 Battery Test Set C - Discharge Time}

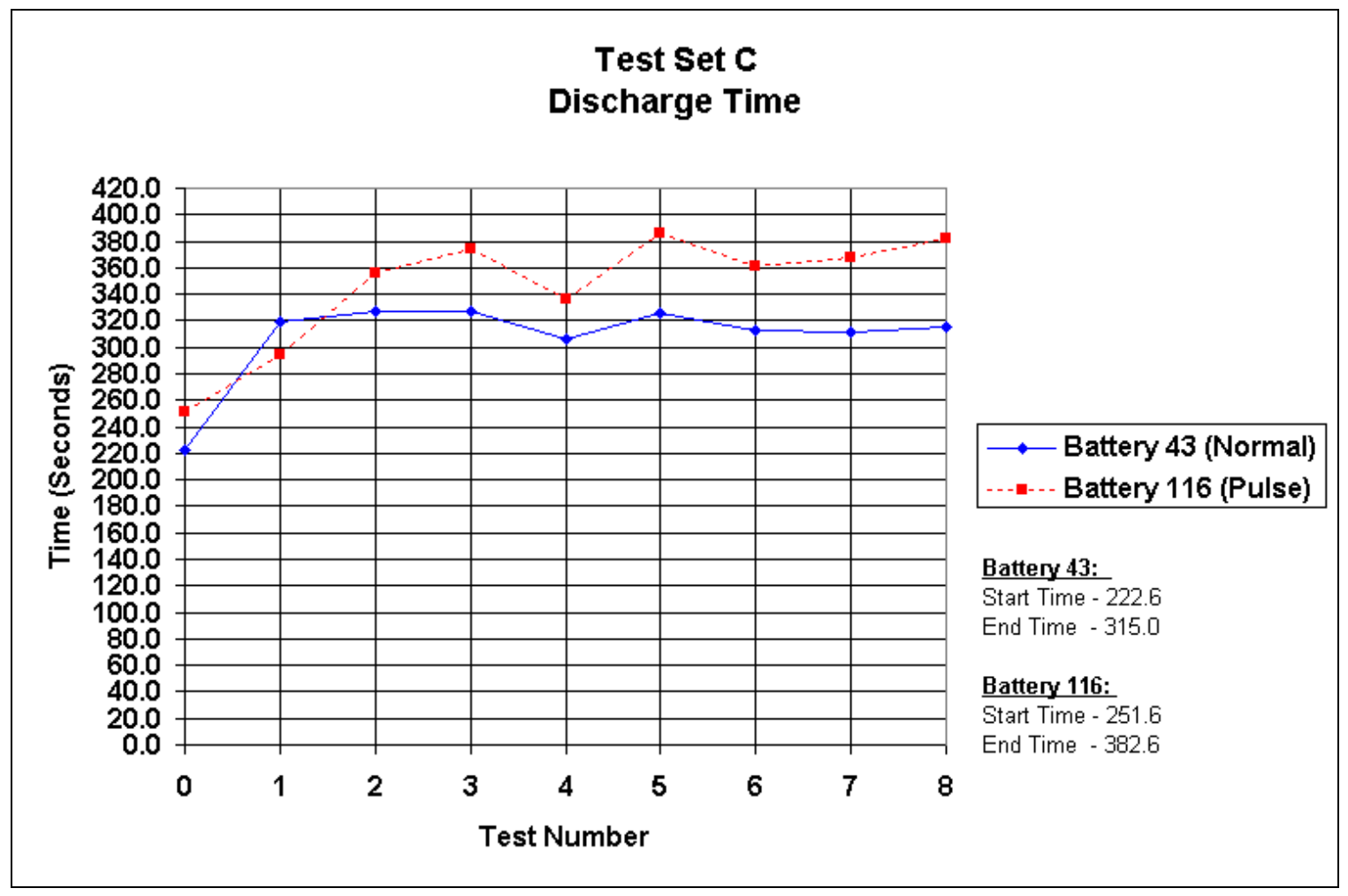

Test Set C Data: Click icon to access file.

Battery 43 Discharge Test Data: Click icon to access file.

Battery 116 Discharge Test Data: Click icon to access file. 


\section{A.4 Battery Test Set D - Discharge Time}

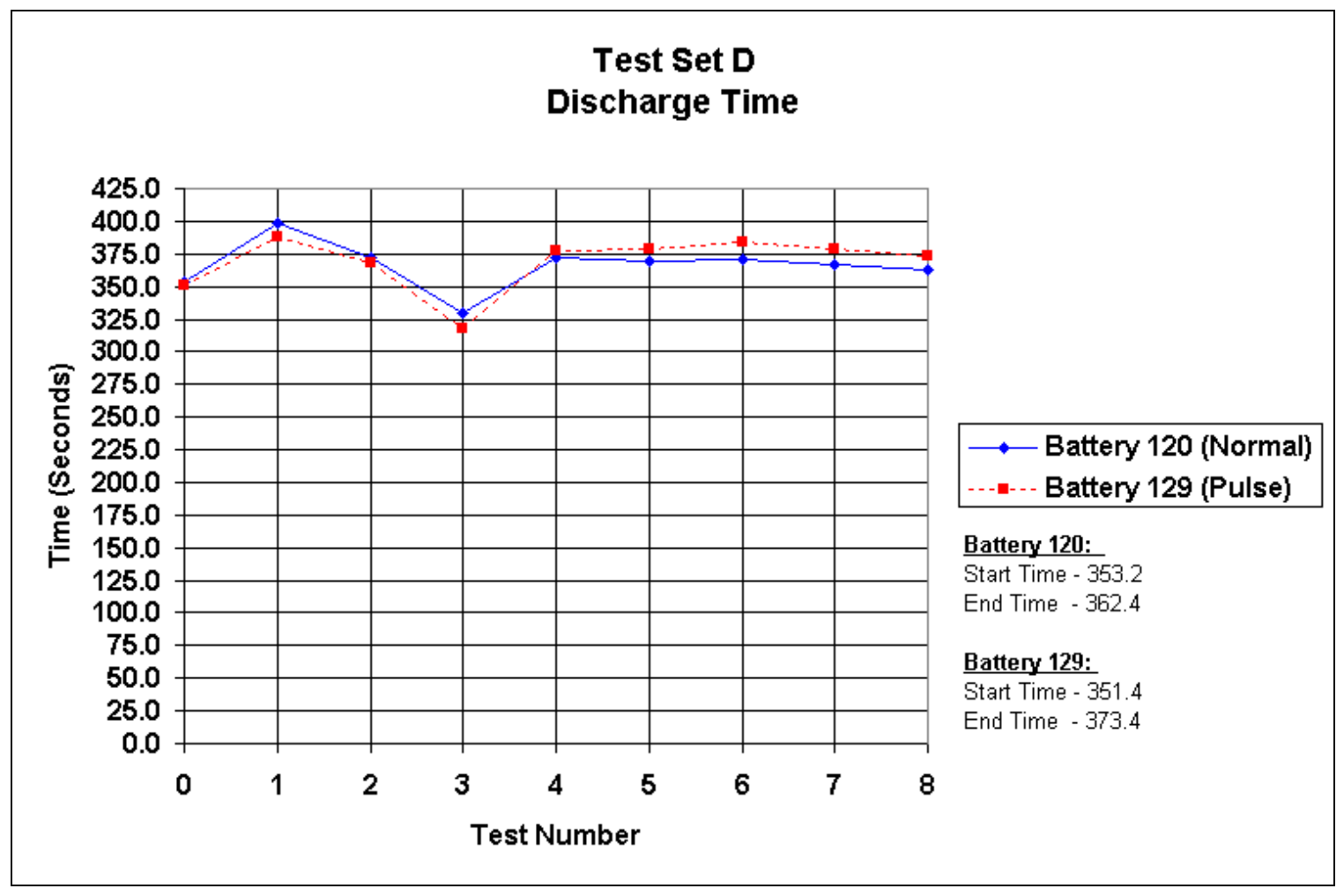

Test Set D Data: Click icon to access file. D

Battery 120 Discharge Test Data: Click icon to access file.

Battery 129 Discharge Test Data: Click icon to access file. 


\section{A.5 Battery Test Set E - Discharge Time}

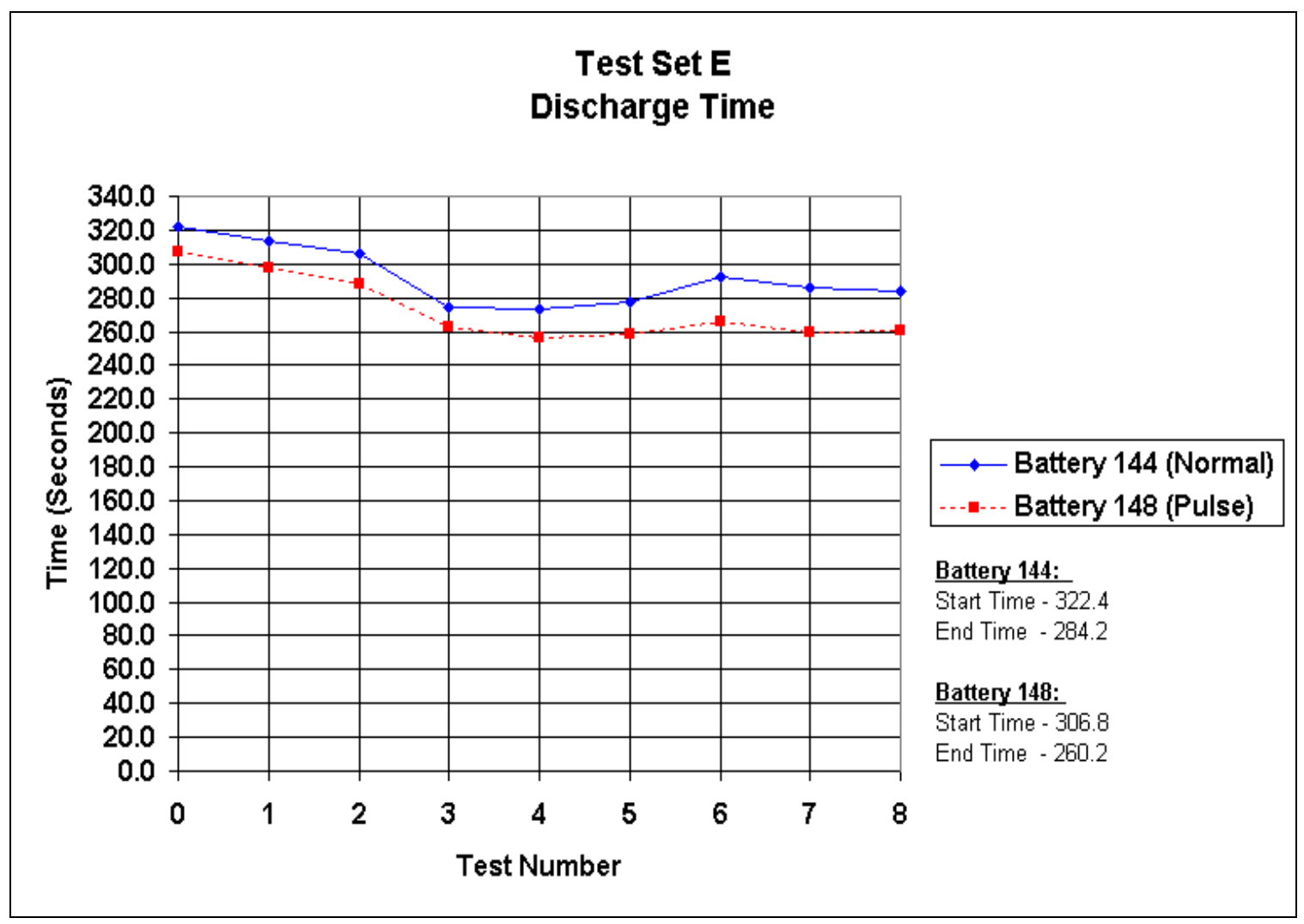

Test Set E Data: Click icon to access file.

Battery 144 Discharge Test Data: Click icon to access file. D]

Battery 148 Discharge Test Data: Click icon to access file. DL 


\section{A.6 Battery Test Set F - Discharge Time}

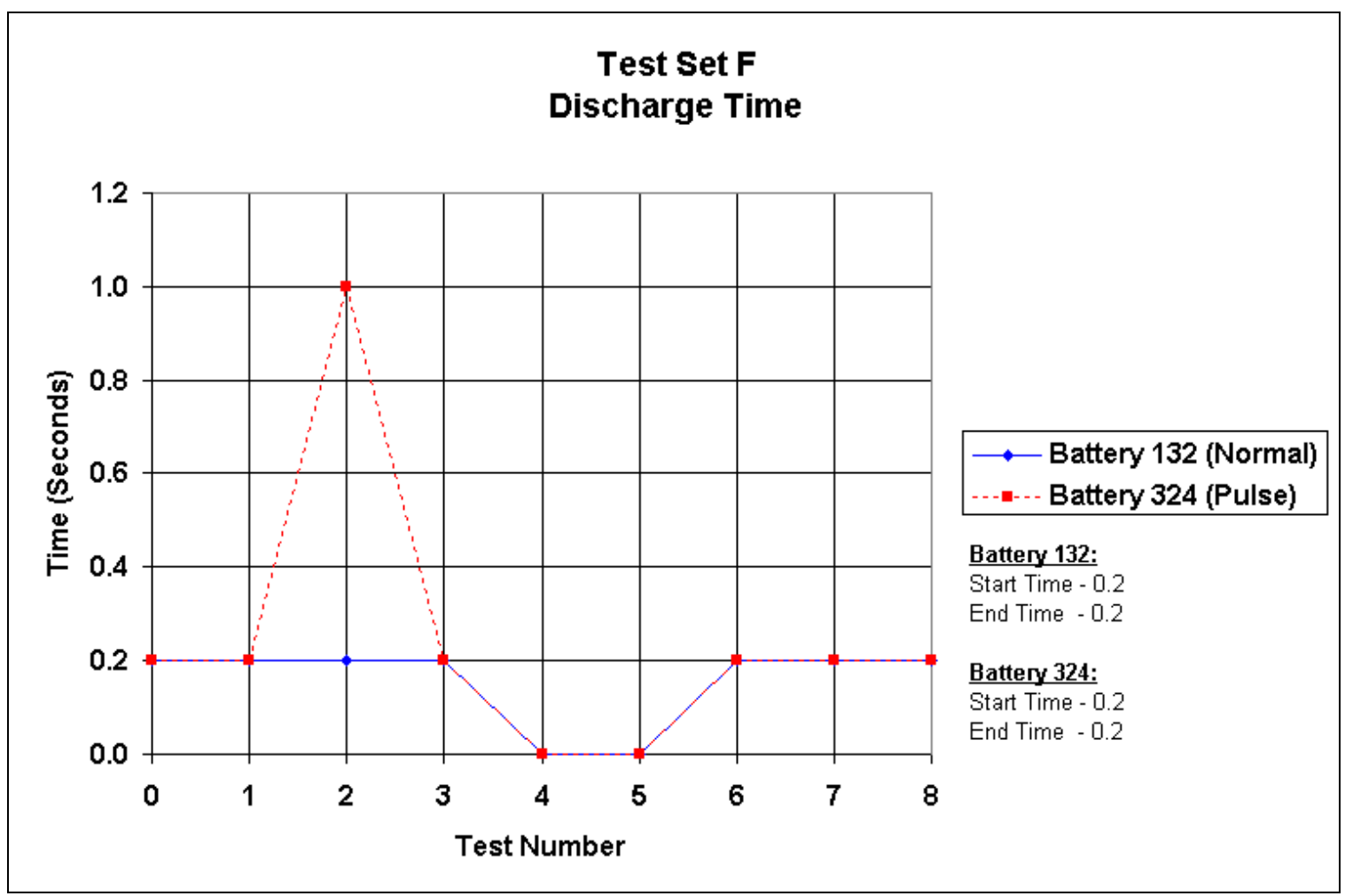

Test Set F Data: Click icon to access file.

Battery 132 Discharge Test Data: Click icon to access file.

Battery 324 Discharge Test Data: Click icon to access file. D] 


\section{A.7 Miscellaneous Battery Tests - Discharge Voltage Curves}

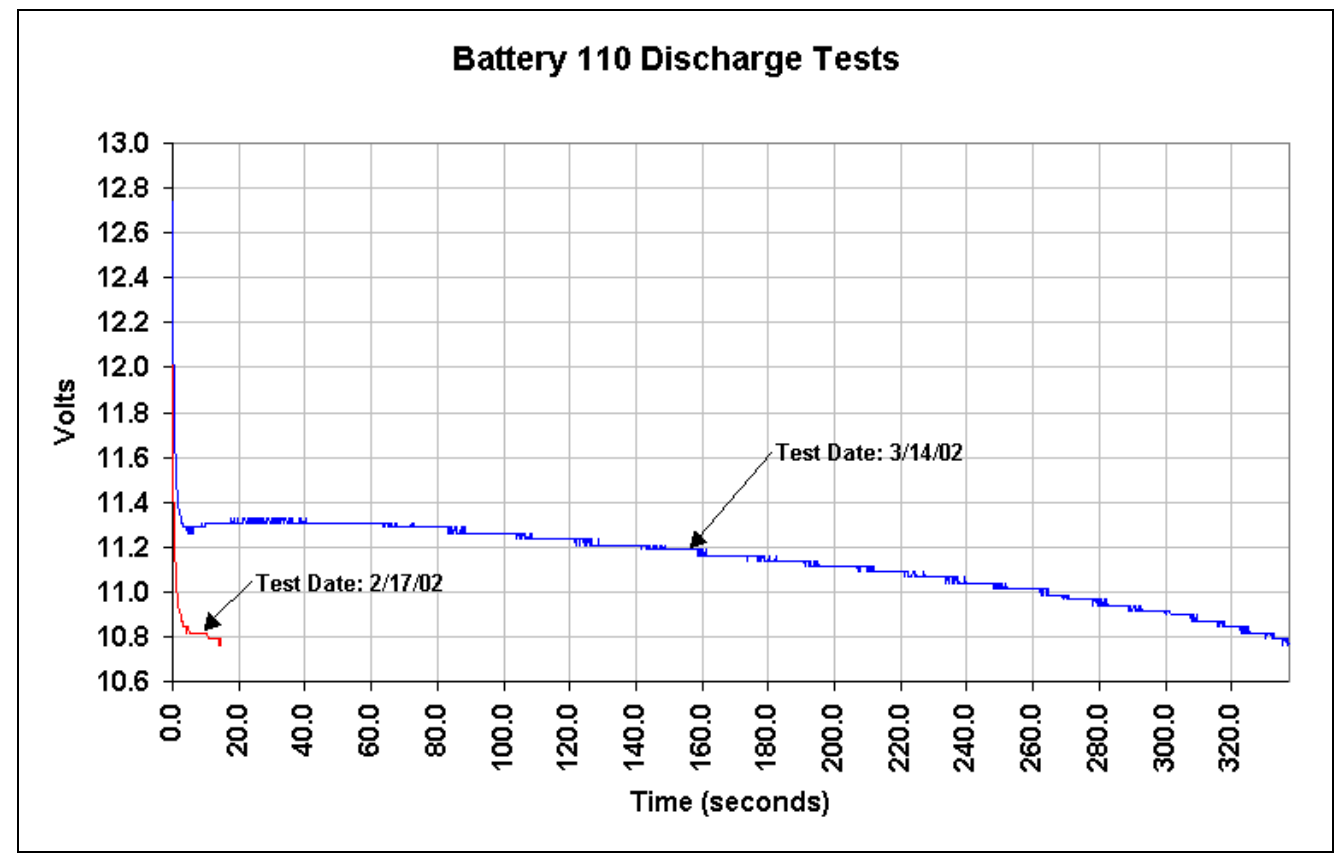

Battery 110 Discharge Test Data: Click icon to access file.

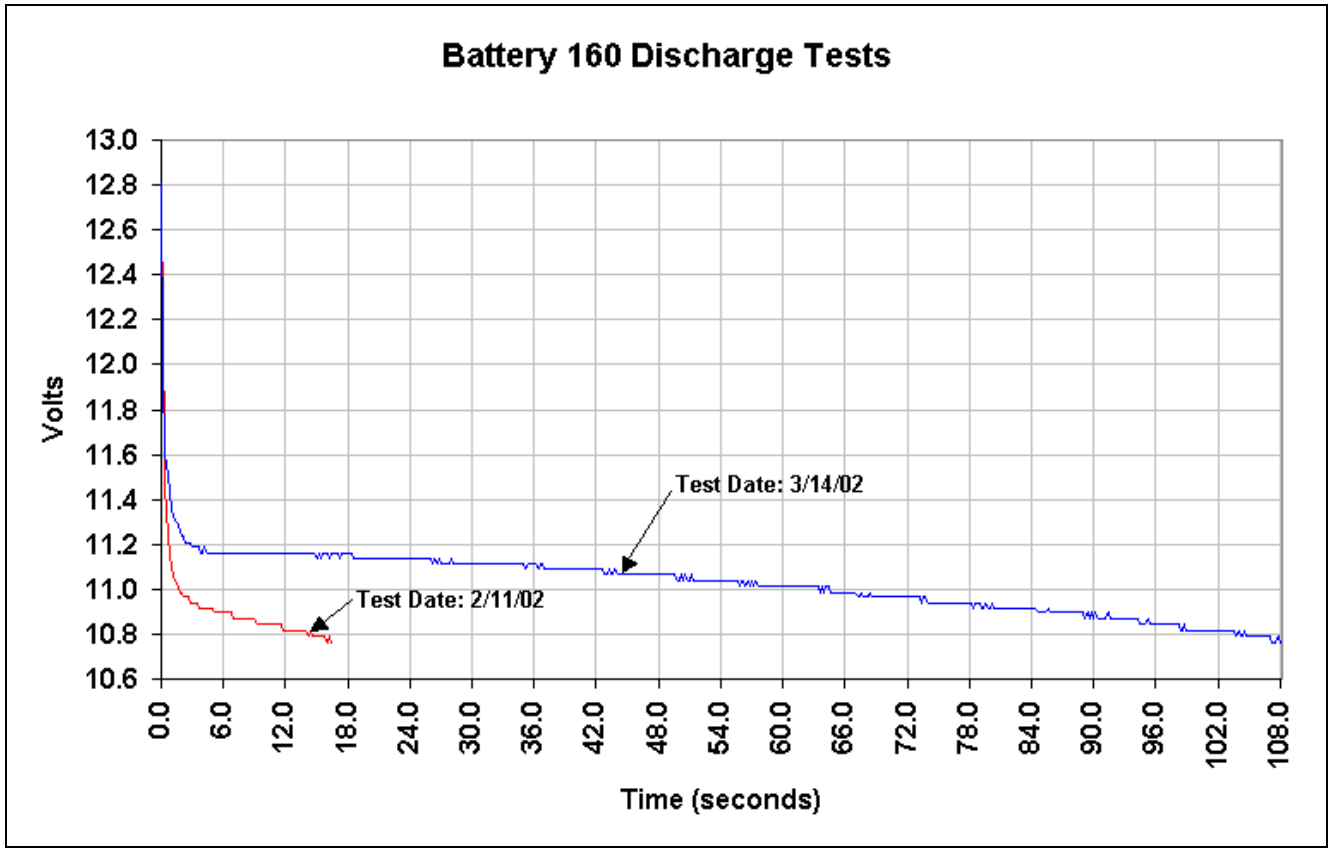

Battery 160 Discharge Test Data: Click icon to access file. 


\section{A.8 Battery Test Set A - Battery Impedance}

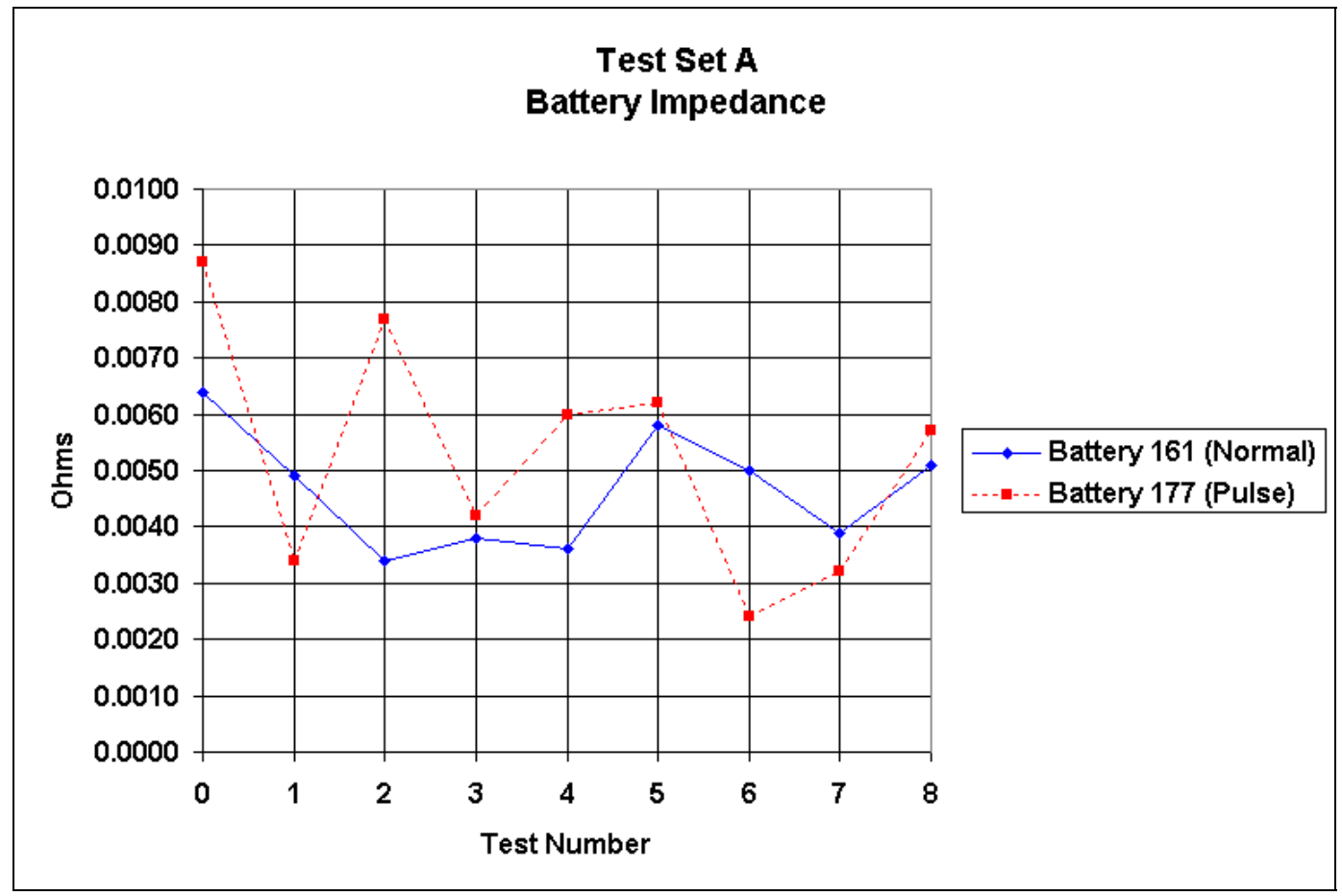

\section{A.9 Battery Test Set B - Battery Impedance}

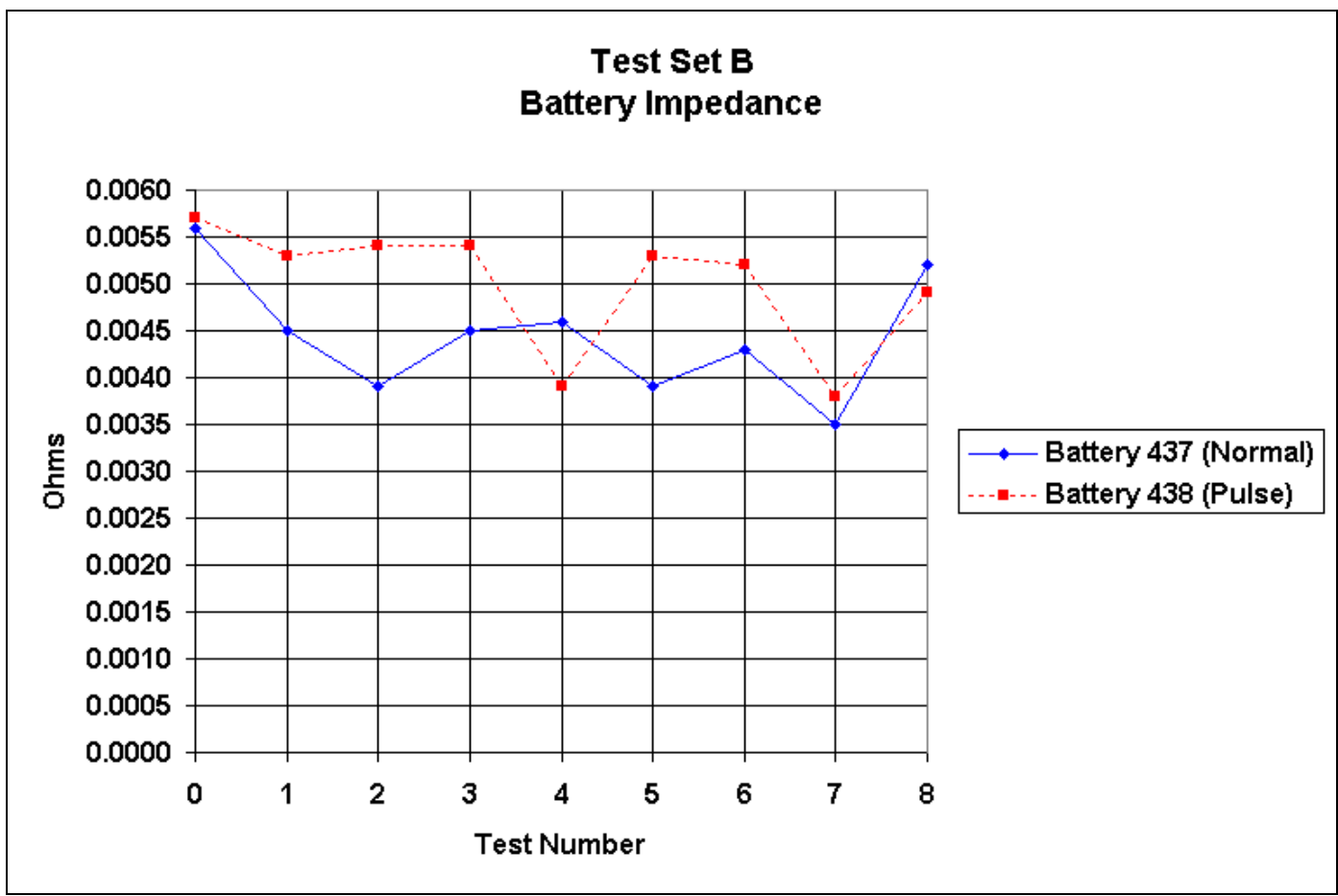




\section{A.10 Battery Test Set C - Battery Impedance}

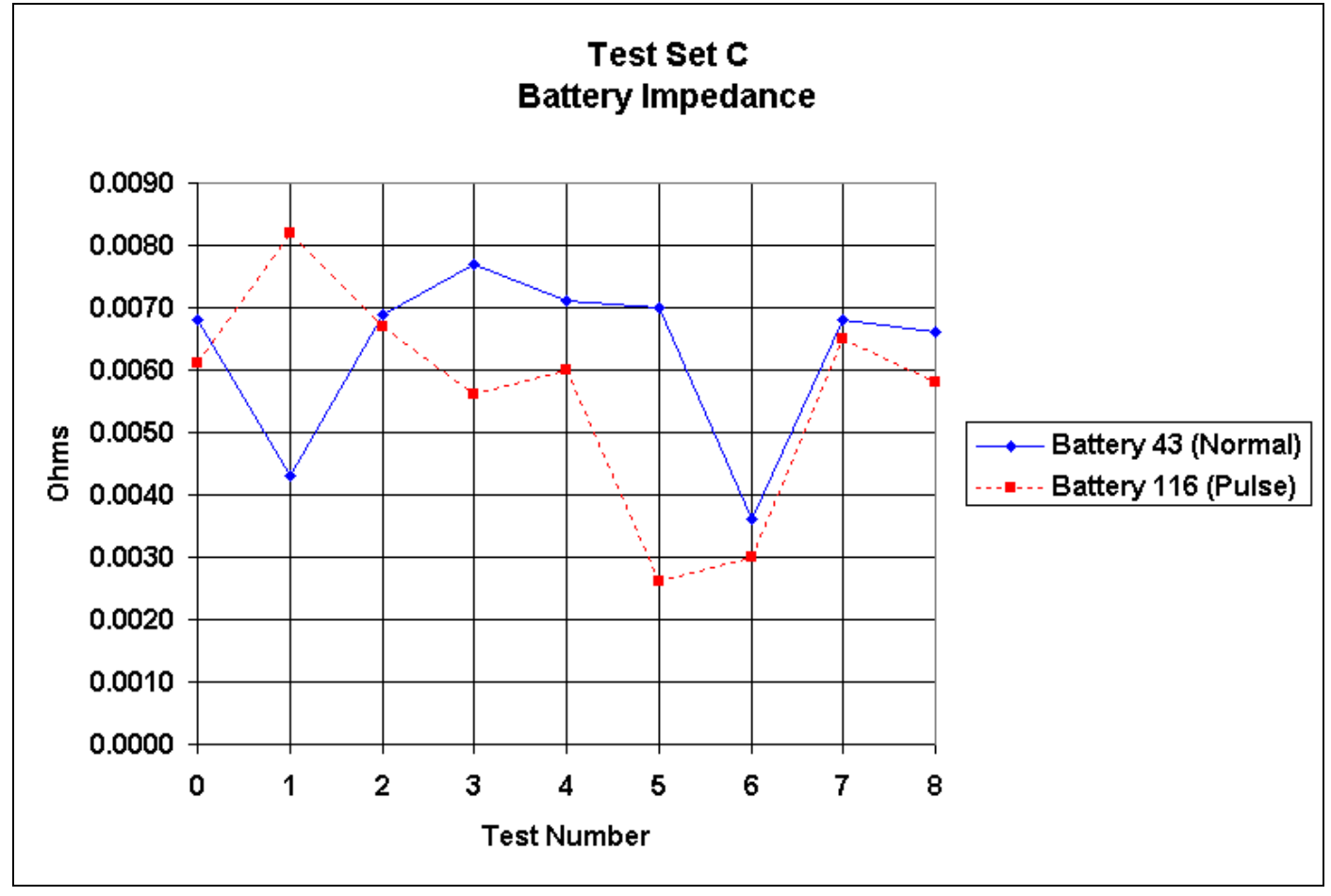

\section{A.11 Battery Test Set D - Battery Impedance}

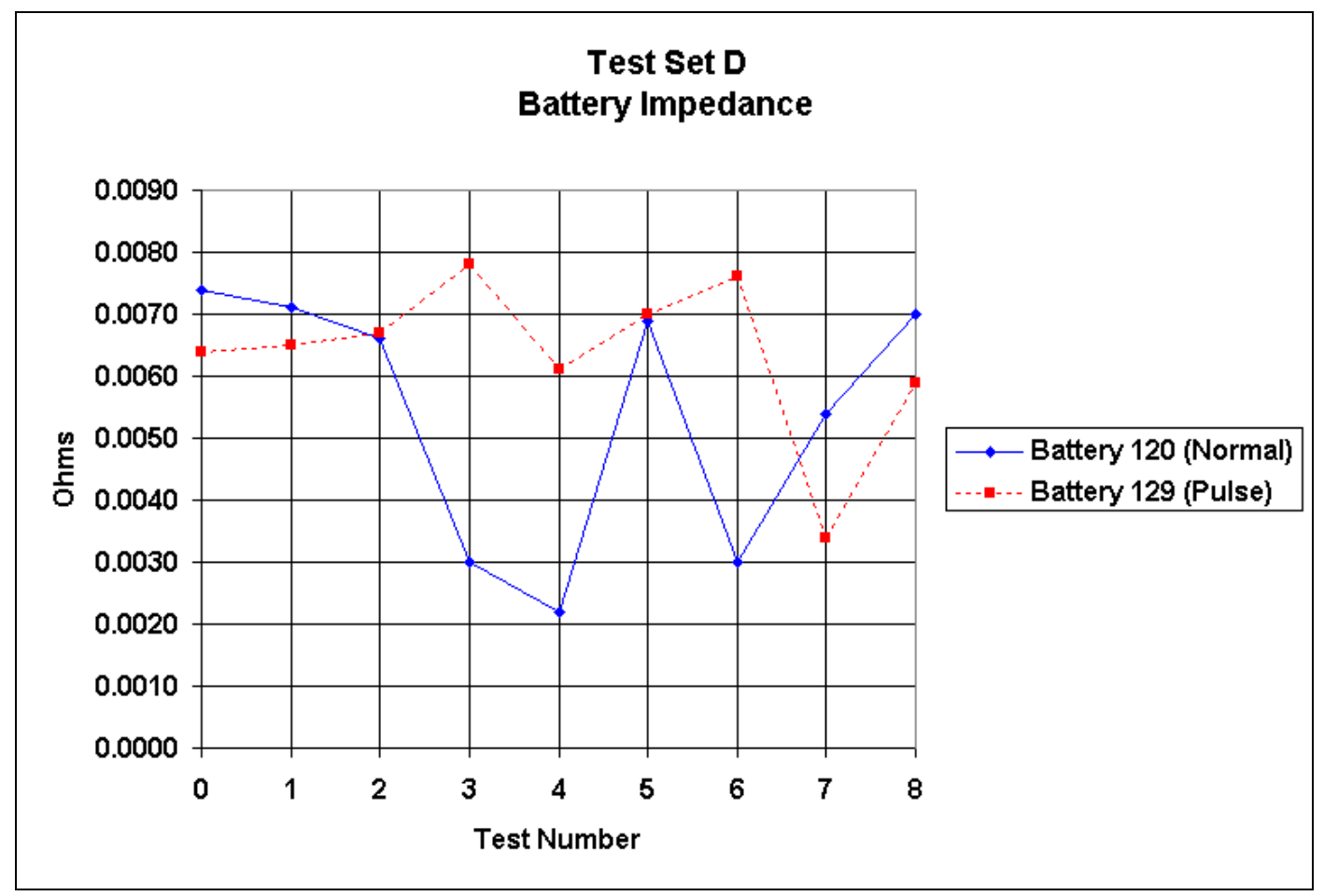




\section{A.12 Battery Test Set E - Battery Impedance}

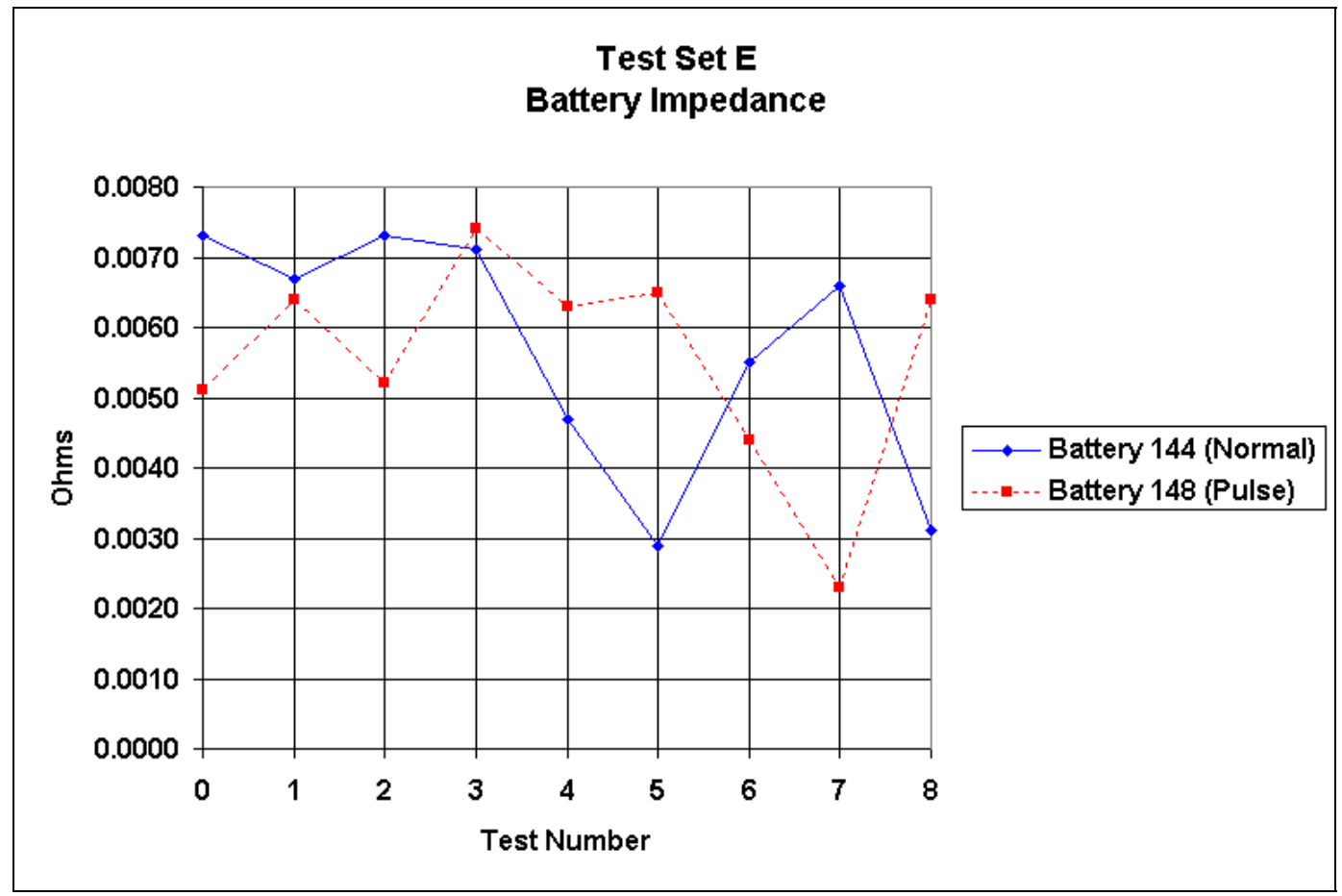

\section{A.13 Battery Test Set F - Battery Impedance}

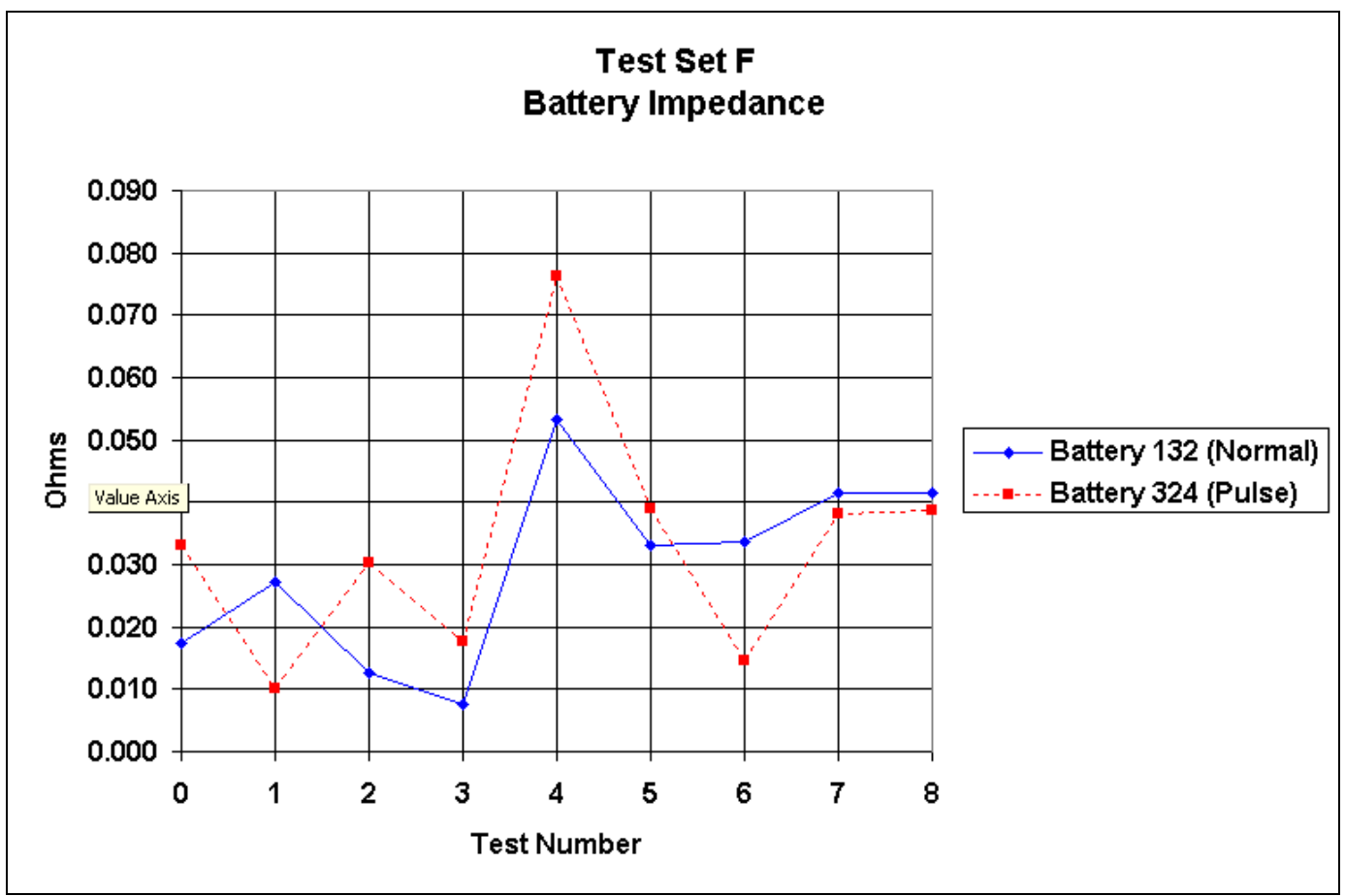




\section{A.14 Battery Test Set A - Post-Charge + 24 Hours Voltage}

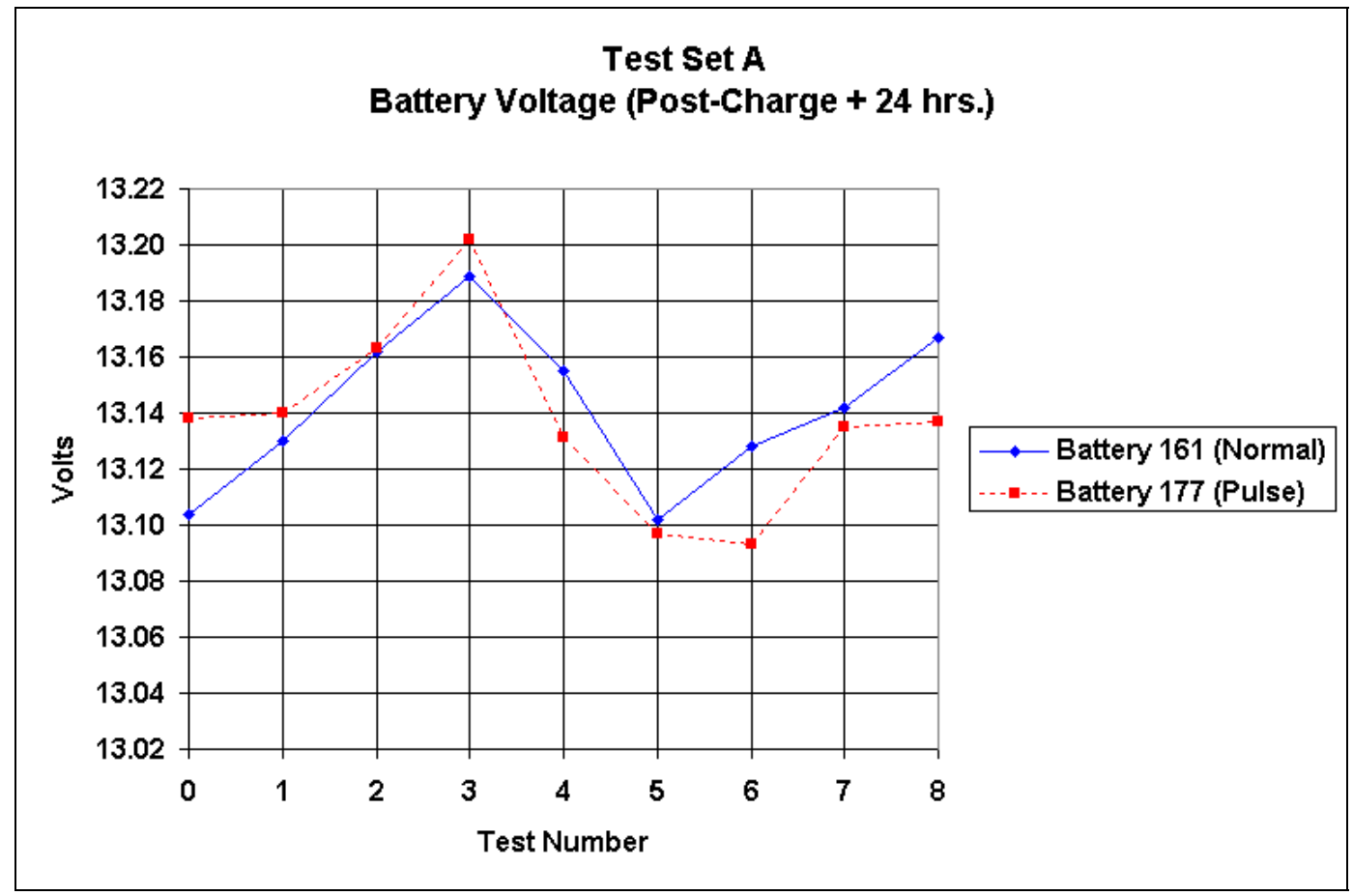

\section{A.15 Battery Test Set B - Post-Charge + 24 Hours Voltage}

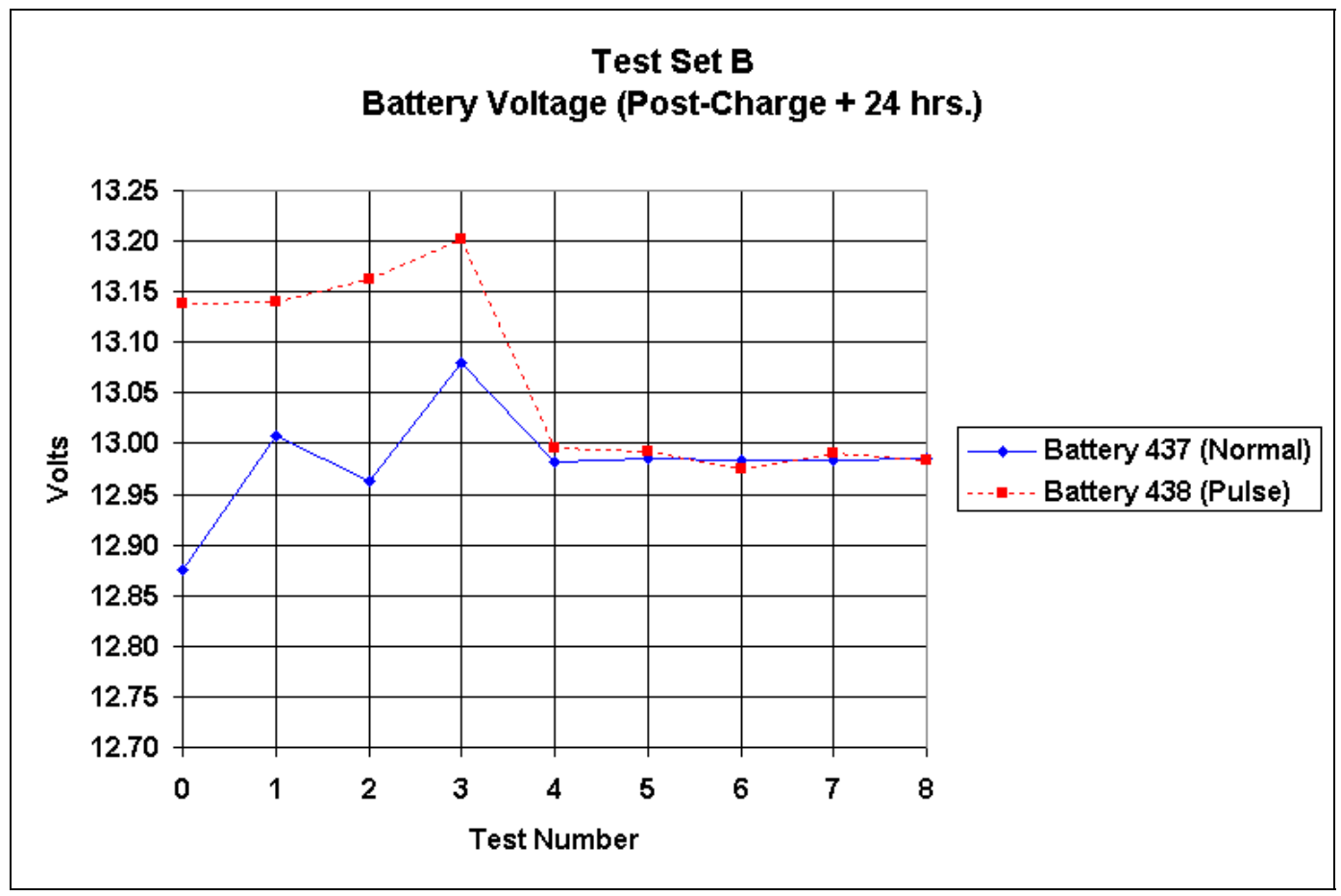




\section{A.16 Battery Test Set C - Post-Charge +24 Hours Voltage}

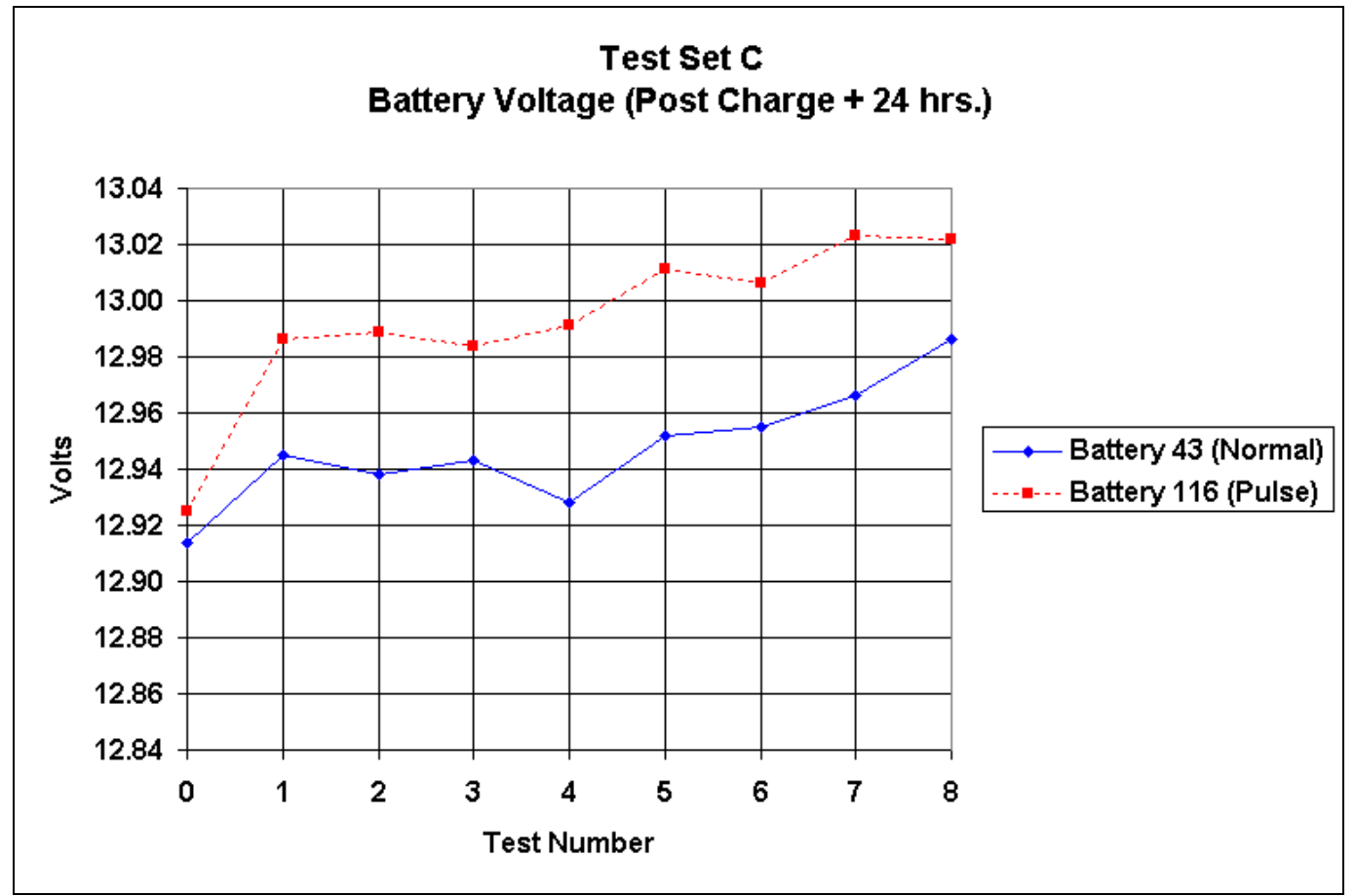

\section{A.17 Battery Test Set D - Post-Charge + 24 Hours Voltage}

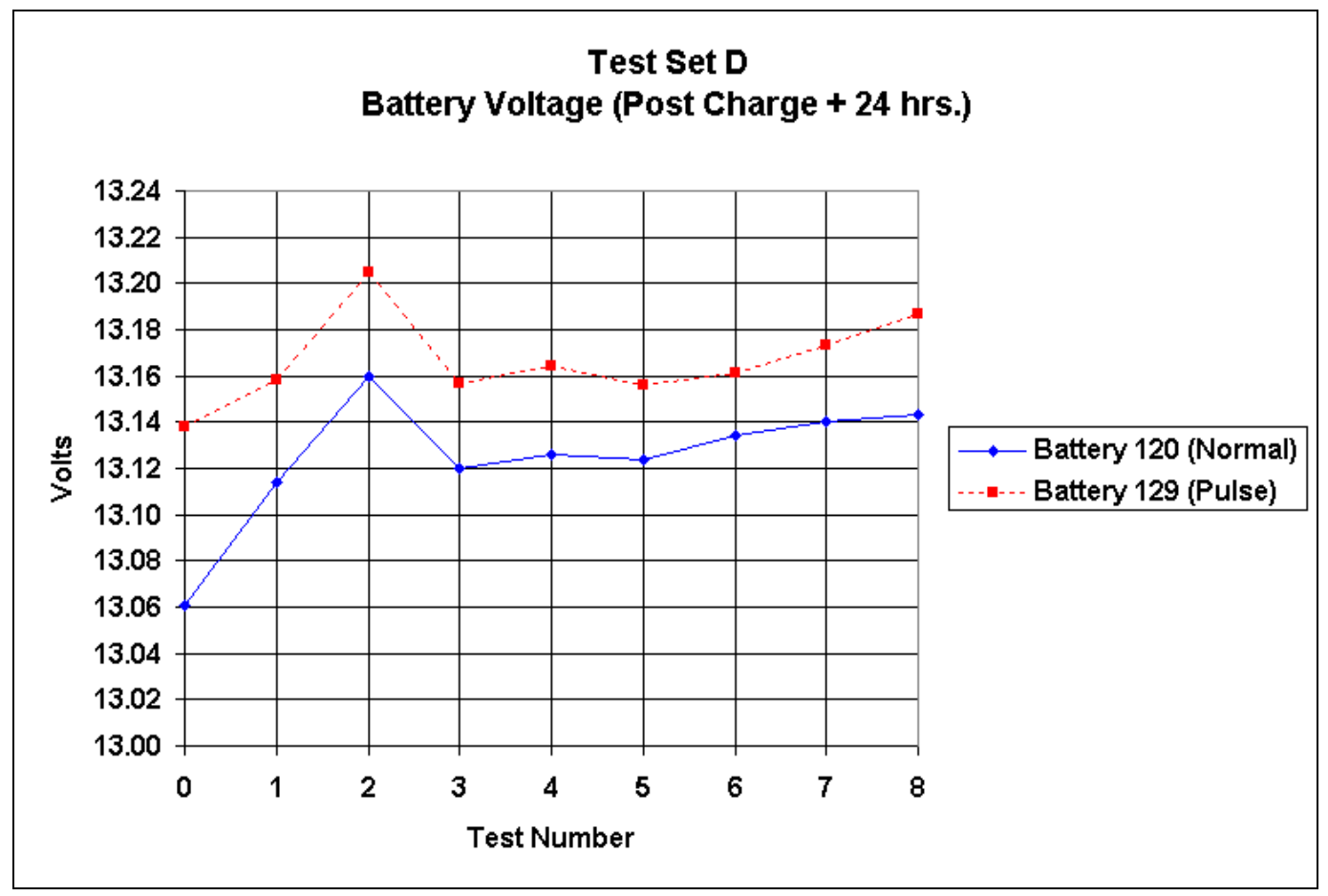




\section{A.18 Battery Test Set E - Post-Charge + 24 Hours Voltage}

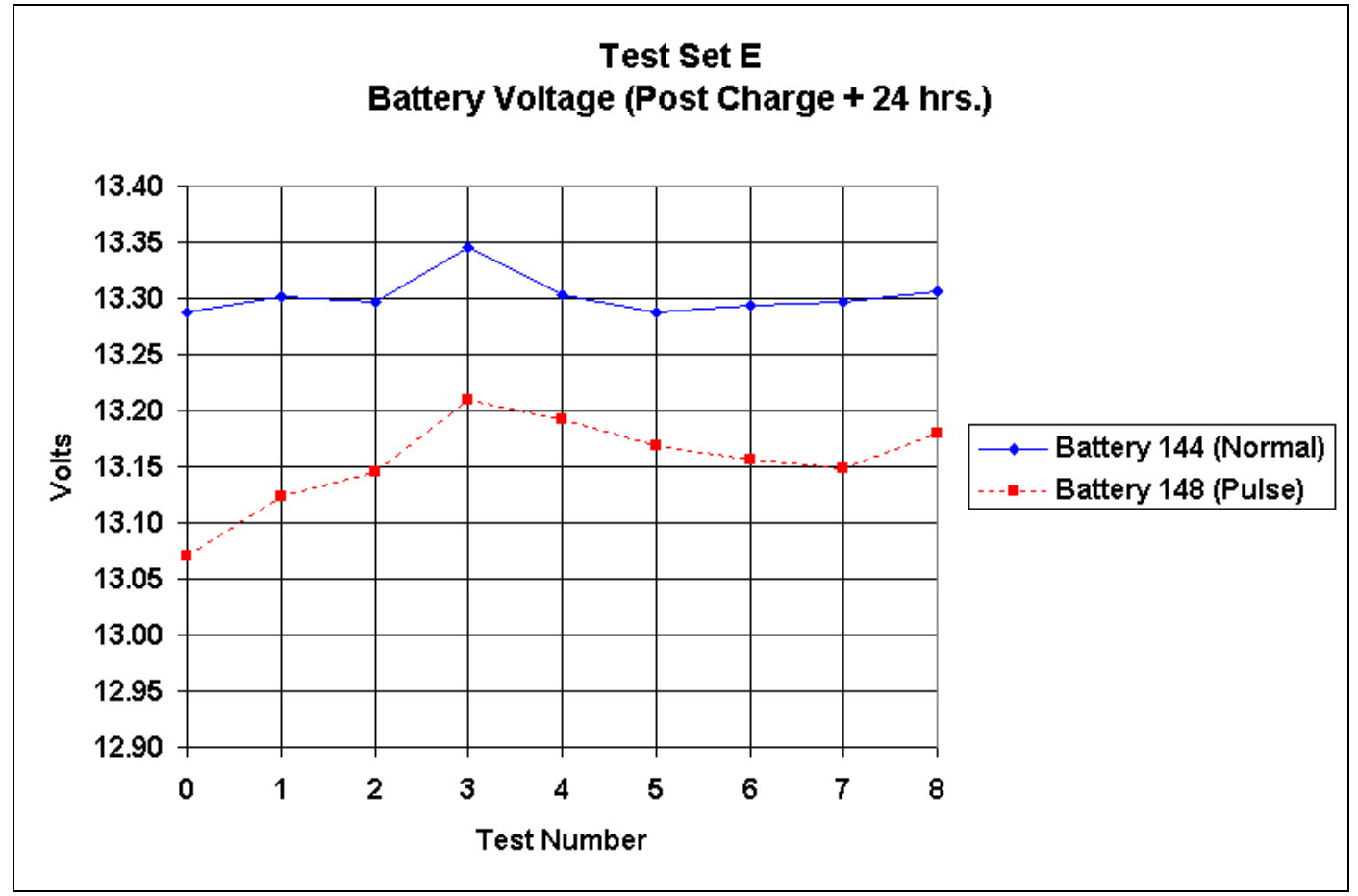

A.19 Battery Test Set F - Post-Charge + 24 Hours Voltage

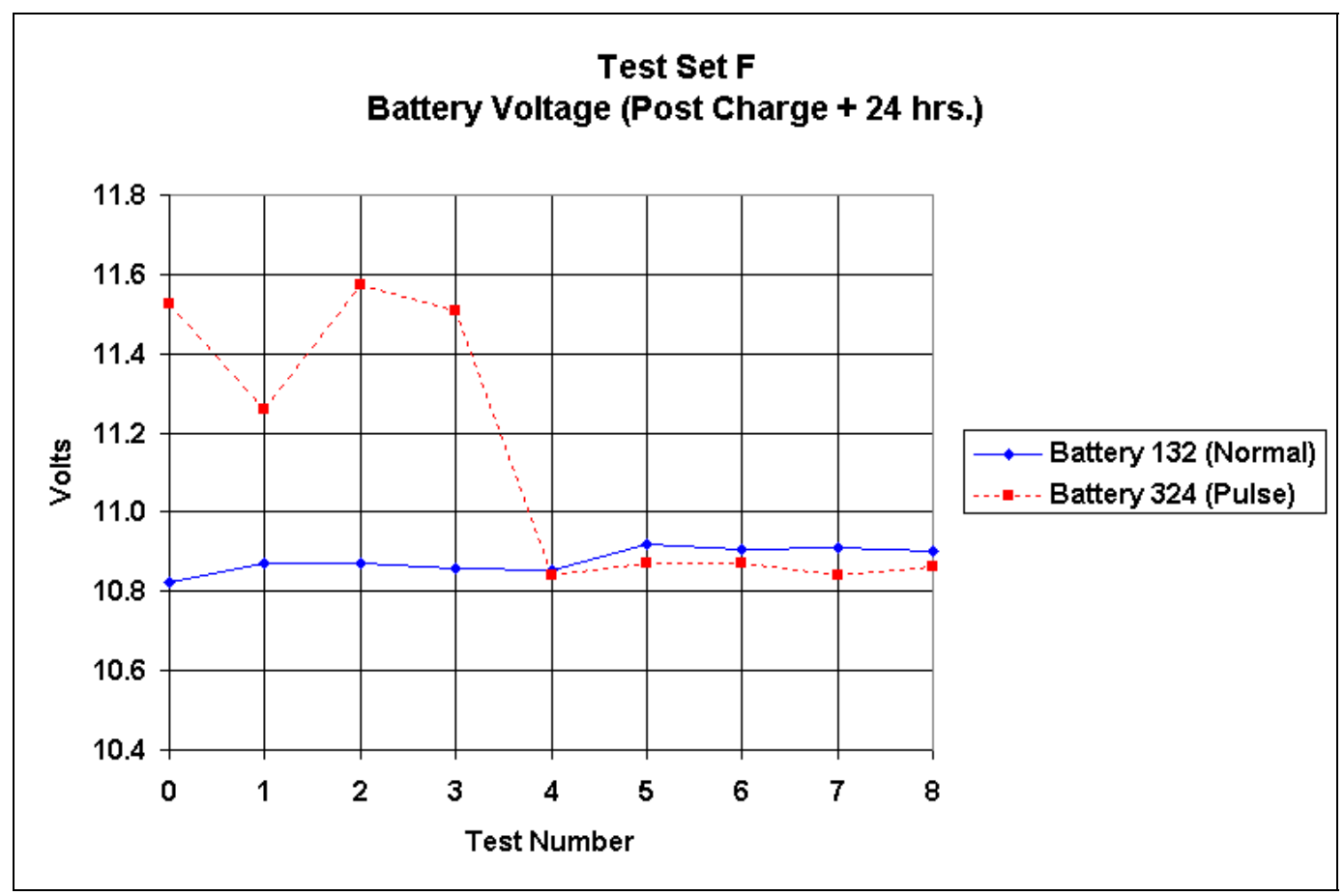




\section{Appendix B: Pulse Charger Schematics}

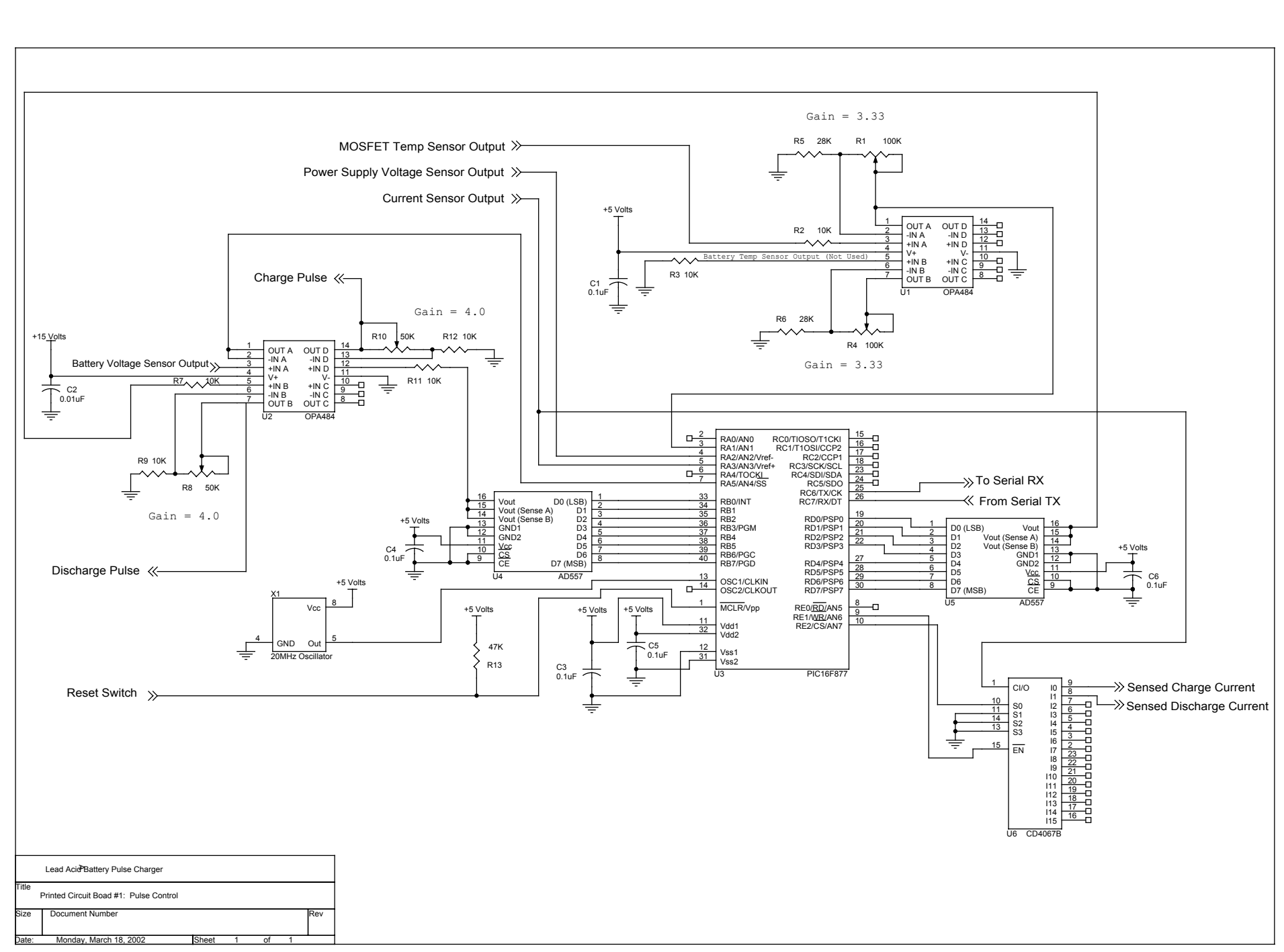


B.2 Schematic for Components on Printed Circuit Board \#2: User Interface

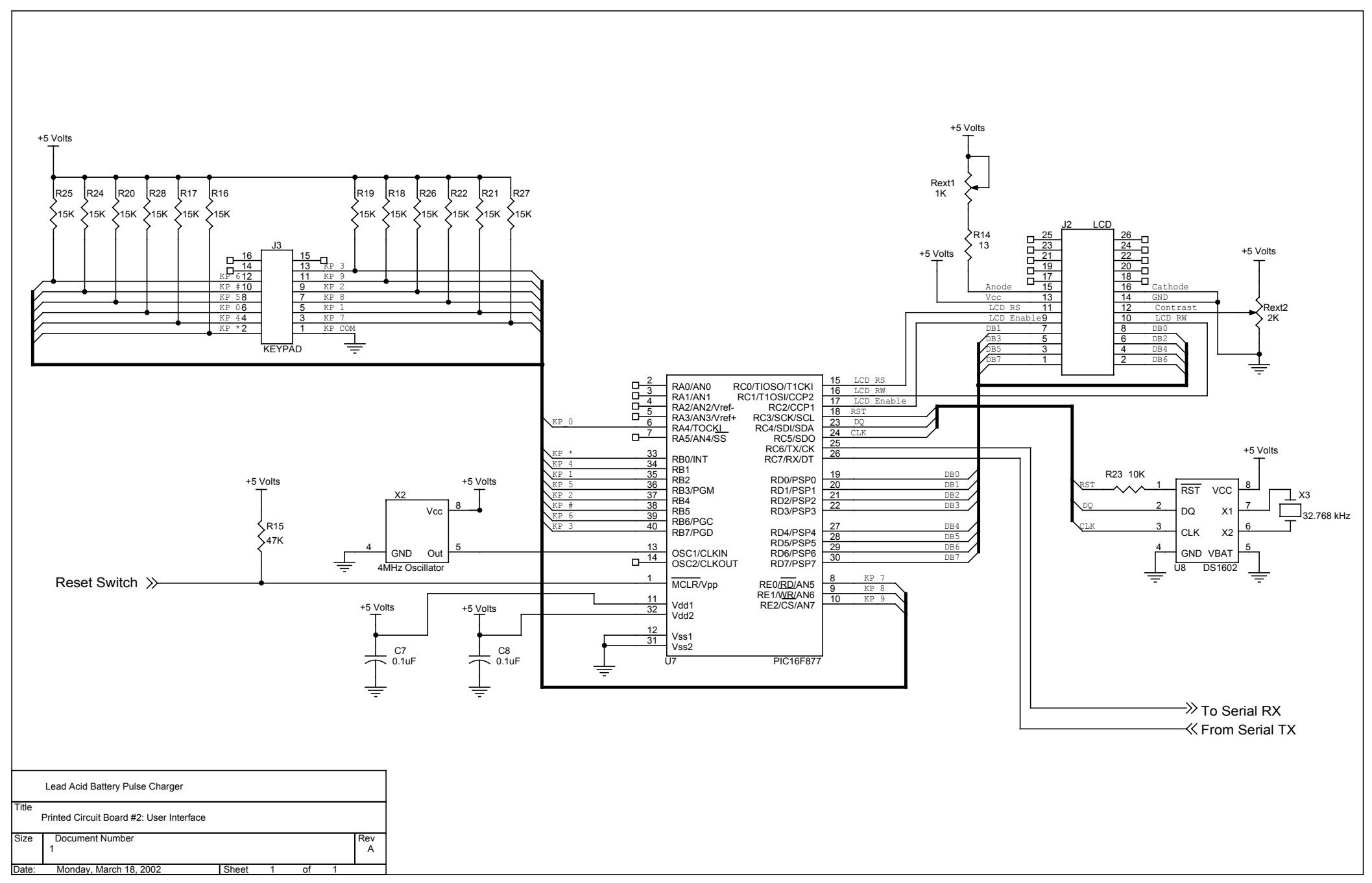




\section{B.3 Schematic for Components on Printed Circuit Board \#3: MOSFETs}

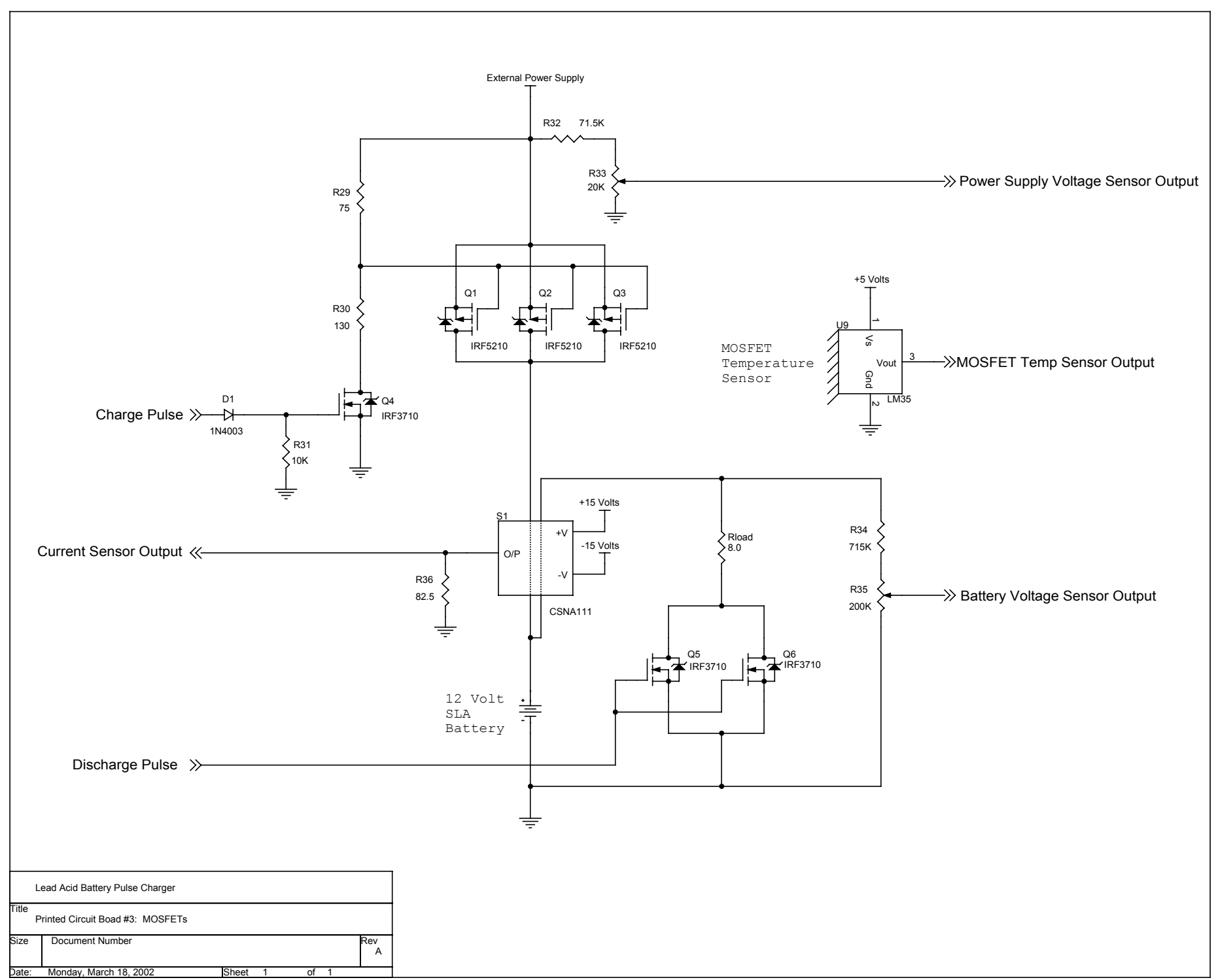


B.4 Schematic for Components on Printed Circuit Board \#4: +5V Supply

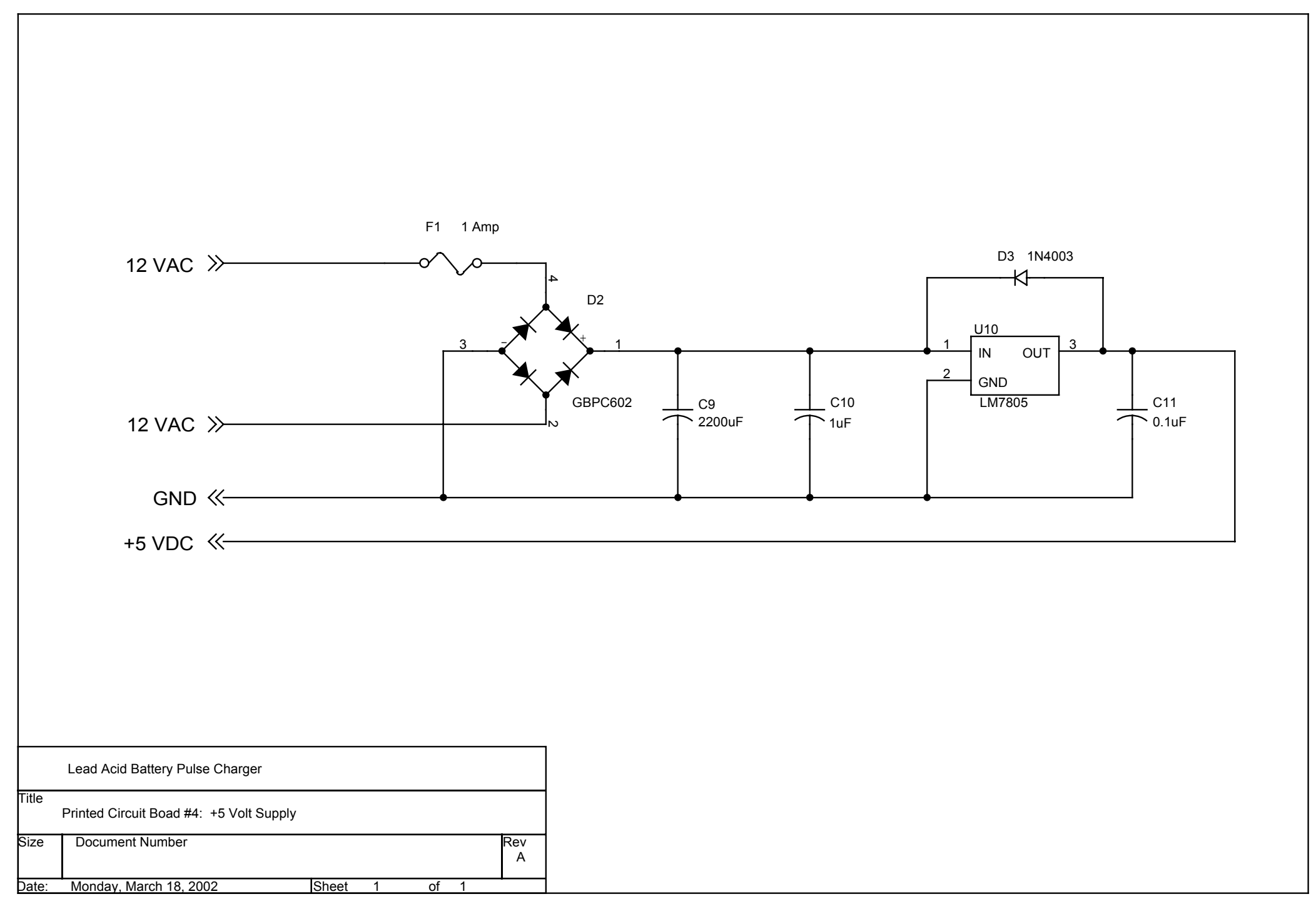


B.5 Schematic for Components on Printed Circuit Board \#5: $\pm 15 V,+12 \mathrm{~V}$

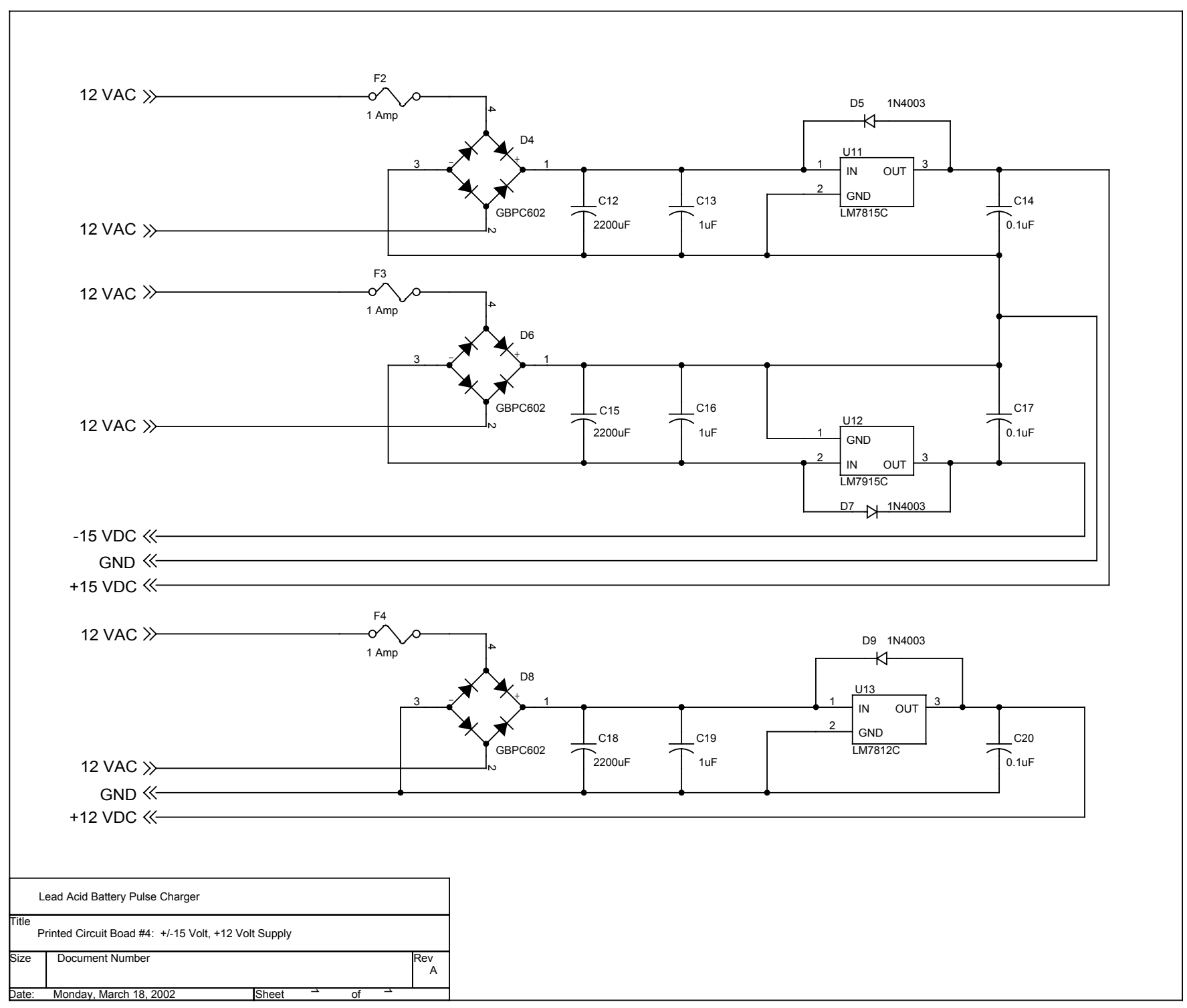




\section{B.6 Schematic for Components Not Mounted on a Printed Circuit Board.}

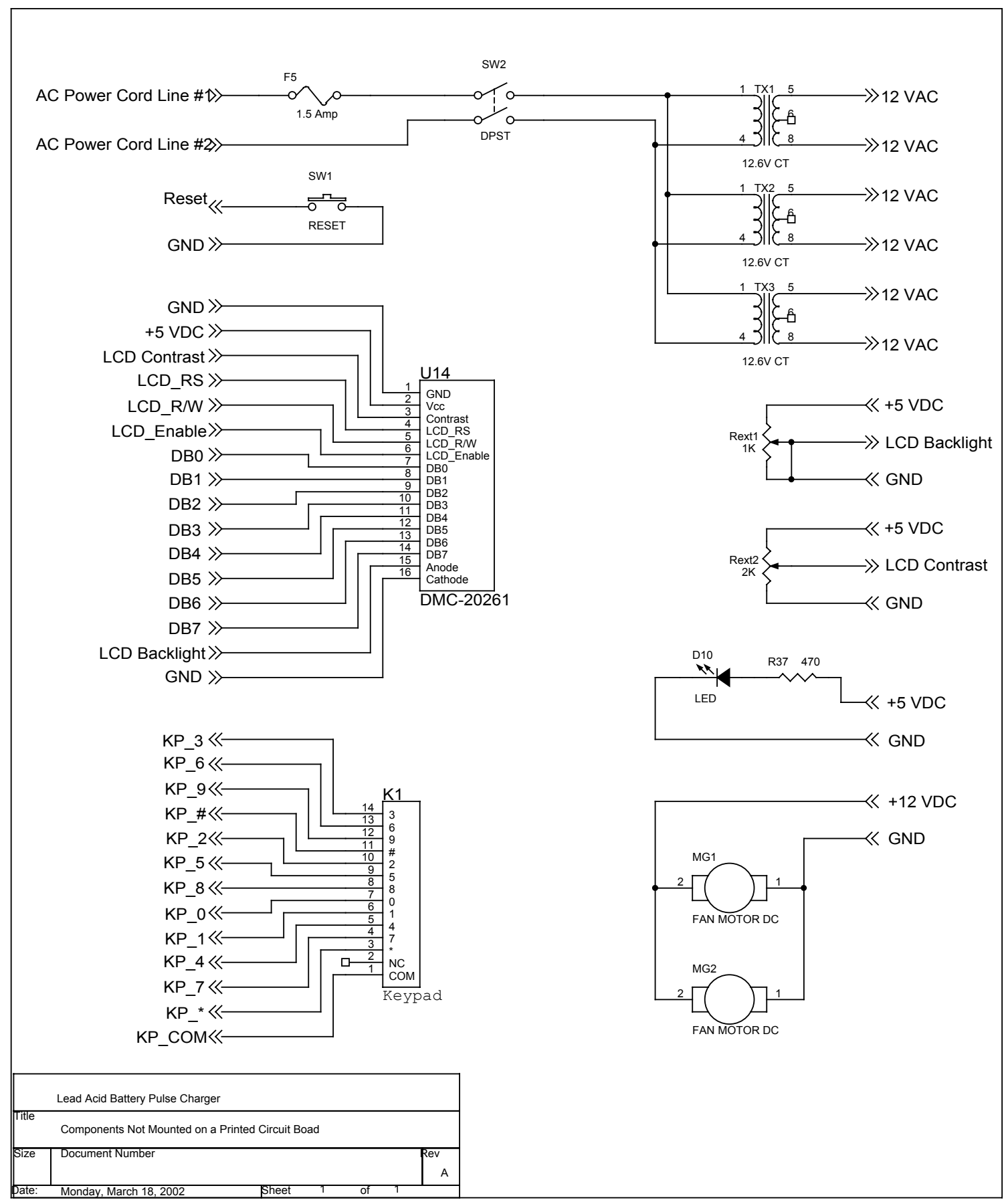




\section{Appendix C: Pulse Charger Source Code}

\section{C.1 User Interface Microcontroller Source Code File LCD_FUNC.C}

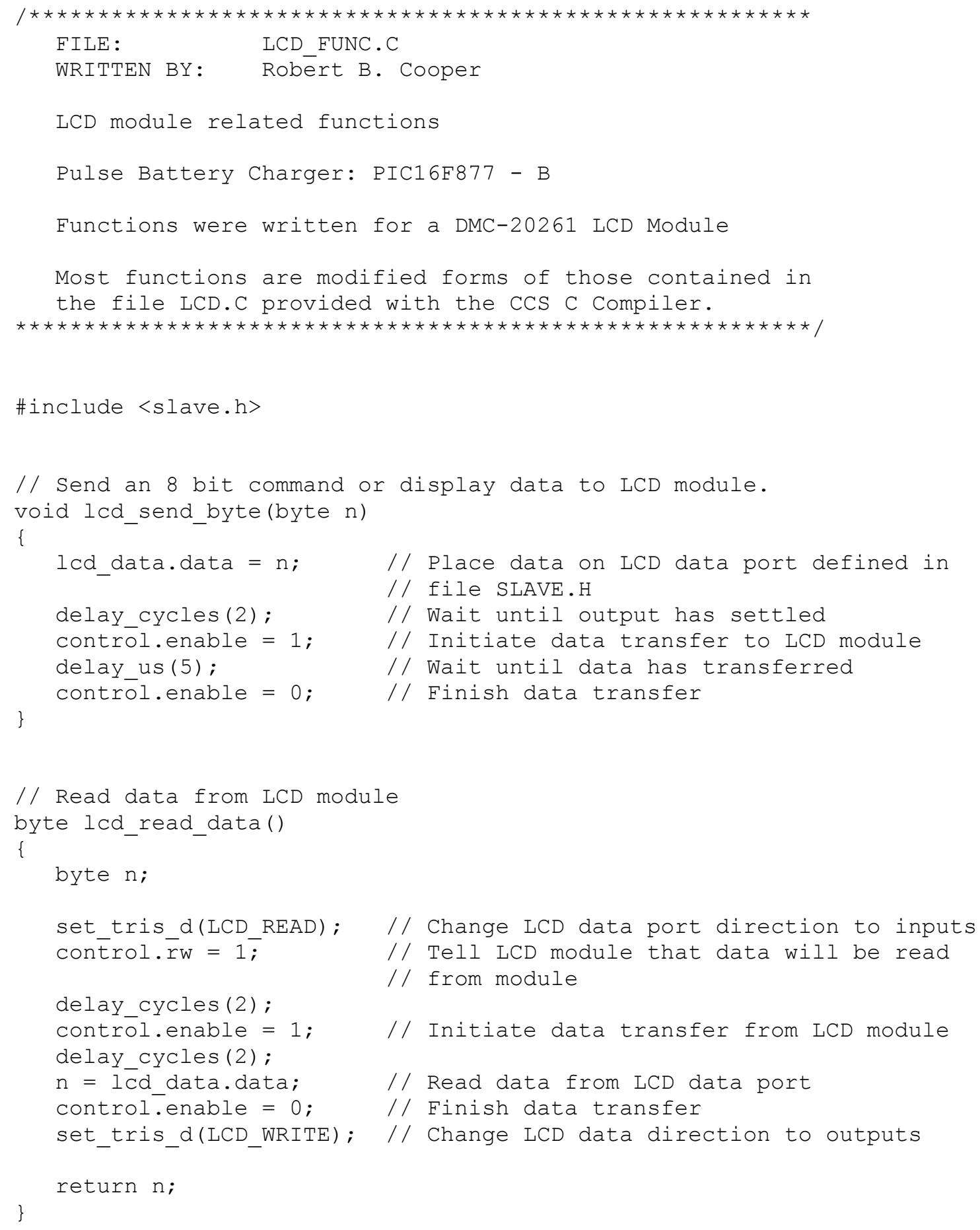




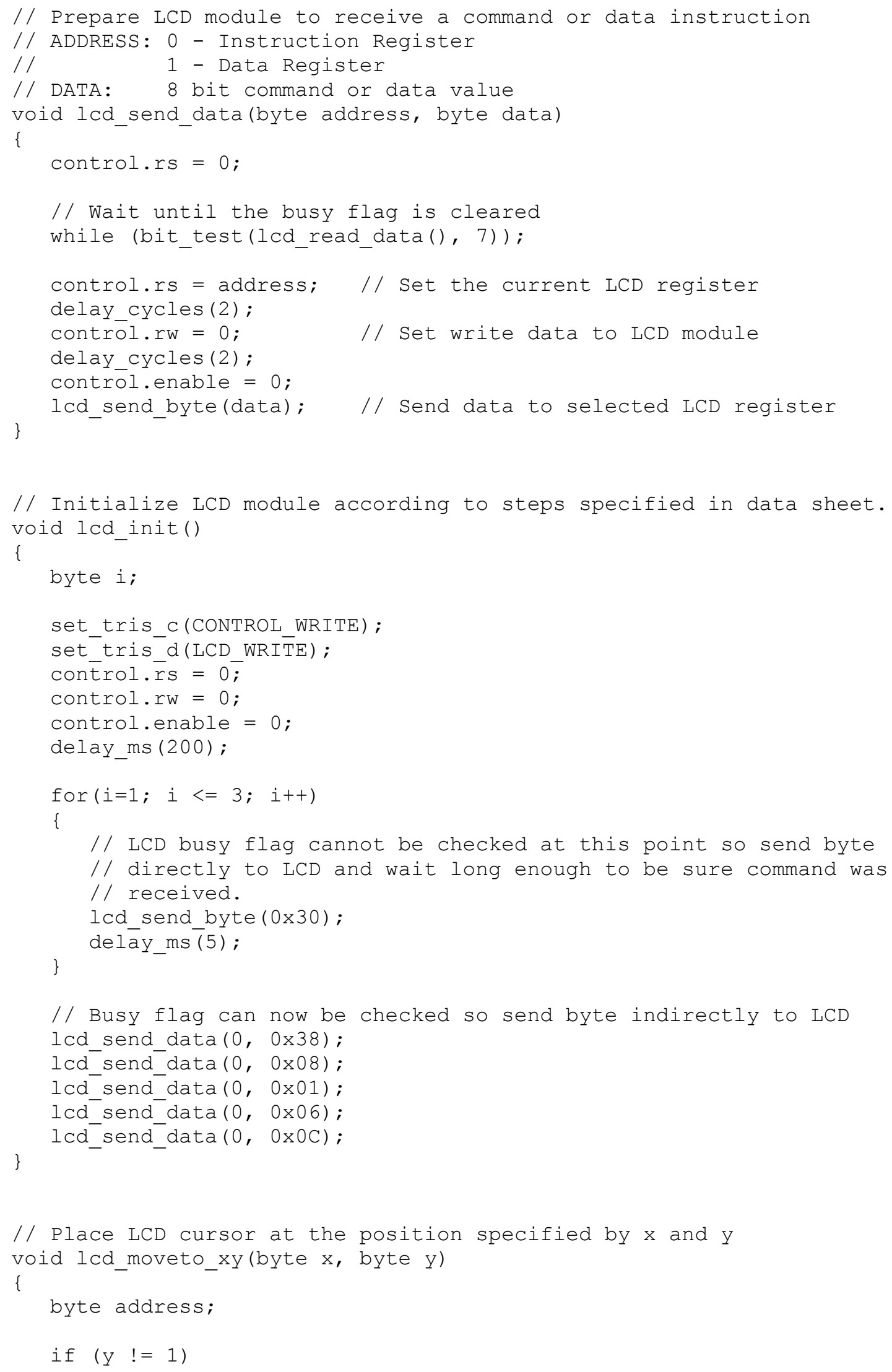




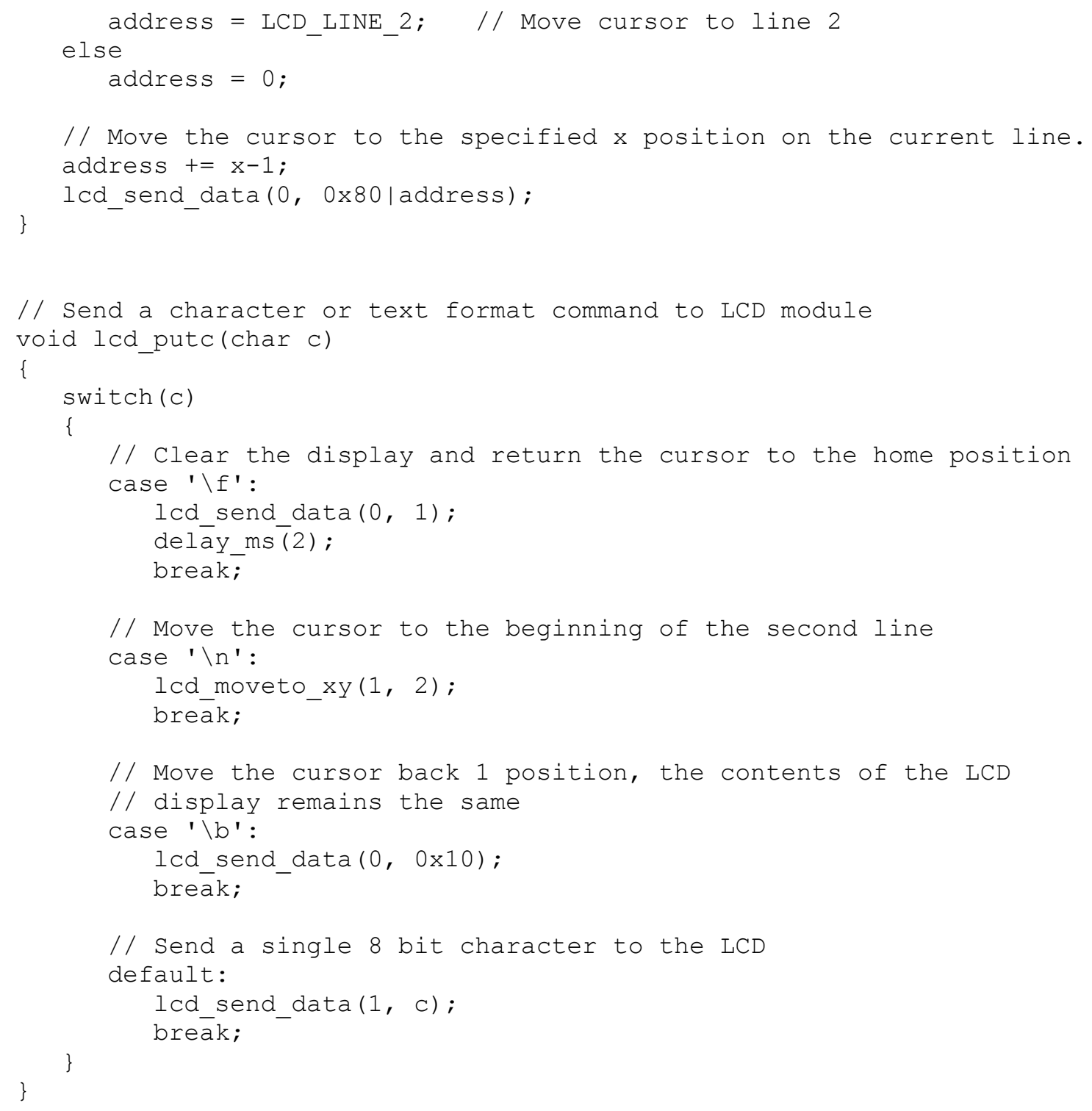

\section{C.2 User Interface Microcontroller Source Code File TMR_FUNC.C}

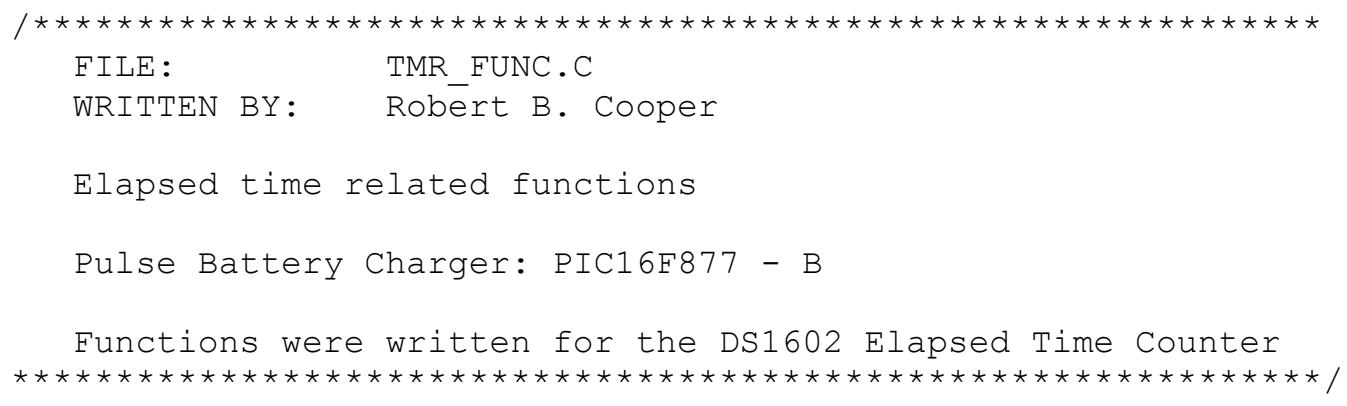


// Send an 8 bit instruction to the timer void timer_send_byte (byte data)

\{

int i;

set tris_c (CONTROL_WRITE);

for $(i=0 ; i<8 ; i+\overline{+})$

\{

// Send least significant bit first

control.dq = data \& $0 \times 01$;

// Toggle DS1602 clock to shift data into DS1602

control.clk = 1 ;

delay_us (2);

control.clk = 0 ;

// Move the next bit of data to the right-most position data $=$ data $>1$;

\}

\}

// Read 8-bits of data from the timer

int timer_read_byte()

\{

int i, data;

set_tris_c(CONTROL_READ_DQ) ;

for $(i=0 ; i<8 ; i++)$

\{

control.clk $=1$

// Receive data from timer, least significant bit first if (control.dq)

data $=($ data $>1) \mid 0 \times 80$;

else

data $=$ data $>1$

control.clk $=0$;

\}

set_tris_c(CONTROL_WRITE);

return data;

\}

// Begin a new data transfer cycle for the DS1602

void timer_begin_data_transfer()

\{

control.rst $=0$;

control.clk $=0$;

control.rst $=1$;

\} 


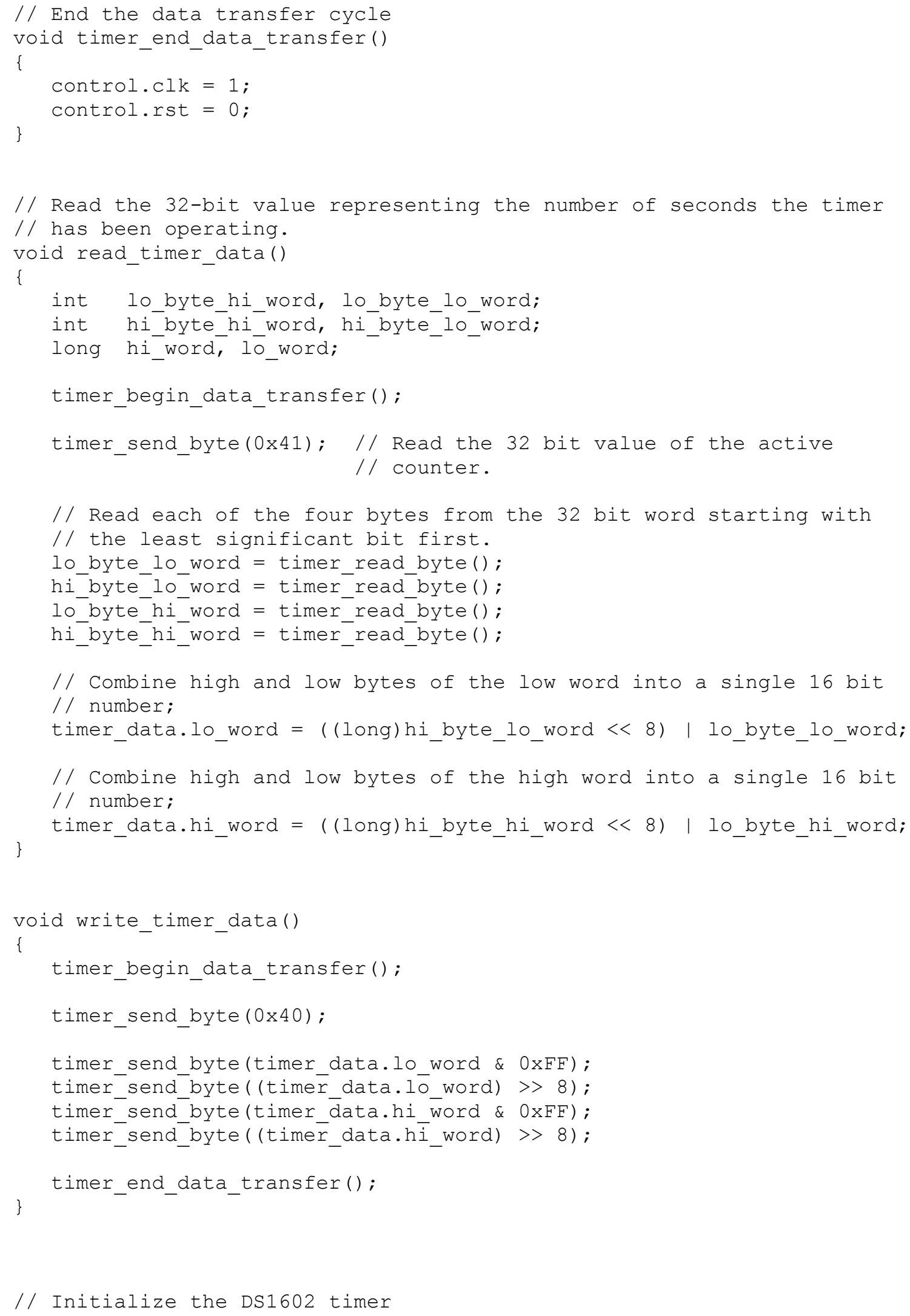




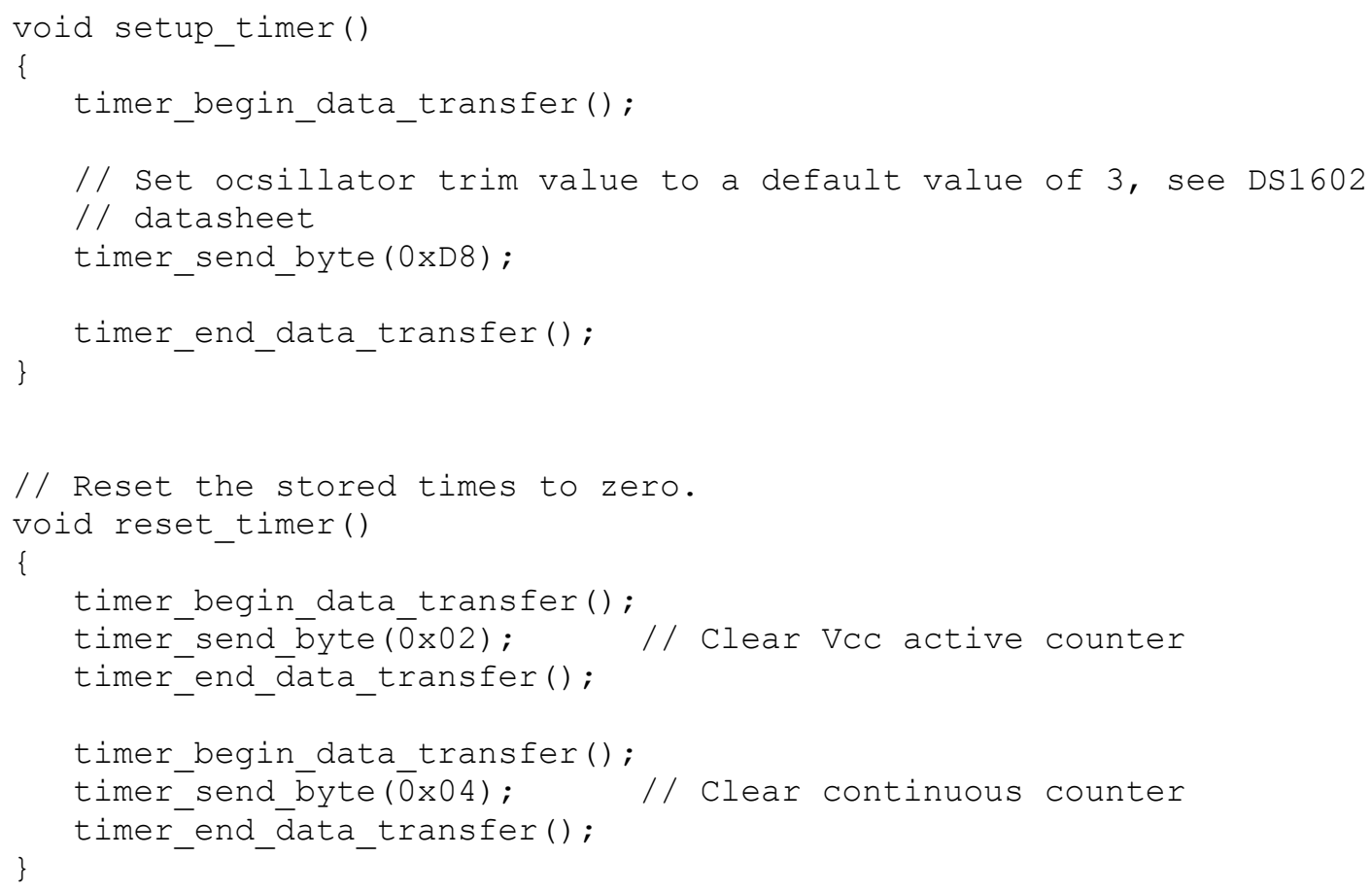

\section{C.3 User Interface Microcontroller Source Code File SLAVE.C}

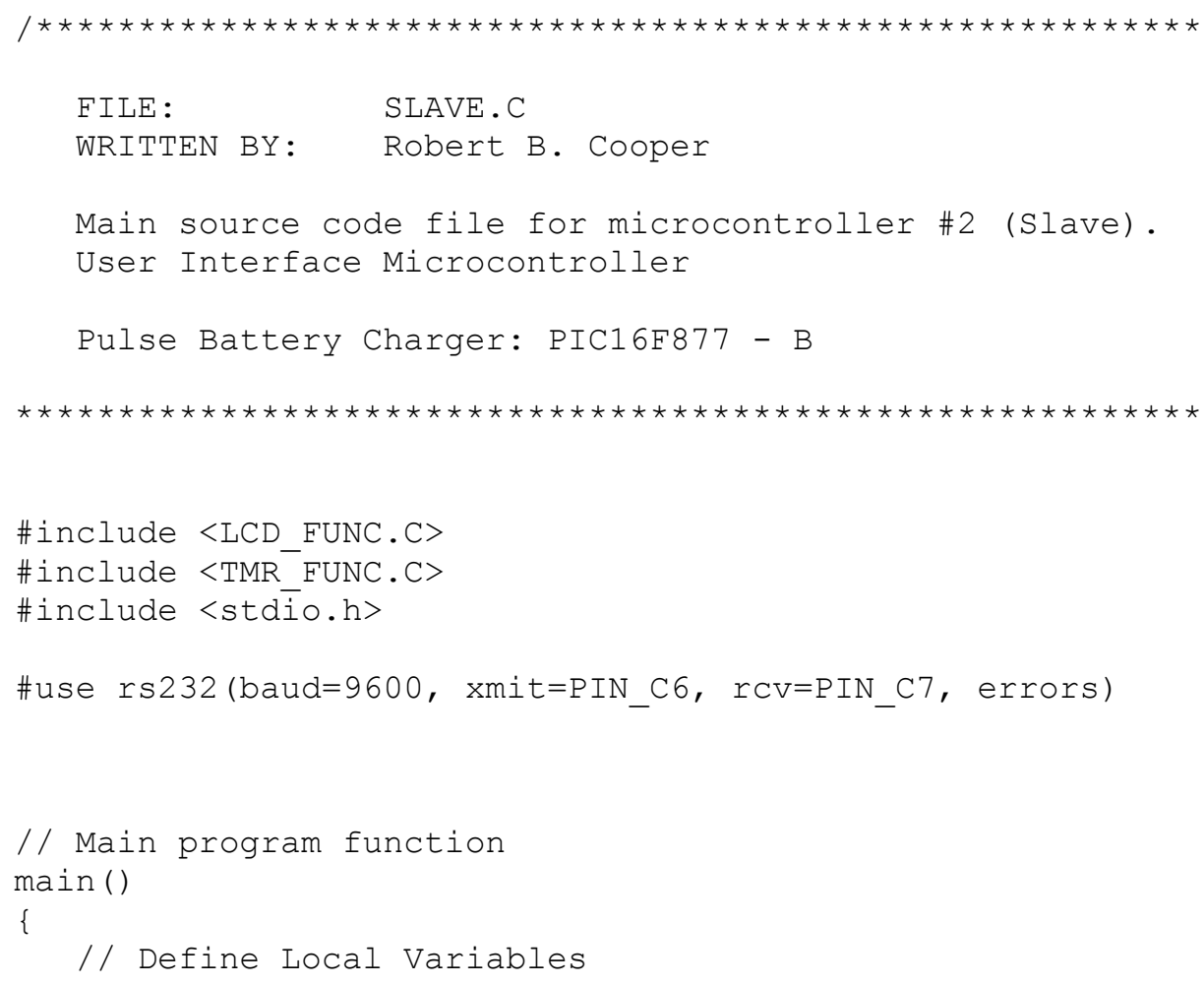




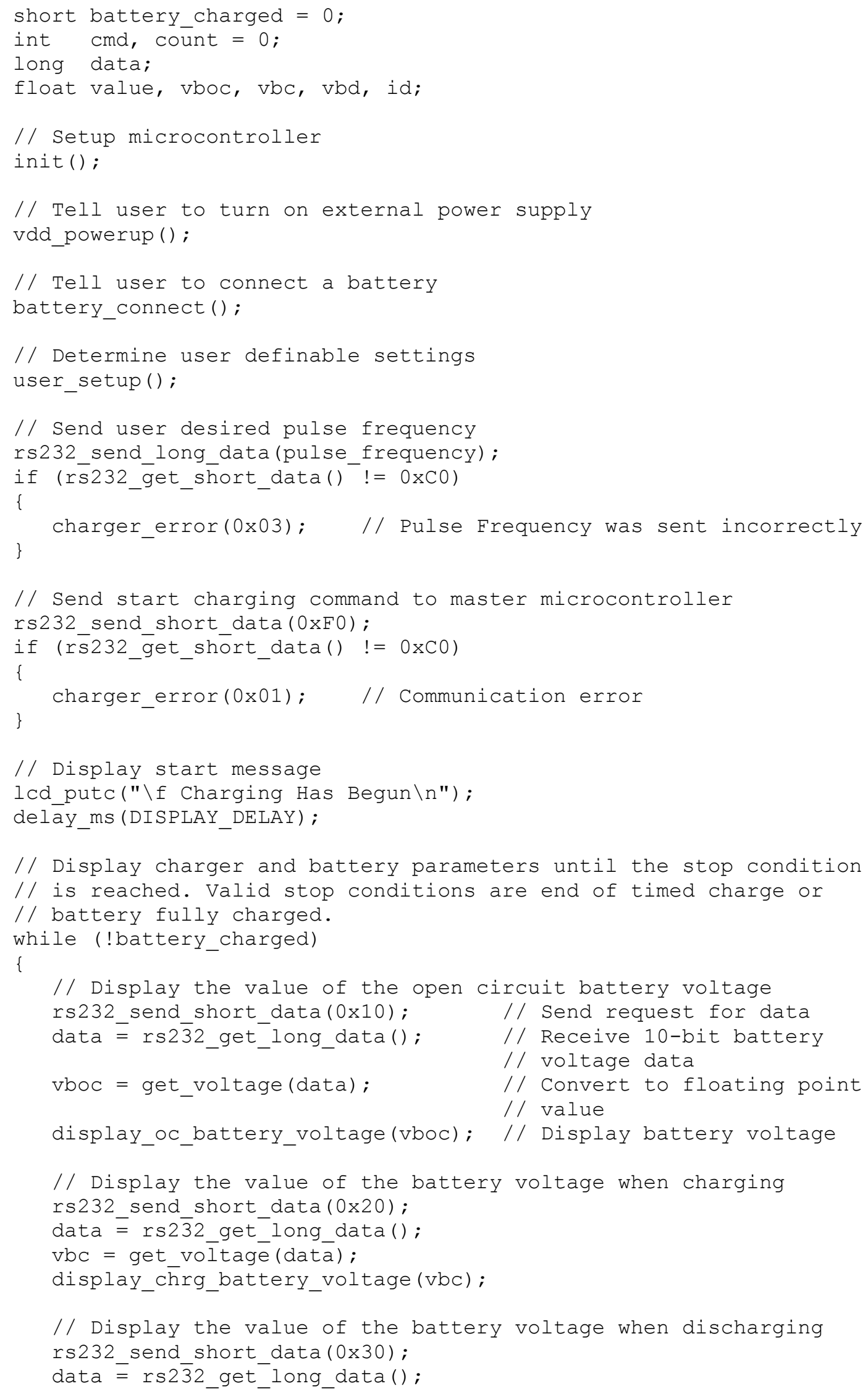




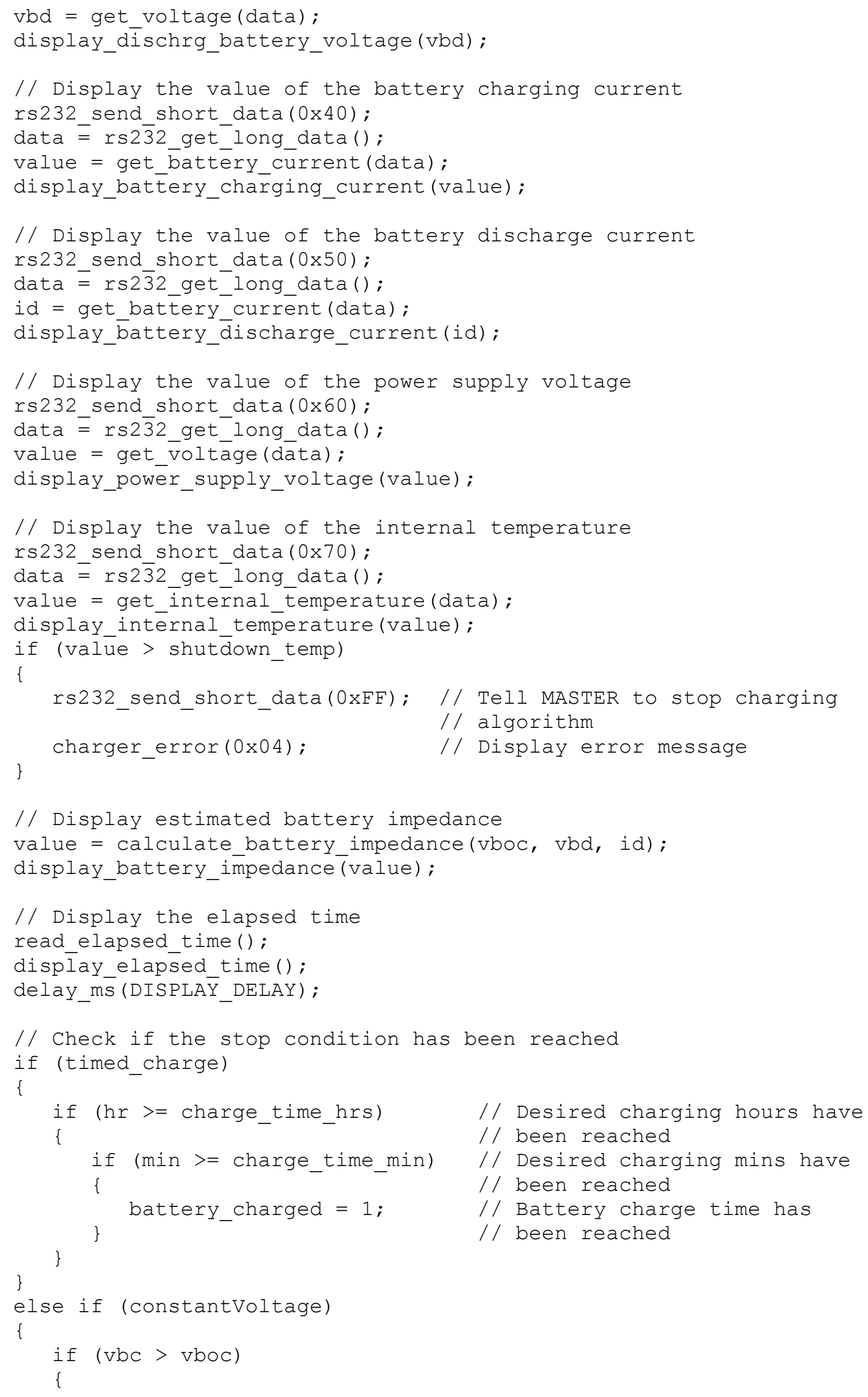




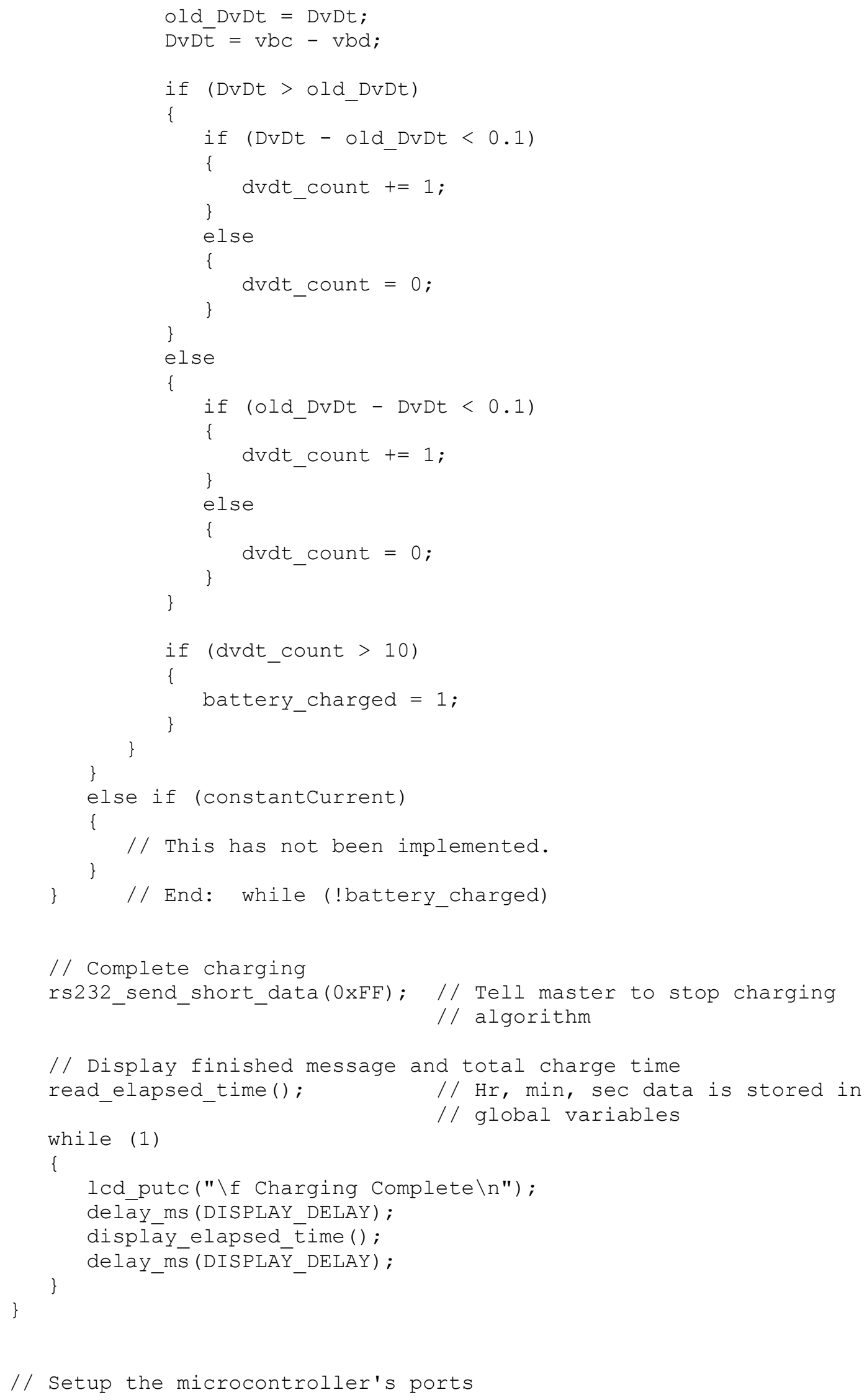




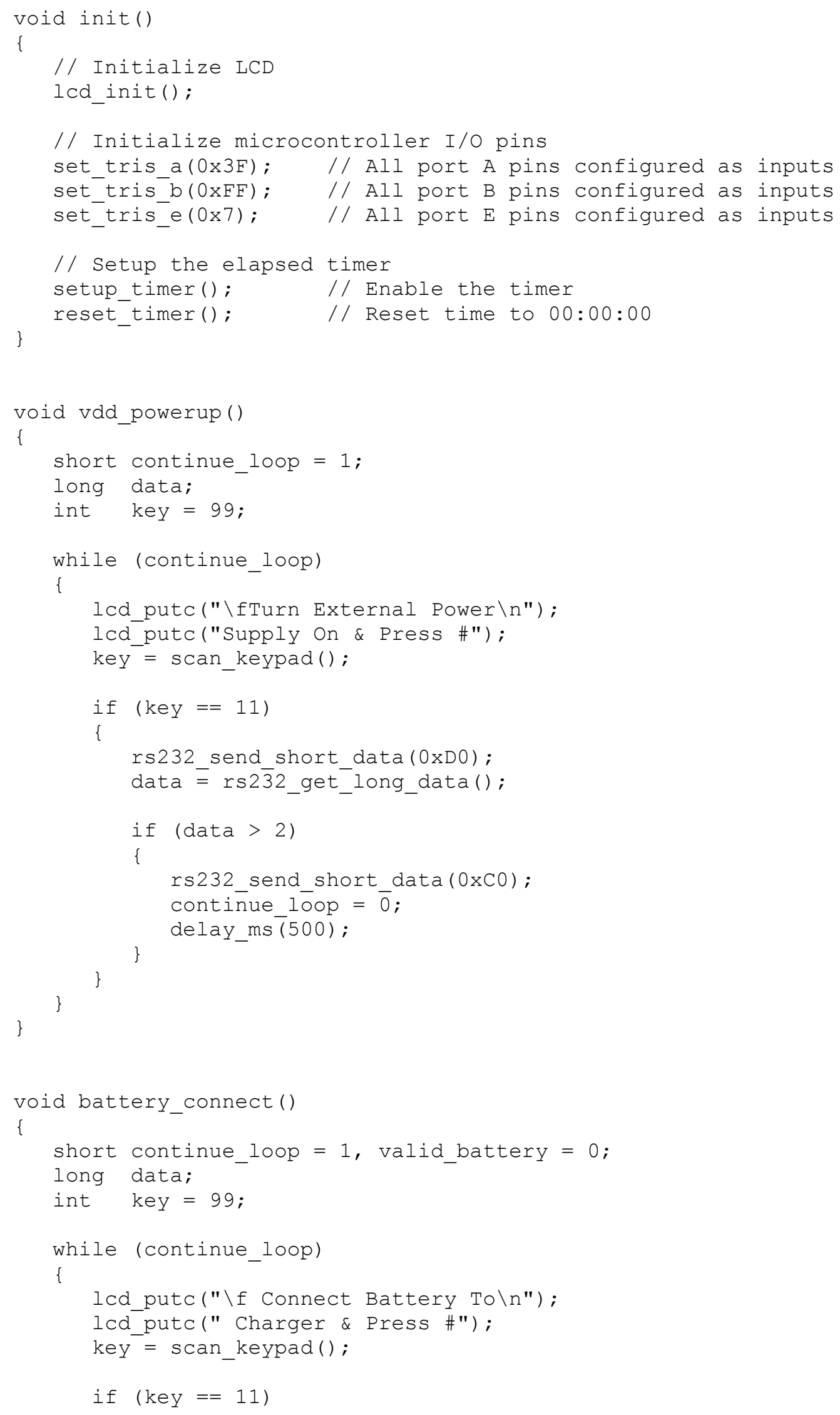




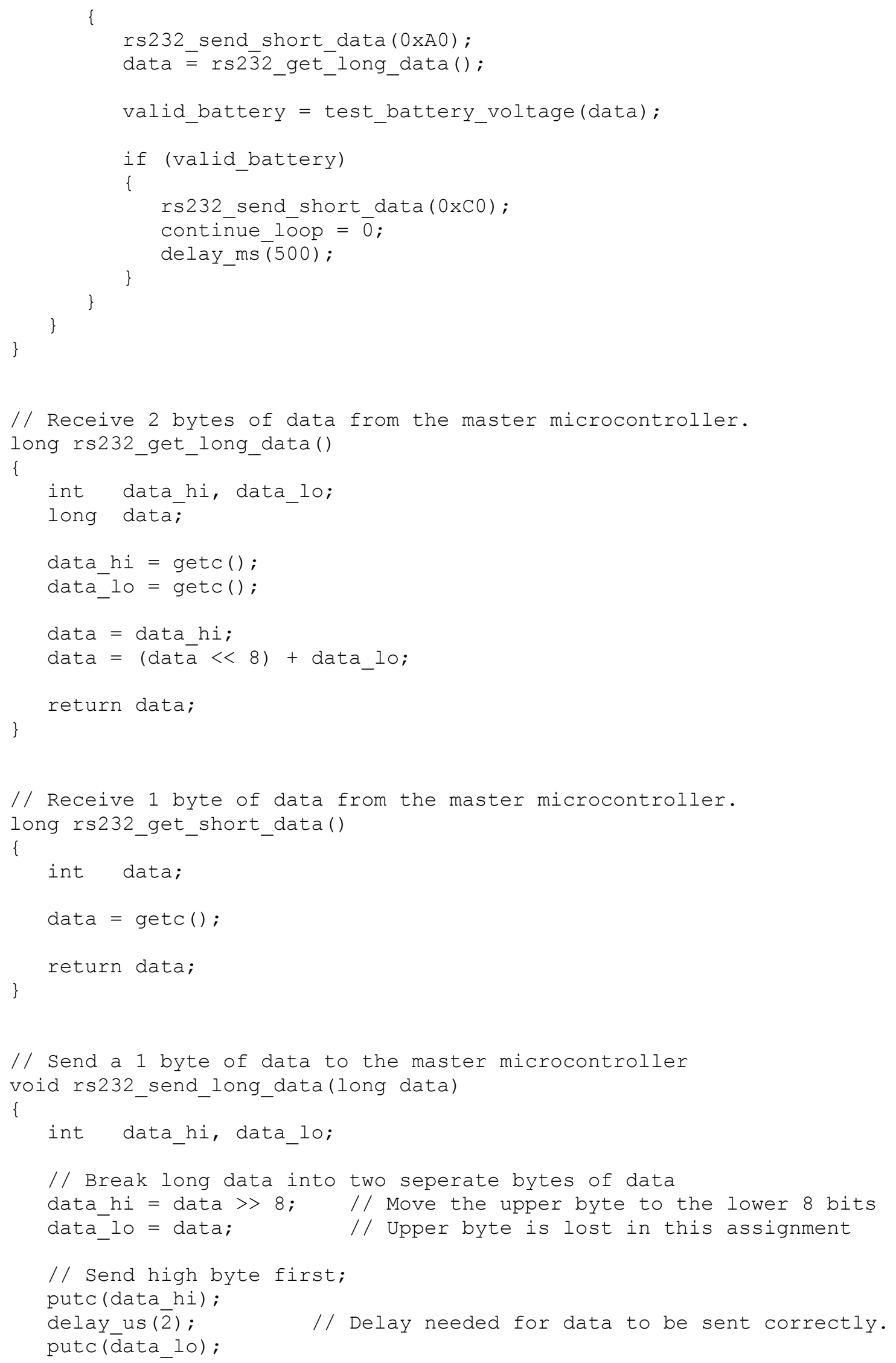


// Send a 1 byte of data to the master microcontroller void rs232_send_short_data(int data)

\{

putc (data);

\}

// Determine if a battery is connected to the charger and if its open // circuit voltage is within a valid range. short test battery voltage(long data)

\{

// No battery is connected to the charger

if (data $<10)$

\{

lcd putc (" \fNo Battery Connected $\backslash n "$ );

lcd_putc(" Press RESET button");

delāy ms (2000);

\}

return 0 ;

I/ Battery voltage is less than 5 volts.

if $($ data $<102)$

\{

lcd_putc("\fBad Battery Voltage \n");

lcd_putc("Voltage < 5 Volts");

delāyms (2000);

return 0 ;

\}

// Battery voltage is greater than 15 volts.

if (data > 307)

\{

lcd putc("\f Batt. Fully Charged \n");

lcd_putc(" Voc > 15 Volts");

delay_ms (2000);

return 0 ;

\}

// Battery voltage is within the valid range of 5 - 15 volts return 1;

\}

// Determine any special user settings.

void user_setup ()

\{

int key, i, j;

boolean continue_loop $=1$;

// Display Setup Message

lcd_putc("\f Charger Setup $\backslash n ")$;

lcd_putc("Press \# to Continue");

while (continue_loop) 


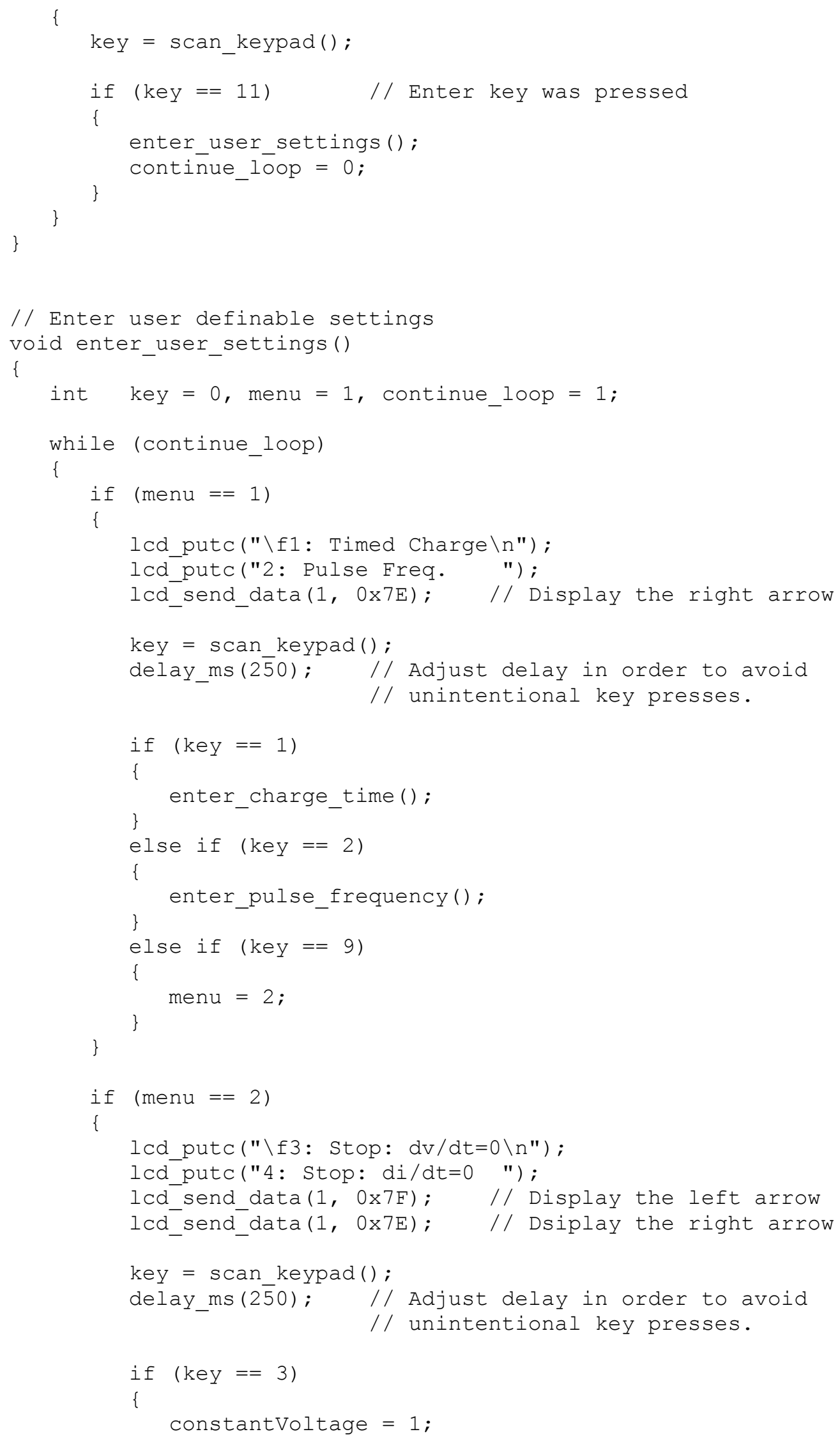




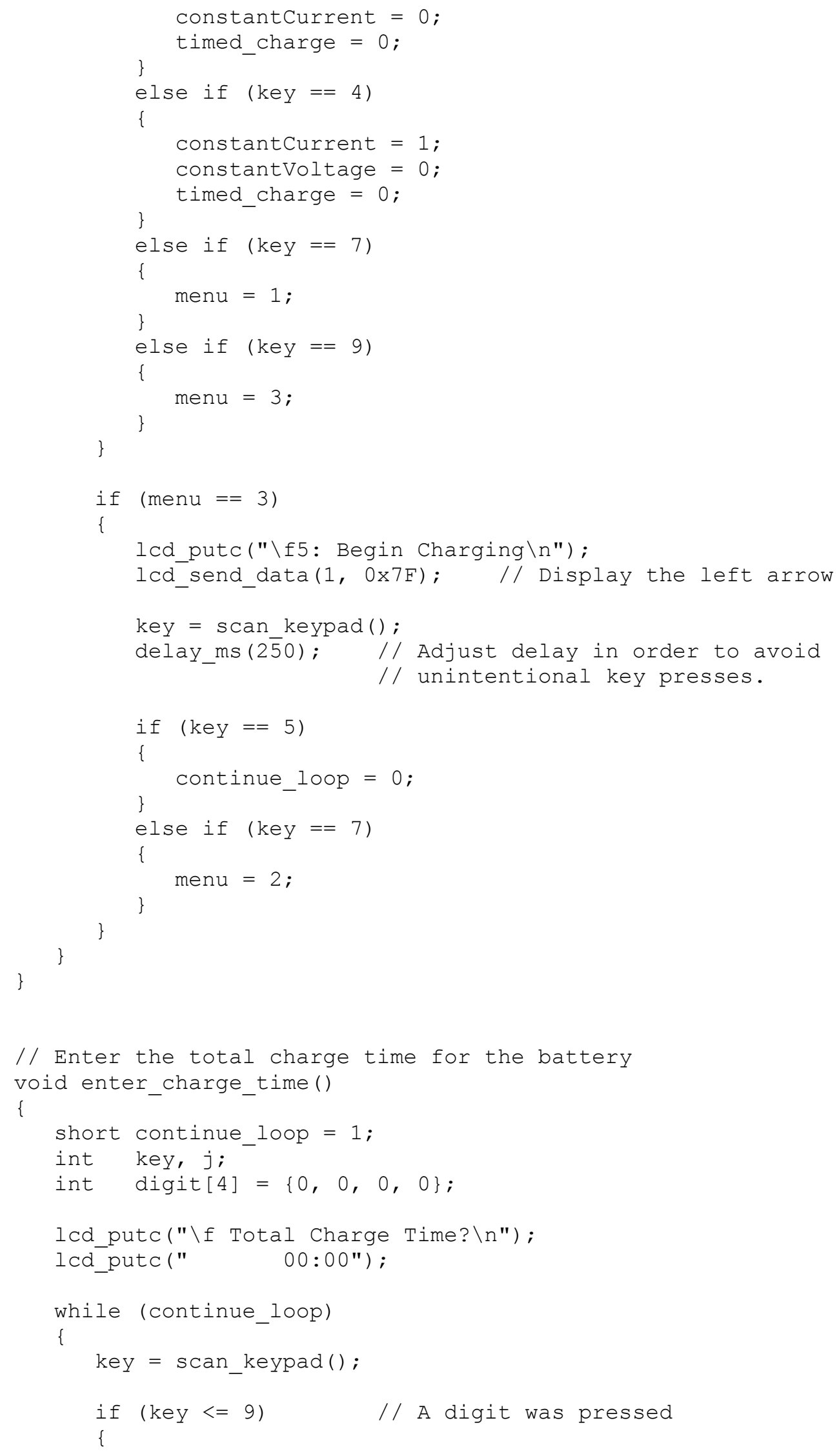




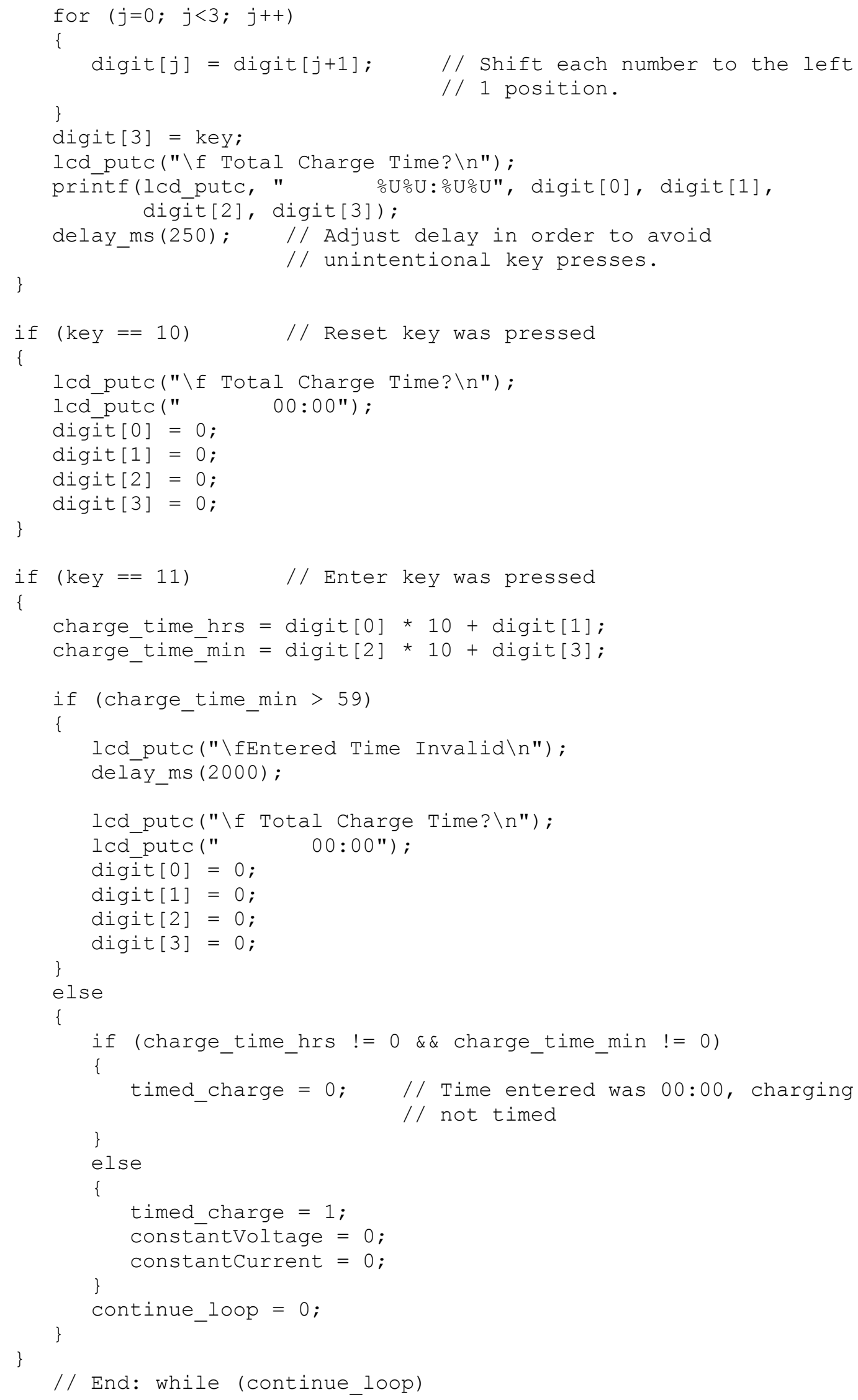




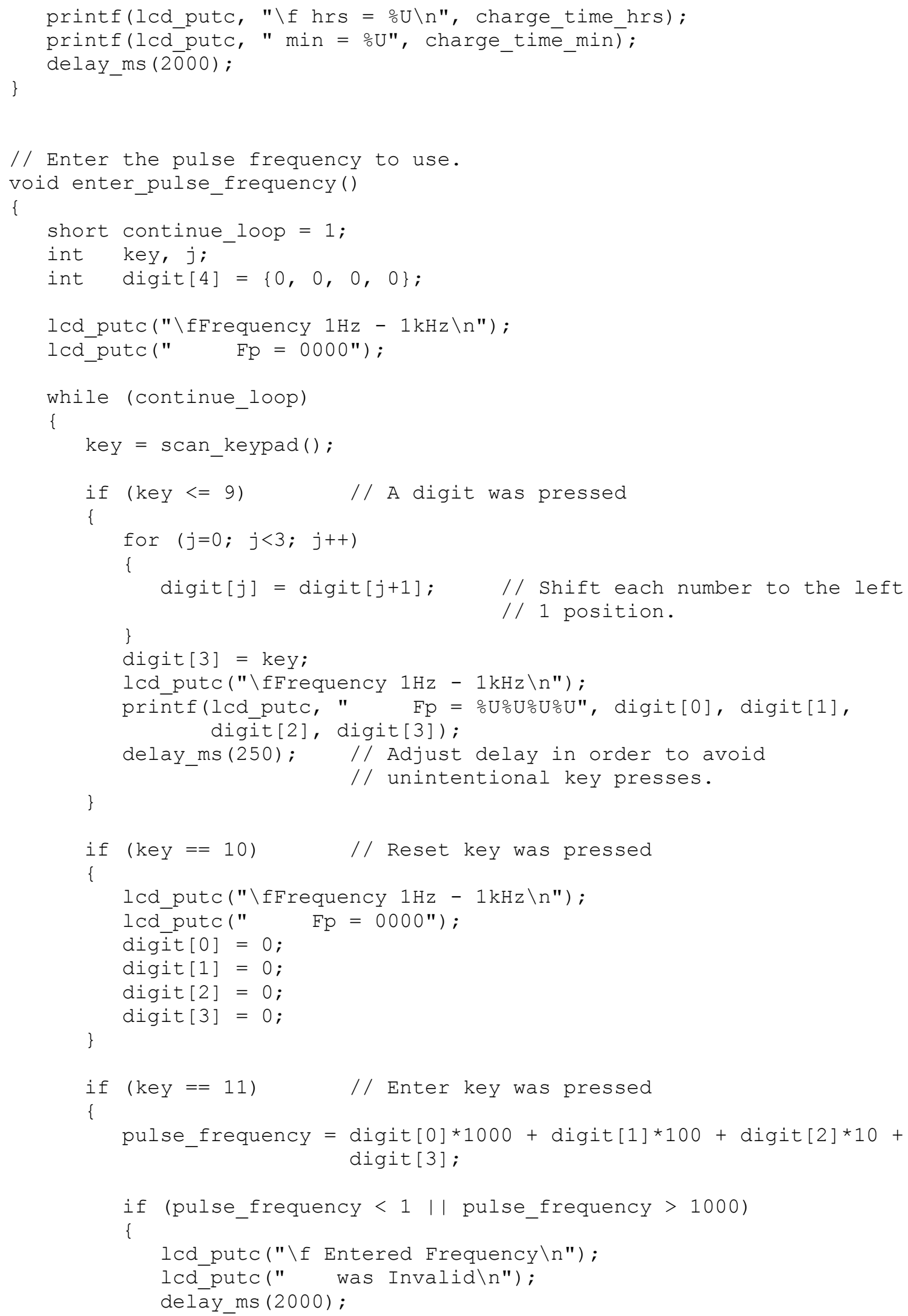




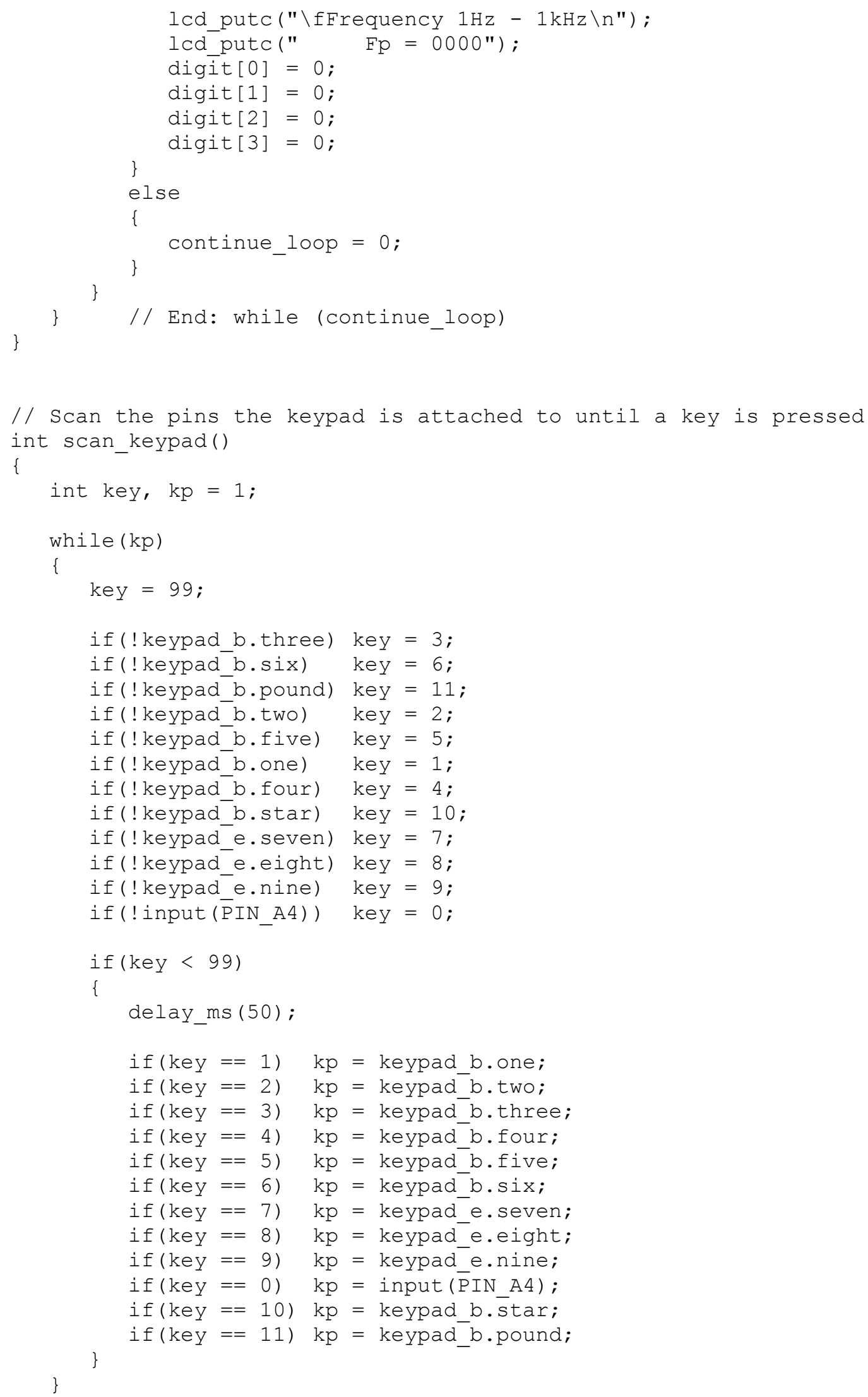




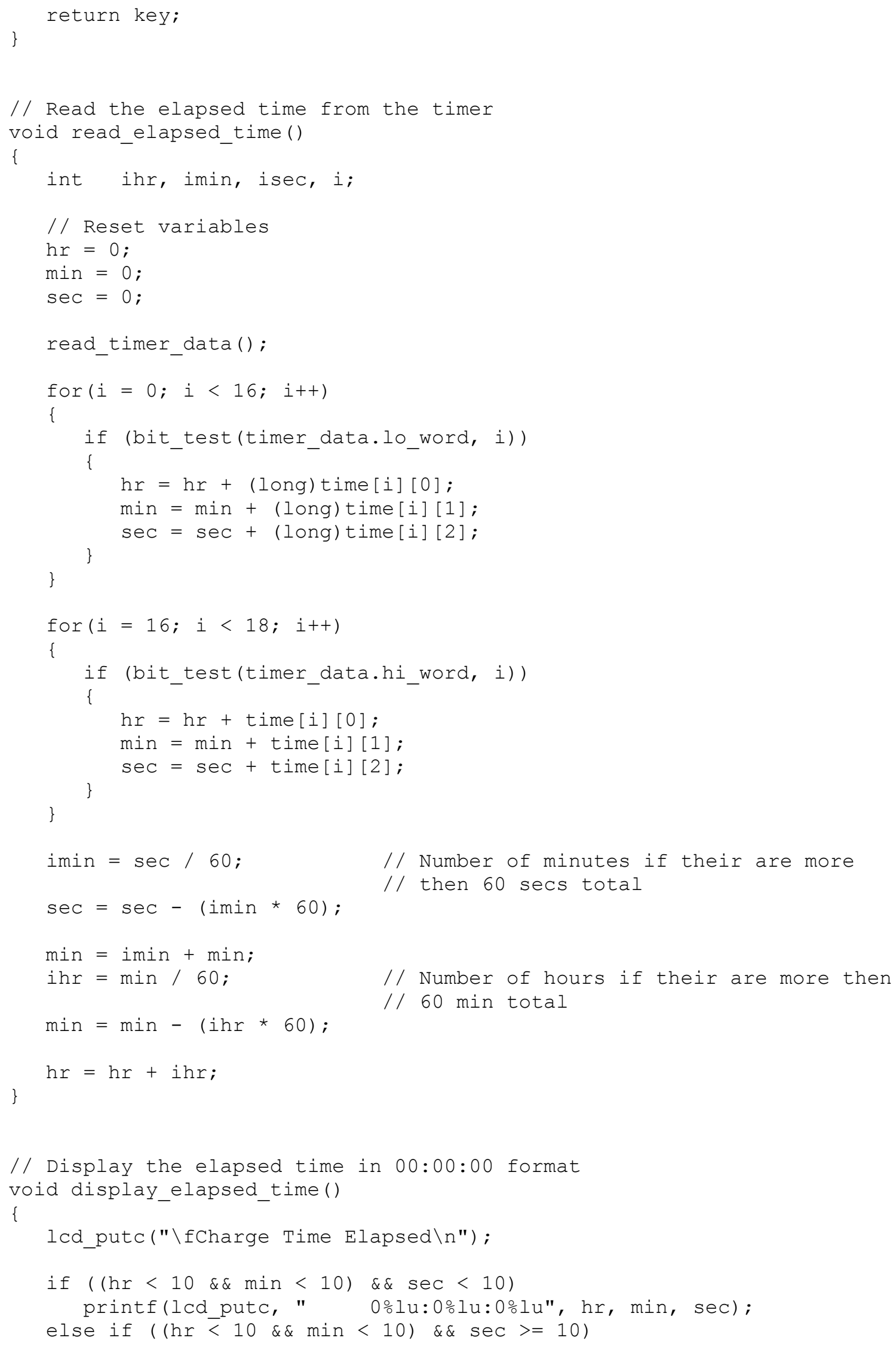




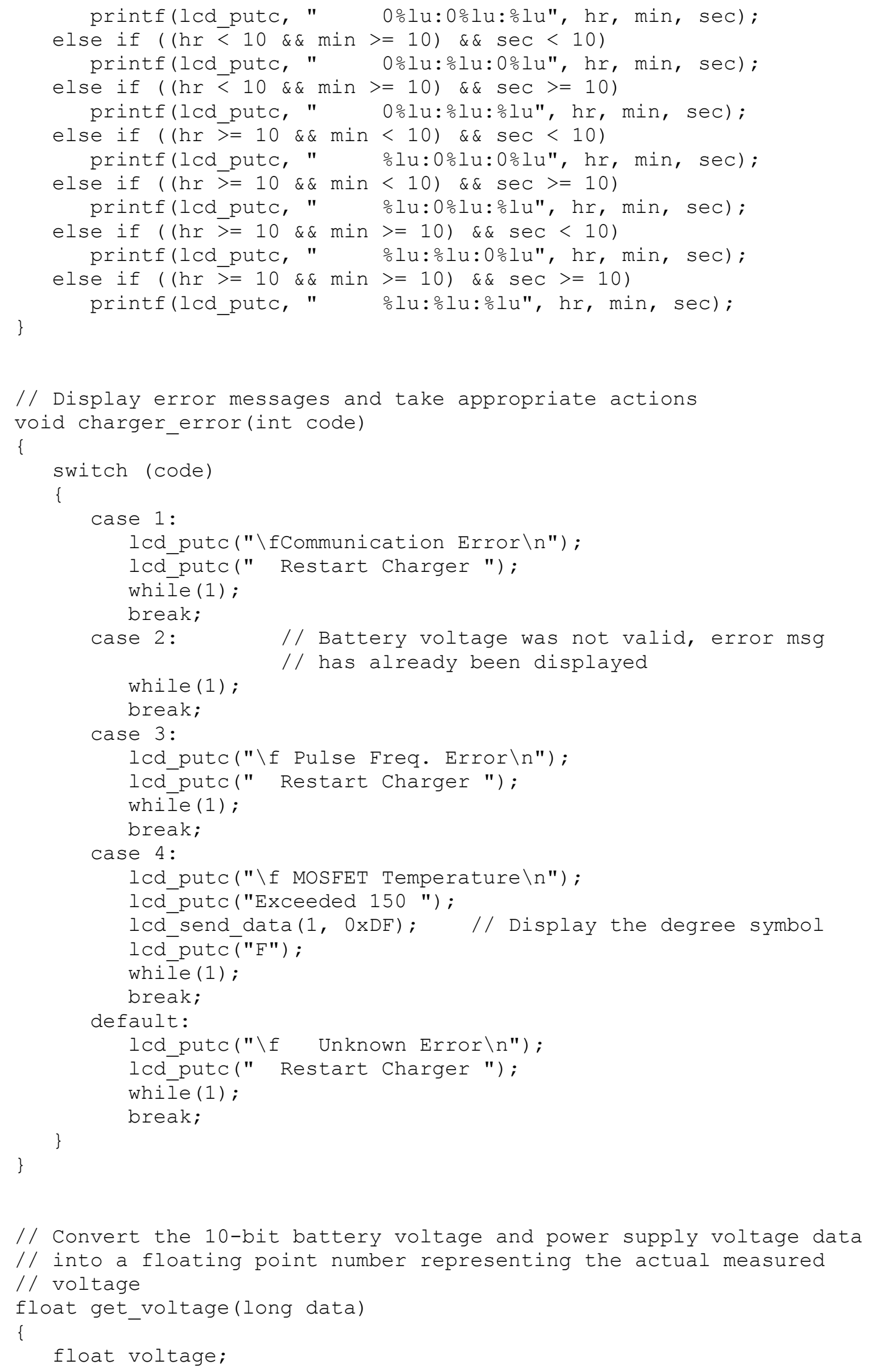




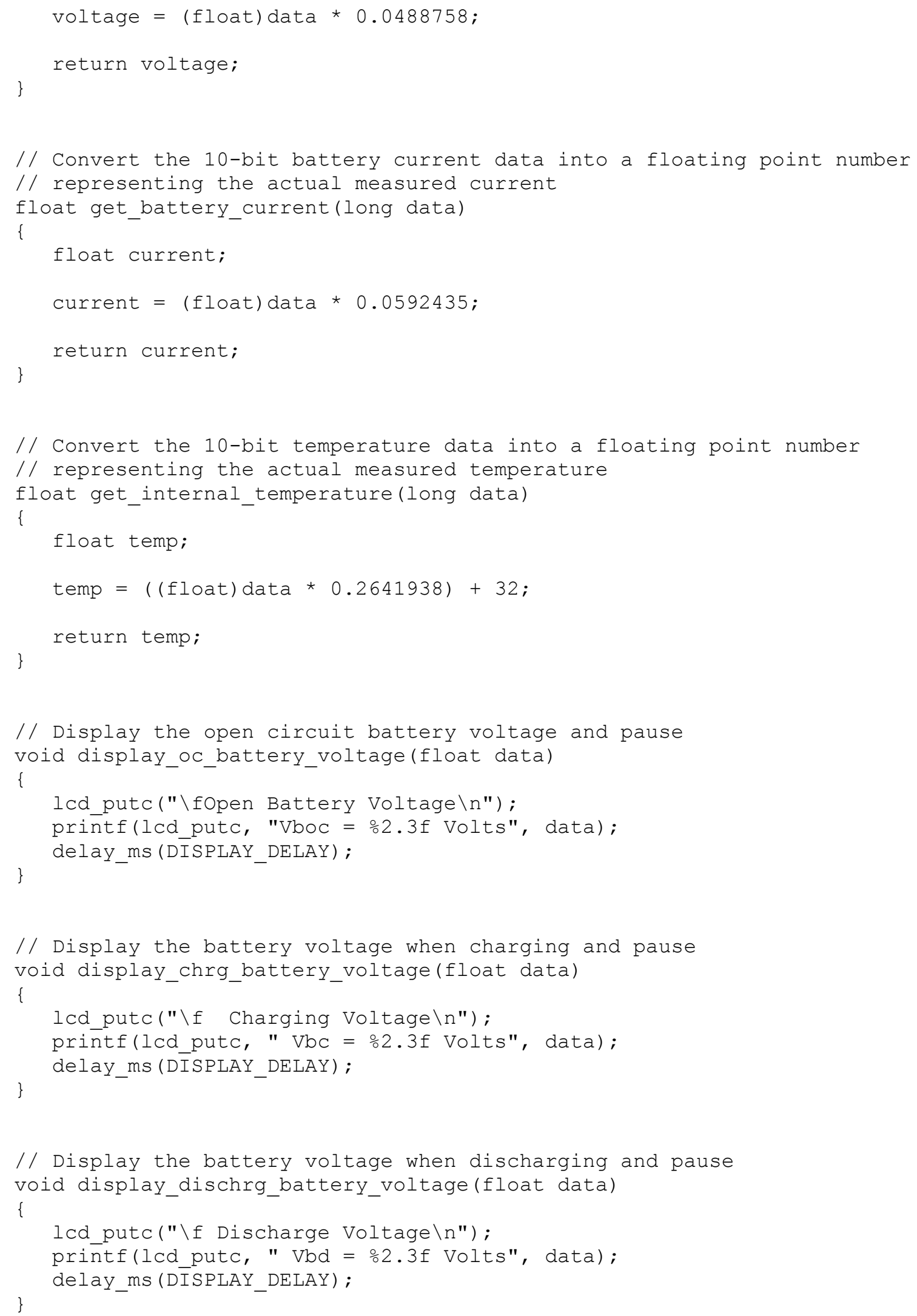


// Display the battery charging current and pause void display_battery_charging_current(float data)

\{

lcd_putc("\f Charging Current\n");

printf(lcd_putc, " Ic $=\frac{\circ}{2} .3 f$ Amps", data);

\} delay_ms (DISSPLAY_DELAY);

// Display the battery discharge current and pause void display_battery_discharge_current(float data)

\{

lcd_putc("\f Discharge Current \n");

printf(lcd putc, " Id = o2.3f Amps", data);

\}

delay_ms (DISPLAY_DELAY);

// Display the battery discharge current and pause void display_power_supply_voltage(float data)

\{

lcd_putc("\fPower Supply Voltage $\backslash n ")$; printf(lcd putc, "Vdd = $2.3 f$ Volts", data); \} delay_ms (DISPLAY_DELAY);

// Display the battery discharge current and pause void display_internal_temperature(float data)

\{

lcd_putc("\fInternal Temperature $\backslash \mathrm{n} ")$;

printf(lcd_putc, " $T=\frac{\mathrm{O}}{2} .3 \mathrm{f} "$, data);

lcd_send_data $(1,0 x D F)$; / / Display the degree symbol

lcd-putc-" "F");

\}

delay_ms (DISPLAY_DELAY);

// Display the battery impedance and pause void display_battery_impedance(float data)

\{

lcd_putc("\f Battery Impedance \n");

if $($ data $=-1) \quad$ // Battery impedance is infinite

\{

\}

lcd_putc(" Zb = infinite");

else

\{

printf(lcd putc, " $\mathrm{Zb}=\frac{0}{\mathrm{~b}} \mathrm{.4f}$ ", data);

\}

lcd_send_dāta $(1,0 x F 4) ; \quad / /$ Display the omega symbol

delay_ms (DISPLAY_DELAY);

\} 


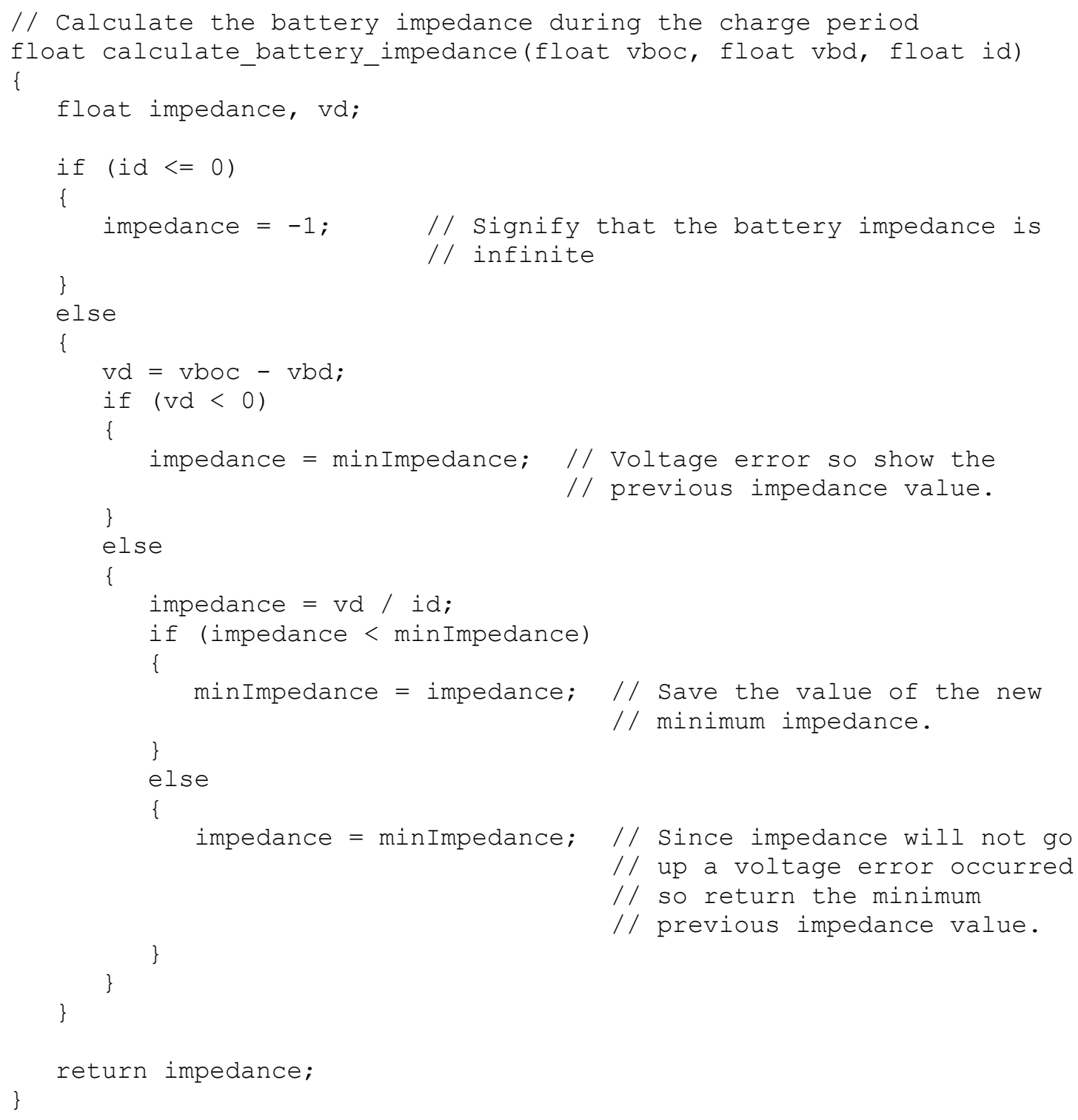

\section{C.4 User Interface Microcontroller Source Code File SLAVE.H}

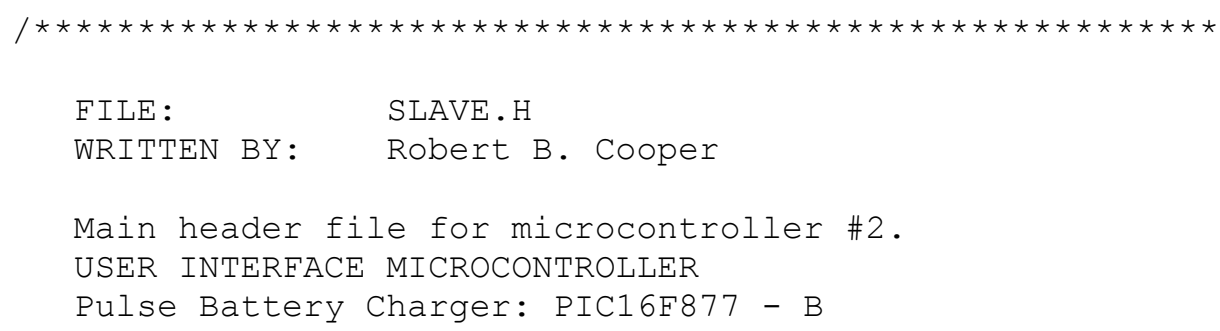




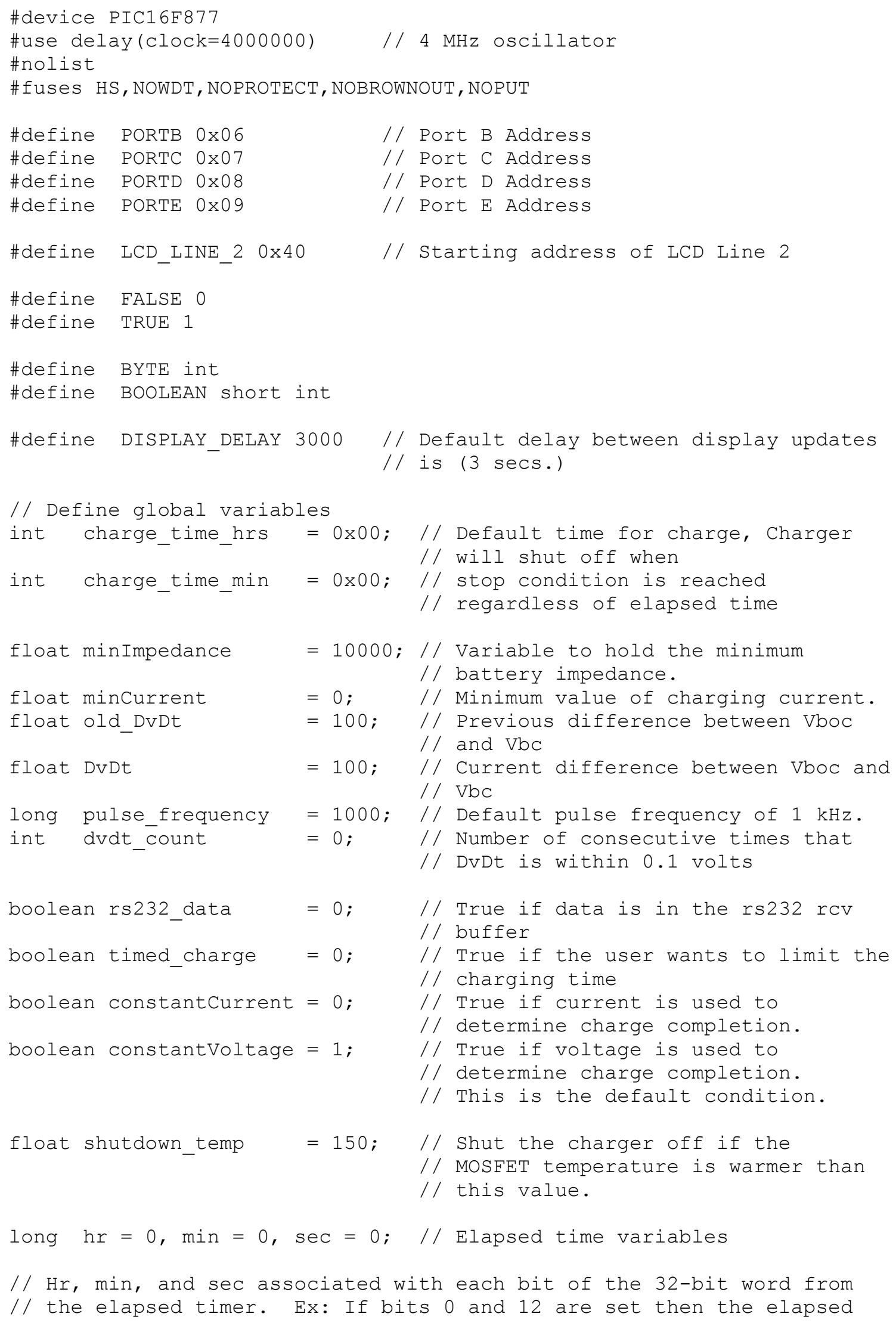




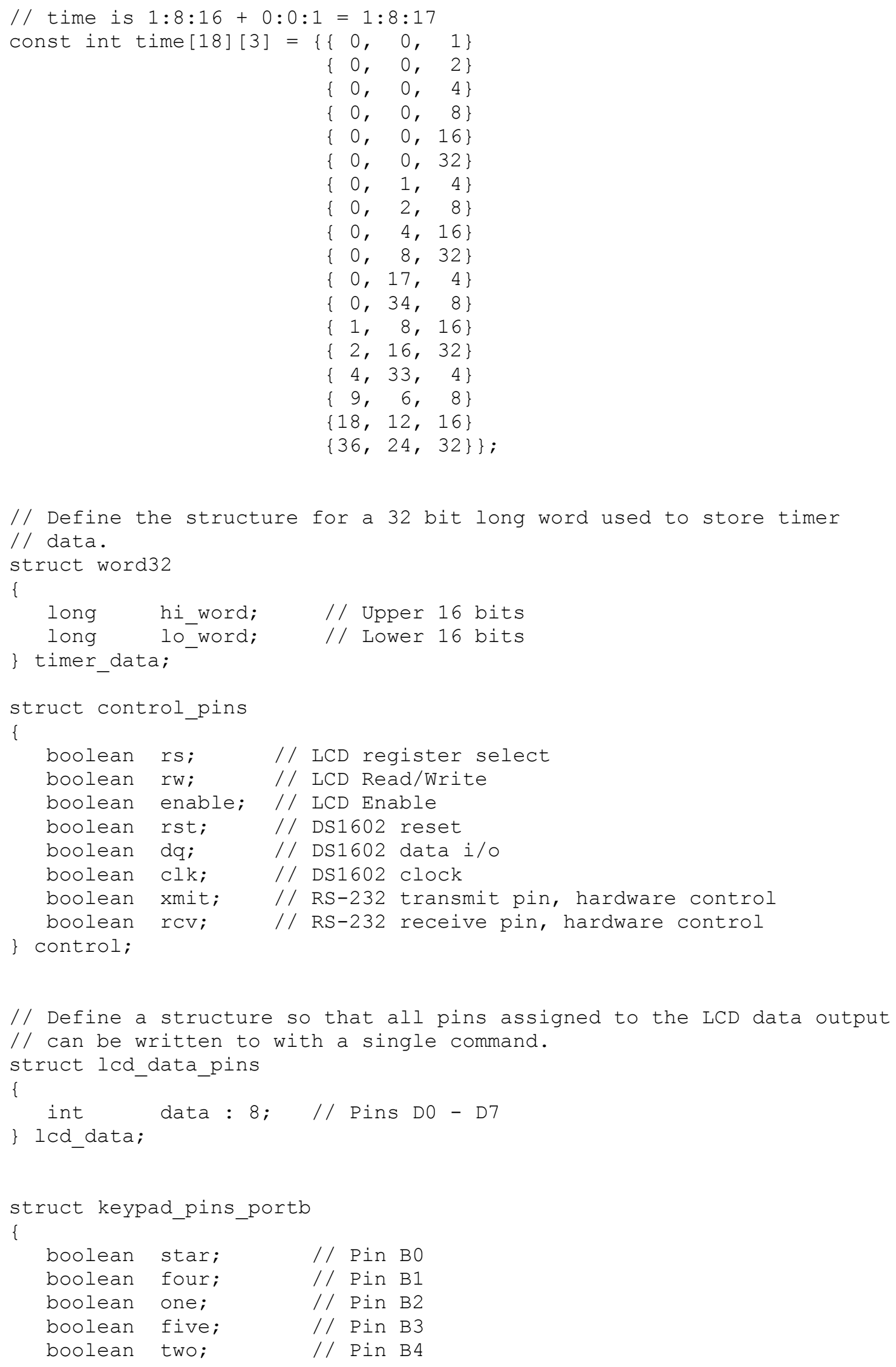




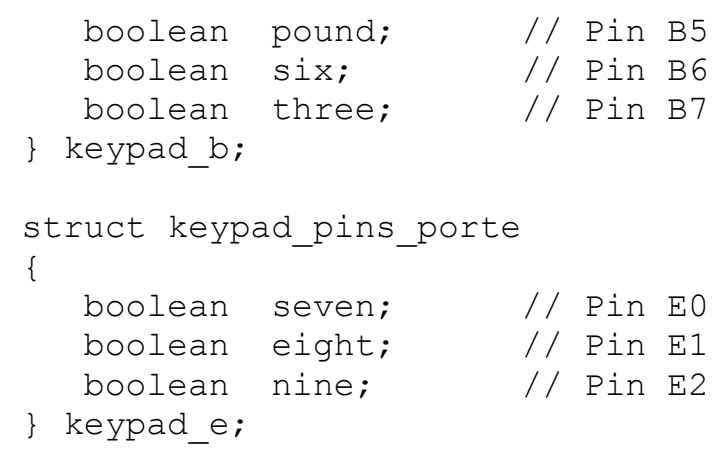




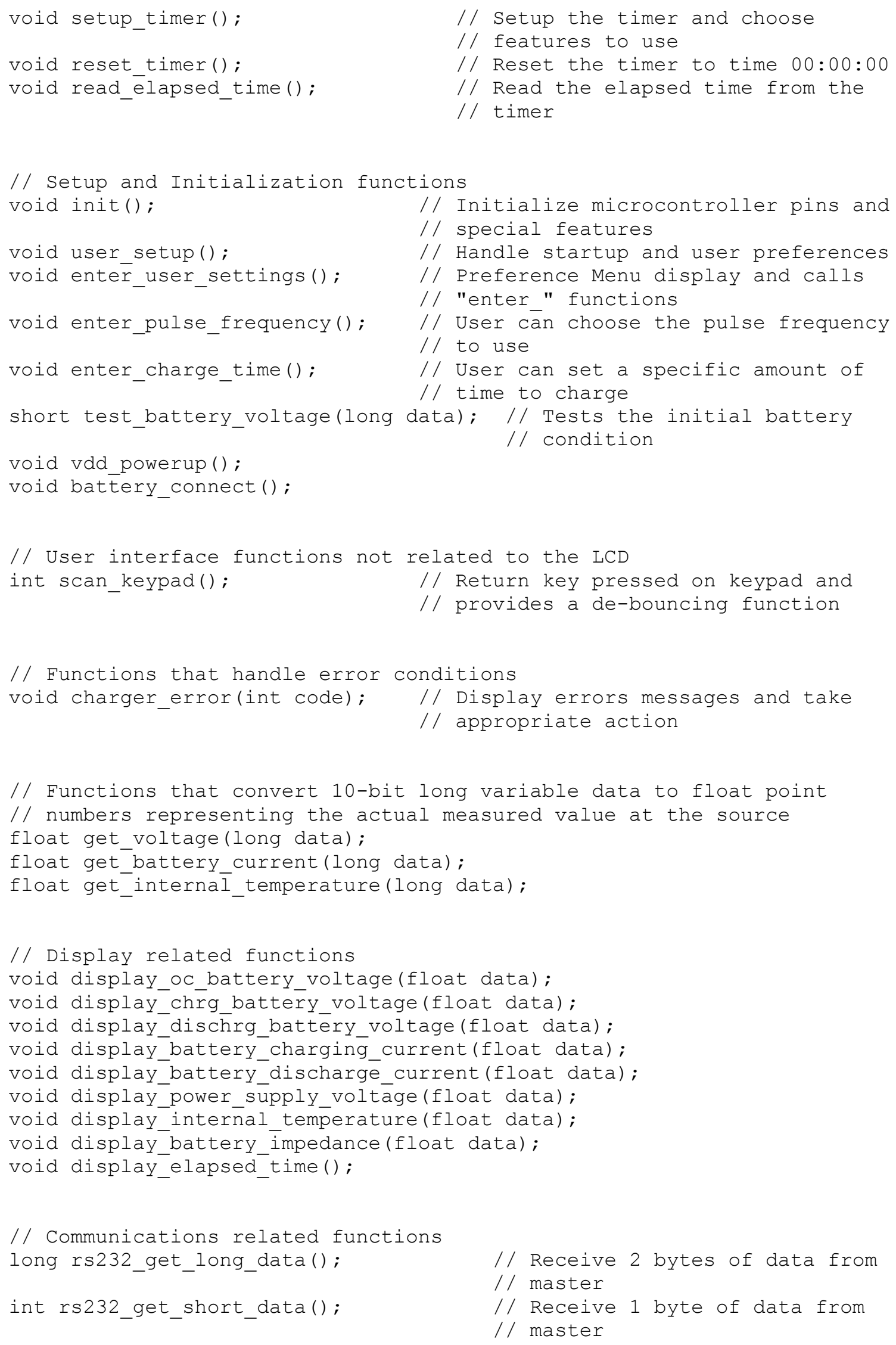




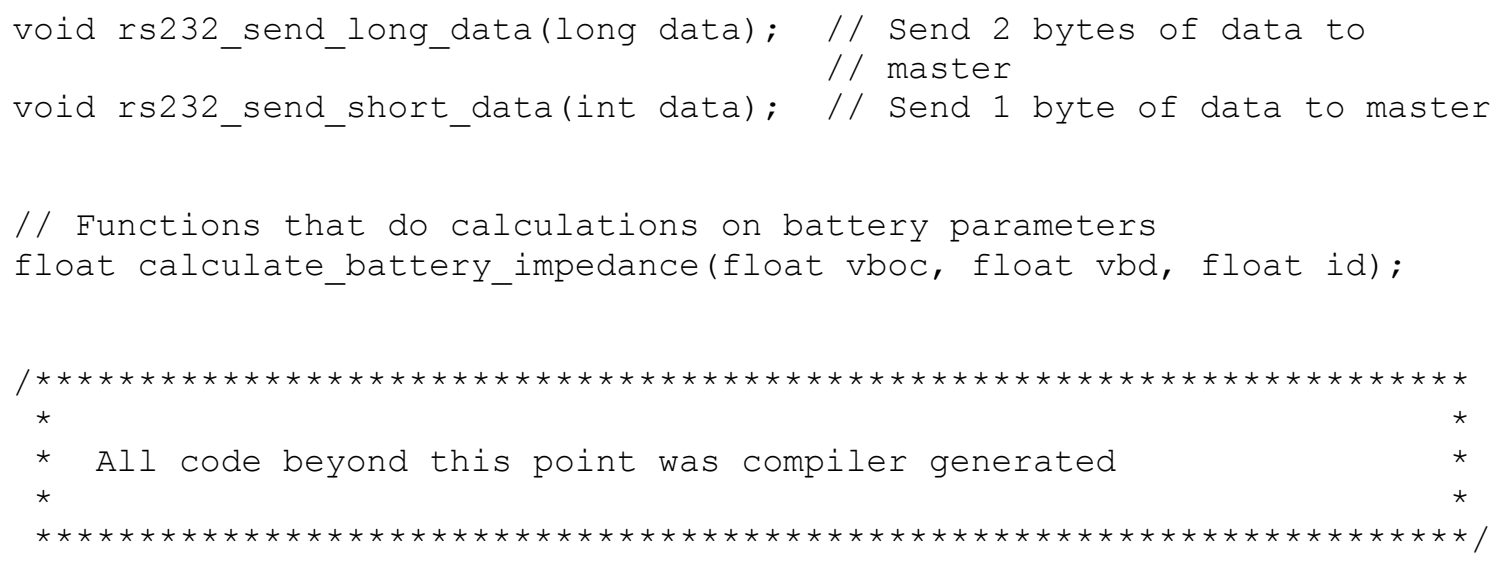




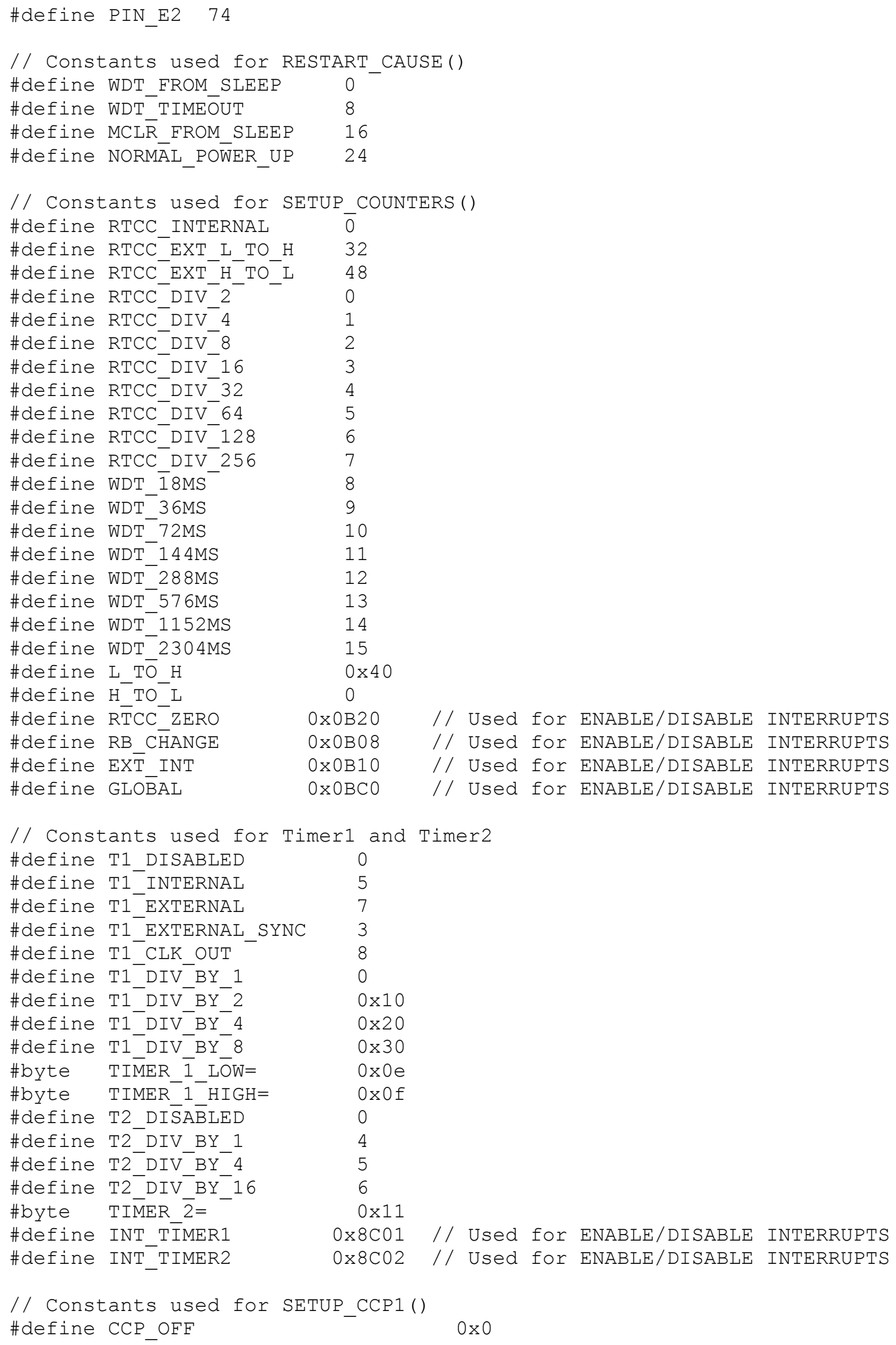




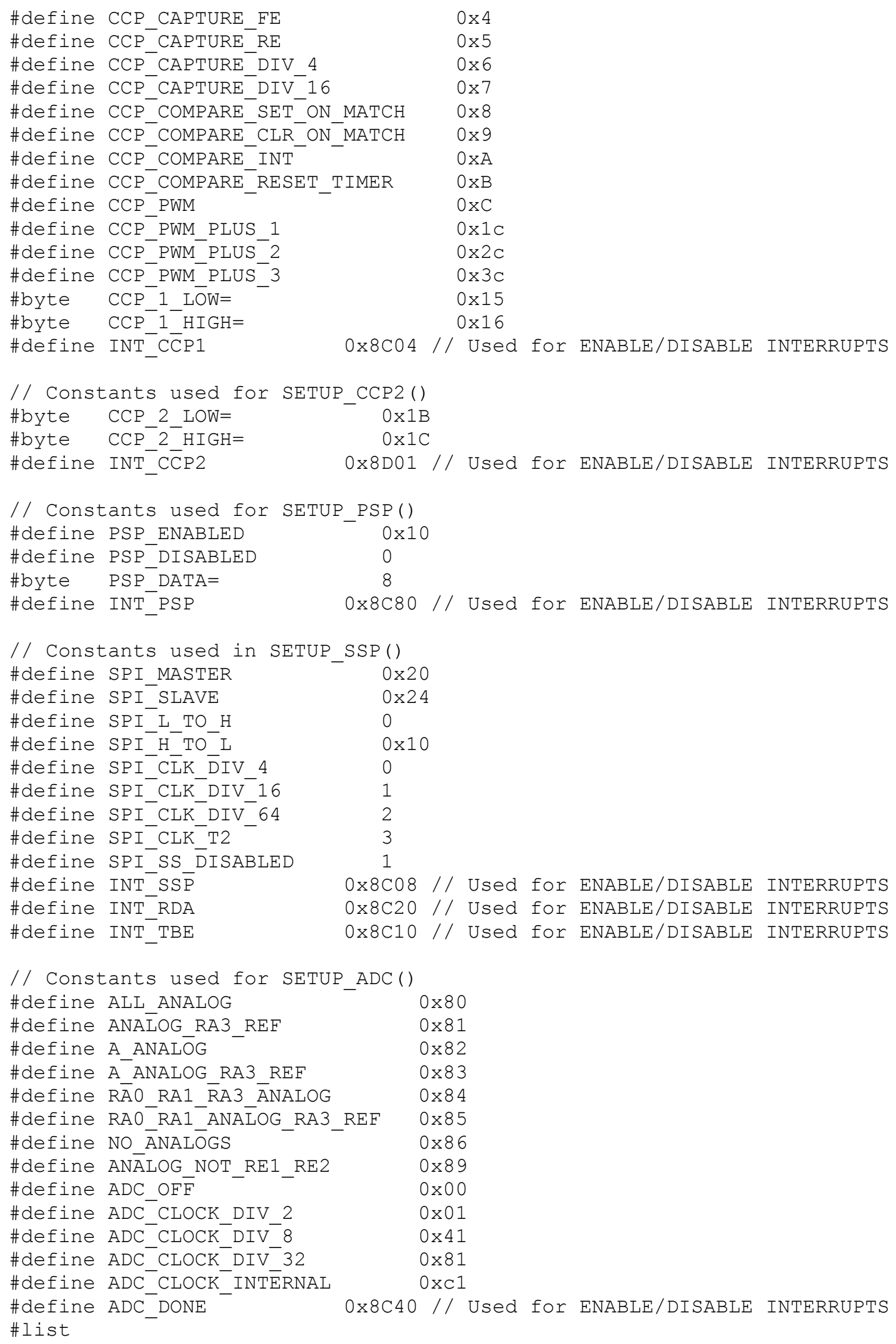




\section{C.5 Pulse Control Microcontroller Source Code File MASTER.C}

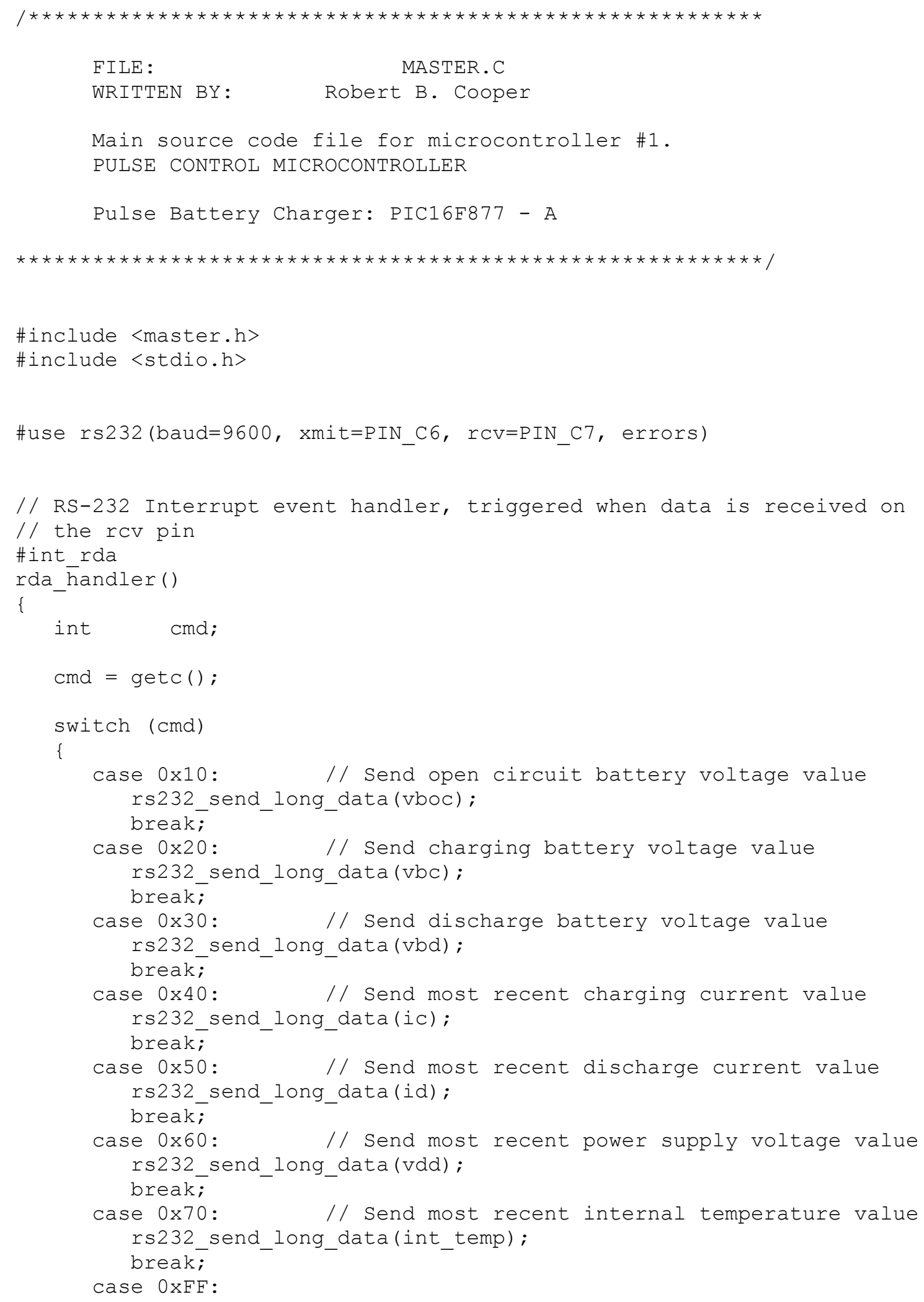




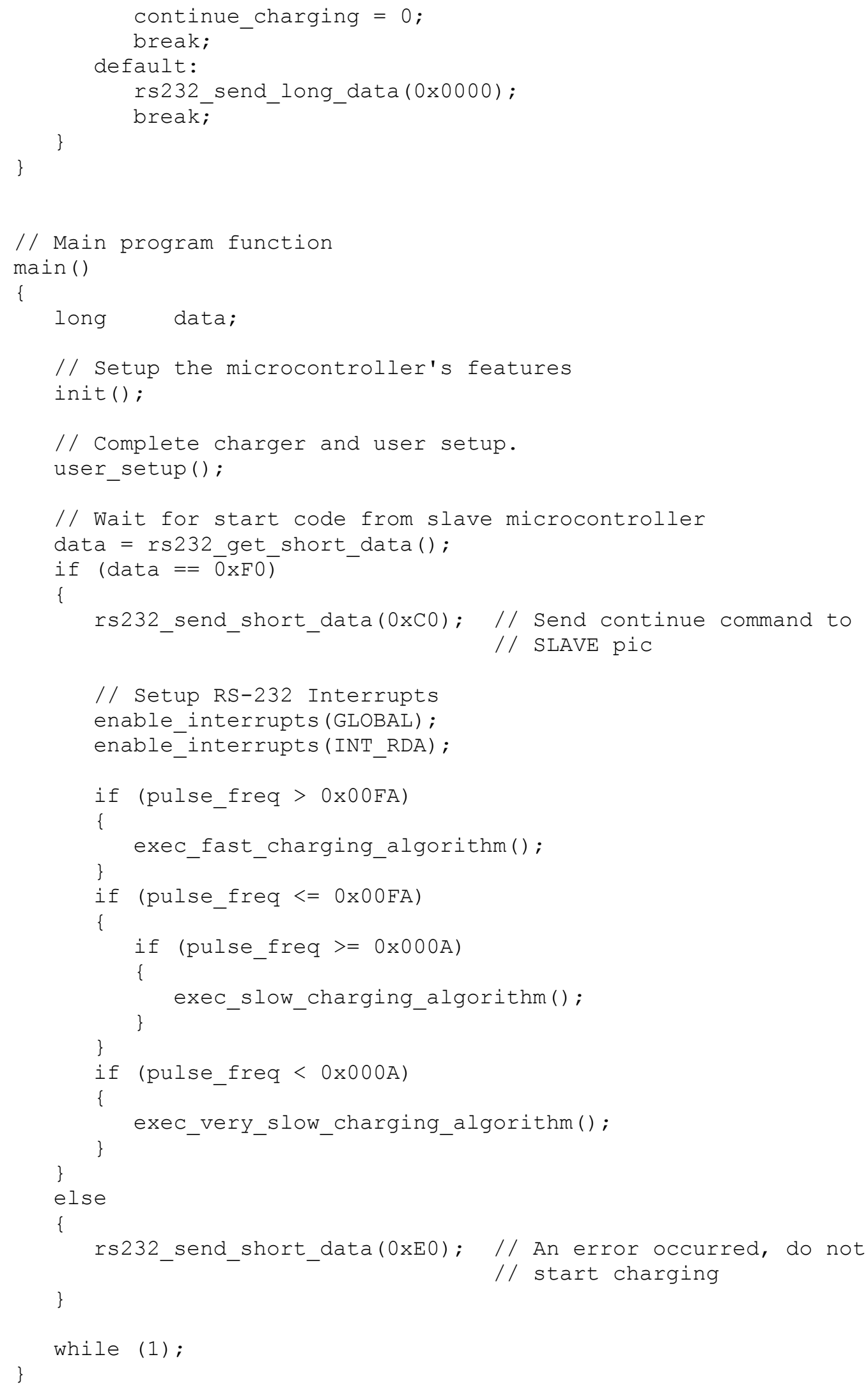


// Initialize the microcontroller

void init()

\{

// Setup ADC Pins

setup_adc_ports (ANALOG_NOT_RE1_RE2); // Activate all analog

// enabled pins except

setup_adc (ADC_CLOCK_DIV_32);

$1 /$ for E1 and E2.

// Set clock division for an

// operating frequency of 20

// $\mathrm{MHz}$.

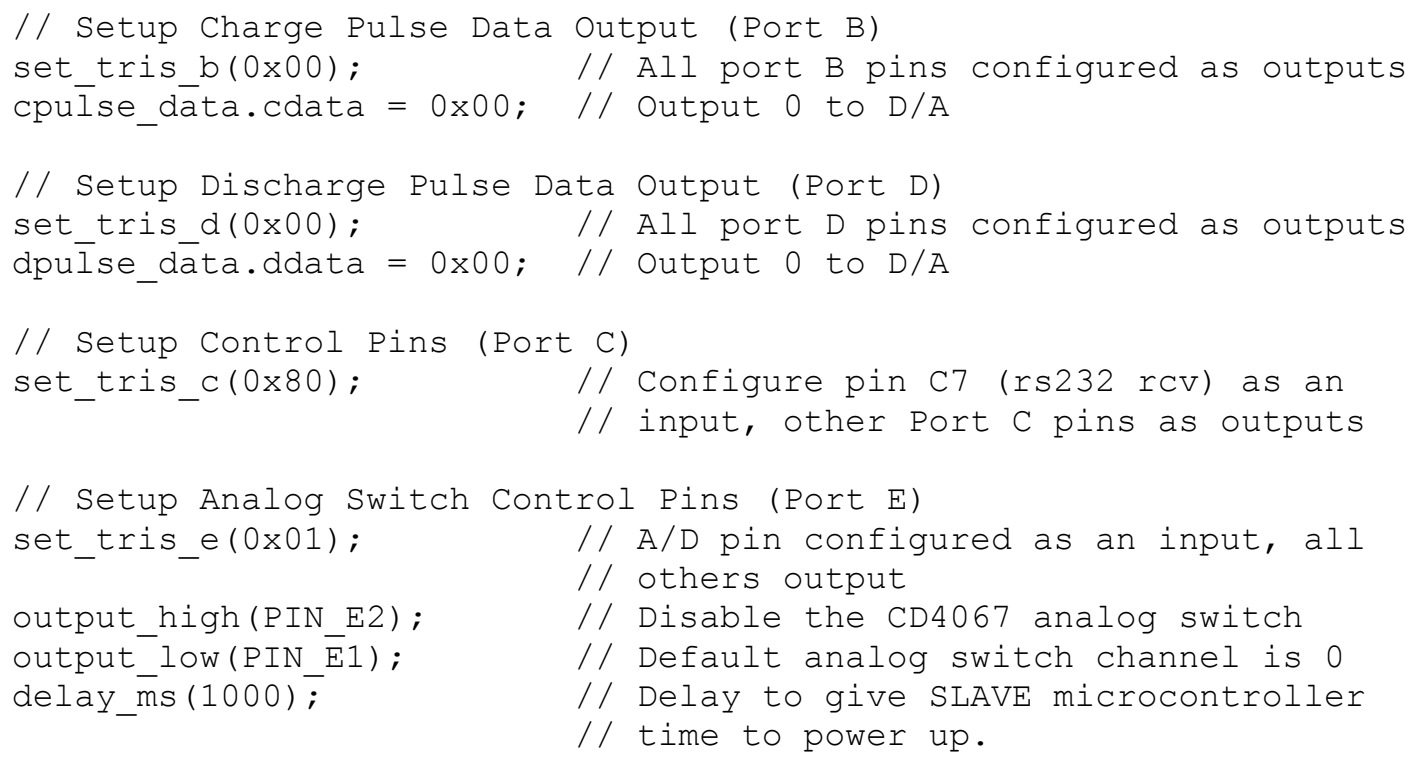




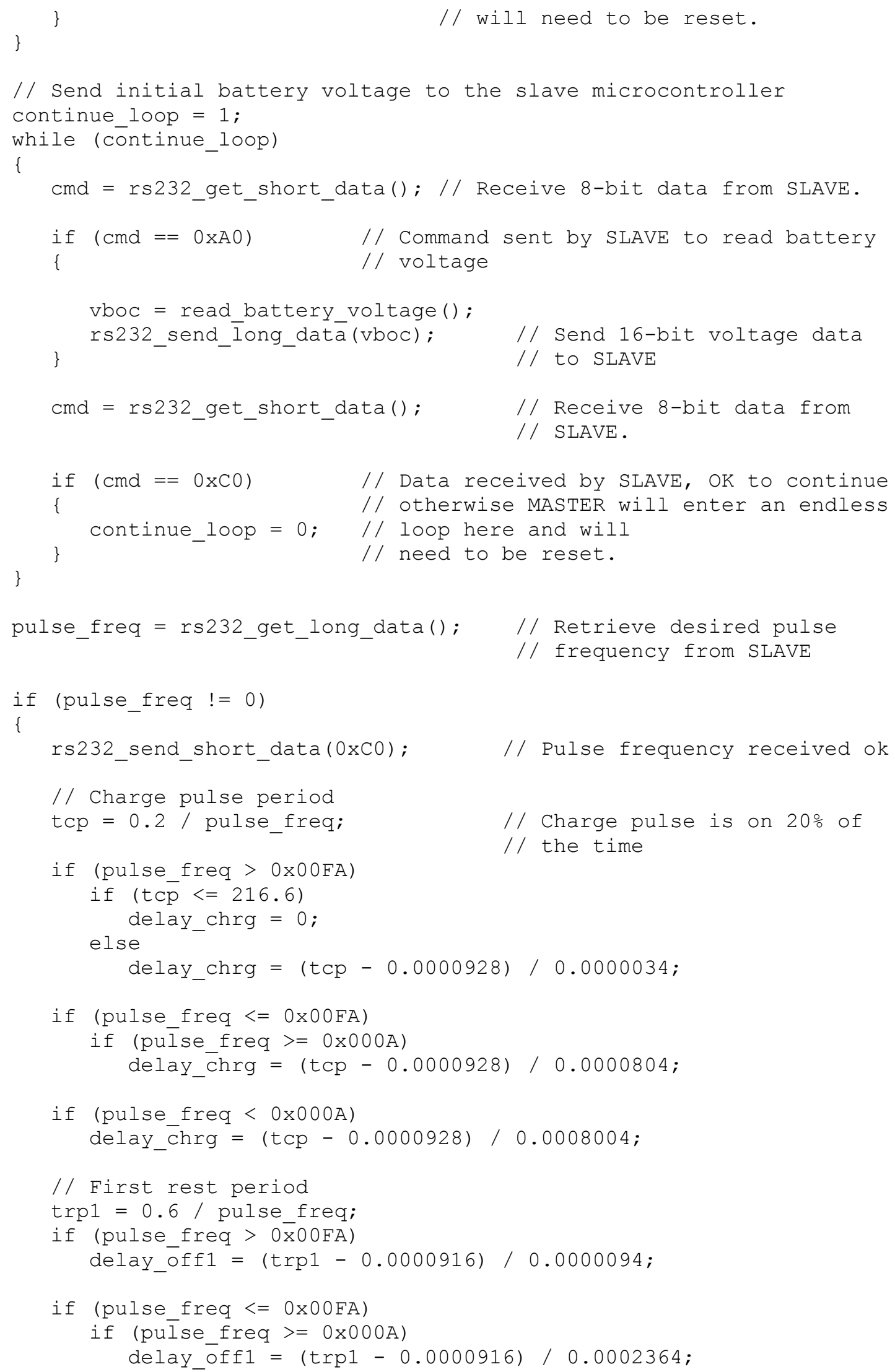




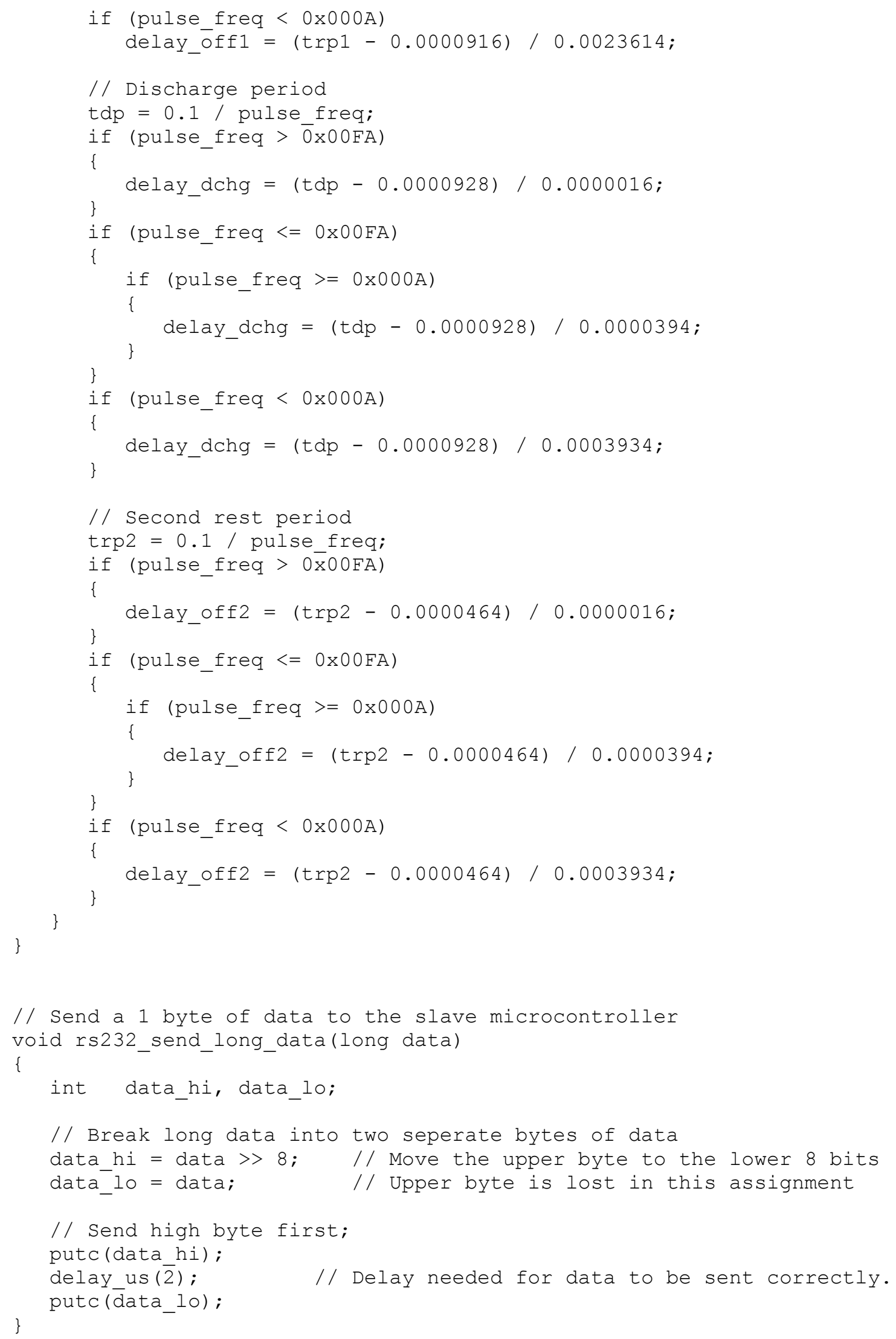


// Send a 1 byte of data to the slave microcontroller void rs232_send_short_data(int data)

\{

putc (data);

\}

// Receive 2 bytes of data from the slave microcontroller. long rs232_get_long_data()

\{

int data_hi, data_lo;

long data;

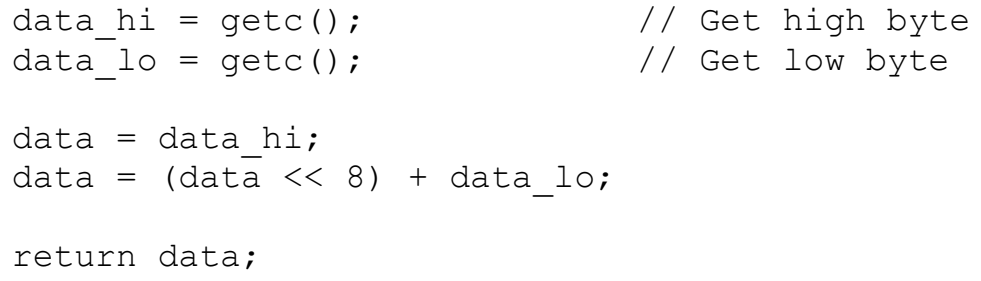




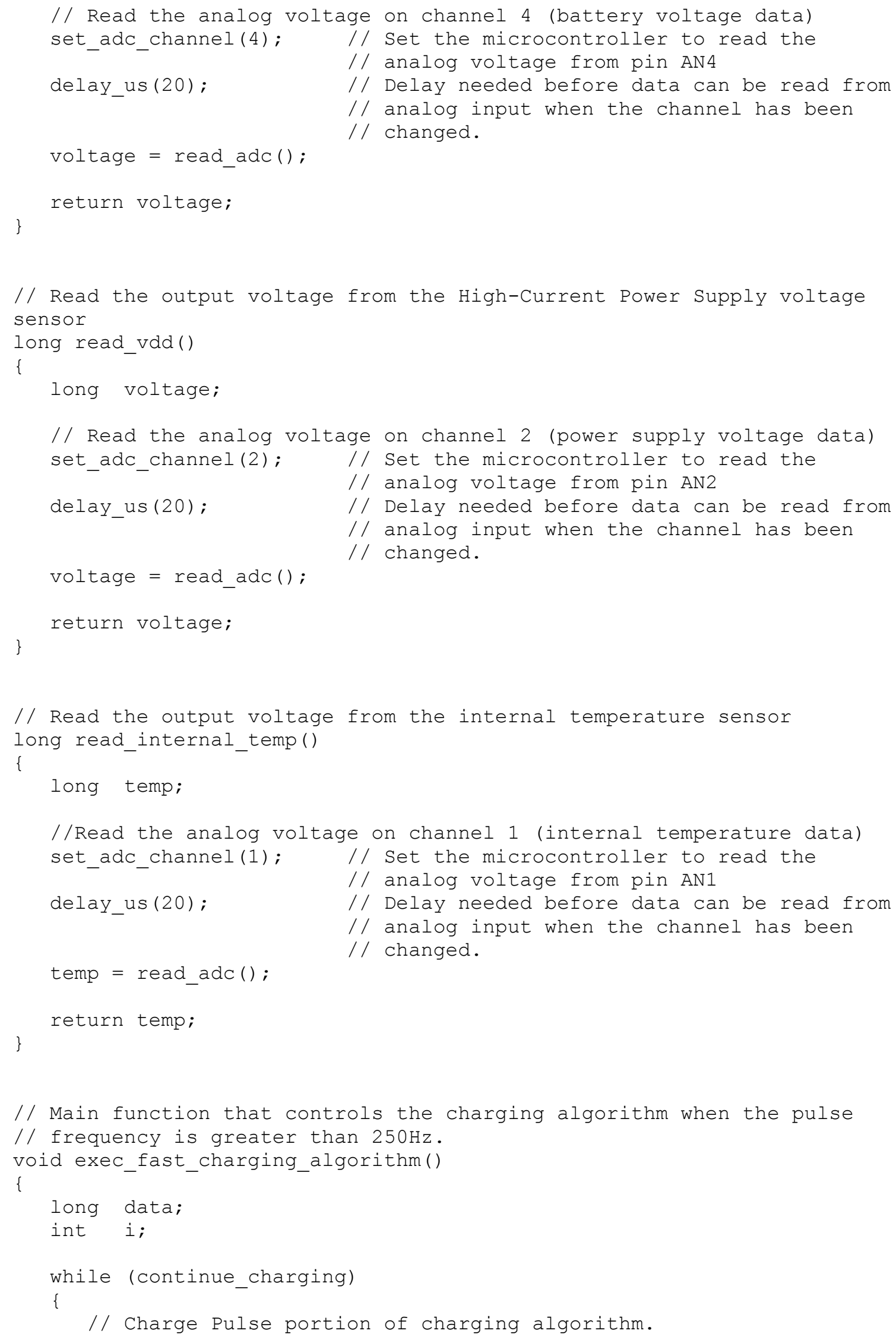




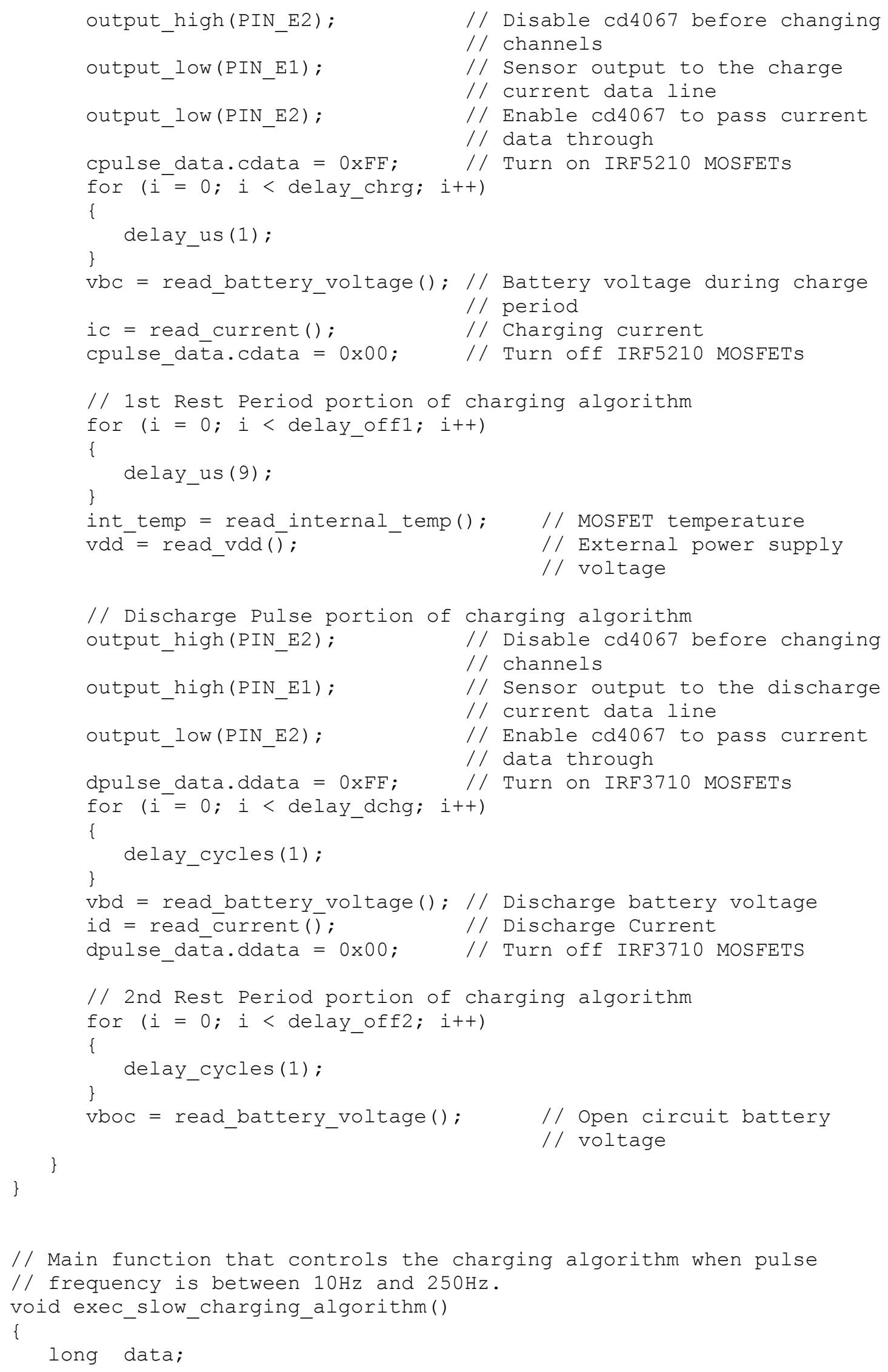




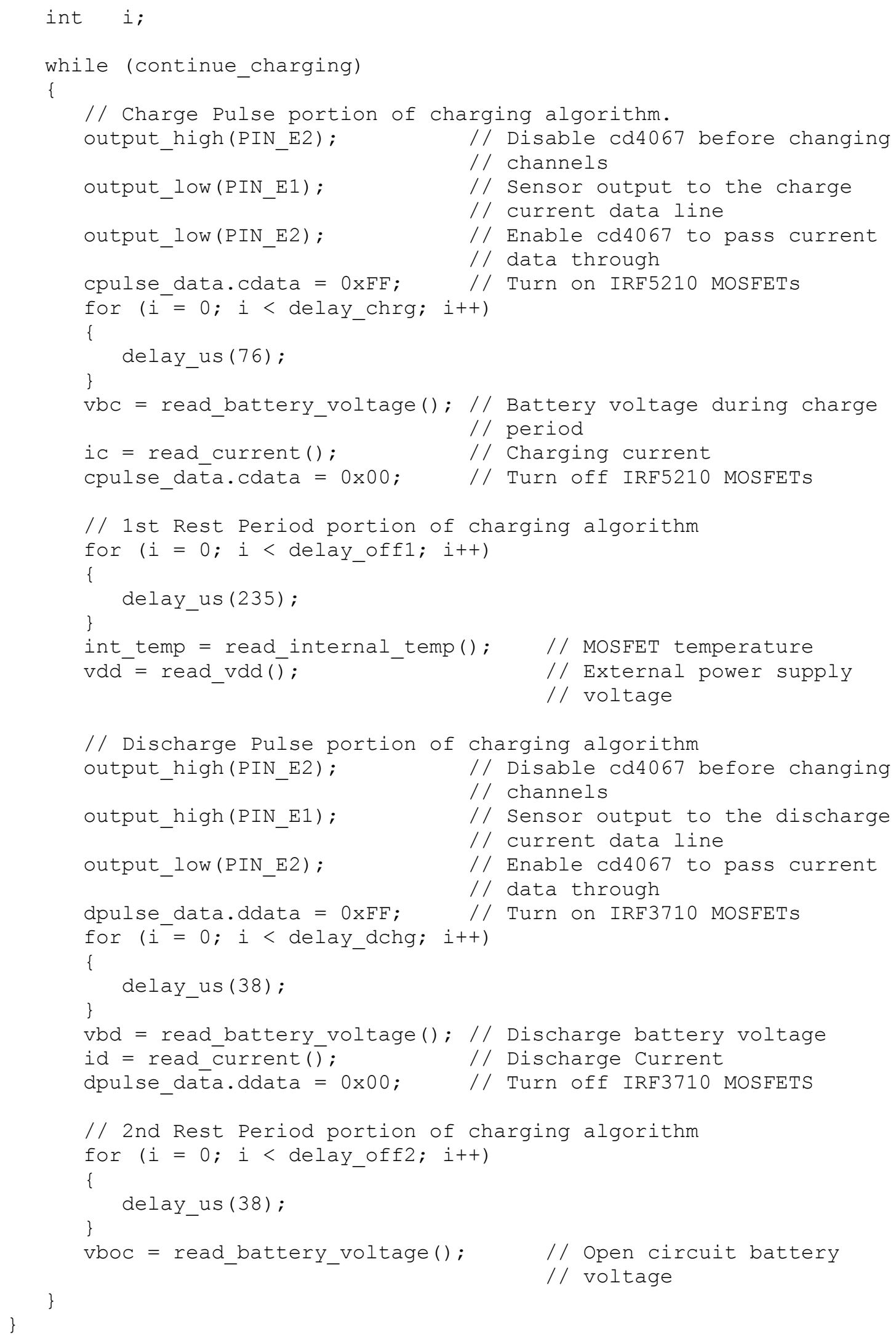


// Main function that controls the charging algorithm when pulse

// frequency is less than $10 \mathrm{~Hz}$.

void exec_very_slow_charging_algorithm()

\{

long data;

int i;

while (continue charging)

\{ // Charge Pulse portion of charging algorithm.

$$
\begin{array}{ll}
\text { output_high(PIN_E2); } & \text { // Disable cd4067 before changing } \\
\text { output_low(PIN_E1); } & \text { // channels } \\
& \text { // Sensor output to the charge } \\
\text { output_low(PIN_E2); } & \text { // current data line } \\
& \text { // Enable cd4067 to pass current } \\
\text { cpulse_data.cdata }=0 \times \mathrm{XFF} ; & \text { // data through } \\
& \text { // Turn on IRF5210 MOSFETs }
\end{array}
$$




\section{C.6 Pulse Control Microcontroller Source Code File MASTER.H}

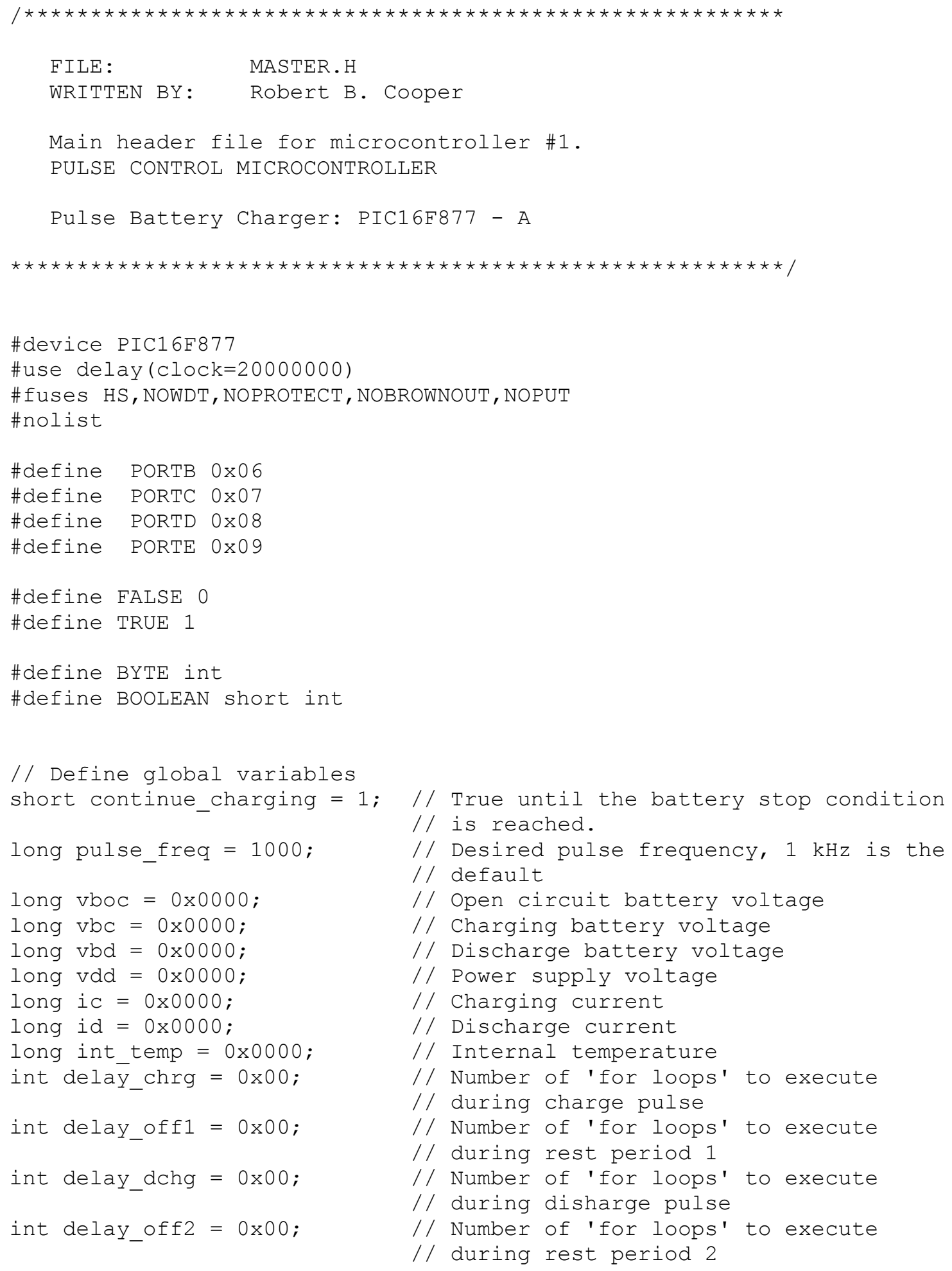


// Define a structure so that all pins assigned to the charge pulse

// output can be written to with a single command.

struct charge_pulse_pins

\{

int cdata : 8;

\} cpulse_data;

// Define a structure so that all pins assigned to the discharge pulse

// output can be written to with a single command.

struct discharge_pulse_pins

\{

int ddata : 8 ;

\} dpulse_data;

\#byte cpulse_data $=$ PORTB // Assign cpulse_data structure to PORTB

\#byte dpulse_data = PORTD // Assign dpulse_data structure to PORTD

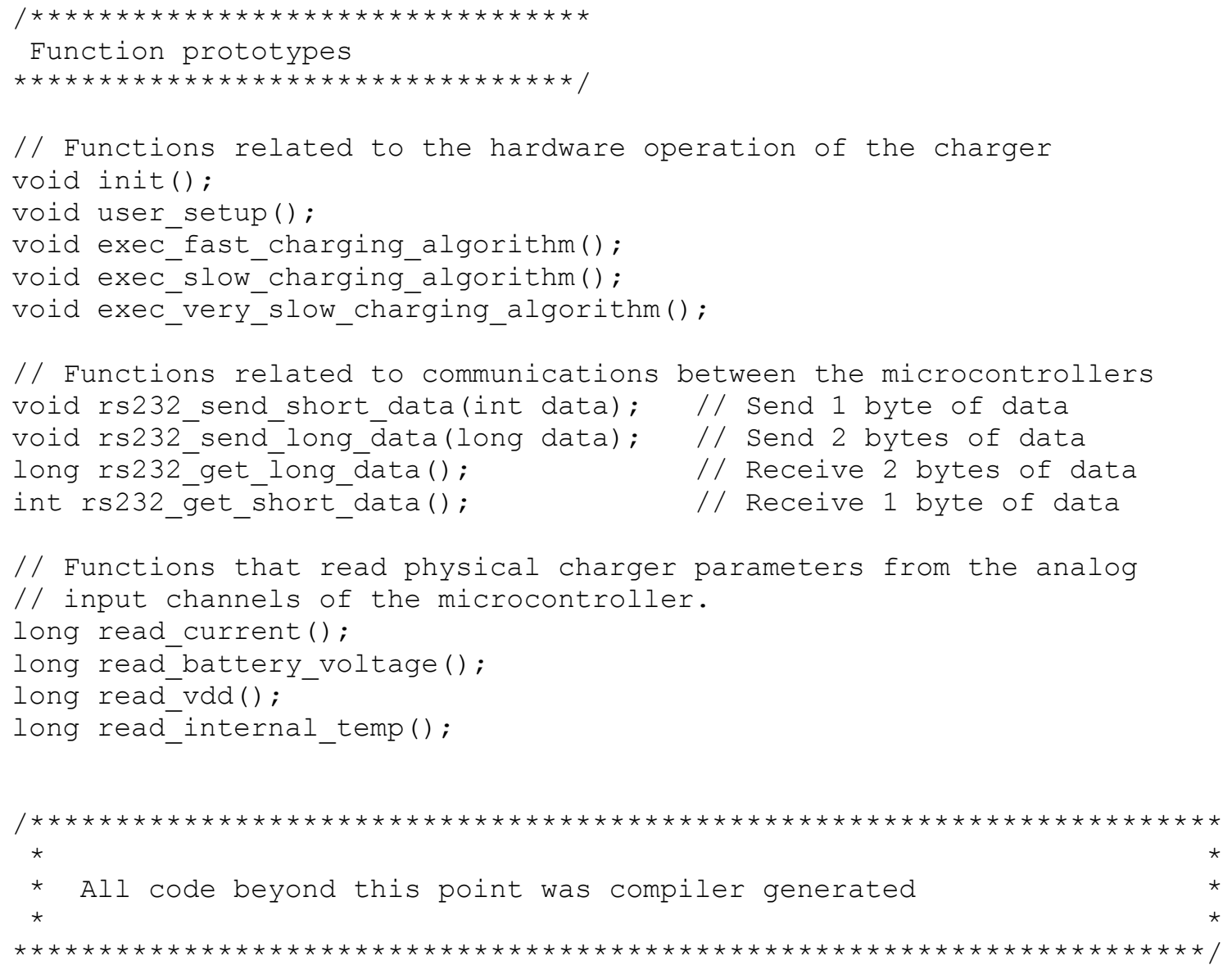


// PORT B pin definitions

\#define PIN_BO 48

\#define PIN B1 49

\#define PIN_B2 50

\#define PIN_B3 51

\#define PIN B4 52

\#define PIN B5 53

\#define PIN_B6 54

\#define PIN_B7 55

// PORT C pin definitions

\#define PIN CO 56

\#define PIN_C1 57

\#define PIN C2 58

\#define PIN_C3 59

\#define PIN_C4 60

\#define PIN ${ }^{-} 561$

\#define PIN C6 62

\#define PIN C7 63

// PORT D pin definitions

\#define PIN DO 64

\#define PIN D1 65

\#define PIN_D2 66

\#define PIN_D3 67

\#define PIN D4 68

\#define PIN D5 69

\#define PIN D6 70

\#define PIN_D7 71

// PORT E pin definitions

\#define PIN_EO 72

\#define PIN E1 73

\#define PIN_E2 74

// Constants used for RESTART_CAUSE()

\#define WDT_FROM_SLEEP 0

\#define WDT TIMEOUT 8

\#define MCL $\bar{R}$ FROM SLEEP 16

\#define NORMĀL_POW̄ER_UP 24

// Constants used for SETUP_COUNTERS()

\#define RTCC INTERNAL 0

\#define RTCC_EXT_L_TO_H 32

\#define RTCC ${ }^{-} \mathrm{EXT}^{-}{ }^{-}{ }^{-} \mathrm{TO}^{-} \mathrm{L} 48$

\#define RTCC_DIV_2 ${ }^{-}-0$

\#define RTCC_DIV_4 1

\#define RTCC_DIV_8 2

\#define RTCC ${ }^{-} \mathrm{DIV}^{-} 16$

\#define RTCC ${ }^{-}{ }^{-D I V} 32$

\#define RTCC_DIV_64 5

\#define RTCC_DIV_128 6

\#define RTCC_DIV_256 7

\#define WDT $\overline{1} 8 \mathrm{MS}^{-}$

\#define WDT $36 \mathrm{MS}$

\#define WDT_72MS 10 


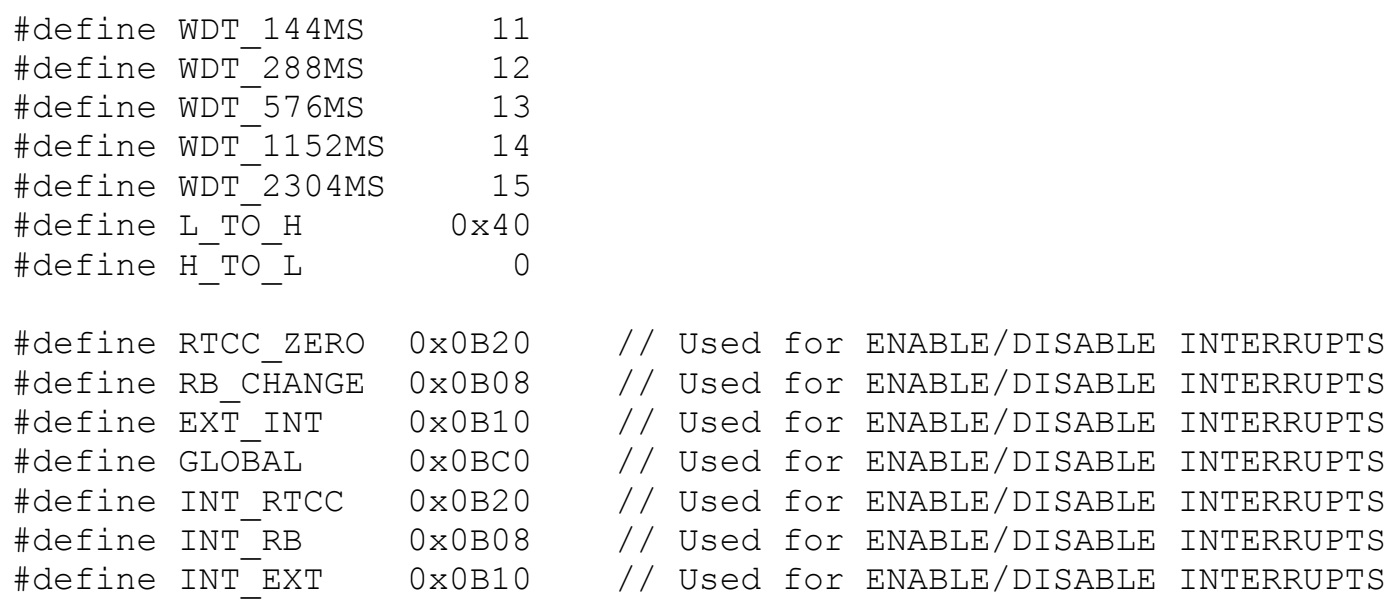

// Constants used for Timer1 and Timer2

\#define T1 DISABLED 0

\#define $\mathrm{T}^{-}$INTERNAL 5

\#define T1_EXTERNAL 7

\#define T1_EXTERNAL_SYNC 3

\#define $\mathrm{T}^{-}{ }^{-} \mathrm{CLK}$ OUT ${ }^{-} \quad 8$

\#define T1 DIV BY $1 \quad 0$

\#define $\mathrm{T}^{-}{ }^{-} \mathrm{DIV}^{-} \mathrm{BY}^{-} 2 \quad 0 \times 10$

\#define T1_DIV_BY-4 $4 \times 20$

\#define T1 DIV BY 8 0x30

\#byte TIM $\bar{M} E R$ L $\overline{1} \bar{O} W=\quad 0 \times 0 e$

\#byte TIMER $^{-}{ }^{-} \mathrm{HIGH}=\quad 0 \times 0 \mathrm{f}$

\#define T2_DI $\bar{S} A \bar{B} L E D \quad 0$

\#define T2 DIV BY 1

\#define T2-DIV_BY-4 5

\#define ${ }^{-}{ }^{-} \mathrm{DIV}^{-} \mathrm{BY}^{-} 16 \quad 6$

\#byte TI $\bar{M} E R \quad \overline{2}=-\quad 0 \times 11$

\#define INT_TIMER1 0x8C01 // Used for ENABLE/DISABLE INTERRUPTS

\#define INT_TIMER2 0x8C02 // Used for ENABLE/DISABLE INTERRUPTS

// Constants used for SETUP_CCP1()

\#define CCP OFF $\quad 0$

\#define CCP_CAPTURE_FE 4

\#define CCP_CAPTURE_RE 5

\#define CCP_CAPTURE_DIV_4 6

\#define CCP_CAPTURE_DIV_16 7

\#define CCP_COMPARE_SET_ON_MATCH 8

\#define CCP COMPARE ${ }^{-} \mathrm{CLR}^{-} \mathrm{ON}^{-} \mathrm{MATCH}$

\#define CCP_COMPARE_INT ${ }^{-}{ }^{-}$OXA

\#define CCP_COMPARE_RESET_TIMER OxB

\#define CCP_PWM $\quad 0 \times C$

\#define $\mathrm{CCP}^{-}$PWM PLUS 1 Ox1C

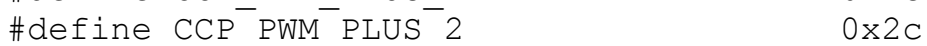

\#define CCP_PWM PLUS ${ }^{-} 3 \quad 0 \times 3 \mathrm{C}$

\#byte $\mathrm{CCP}^{-}{ }^{1} \mathrm{~L} \overline{\mathrm{O}} \mathrm{W}={ }^{-} \quad 0 \times 15$

\#byte $\quad \mathrm{CCP}_{-}{ }^{-}{ }_{-}^{-} \mathrm{HIGH}=\quad 0 \times 16$

\#define INT_C $\bar{C}$ P 1 // Used for ENABLE/DISABLE INTERRUPTS

// Constants used for SETUP CCP2()

\#byte CCP_2_LOW= $0 \times 1 \mathrm{~B}$ 


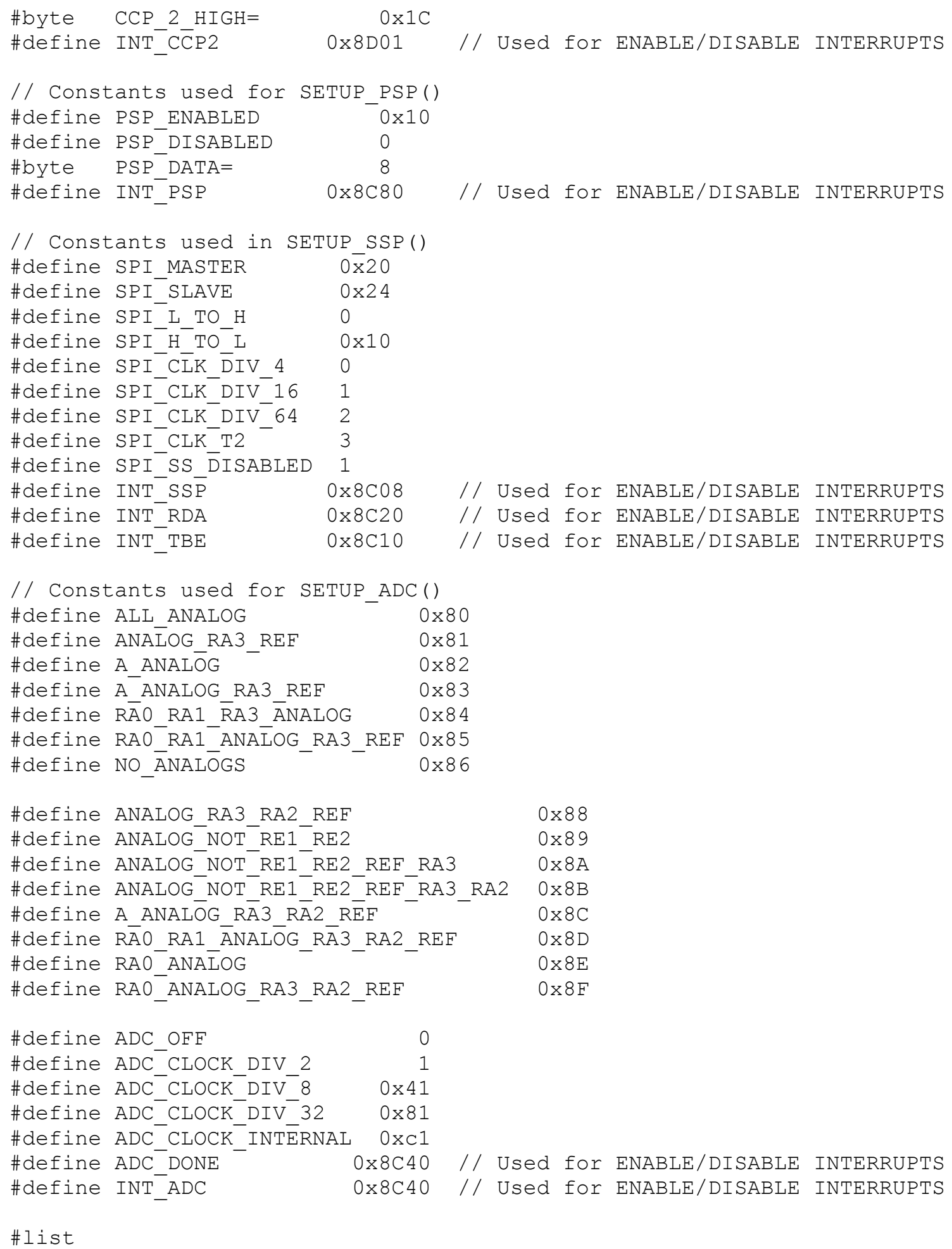




\section{References}

[1] David Linden, "Handbook of batteries $2^{\text {nd }}$ edition", McGraw-Hill, (1995), p24.7

[2] D. Pavlov, I. Pashmakova, "Influence of the size of $\mathrm{PbSO}_{4}$ crystals on their solubility and the significance of this process in the lead-acid battery", Journal of Applied Electrochemistry, vol. 17, (1987), pp1075-1082.

[3] Tom Hund, "Capacity loss in PV batteries and recovery procedures", Photovoltaic System Applications Department, Sandia National Laboratories.

[4] "Ability to recover lost battery capacity", Morningstar Corporation, http://www.morningstarcorp.com/addendum.html, (Jun 26, 2001).

[5] “Pulse Technology What's it all about?", Rhino-Charge Engineering, http://www.rhino-charge.com/pulsetech_faq.html, (Jun 26, 2001).

[6] J J A Wilkinson, et al., "A new pulse charging methodology for lead acid batteries", Institute of Professional Engineers New Zealand (IPENZ) Transactions, vol. 25, No. 1/EMCh, (1998).

[7] John J. Smithrick, "Effect of positive pulse charge waveforms on the energy efficiency of lead-acid traction cells", NASA TM-82709, (1981). 
[8] L.T. Lam, et al., "Pulsed-current charging of lead/acid batteries - a possible means for overcoming premature capacity loss?", Journal of Power Sources, 53, (1995), pp215228

[9] Frank A Fleming, et. al., "Rapid recharge capability of valve regulated lead acid batteries for EV \& HEV applications", Hawker Energy Products

[10] Matthew A. Keyser, "Charging algorithms for increasing lead acid battery cycle life for electric vehicles", EUS17

[11] Robert A. Gelbman, "Apparatus for charging and desulfating lead-acid batteries", United States Patent \# 6184650, (Feb 6, 2001).

[12] Ronald W. Pittman and Hafthor Stefansson, "Method and apparatus for rapidly charging and reconditioning a battery”, United States Paten \#5998968, (Dec 7, 1999).

[13] Hirokazu Hasegawa, et. al., "Pulse charging method and a charger", United States Patent \#5945811, (Aug 31, 1999).

[14] Douglas F. Eryou and Vladimir Federman, "Method and device for charging and conditioning batteries”, United States Patent \#5648714, (Jul 15, 1997). 
[15] William E. Gregory and Chester C. Allen Jr., "Lead acid battery rejuvenator", United States Patent \#5592068, (Jan 7, 1997).

[16] Southiphone T. Phommarath, "Pulsed battery rejuvenator having variable trailing edge shaped pulses”, United States Patent \#5525892, (Jun 11, 1996).

[17] William E. Gregory and Chester C. Allen Jr., "Lead acid battery rejuvenator", United States Patent \#5491399, (Feb 13, 1996).

[18] Carl E. Gali, "Solar radiation powered battery reclaimer and charger", United States Patent \#5276393, (Jan 4, 1994).

[19] Carl E. Gali, "Lead acid battery rejuvenator and charger", United States Patent \# 5063341, (Nov 5, 1991). 